Portland State University

PDXScholar

Spring 6-6-2014

\title{
Macroinvertebrates and Excessive Fine Sediment Conditions in Oregon Coastal Streams
}

\author{
Patrick M. Edwards \\ Portland State University
}

Follow this and additional works at: https://pdxscholar.library.pdx.edu/open_access_etds

Part of the Fresh Water Studies Commons, and the Sedimentology Commons Let us know how access to this document benefits you.

\section{Recommended Citation}

Edwards, Patrick M., "Macroinvertebrates and Excessive Fine Sediment Conditions in Oregon Coastal Streams" (2014). Dissertations and Theses. Paper 1831.

https://doi.org/10.15760/etd.1830

This Dissertation is brought to you for free and open access. It has been accepted for inclusion in Dissertations and Theses by an authorized administrator of PDXScholar. Please contact us if we can make this document more accessible: pdxscholar@pdx.edu. 
Macroinvertebrates and Excessive Fine Sediment Conditions in

Oregon Coastal Streams

by

Patrick Michael Edwards

A dissertation submitted in partial fulfillment of the requirements for the degree of

Doctor of Philosophy

in

Environmental Sciences and Resources

Dissertation Committee:

Yangdong Pan, Chair

Ian Waite

Heejun Chang

Sherri Johnson

Alan Yeakley

Portland State University

2014 


\begin{abstract}
The Pacific Coastal ecoregion contains large tracts of economically important forestlands that also serve as critical stream habitat for endangered Salmonids. Excessive fine sediment deposition in streams of this region is a major environmental concern in the region but difficult to measure directly. The use of stream invertebrates to monitor fine sediment conditions in streams requires careful consideration of several important factors that complicate their use as bioindicators including high spatial and temporal variability and covariance with other environmental variables.
\end{abstract}

To evaluate the use of stream invertebrates as bioindicators of excessive fine sediment, three hypotheses were tested. The first hypothesis was that invertebrates would be related to broad-scale climate variables (Chapter 2). The second hypothesis was that functional aspects of the invertebrate community would serve as useful indicators of excessive fine sediment condition. (Chapter 3). The third hypothesis was that invertebrates in streams with naturally high levels of sediment would be tolerant to fine sediment ( $<2 \mathrm{~mm}$, Chapter 4). Hypotheses were tested using a temporal data set at two streams in western Oregon, spatial data from 214 sites across the Oregon Coast Range, and in-situ experiment conducted in streams with erosive or resistant geologies.

In the temporal study, both invertebrate density and functional traits were positively related to El Niño strength $\left(\mathrm{R}^{2}\right.$ range $=0.22-0.36, \rho$ range $\left.=0.008-0.04\right)$ and air temperature $\left(\mathrm{R}^{2}\right.$ range $=0.32-0.49, \rho$ range $\left.=0.002-0.01\right)$. The spatial study identified several environmental and hydrological factors that exhibited strong negative controls on both fine sediment (Mantel $r$ range $0.14-0.25, \rho$ range $=0.001-0.01$ ) and invertebrate 
Scrapers $\left(\mathrm{R}^{2}\right.$ range $=0.11-0.14, \rho$ range $\left.=0.001-0.04\right)$. The result of the experimental study provide evidence that invertebrates in streams with erosive geologies exhibit tolerance to sediment addition when compared to invertebrates in resistant geologies (mean loss $=15 \%, \rho<0.01$ ) and that invertebrate grazing traits were most strongly associated with fine sediment dosing frequency $(\rho<0.05)$.

The findings of this research demonstrate the role of geology in shaping invertebrate communities and their functional response to fine sediment addition and identify functional indicators that may be useful in different geologic settings. For environmental managers in the Pacific Coastal ecoregion, these findings are of potential value in assisting with the identification of biologically-relevant changes in stream fine sediment conditions and support efforts to balance economic needs in the region while protecting critical Salmonid habitat. 


\section{Acknowledgements}

Many thanks to my advisor, Dr. Yangdong Pan. Dr. Pan provided thoughtful advice and support through every step of my degree. I would also like to thank my committee members: Dr. Heejun Chang, Dr. Sherri Johnson, Dr. Ian Waite and Dr. Alan Yeakley, all of whom provided many insightful suggestions and advice about my research. The Oregon Department of Environmental Quality provided me the data for Chapter 3 and Shannon Hubler was always happy to answer questions and give helpful advice about the data.

I would also like to thank the graduate students of Dr. Pan's lab. Without their help, I could not have finished this work.

I'm also grateful for the financial support I have received from Portland State University and the Cascades to Coast GK-12 Program.

Data and facilities were provided by the HJ Andrews Experimental Forest research program, funded by the National Science Foundation's Long-Term Ecological Research Program (DEB 0823380), US Forest Service Pacific Northwest Research Station, and Oregon State University.

And finally, I'd like to thank my family and friends for their encouragement and support. 


\section{Table of Contents}

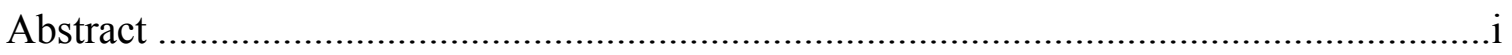

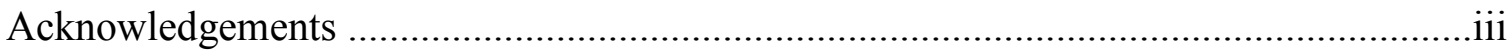

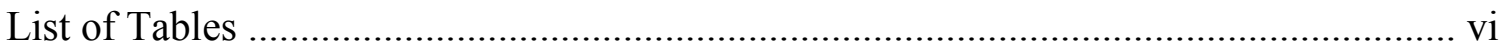

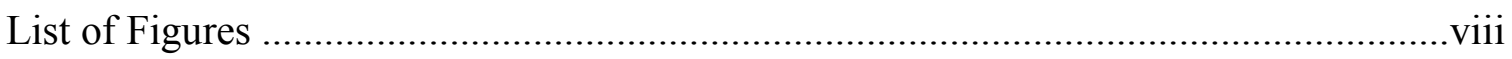

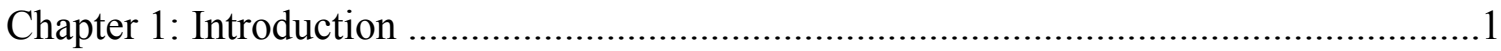

SEDIMENT POLLUTION OF SMALL STREAMS IN THE UNITED STATES ...........1

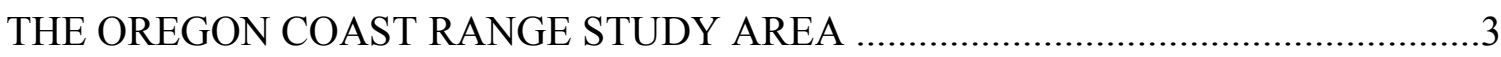

FINE SEDIMENT DYNAMICS IN OREGON COAST RANGE STREAMS ................3

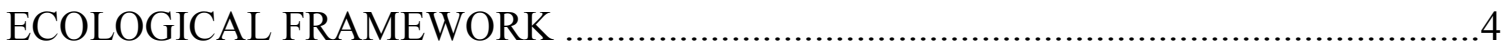

ABIOTIC AND BIOTIC CONTROLS OF INVERTEBRATE ASSEMBLAGE IN

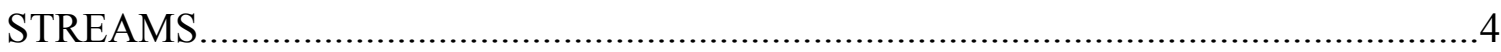

HIERARCHICAL CONTROLS OF INVERTEBRATE ASSEMBLAGE......................6

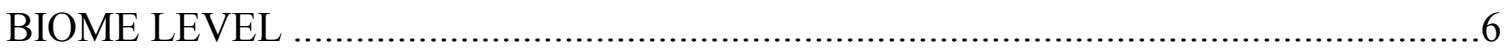

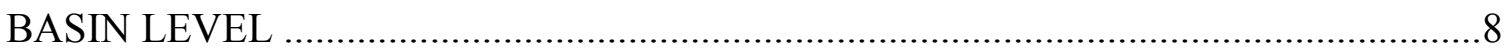

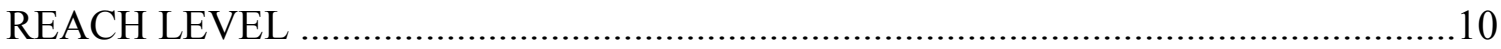

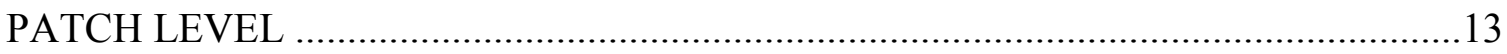

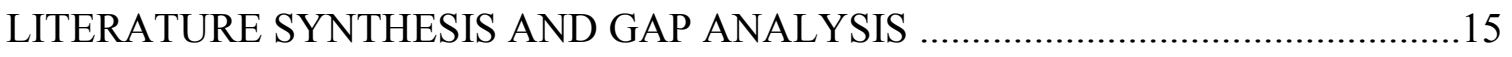

IMPACT OF EXCESSIVE FINE SEDIMENT ON INVERTEBRATE........................15

MECHANISMS OF FINE SEDIMENT IMPACTS ON INVERTEBRATES AT

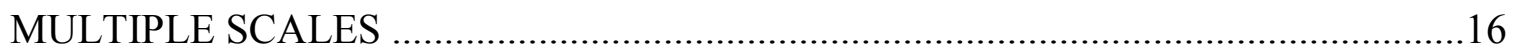

INVERTEBRATE MOUTHPARTS AS INDICATORS OF EXCESSIVE FINE

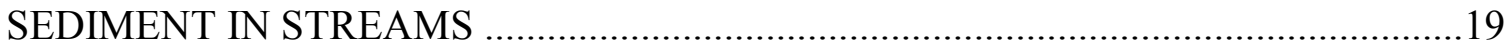

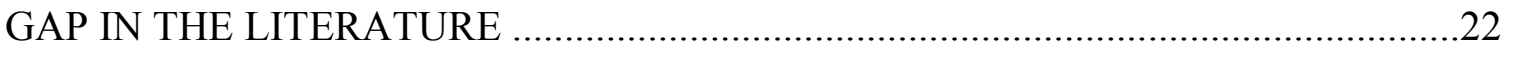

Chapter 2: Stream Invertebrate and Climate Relationships in the Pacific Coastal

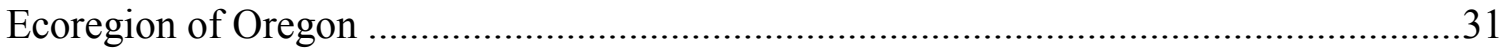

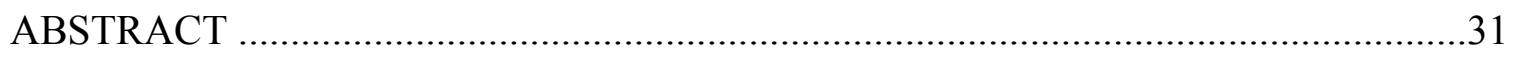

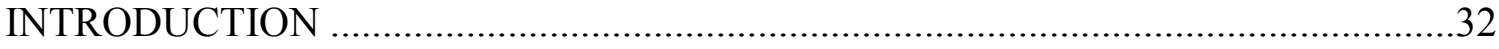

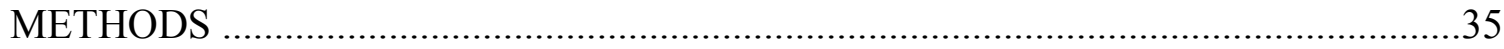




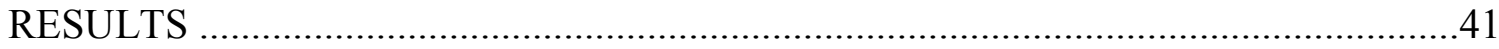

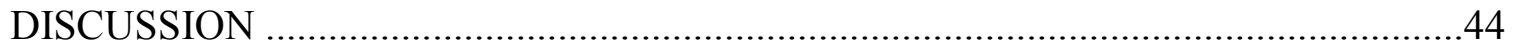

Chapter 3: Invertebrate Indicators of Excessive Fine Sediment in Streams of the Oregon

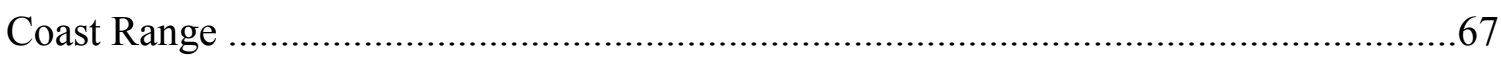

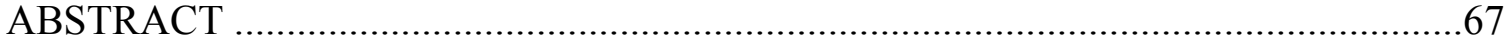

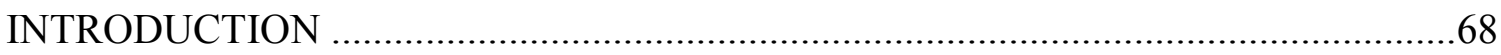

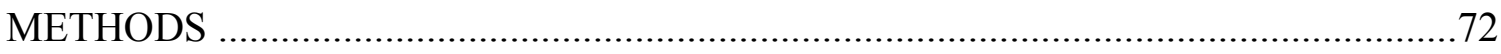

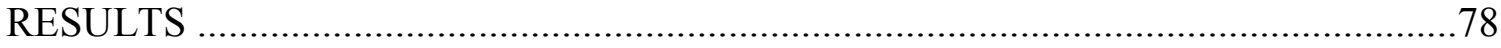

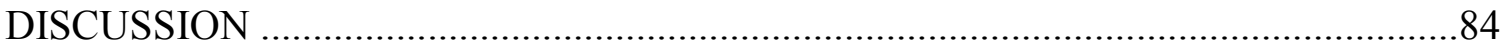

Chapter 4: An in-situ experiment to test the effect of natural sediment supply on stream invertebrate response to fine sediment addition in naturally colonized mesocosms ......103

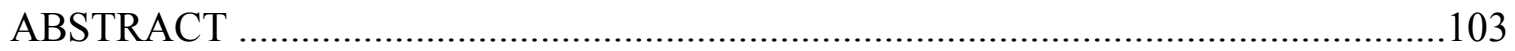

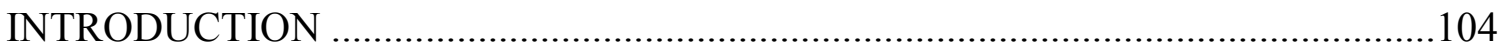

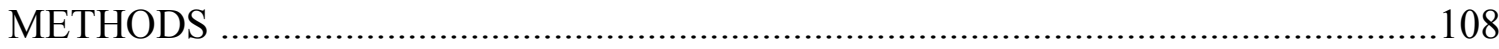

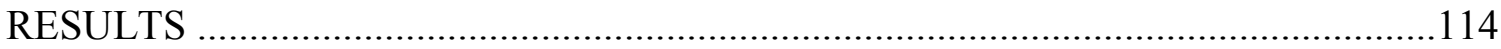

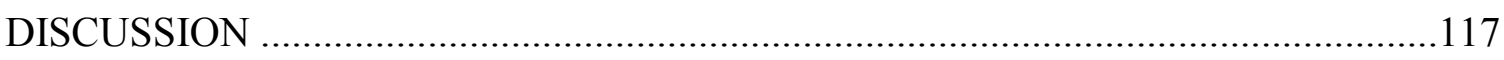

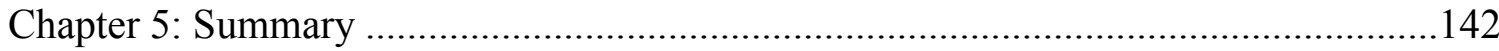

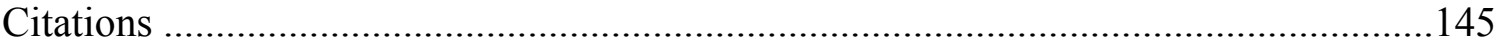

APPENDIX: Supplementary data and images …………..........................................168 


\section{List of Tables}

Table 2.1. Basin characteristics, stream physiochemical and climate summary data for study streams. Less than detection limit (LDL). Balch Land use data were obtained from RLIS (2001) and Lookout land cover data were obtained from the NLCD (Fry et al 2006). Elevation data were obtained from the USGS (2014).....................................62

Table 2.2. Summary invertebrate data. Fall (F), Spring (S). .....................................63

Table 2.3. Results of ANOSIM tests of differences between streams and season. Lookout Creek Sites 1 and 2 (LCS 1, LCS 2). Balch Creek (BCS 1).

Table 2.4. Functional attributes for taxa representing 95\% of total abundance.

Multivoltine (MV), Univoltine (UV), Semivoltine (SV).

Table 2.5. Results of vector analysis. Only vectors with $\rho$-values $<0.20$ are shown. Lookout Creek Sites 1 and 2 (LCS 1, LCS 2). Balch Creek (BCS 1) $r^{2}=$ psuedo $r^{2} \ldots \ldots . . .66$

Table 3.1. Environmental variables used in indicator analysis and subset of variables used for indicator analysis (X) Standard deviations (SD).

Table 3.2. Invertebrate functional metrics and selected taxa used for indicator selection for both geologies. Relative abundance (RA) used in final analysis (X). ......................95

Table 3.3. Factor loading for each variable on PC Axis I, II and III. .96

Table 3.4. Spearman Correlation Coefficients for latitude, slope, canopy and fines in Resistant (R) and Erosive (E) basins. Table shows a correlation matrix for four variables in each geology.

Table 3.5. Results from vector analysis for environmental variables in resistant $(n=55)$ and erosive geologies $(n=159)$. Values are pseudo $\left(r^{2}\right)$ with $\rho$ values: $\rho<0.10 \times, \rho<0.05 *$, $\rho<0.01^{* *}, \rho<0.001^{* * *}$, Not significant (NS).

Table 3.6. Results from Mantel test relating environmental matrices to invertebrate matrix at three scales in both lithologies. Mantel $r$ statistic and $\rho$ value is shown. $\rho<0.10$

$\mathrm{x}, \rho<0.05^{*}, \rho<0.01^{* *}, \rho<0.001^{* * *}$, Not significant (NS).

Table 3.7. Results from partial Mantel test relating environmental matrices to invertebrate matrix at three scales in both lithologies. Model shows the relationship with fines after the effect of slope on invertebrates has been removed. Mantel $r$ statistic is shown. $\rho<0.10 \mathrm{x}, \rho<0.05^{*}, \rho<0.01 * *, \rho<0.001^{* * *}$, Not significant (NS)................100 
Table 3.8. Adjusted $\mathrm{R}^{2}$ and $\rho$-values for selected indicators and correlation with slope and $\%$ fines (Fines) in resistant $(n=30)$ and erosive $(n=67)$ streams. Relative abundance (RA). Slope direction indicated (+/-). $\rho<0.10 \mathrm{x}, \rho<0.05 *, \rho<0.01^{* *}, \rho<0.001^{* * *}$, Not

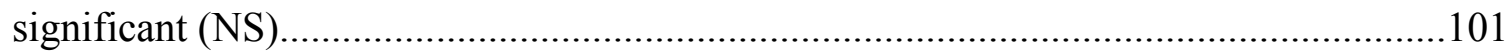

Table 3.9. Adjusted $\mathrm{R}^{2}$ and $\rho$-values for selected indicators residuals (rsd) and correlation with bed stability (Bed Stbl) and \% fines (fines) in resistant $(n=30)$ and erosive ( $n=67)$ streams. Relative abundance (RA). Slope direction indicated $(+/-)$. $\rho<0.10 \mathrm{x}, \rho<0.05 *, \rho<0.01 * *, \rho<0.001^{* * *}$ not significant (NS)

Table 4.1. Summary invertebrate data by creek and geology. Both Controls and Treatment (Treat.) mesocosms are shown. Data are summarized as mean, standard deviation (SD) and coefficient of variation (CV)...

Table 4.2. Summary environmental data by creek and geology. $\rho<0.10 \mathrm{x}, \rho<0.05 *$, $\rho<0.01 * *$, Not significant (NS).

Table 4.3. Summary data and t-test results comparing control mesocosms (meso) and instream sediment data for each geology. Values are expressed as mean, minimum (min) and maximum ( $\max$ ) for biotic, environmental and sediment size-class data (\% volume). Note sample size is different for in-stream sediment samples. $\rho<0.10 \mathrm{x}, \rho<0.05 *$, $\rho<0.01 * *, \rho<0.001 * * *$, Not significant (NS).

Table 4.4. Summary data and t-test results comparing treatment mesocosms (meso) in each geology. Values are expressed as mean, minimum (min) and maximum (max) for biotic and environmental data in both resistant and erosive geology. $\rho<0.10^{\mathrm{x}}, \rho<0.05 *$, $\rho<0.01^{* *}$, Not significant(NS).

Table 4.5. Summary data and t-test results comparing treatments and controls or disturbed and undisturbed mesocosms (meso) in each geology. Sample size is for each analysis is indicated in parenthesis $(\mathrm{N} / \mathrm{N})$ and grouping variable is indicated in the grouping column. indicated in $\rho<0.10^{\mathrm{x}}, \rho<0.05 *, \rho<0.01^{* *}$, Not significant $(\mathrm{N}) \ldots 139$

Table 4.6. Mouthpart structure and food source information. Total and mean invertebrates in each geology. References: Chapman and Demory (1993, CD), Hawkins (1985, H) Hawkins and Sedell (1981, HS), McShaffrey and McCafferty (1988, MM), Karouna and Fuller (1992, KF), Adams (2004, AD).

Table 4.7. Results of ANOVA analysis and linear models. F values, adjusted $\mathrm{R}^{2}$ and $\rho$ values are shown for sediment dose frequency (Dose Freq) and habitat loss (inorganic sediment remaining in mesocosms). Grazing traits are represented as relative abundance (RA). Slope direction indicated by + or -. $\rho<0.10 \mathrm{x}, \rho<0.05 *, 0.01 * *, 0.001 * * *$, Not significant (NS). 


\section{List of Figures}

Figure 1.1 Conceptual model of sediment supply and delivery to streams in Oregon Coast Range watersheds. Boxes represent process taking place throughout the watershed (dashed lines) and those taking place within the stream (solid line).....

Figure 1.2. Temporal and spatial ecological relationships of invertebrate communities. The y-axis shows changing scale over 15 orders of magnitude with larger values at the bottom. Each level represents a nested model of a stream system ranging from the biome scale to the patch scale and from long-term to short-term process. The diagram illustrates the spatial and temporal complexity and hierarchical connectivity of stream ecosystems

Figure 1.3. Sediment effects on stream function and the invertebrate community. Mitigating factors interact and feedback with sediment supply and stream function to shape invertebrate community.

Figure 1.4 Conceptual diagram shows sources of increased fines in streams and their mechanistic effects on invertebrates and benthic habitat. Excessive fine sediment can degrade benthic habitat and reduce invertebrate fitness resulting in altered communities and loss of function. The grey area represents the focus-area of this research

Figure 1.5 Illustration of the different mouthpart structures and feeding strategies of two mayfly grazers: Rhithrogena and Paraleptophlebia. Photos by Karouna and Fuller (1992) and McShriffey and McCafferty (1988). Rhithrogena mouthparts contain combs (A) that are used to scrape-up periphytic algae and molae (B) to grind food particles. In contrast, Paraleptophlebia uses hairs (C) to brush-up loose organic material and teeth to cut-up food particles (D). It is hypothesized that invertebrate response to fine sediment in food sources will be largely dependent on feeding traits.

Figure 1.6 Images showing experimental results on the effect of inorganic sediment on Rhithrogena mouthpart brushes and bristles. Lower panels show increasing wear on Rhithrogena bristles caused by feeding on algal food resources growing on sand paper (Arens 1990).

Figure 2.1 Map of study streams and basins in Oregon. Black circles represent data collection locations. Dark area is the Portland urban growth boundary.

Figure 2.2 Randomized field technique. Three D-net benthic samples are collected (a), composited into a plastic tub (b) and then transferred to the Field subsampling tray (c). Five cells $(\mathrm{X})$ are randomly chosen from which macroinvertebrates are counted and identified.

Figure 2.3 Invertebrate abundance per area for the three study streams. X axis shows Fall (F) and Spring (S) samples from 2005-2012. 
Figure 2.4 Invertebrate density over time (z score) for three streams (a), ENSO and all streams (b), temperature and Balch (c) and Lookout sites (d), precipitation and Balch (e) and Lookout sites ( $\mathrm{f}$ ). The $\mathrm{Y}$ axis shows standardized invertebrate density and the $\mathrm{X}$ axis shows Fall (F) and Spring (S) samples from 2005-2012 ...............................................54

Figure 2.5 LOESS (span $=0.65$ ). Stream comparison of invertebrate density using Kendalls $\tau$. X axis shows Fall (F) and Spring (S) samples from 2005-2012.................. 55

Figure 2.6 Assemblage in Balch Creek and Lookout Creek (Sites 1 and 2) for all seasons

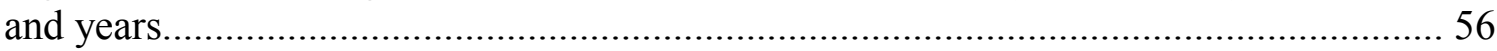

Figure 2.7 Ordinations based on relative abundance with climate vectors for Balch Creek 1 (BCS 1), Lookout Creek 1 (LCS 1) and Lookout Creek ( LCS 2). Only vectors with $\rho$ $<0.20$ are shown. Filled symbols are Spring, open symbols are Fall. Stress $<15$ for all ordinations. Mean Temperature (Temp), Total Precipitation (Precip)..

Figure 2.8 Ordinations based on functional feeding group with climate vectors. Only vectors with $\rho<0.20$ are shown. Filled symbols are Spring, open symbols are Fall. Stress $<10$ for all ordinations.

Figure 2.9 Balch Creek and Lookout Creek ordinations based on functional feeding group (a, b) and life length (c). Bubble plots show relative abundance of scrapers or semivoltine. Only temperature and climate vectors with $\rho<0.20$ are shown..

Figure 2.10 Scatter plots for significant linear models of standardized ( $\mathrm{Z}$ score) invertebrate density as a function of ENSO $(a, b)$ or mean maximum temperature (Max Temp c,d). $\mathrm{R}^{2}$ and $\rho$-value for each model shown in plot. Only models with $\rho<0.10$ are shown. Symbols are Fall (F) and Spring (S). There were no significant models for Lookout Site 2 .

Figure 2.11 Standardized ( $Z$ score) invertebrate functional density for scrapers $(a, b, c)$ and voltinism (d,e,f) as a function of average monthly maximum temperature (Max Temp, a,b,c,d,e) and average monthly precipitation (f). $\mathrm{R}^{2}$ and $\rho$-value for each model shown in plot. Only models with $\rho<0.10$ are shown. Symbols are Fall (F) and Spring (S)...

Figure 3.1 Map of study sites in Oregon's Coast Range. Dark and stippled areas are resistant geology, grey areas are erosive geology...... 88

Figure 3.2 Ordination of invertebrates and hypothesized major environmental gradient. Grey-dashed line represents an orthogonal gradient. Closed circles are resistant and open circles are erosive geologies. Gradients were interpreted and only used as a framework for exploratory analysis.

Figure 3.3 Relationships between major significant environmental gradients and invertebrate assemblage within resistant and erosive geologies. Slope and size are 
important in both basins, while landuse is only significant in erosive basins. Figure also illustrates the different associations between assemblage and vectors within each geology.

Figure 3.4 Linear models of selected indicator residuals as a function of percent fines in both geologies. Residuals are unexplained variance from a linear model of slope and each indicator. Dashed trend line is for erosive sites, solid line is for resistant sites. Significant relationships for both geologies were found in Scrapers (a) and Gougers (c). In Erosive geologies, Brushers (b) and Rhithrogena (d) were significant. In resistant geologies, Paraleptophlebia (e) and External Gills (f) were significant. See Table 3.9 for $\mathrm{R}^{2}$ and $\rho$ values

Figure 3.5 Illustration of the different mouthpart structures and feeding strategies of two mayfly grazers: Rhithrogena and Paraleptophlebia. Photos by Karouna and Fuller (1992) and McShriffey and McCafferty (1988). Rhithrogena mouthparts contain combs (A) that are used to scrape-up periphytic algae and molae (B) to grind food particles. In contrast, Paraleptophlebia uses hairs (C) to brush-up loose organic material and teeth to cut-up food particles (D). It is hypothesized that invertebrate response to fine sediment in food sources will be largely dependent on feeding traits..

Figure 3.6 Boxplots of percent fines and sand covering the stream substrate in each geology.

Figure 4.2 Mouthpart structures of Rhithrogena (Brusher), and Baetis (Gouger). Note Scale difference, image by Arens (1989).

Figure 4.3 Map of study area and final site selections. Erosive basins: Beaver (Bevr), Pebble (Peb), Scappoose (Scap) and Northrup (North). Resistant basins: Drift, Jones, Jordon (Jord) and South Fork of the Wilson River (SF).

Figure 4.4 Schematic diagram showing basin selection process. Data source shown in italics. Geology data were obtained from USGS and based on the maps of Walker and MacLeod (1991), logging data were obtained from the Coastal Analysis and Modeling Study (CLAMS 2005), and landcover data were obtained from the National Landcover Data base (NLCD 2006).

Figure 4.5 Sampling schematic and planned dosing schedule. Top figure illustrates experimental set-up with randomly selected treatment (solid lines) and control (dashed lines) mesocosms. The lower figure shows the dosing and sampling schedule and amount of sediment added to each mesocosm. High flows on the third day of sampling resulted in an alteration of the schedule and only three sediment doses.

Figure 4.6 Presence/absence chart of taxa found in Erosive sites. Stream names: Beaver (B), Pebble (P), Scappoose (S), and Northrup (N). Invertebrate Orders are shown in parenthesis: mayfly (E), stonefly (P), caddisfly (T), Diptera (D), and Coletoptera (C). 
Sum is the total number of each taxon.

Figure 4.7 Presence/absence chart of taxa found in Resistant sites. Stream names: Drift (D), Jones (JO), Jordon (JR), and South Fork (SF). Invertebrate Orders are shown in parenthesis: mayfly (E), stonefly (P), caddisfly (T), Diptera (D), and Coletoptera (C). Sum is the total number of each taxon..

Figure 4.8 Ordinations based on presence/absence and relative abundance of all streams within each geology.

Figure 4.9 NMDS ordinations based on relative abundance of each mesocosm and dosing frequency for each stream. Symbols correspond to symbols in Figure 4.7. Numbers show dosing frequency associated with each mesocosm assemblage at each stream. Northrup samples were mixed up in the high flow event. No significant relationship between dosing frequency and assemblage was observed in any of the streams..

Figure 4.10 Dose frequency boxplots of invertebrates for both geologies showing the response of invertebrate abundance (number per mesocosm, a), richness (b), biomass (c), and grazer (d), brusher (e) and gouger (f) relative abundance (Rel. Abund). Results of ANOVA analysis shown (NS=not significant).

Figure 4.11 Ordinations and sediment (Sed.) vectors for both geologies (a,b). Bubble plots show relative abundance of grazer $(c, d)$, brushers $(e, f)$ and gougers $(g, h)$..

Figure 4.12 Linear models of velocity-adjusted models of invertebrates as a function of inorganic sediment remaining in mesocosms. $\rho<0.10+, \rho<0.05^{*}, \rho<0.01 * *$. 


\section{Chapter 1 Introduction}

\section{Sediment Pollution of Small Streams in the United States}

While sedimentation is a natural component of lotic systems, erosion from anthropogenic activities, such as logging, agriculture and urban development, can deliver excessive levels of fine sediment to streams where it degrades habitat and affects algal communities, invertebrates and fish (Waters 1995; Wood and Armitage 1997). A 2006 study by the United States Environmental Protection Agency (USEPA) found $42 \%$ of United States' stream miles are in poor condition due to excessive fine sediments and nutrients acting as major stressors to aquatic systems (USEPA 2006). In response to growing concern for the condition of national streams, the USEPA designed and implemented the National Wadeable Streams Assessment (WSA) from 2000-2004. The WSA was the first statistically sound survey of the country's wadeable streams (Paulsen et al. 2008). The WSA examined $90 \%$ of the total length of perennial, first through fifth order streams in the United States (USEPA 2006) and identified key water-quality stressors which are likely impacting the chemical, physical and biological processes of wadeable streams. The WSA documented excessive nutrients and sediments as major sources of impairment for nearly a third of all stream length in the United States. In the Pacific Northwest, the WSA found nearly $20 \%$ of streams in poor condition due to excessive fine sediment (USEPA 2006). The WSA also determined stream-bed fine sediments as one of the greatest relative risks to biological condition (USEPA 2006).

Logging, land development and other human activities in the Oregon Coast Range have altered the hydrology and sediment dynamics of forested watersheds (Hartman 
2004), thus contributing to fine sediment pollution of small streams and degrading lotic habitat and impacting ecologic function (Poole 2010). However, benthic fine sediment is difficult to measure quantitatively, thus new management tools need to be developed to identify excessive fine sediment conditions and monitor their effect on stream function and resident biota. Stream invertebrates are integrators of environmental condition (Karr 1998) and thus may be a useful tool for monitoring the impact of land use in the Coast Range on ecological processes. This dissertation will explore the use of stream invertebrates as bioindicators of sediment pollution in small streams of the Oregon Coast Range.

The goal of the dissertation is to examine fine sediment-invertebrate relationships in the Coast Range from a temporal, spatial and causal-effect perspective. The major objectives are to: 1) Evaluate nine years of stream invertebrate data collected from two streams in western Oregon, 2) Examine invertebrate and environmental conditions with an emphasis on sediments in wadeable streams across the Coast Range ecoregion and to identify potential bioindicators of excessive sediment, and 3) Examine the role of geology in shaping invertebrate responses to excessive fine sediment and test invertebrate bioindicators that may be useful for biomonitoring fine sediment. The results of this research will provide insights about relationships among environmental factors, fine sediment and stream invertebrate communities in wadeable streams of the Oregon Coast Range streams; and thereby, will contribute to management efforts in a region experiencing increasing logging or urbanization pressure. 


\section{The Oregon Coast Range Study Area}

The Pacific Coastal ecoregion is characterized by a maritime climate with high winter precipitation and cool, dry summers (Naiman and Bilby 1998). Oregon's Coast Range is covered by dense coniferous forests of hemlock, firs and redwoods (Naiman and Bilby 1998). The aquatic systems draining these forests support large runs of anadromous fish, including the endangered Chinook and coho Salmon, sensitive amphibians and birds. The Oregon Coast Range physiographic province is an economically and ecologically important region of the Pacific Northwest. The forestlands of this region are a major source of timber and a critical habitat for salmon and other endangered species (Hall et al. 2004). As second growth forests mature in the Oregon Coastal ecoregion, there is increased interest in developing best management practices reflecting knowledge of key ecological mechanisms and linkages in streams (Spies and Johnson 2007).

\section{Fine Sediment Dynamics in Oregon Coast Range Streams}

It is well known that forest management practices alter hydrologic processes in a watershed and can degrade the ecological function of both the watershed and streams (Hartman 2004). Silviculture and related timber harvesting activities in coastal Oregon can lead to changes in stream ecosystems that may degrade critical coastal habitat (Spies et al. 2007). Aquatic ecosystems are closely linked to near-stream land cover and watershed characteristics (Naiman et al. 2000), thus effective management of coastal forestlands is dependent on understanding the impact of land use and land cover on stream hydrology (Naiman and Bilby 1998; Spies and Johnson 2007).

In small forest-covered watersheds, there are both internal and external pathways for transport and deposition of fine sediment (Gomi et al. 2005). Figure 1.1 shows a 
conceptual model of the key physical processes and pathways related to stream sediment production and yield. In Oregon's mountain forests, external watershed characteristics such as slope, land cover, climate, geology and soils control mass movements and landslides and deliver large amounts of sediment to streams (Swanson et al. 1987; Grant and Wolff 1991; Benda et al. 1998; Hassan et al. 2005). In the heavily-forested watersheds of the Oregon Coast Range, most of the precipitation infiltrates into welldeveloped organic horizons, so overland runoff and erosion are rare; thus, the most likely mechanism of sediment flux into streams is through soil slumping (Cheng 1988). However, erosion from tree harvesting (Rice et al. 2004) and road building (Waters 1995; Luce and Black 2001) can increase sediment production and delivery to streams. Internal controls on sediment are related to mechanisms and processes that store, transport and deposit fine sediment within the stream. Stream substrate has been shown to store and release fine sediment from behind large boulders, while downed logs can trap significant volumes of sediment (Hassan et al. 2005). Flow dynamics, such as hydrograph shape, and seasonal conditions, such as fall flushing and tributary characteristics, are also important factors related to sediment transport and deposition (Gomi et al. 2005).

\section{Ecological Framework}

\section{Abiotic and biotic controls of invertebrate assemblage in streams}

The assemblage structure of organisms in an ecosystem is the result of interactions between the abiotic and biotic determinants (Power et al. 1988) operating at multiple spatial and temporal scales (Hilborn and Stearns 1982; Poff 1997; Leibold et al. 2004; Allan 2004). In lotic systems, assemblage patterns are associated with physical forces, ecosystem processes and biotic interactions that vary spatially (Usseglio-Polatera 
and Tachet 1994) and temporally within a stream network (Vinson and Hawkins 1998; Allan and Castillo 2007; Winemiller et al. 2010). Invertebrate assemblage is spatially related to a range of discontinuous processes occurring across the biome scale to the individual rock within a stream (Cellot et al. 1994; Poole 2002; Wiens 2002). In the temporal dimension, invertebrate assemblages are shaped by a wide range of processes that vary climatically (Durance and Omerod 2007), yearly (McElravy et al. 1989), seasonally (Reece et al. 2001) and daily (Waters 1962).

Recent lotic research has emphasized the model of patch dynamics derived from the physical habitat template (Pringle et al. 1988; Townsend 1989; Thompson and Lake 2010) as a hierarchical framework for explaining assemblage structure and composition in streams (Frissell et al. 1986; Pringle et al. 1988; Wiens 2002; Winemiller et al. 2010). In this model, patches are defined as an assemblage or functional process zone (e.g. Thorp et al. 2008) that are surrounded by a shifting mosaic of dissimilar assemblage or area (Forman and Gordon 1981; Pickett and White 1985). Stream patches are related to both abiotic and biotic processes and scale-dependent mechanisms operating synergistically throughout the landscape. In stream systems, habitat patches are structured hierarchically and range in size from the biome scale to the individual rock in a stream (Figure 1.2; Frissell et al. 1986; Poff 1997; Wiens 2002; Parsons et al. 2003; Thorp et al. 2006; Thorp et al. 2008). Ultimately, the interactions between abiotic and biotic patches, at multiple spatial and temporal scales, act as linked environmental filters shaping habitat and the invertebrate assemblage (Schumm 2005; Thorp et al. 2008).

A stream's structure and ecological function is hierarchical, highly variable and shaped by the landscape mosaic in which they flow (Thorp et al. 2008; Allan and Castillo 
2007; Ward et al. 2002). Therefore, modeling the structure, function and processes related to fine sediment deposition in lotic systems is dependent on models that account for both spatial and temporal scales and reflect understanding of key mechanisms shaping the stream environment and the invertebrate assemblage (Frissell et al. 1986). In this sense, it is useful to conceptualize the ecology of streams and the related biotic assemblage using a framework of geomorphologically-derived levels representing the ecosystem mechanism at work (e.g. Frissell et al. 1986). Viewing lotic systems in this way provides several benefits including: 1) reducing the number of variables needed to model a system, 2) improving model performance, and 3) providing useful information for watershed managers (Frissell et al. 1986). Clearly, the processes discussed below are linked and active across multiple scales, but for the purposes of this discussion, the stream ecosystem is examined at four levels: biome, watershed basin, stream reach and habitat patch (Figure 1.2).

\section{Hierarchical controls of invertebrate assemblage}

\section{Biome Level}

At the Biome level, large-scale environmental factors such as climate, surface geology and valley geomorphology act as indirect filters on local stream conditions and invertebrates assemblage (e.g. Parsons et al. 2003; Townsend et al. 2003). Large-scale mechanisms are related to stream assemblage through processes such as climate, hydrology and energetics. A study by Minshall et al. (1983) found that the differences in invertebrate assemblage across four biomes were related to precipitation and stream flow patterns, organic matter processing and basin geomorphology. Long-term climate patterns such as precipitation, runoff and flow affect invertebrate assemblage largely 
through hydrologic patterns and timing. Poff and Ward (1989) argued that flow-related characteristics such as flood variability and predictability strongly influence assemblage structure by controlling ecological processes and related biotic interactions. For example, high flow variability and low flow predictability result in dominance by abiotic processes while low variability and high predictability support an assemblage shaped mainly through biotic interactions (Poff and Ward 1989). Long-term precipitation patterns also influence assemblage structure through the timing and duration of rainfall and stream flow. During wet years, stream habitat is more complex and flow more stable therefore, invertebrate populations are denser and more variable (Bêche et al. 2006). Invertebrates with drought-resistant biological traits are more common in dry years, while traits resistance to high flows and flooding are more common in wet years (Bêche and Resh 2007). Another important biotic control of assemblage is simply the distance between regions or basins. Stream invertebrates are generally poor fliers and can only migrate relatively short distances during their terrestrial stages. Analysis of genetic variation among stream invertebrate populations suggests that dispersal capability and reproductive strategy of adult invertebrates is a limiting factor in their ability to move across large spatial scales (Bunn and Hughes 1997).

Other geomorphic processes can act as regional or watershed-scale controls on local habitat conditions. For example, streams underlain with igneous rocks often have low hardness, which limits uptake of dissolved organic material (Minshall et al. 1983). Furthermore, igneous surface geology shapes alkalinity, which limits buffering capacity, thereby shaping assemblage through increased level of aluminum present in streamwater with low pH (Rosemond et al. 1992). Energy inputs are closely linked to stream width, 
which is related to basin size, thereby controlling feeding strategy and assemblage (Richards et al. 1996). Landform characteristics such as gradient and valley formation have a strong effect on substrate type and canopy cover (Richards et al. 1996), which, in turn, influences organic matter inputs and retention. For example, high gradient streams with large boulders or woody debris have higher organic matter retention than low gradient high order streams; therefore, making headwaters streams functionally more stable (Minshall et al. 1983). Catchment land cover is also a determinant of invertebrate density and assemblage. A study of three different biomes in Canada representing different types of land cover (grasslands, eastern deciduous forest and western coniferous forests) showed significant differences between invertebrate assemblage and density (Corkum 1992) at the biome level, but differences were mainly due to local land use and riparian vegetation.

\section{Basin Level}

Stream structure and process within a basin are highly variable and related to catchment-scale characteristics such as geomorphology, hydrology, energetics and land cover. Geomorphologic factors such as relief, basin form and drainage area act as major controls on hydrology, channel shape and stream function thus shaping invertebrate assemblage (Frissell et al. 1986; Statzner et al. 1988). In a study of New Zealand streams, catchment-scale characteristics such as relief, basin form and drainage area accounted for most variation in invertebrate assemblage (Townsend et al. 2003). The stream network within a basin is also a source of assemblage variation (Rice et al. 2001; sensu Fisher et al. 2004). Geology and topography are also important characteristics shaping invertebrate assemblage through controls on channel form (Richards et al. 1996; Richards et al. 1997; 
Benda et al. 1998), local habitat conditions (Davies et al. 2000) and interactions with land use (Shearer and Young 2011) and forest cover (Shearer and Young 2011). Stream sediment recruitment points at tributary junctions, where coarse substrate is abundant and sediment fining is reduced, show significantly higher biodiversity and abundance of taxa that prefer course substrate (Rice et al. 2001). Invertebrates richness decreases with increased elevation likely due to the difficulties associated with colonizing and inhabiting the extreme upper reaches of a stream (Allan 1975). Maximum taxa richness occurs at mid-order streams where intermediate flood disturbance regimes provide high habitat diversity (Stanford and Ward 1983) including substrate size and type (Grubaugh et al. 1996) and yearly temperature variance (Ward and Stanford 1982; Minshall et al. 1985). Downstream shifts in other basin-related hydraulic properties, such as flow velocity and flow duration, exert extreme forces on benthic invertebrates that shape taxonomic composition and is reflected in biotic characteristics such as body form, feeding, movement and drift (Statzner et al. 1988; Poff and Ward 1989). Flow permanence of a stream also has a large effect on assemblage. Invertebrates assemblage in perennial streams is more abundant and different than the assemblage found in intermittent and ephemeral streams (Rosalie and Resh 2000; Halwas et al. 2005).

The energetics of a stream, such as organic matter input, retention, processing and transport, act as controls of invertebrates assemblage. The River Continuum Concept (RCC) describes a downstream longitudinal shift of invertebrates assemblage due to habitat change and energy inputs (Vannote et al. 1980). The RCC predicts energy sources should shift downstream, from allochthonous to autochonous derived, invertebrates assemblage shifts. While the RCC is a useful framework for conceptualizing the 
longitudinal characteristics of a river, its predictive power is limited (Statzner and Higler 1985). A study by Minshall et al. (1983) demonstrated energetics and invertebrates feeding followed the shift postulated by the RCC, but local factors, such as riparian condition and hydrological variations, caused deviations from the predicted continuum. Other basin-related energetics are also related to invertebrates assemblage. For example, floods inundate the surrounding riparian zone and draw large amounts of organic material into streams as the flood recedes (Junk et al. 1989). In small streams, flood pulses are shorter and less predictable leading, whereas in larger streams, flood duration is long and more predictable. In high order streams, these processes lead to longer food chain length, thereby increasing ecological stability (Sabo et al. 2010).

Land cover and land use are both related to natural basin characteristics and human-derived factors. Land use within a basin, in conjunction with natural conditions, can also shape assemblage. Basin-wide land use, such as urbanization and farming are known to affect stream integrity and invertebrates assemblage (Quinn and Hickey 1990; Allan et al. 1997). The effects of land use can be mediated by natural basin characteristics (Quinn and Hickey 1990) and the proximity of land use to the stream (Sponseller et al. 2001; Townsend et al. 2003).

\section{Reach Level}

Within a stream reach there are a range of abiotic and biotic processes which directly and indirectly shape invertebrates assemblage, resulting in high within-reach variability that can be greater than among-stream variation (Angradi 1996; Halwas et al. 2005). In general, different habitats within a reach support different kinds of taxa and functional processes (Hawkins et al. 1982; Logan and Brooker 1983; Huryn and Wallace 
1987; Angradi 1996; Scullion et al. 1982; Halwas et al. 2005). However, invertebrates assemblage, abundance and production are highly variable and strongly related to localized habitat features such as channel form, riparian land cover, disturbance and recovery. Reach gradient is related to invertebrates assemblage through stream velocity and organic matter entrainment and retention. For example, filtering organisms with attachment structures are common in fast currents, while crawling shredders are more common in slow water habitat (Huryn and Wallace 1987; Angradi 1996). Stream geomorphology is also an important filter of assemblage. Invertebrates abundance, assemblage and functional feeding group are different in bedrock, riffles and pools mainly due to differential organic matter dynamics (Huryn and Wallace 1987). Bedrock habitats have high organic matter entrainment and low retention, pools have low entrainment and high retention and riffles have intermediate levels of organic matter entrainment and retention (Newbold et al. 1982). Macroinvertebrates are often more abundant and diverse in riffles (Logan and Brooker 1983; Brown and Brussock 1991; Halwas et al. 2005) where the interstitial space of substrate common in riffles is optimized for collecting organic material and protection from stream current (Stanford and Ward 1983). Collector-filterers are more common in high entrainment bedrock habitats, shredders more common in high retention pool habitat and collector-gatherers present in all habitat types (Huryn and Wallace 1987). Downed logs and large woody debris in streams alter the hydrology of a stream and the invertebrates assemblage structure and function (Wallace et al. 1995; Johnson et al. 2003). In streams with large amounts of downed logs and woody debris, associated debris damns and pools are rich in 
organic matter and can support high densities of invertebrates and different functional characteristics than plunge pools (Angradi 1996).

Canopy cover and riparian inputs are an important determinant of assemblage, which can mask other disturbances such as logging (Frady et al. 2007). In small streams, allochthonous inputs from the surrounding vegetation are a major source of energy for stream invertebrates that feed on leaves and coarse organic material (Fisher and Likens 1973; Cummins and Klug 1979). In addition, the leaf type and nutrient content have an effect on shredder consumption (Irons et al. 1988). Streams without shading have higher abundance and different feeding groups than shaded streams (Hawkins et al. 1982). Forest structure and composition can influence the assemblage of caddisfly shredders and grazers (Molles 1982) and the species composition and nutrient status of riparian vegetation relates to Trichopteran shredder activity (Irons et al. 1988).

Disturbance is an important abiotic factor related to invertebrates assemblage. Resh et al. (1988) define disturbance as "any relatively discrete event in time that disrupts ecosystem, assemblage, or population structure, and that changes resources, availability of substratum or the physical environment." In lotic systems, disturbance can occur as floods or droughts that occur at an unpredictable intensity and frequency (Resh et al. 1988; Lake 2003). Floods tend to increase downstream and lateral linkages while droughts discontinue or fragment downstream connections (Lake 2000). In streams, disturbance acts to maintain abiotic and biotic patches through generating disequilibrium conditions (Pickett and White 1985; Minshall and Peterson 1985), maintaining maximum diversity at intermediate levels (Connell 1978; Ward and Stanford 1983; De'ath and 
Winterbourn 1995; Townsend and Scarsbrook 1997) and/or influencing net species interactions (Huston 1979; Hemphill and Cooper 1983).

Succession and colonization are important biotic factors that shape assemblage and establish long-term patterns of invertebrates assemblage. When a stream is disturbed, most frequently by flooding, it is rapidly re-colonized by periphytic algae and invertebrates (Fisher et al. 1982). Drifting invertebrates from upstream can quickly colonize recently disturbed habitat and dominate the early assemblage (Brittain and Eikeland 1988). For example, several studies document mayflies (Baetidae) and midges as the first to colonize disturbed habitat and are gradually displaced by invertebrates with lower dispersal abilities (Fisher et al. 1982; Milner et al. 2008). However, at least one study found the successional pattern of assemblage can take more than 20 years to fully develop and is related to invertebrate dispersal ability, tolerance and stream habitat (Flory and Milner 2000; Milner et al. 2008).

\section{Patch level}

The patch level represents processes operating at scales relative to algae, invertebrates and fish. These processes include abiotic and biotic mechanisms largely controlled by substrate, nutrient availability and feeding (Minshall and Minshall 1977; Erman and Erman 1984; Frissell et al. 1986; Pringle et al. 1988). Invertebrates are generally most abundant on cobble- to boulder-sized particles, as this size-class acts to better trap organic matter retention, provides a stable living surface in strong currents and promotes nutrient delivery and exchange through increased turbulence (Rabeni and Minshall 1977; Erman and Erman 1984; Quinn and Hickey 1990). The condition and composition of the substrate is also an important determinant of assemblage. The addition 
of sand to substrate begins to affect assemblage only at relatively larger amounts $(>75 \%)$, whereas the presence of a light covering of silt significantly reduces richness (Hawkins et al. 1982; Angradi 1999). Substrate heterogeneity and texture relates to invertebrate assemblage; mixed substrata have higher invertebrate richness than a single substrate type (Allan 1975). Richness relates to medium particle size (Erman and Erman 1984), substrate heterogeneity and patch compactness (Boyero 2003) and size (Matias et al. 2010). Substrate surface texture relates to assemblage with higher richness associated with complex texture (Hart 1978; Downes et al. 2000). Erosion and movement of substrate influences the shape and degree of sorting, thus causing drift or mortality as the rocks move or begin to erode (Holomuzuki and Biggs 2003).

Small-scale nutrient dynamics also act to shape primary productivity in stream communities. At very small temporal (hourly) and spatial $(\mathrm{cm})$ scales, variability of stream water chemistry is a major determinant of nutrient availability and uptake (Pringle et al. 1988). For example, algae growth is often concentrated in fast currents where nutrient delivery is highest (Pringle and Bowers 1984; Pringle et al. 1988) or near metabolic activity such as midge larvae or caddisfly retreats (Pringle 1985). Algal assemblage relates to behavioral and feeding responses of invertebrates, including density (Rabeni et al. 2005), feeding strategy (Hart 1981) and territoriality (Hart 1985).

It appears that fish predation on invertebrates plays a marginal role in shaping stream invertebrate assemblage. Predation by vertebrates and invertebrates affects specific morphological features and behavior of taxa in single-organism experiments (Feltmate and Williams 1991) but in whole-stream studies was found to have a minimal effect on invertebrate assemblage, likely because of high emigration rates from drift or 
substrate (Thorp and Bergey 1981; Culp 1986; Vinson and Hawkins 1998; Clements 1999) or the effect is masked by high habitat variability (Brown and Lawson 2010). However, predation can have strong indirect effects on stream function such as leaf litter processing (Obernborfer et al. 1984) and diatom assemblage (Koetsier 2005).

\section{Literature Synthesis and Gap Analysis Impact of excessive fine sediment on invertebrates}

While sediment is a natural part of lotic systems, excessive sediment delivery from human activities can negatively impact stream invertebrate assemblage (Waters 1995; Wood and Armitage 1997). For example, road constructing (Lenat et al. 1981), dam flushing (Gray and Ward 1982; Erman and Lignon 1988), mining activities (Quinn et al. 1992), logging (Lemly 1982; Montgomery et al. 2000) and agriculture (Richards et al. 1993; Matthaei et al. 2006) have been shown to increase fine sediment supply, delivery and deposition in the stream, which results in a loss of invertebrate abundance and richness and alters benthic communities. Sediment in the stream is carried by suspended load or saltation and is deposited on the benthos when stream velocity drops below settling velocity (Wood and Armitage 1997). Suspended sediment and stream turbidity results in invertebrate drift (Doeg and Milledge 1991) and lowers invertebrate abundance and richness (Quinn et al. 1992). Saltation is the rolling or bouncing of sediment particles carried in the bedload along the bottom of the stream. Saltation scours the benthos, altering benthic communities and mediating biotic interactions (Culp 1986; Schofield et al. 2004). Deposited sediment covers the substrate, embeds individual rocks or infiltrates into the substrate and fills interstitial space (Wood and Armitage 1997). 
Stream invertebrates are strongly related to benthic substrate size (Rabeni amd Minshall 1977; Hawkins 1982), composition (Allan 1975; Erman and Erman 1984; Bourassa and Morin 1995) and texture (Downes et al. 2000). As the proportion of sand and clay fines in substrate composition increases, invertebrate assemblage is altered (Quinn et al. 1992; Richards et al. 1993), richness is reduced (Larsen and Ormerod 2010; Larsen et al. 2010) and abundance is decreased (Bourassa and Mourin 1995). The effect on invertebrates by increasing deposition of fine sediment in the substrate has been observed at a $5 \%$ increase in fines $(0.2 \mathrm{~cm}$; Angradi 1999) with thresholds evident around 10\% (Kaller and Hartman 2004; Larsen et al. 2010). However, this relationship may not be the same in small mountain streams where invertebrates may be highly tolerant of sand-sized substrate (Williams and Mundie 1978; Hawkins et al. 1982; Culp 1986). Deposited fine sediment infiltrates into substrate where it affects invertebrates living in the hyporheos. A study by Richards and Bacon (1994) found fine sediments were greatest at a depth of $30 \mathrm{~cm}$ and resulted in a corresponding $60 \%$ reduction of invertebrates. A light covering of fines on the surface of substrate is also detrimental to invertebrates. Excessive surface fining is related to land cover (Roy et al. 2003) and upstream bank erosion (Larsen et al. 2009) and has been shown to reduce richness (Zweig and Rabeni 2005; Matthaei et al. 2006; Larsen et al. 2009), alter functional feeding (Rabeni et al. 2001) and affect specific taxa (Cover et al. 2008; Larsen and Ormerod 2010).

\section{Mechanisms of fine sediment impacts on invertebrates at multiple scales}

The effects of stream sedimentation operate across a wide range of temporal and spatial scales (Richards et al 1996; Larsen et al. 2009) and are mediated by environmental characteristics (Figure 1.3, Griffith et al. 2009) and mitigated by invertebrate tolerance 
and avoidance (Roy et al. 2003). For example, Larsen et al. (2009) found sediment supply from bank erosion $500 \mathrm{~m}$ upstream was strongly related to downstream fine sediment cover, but invertebrates were most affected by sediment-related dynamics at the patch scale.

At the patch scale, the negative impact of fine sediment on invertebrates is related to alteration of food webs, selection of tolerant functional characteristics and the physical effects on invertebrates. Fine sediment contamination of algae reduces mayfly feeding (Suren 2005), growth (Peeters et al. 2006) and assimilation rates (Broekhuizen et al. 2001). Snail growth, however, was found to be highest at intermediate levels of contamination, suggesting they derive trace nutrients from the sediment (Broekhuizen et al. 2001). The harsh conditions generated by sediment saltation and deposition may also affect biotic interactions (Walde 1986). In a study by Schofield et al. (2004), sediment addition reduced predator feeding on invertebrates, allowing for more mayfly grazing, thus altering algal assemblage. Excessive sedimentation likely disrupts feeding strategies of invertebrates whose filtering structures or nets may be clogged by fine sediment (Rabeni et al. 2005). A study by Larsen et al. (2010) found that invertebrates with short life cycles and external gills were reduced by fine sediment cover and resulted in a nested assemblage pattern, suggesting that sedimentation selects for specific traits. This is supported in a study by Lemly (1982), which documented the bacterial infection of invertebrate gills covered by fine sediment.

At the reach scale, there are several mechanisms related to the effect of suspended and deposited sediment on invertebrate assemblage. Suspended sediment reduces light penetration to the stream bottom, thus altering benthic periphyton assemblage (Davies- 
Colley et al. 1992), reducing organic content of the epilithon (Davies-Colley et al. 1992) and limiting stream productivity (Parkhill and Gulliver 2002). Increased flow and saltation scours benthic communities, altering algal assemblage and reducing biomass, particularly on upstream rock faces (Francouer and Biggs 2006). However, saltation and flow are directly related, so it is likely that invertebrate drift is actually a response to increased stream flow and not increased sediments in the bedload (Bond and Downes 2003). For example, two experiments found invertebrate drift is induced at velocities just below critical flow when the substrate begins to move (Bond and Downes 2003; Gibbins et al. 2007). The duration of the sediment pulse also affects invertebrates. A study by Shaw and Richardson (2001) found invertebrate richness and abundance steadily decreased as pulse duration increased.

Deposited sediment also affects invertebrates by filling interstitial space in the hyporheos (Richards and Bacon 1994), reducing habitat availability (Suttle et al. 2004), affecting primary production (Rier and King 1996) and altering functional characteristics such as life history (Larsen et al. 2010) and colonization (Richards and Bacon 1994). Substrate stability is related to the size of the substrate particle (Matthaei et al. 1999). As fines increase in the substrate, bed stability is decreased and periphyton are reduced by the lack of stable habitat (Rier and King 1996), resulting in a reduction of invertebrate richness (Roy et al. 2003). Fine sediment cover on substrate reduces invertebrate richness and density (Zweig and Rabeni 2001; Matthaei et al. 2006) by altering periphyton assemblage and disrupting functional processes (Griffith et al. 2009). For example, in a study by Rabeni et al. (2005), scrapers and filterer-feeders declined in response to increasing fine sediment cover, suggesting a disruption of feeding mechanisms. 
Relatively few studies have examined relationships between sediment and invertebrates at spatial scales above the reach level. Zweig and Rabeni (2001) examined four streams across a large spatial area and observed reduced invertebrate richness associated with increasing percent fine cover. Cover et al. (2008) examined six mountain streams and observed a negative correlation between specific taxa and depth of fine sediment. In this study, benthic sediment was correlated with basin scale sediment inputs, but the relationship with watershed-scale characteristics was not evaluated. Richards et al. (1993) examined 80 streams across a large $\left(40,000 \mathrm{~km}^{2}\right)$ basin and observed substrate size was strongly related to stream invertebrates in clay soil-type regions.

The impacts of fine sediment are confounded by invertebrate adaptation to naturally variable sediment conditions and the development of tolerant invertebrate assemblage across spatial scales (Larsen et al. 2010). Behavioral adaptations mitigating the effect of sedimentation include: delayed drift (Culp 1986; Larsen and Ormerod 2010), movement to sediment free areas (McClelland and Brusven 1980; Peeters et al. 2006; Francouer and Biggs 2006), modification of feeding strategy (Rundle and Hellenthal 2000b) and tolerance to naturally high levels of sediment (Cline et al. 1982; Kreutzweiser et al. 2005; Rundle and Hellenthal 2000a). Moreover, sediment tolerance is facilitated by the short duration of a typical sediment pulse (Shaw and Richardson 2001) and the presence of refugia habitat at multiple scales (Roy et al. 2003; Francouer and Biggs 2006). This helps explain the minimal effect of sediment on stream invertebrates found in several studies (i.e. Lenat et al. 1981; Cline et al. 1982; Kaller and Hartman 2004; Kreutzweiser et al. 2005), particularly those at larger spatial scales (Cover et al. 2008).

\section{Invertebrate mouthparts as indicators of excessive fine sediment in streams}


Macroinvertebrate sensitivity to sediment fining is well-documented and considerable effort has been devoted to developing related metrics, indices and tolerance values (e.g. Relyea et al. 2012, Figure 1.3). Observational and experimental research has demonstrated that increased sediment fines in the benthos can alter macroinvertebrate assemblage (Larsen et al. 2010; Extence et al. 2013), reduce diversity (Matthaei et al. 2006; Larsen et al. 2010) and alters function (Schofield et al. 2004; Griffith et al. 2009). There are several mechanisms thought to be responsible for the observed effects of fine sediment on stream invertebrates. Figure 1.4 summarizes the sources and effects of fine sediment on invertebrates and benthic habitat. Excessive fine sediment in the washload reduces habitat availability (Richards and Bacon 1994), lowers productivity (Parkhill and Gulliver 2002) and creates harsh conditions through sediment scouring and saltation (Culp 1986). Sediment deposition on the stream benthos alters periphyton communities and food webs (Schofield et al. 2004) and buries critical interstitial habitat (Suttle et al. 2004). Fine sediment has also been shown to affect the macroinvertebrate physiology by acting as a vector for gill infections (Lemly 1982) and/or reducing assimilation rates (Broekhuizen et al. 2001). Macroinvertebrate mouthpart morphology and wear may also be a causal mechanism related to fine sediment; however, few studies have specifically examined it as a potential indicator of excessive fine sediment conditions. Considerable effort has been devoted to identifying invertebrate indicators of sediment fining and several community metrics and functional characteristics have been proposed (Larsen and Ormerod 2010; Extence et al. 2013). However, there is neither a consensus on which metrics are reliable across broad regions nor an adequate understanding of the mechanistic drivers associated with indicators. 
The functional feeding group, in particular invertebrate scrapers, has been identified in several studies as a potential indicator taxa of excessive fine sediment (Zweig and Rabeni 2001). This suggests that invertebrate sensitivity to sediment may be acting through damage to scraper mouthparts or through wear caused by inorganic sediment particles in algal food sources. A study conducted by Arens (1989) showed that scraper mouthparts were substantially worn down when scrapers were forced to feed on sandpaper. The increased wear on mouthparts did not change molting frequency, suggesting that scraping organisms must cope with lost feeding efficiency due to mouthpart wear. While the example above represents an extreme case, there are few published spatial studies that examine the mouthpart wear of mayfly scrapers living in highly sedimented streams.

Scrapers have highly specialized mouthparts for harvesting and transferring epilithic algal cells to the mouth opening for consumption. To remove algae, invertebrates move brushes, rakes or rasps across the rock surface. These structures become worn after use, but are restored each time the invertebrate molts (Arens 1989; Arens 1990). Rhithrogena and Paraleptophlebia, two mayflies, both feed on epilithic algae, but have different mouthparts and mechanisms for feeding. The mandibles of Rhithrogena consist of short brushes composed of stiff bristles to scrape food off of rocks and into the mouth where the algae is strained by the mandibular molae before it passes into the stomach (Figure 1.5, McShaffrey and McCafferty 1988). The mandibles of Paraleptophlebia contain long fine hairs used to brush deposited organic material into the mouth, where it is cut and crushed into smaller pieces (Figure 1.6, Mattingly 1987). Fine sediment may wear down the stiff bristles of Rhithrogena and reduce feeding efficiency 
(Figure 1.6, Arens 1990; Lancaster and Downes 2013). In contrast, Paraleptophlebia may be tolerant to sediment in food sources because the maxillae hairs and mandibles are not affected by hard inorganic particles and the sweep action of the maxillae does not result in sediment moving to the mouth. While observational research has found that Rhithrogena are sensitive to sediment and Paraleptophlebia are tolerant (McClelland and Brusven 1980; Angradi 1999), there is relatively little quantitative research on these relationships. Research on other taxa (Chironomidae; Hudson and Ciborowski 1996) supports mouthpart structure and wear as mechanisms for invertebrate sensitivity to fine sediment.

\section{Gap in the literature}

Management of land use and related impacts to stream processes often require a landscape-scale approach; however, at these scales, watershed complexity and natural gradients act as strong controls on assemblage. In large-scale studies, the noise from natural systems may equal or overwhelm the anthropogenic signal (Richards et al. 1997; Shearer and Young 2011), thereby increasing the probability of a Type II error. Using bioassessment as a management tool depends on the ability to separate natural variability from the anthropogenic influence on stream biota. This is a particularly important consideration in the Oregon Coast Region where stream biota are strongly related to natural gradients of substrate, elevation, forest cover and geology (Herlihy et al. 2005; Cole et al. 2003). Few studies have assessed the strength of natural variance on the relationship between fine sediment and stream invertebrates. Richards et al. (1996) observed geology and land use had similar effect magnitudes on the relationships between stream invertebrates and fine sediment in low elevation lacustrine and outwash 
plains. Richards et al. (1993) found significant invertebrate relationships with substrate quality in clay-type but not in sand-type soils in a large agriculture basin. A literature review found no published studies of fine sediment that partition the natural variance, such as geology, from invertebrate response.

Sediment measurements are another source of variance in bioassessment.

Sediments are difficult to quantify in situ, thus many of the measures used are qualitative visual estimates (Zweig and Rabeni 2001) or semi-quantitative grid-point counts (Cover et al. 2008). Traditional quantitative estimates, such as the shovel method (Kaller and Hartman 2004) or Wollman pebble counts, cannot measure sediment size less than sand. Furthermore, in-stream measurements only provide a snap shot of sediment conditions. One possible improvement is to use a hydrologic model to predict sediment volume delivered to the stream. Doing so may provide a more realistic measure of sediment and reduce uncertainties related to sediment measurements. Models have been used to estimate other stream parameters such as nutrients (Wise and Johnson 2011). However, there is only one published study which correlated predictions from a sediment model to stream invertebrates (Cover et al. 2008). In this study, a landslide model (de la Fuente and Haessig 1993) and erosion model (Wischmeier 1976) were used to simulate sediment supply from six watersheds. Sediment estimates were correlated with in situ measurements $\left(0.79<\mathrm{R}^{2}<0.83\right)$ but not with invertebrates, likely due to naturally low levels of sediment observed in the streams.

In order to evaluate the use of stream invertebrates as bioindicators of excessive fine sediment, three investigations were conducted. The first examined nine years of data collected bi-annually from two streams in western Oregon (Chapter 2). The second study 
used an Oregon Department of Environmental Quality data set to examine invertebrate and environmental conditions in wadeable streams across the Coast Range ecoregion and to identify potential bioindicators of excessive fine sediment (Chapter 3). The final study used in situ experiment to examine the role of geology in shaping invertebrate response to excessive fine sediment conditions in the benthos and to evaluate grazing traits as indicators for biomonitoring fine sediment (Chapter 4). Three hypotheses were tested. The first hypothesis was that invertebrates would be related to broad-scale climate variables (Chapter 2). The second hypothesis was that functional aspects of the invertebrate community would serve as useful indicators of excessive fine sediment condition. (Chapter 3). The third hypothesis was that invertebrates in streams with naturally high levels of sediment would be tolerant to fine sediment ( $<2 \mathrm{~mm}$, Chapter 4$)$. 
Figure 1.1 Conceptual model of sediment supply and delivery to streams in Oregon Coast Range watersheds. Boxes represent process taking place throughout the watershed (dashed lines) and those taking place within the stream (solid line).

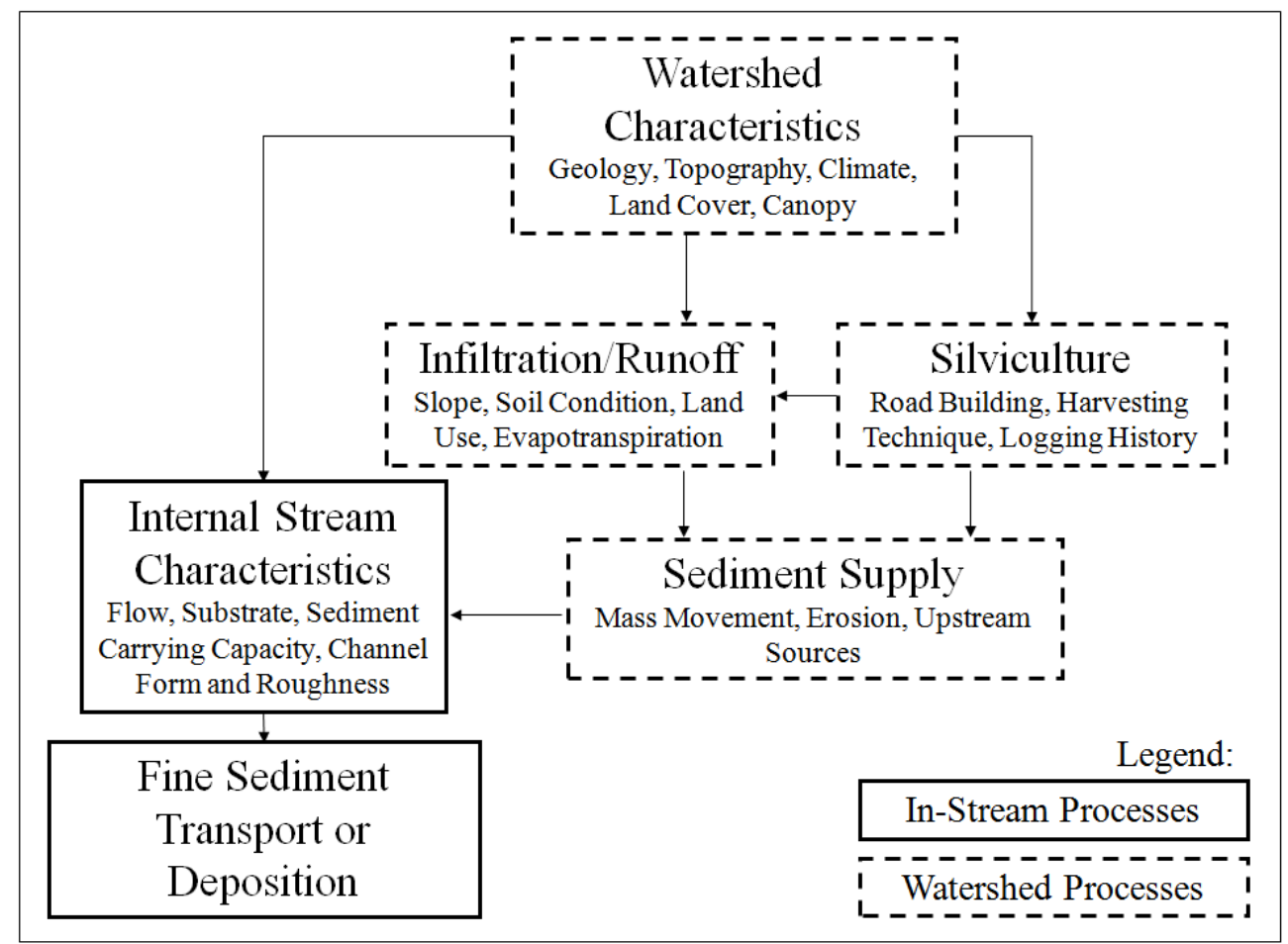


Figure 1.2 Temporal and spatial ecological relationships of invertebrate communities. The y-axis shows changing scale over 15 orders of magnitude with larger values at the bottom. Each level represents a nested model of a stream system ranging from the biome scale to the patch scale and from long-term to short-term process. The diagram illustrates the spatial and temporal complexity and hierarchical connectivity of stream ecosystems.

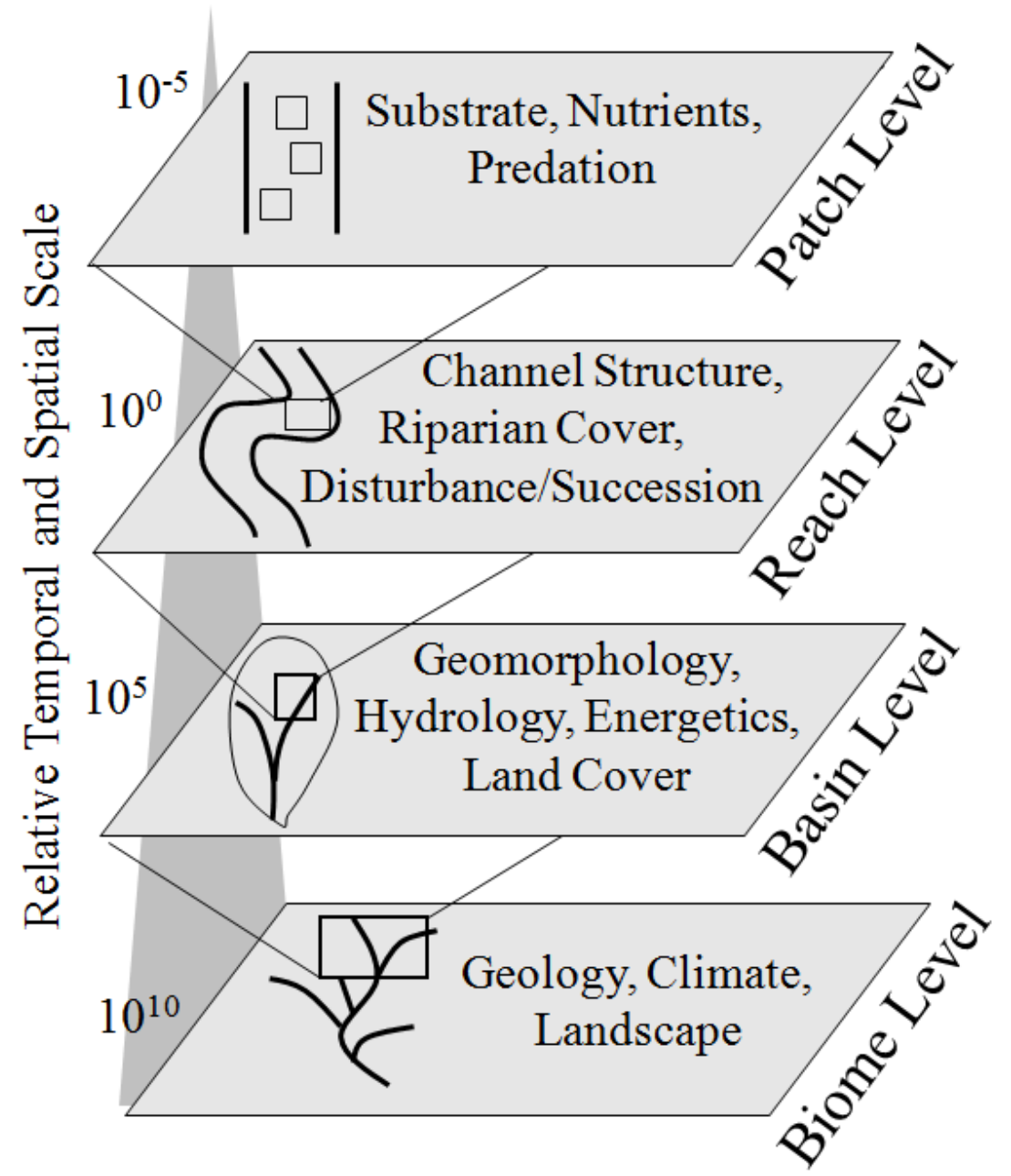


Figure 1.3 Sediment effects on stream function and the invertebrate community. Mitigating factors interact and feedback with sediment supply and stream function to shape invertebrate community.

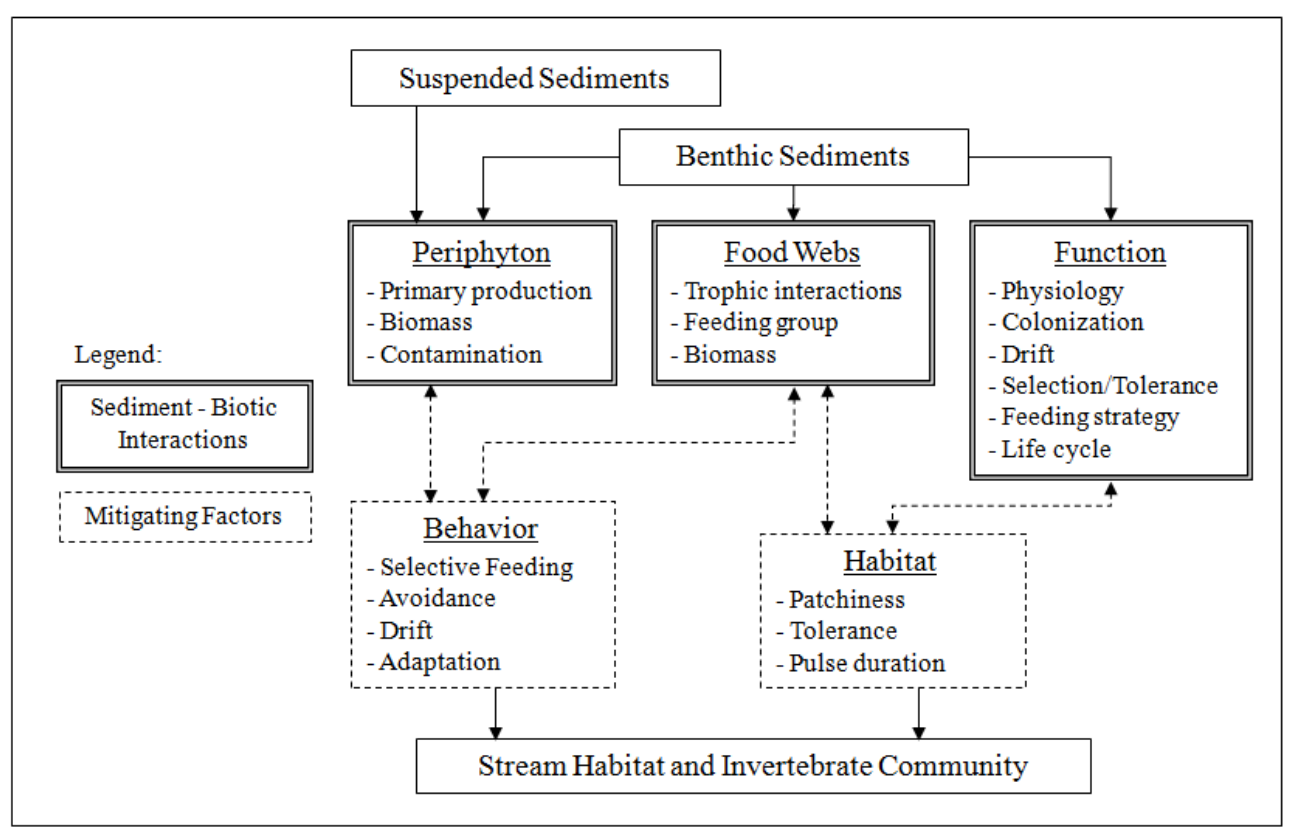


Figure 1.4 Conceptual diagram shows sources of increased fines in streams and its mechanistic effects on invertebrates and benthic habitat. Excessive fine sediment can degrade benthic habitat and reduce invertebrate fitness resulting in altered communities and loss of function. The grey area represents the focus-area of this research.

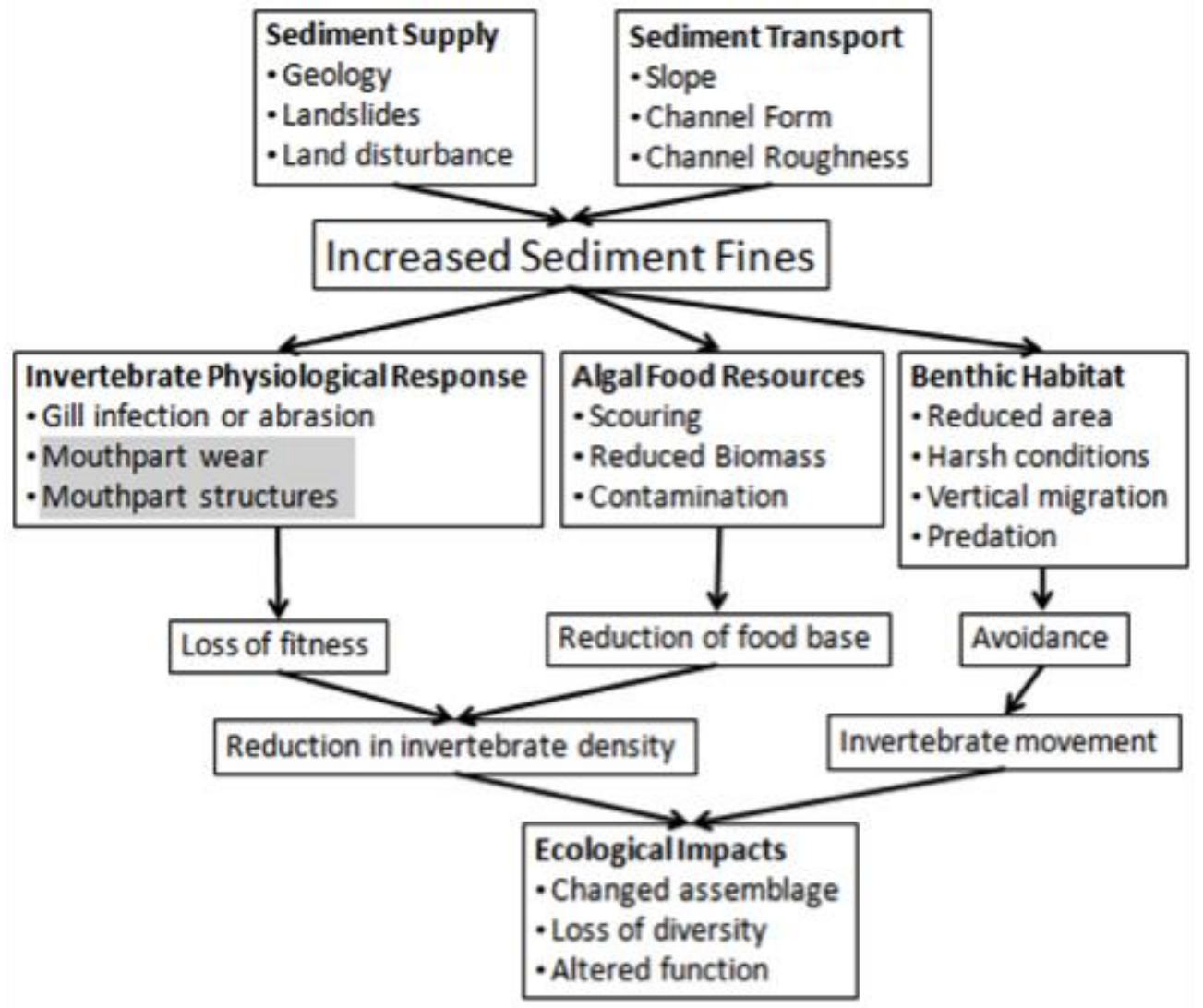


Figure 1.5 Illustration of the different mouthpart structures and feeding strategies of two mayfly grazers: Rhithrogena and Paraleptophlebia. Photos by Karouna and Fuller (1992) and McShriffey and McCafferty (1988). Rhithrogena mouthparts contain combs (A) that are used to scrape-up periphytic algae and molae (B) to grind food particles. In contrast, Paraleptophlebia uses hairs (C) to brush up loose organic material and teeth to cut-up food particles (D). It is hypothesized that invertebrate response to fine sediment in food sources will be largely dependent on feeding traits.
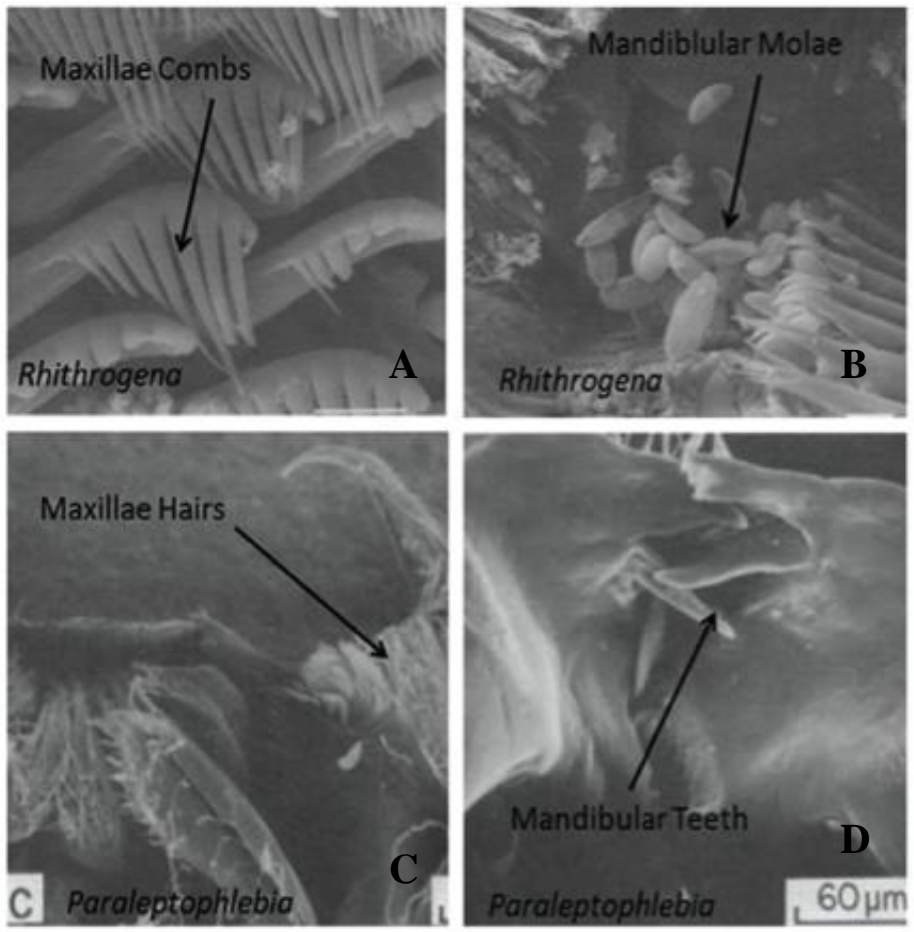
Figure 1.6 Images showing experimental results on the effect of inorganic sediment on Rhithrogena mouthpart brushes and bristles. Lower panels show increasing wear on Rhithrogena bristles caused by feeding on algal food resources growing on sand paper (Arens 1990).

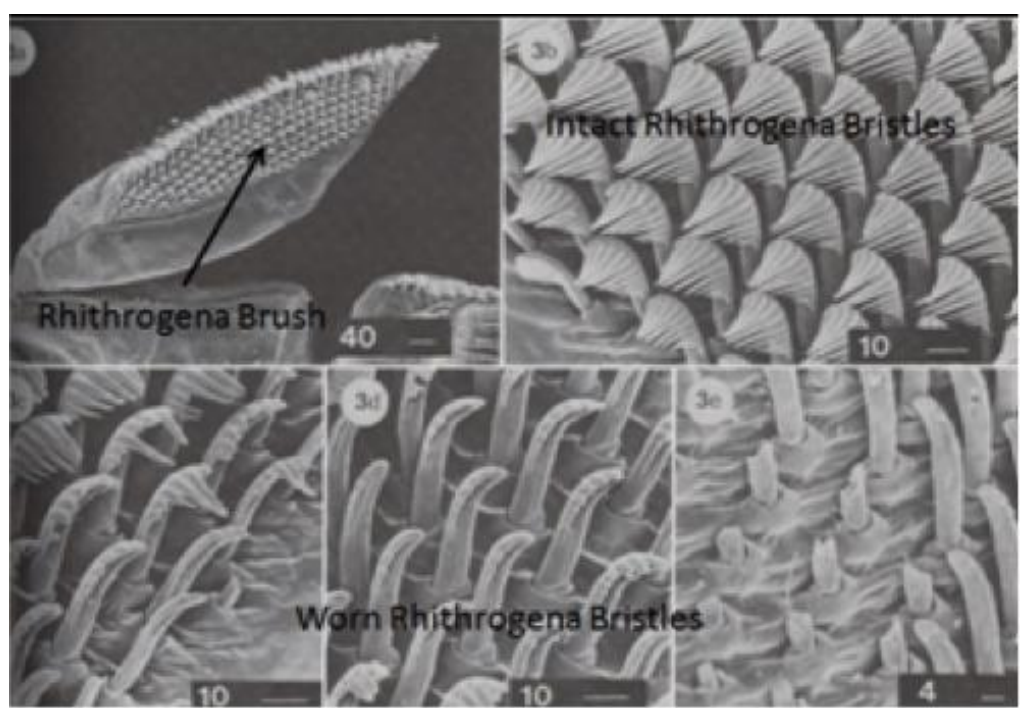




\title{
Chapter 2 Stream Invertebrate and Climate Relationships in the Pacific Coastal Ecoregion of Oregon
}

\author{
Abstract \\ There are few published long-term studies of stream invertebrates and climate \\ relationships in the maritime climate of the Pacific Coastal ecoregion. This study presents \\ nine years (2005-2012), of invertebrate and climate data from three sites at two streams \\ in two different ecoregions of Oregon. At two of the three sites, invertebrate density was \\ significantly related to El Niño Southern Oscillation Index $\left(\mathrm{R}^{2}\right.$ range $=0.22-0.36, \rho$ \\ range $=0.008-0.04)$ and mean maximum air temperature $\left(\mathrm{R}^{2}\right.$ range $=0.32-0.49, \rho$ range $=$ \\ 0.002-0.01). At one of the three sites, precipitation was significantly associated with \\ assemblage (psuedo $\mathrm{r}=0.60, \rho=.002$ ) but not density. Trait-based characteristics also \\ showed significant correlations with climate temperature and precipitation. Scrapers were \\ correlated with air temperature $\left(\mathrm{R}^{2}\right.$ range $=0.14$ to $0.45, \rho$ range $\left.=0.01-0.002\right)$, \\ univoltinism (one generation per season) was correlated with mean maximum \\ temperature $\left(\mathrm{R}^{2}\right.$ range $=0.28$ to $0.50, \rho$ range $\left.=0.001-0.03\right)$ and semivoltinism (less than \\ one generation per season) was correlated with precipitation $\left(\mathrm{R}^{2}=0.41, \rho=0.004\right)$. The \\ findings of this study suggest that temperature may be a climate-related driver of \\ invertebrate population variability in the Pacific Northwest. The findings of this study \\ have possible implications for understanding the role of climate in shaping stream \\ invertebrate communities and monitoring the impacts of climate change.
}




\section{Introduction}

Stream invertebrates are often used to monitor the impacts of human activities on aquatic systems (Rosenberg and Resh 1993). Since all ecological systems are inherently variable, observed changes in stream invertebrate communities should be evaluated with respect to natural variability. This is particularly true for stream invertebrates, which are known to be highly variable across wide temporal scales from short-term seasonality to long-term climate variability (Townsend et al. 2003). Therefore, long-term data sets are needed to adequately characterize variability. Unfortunately, there are few long-term studies of stream invertebrates, so the natural variability of these systems is not well known (Jackson and Füreder 2006).

The value of long-term studies for understanding important ecological processes and monitoring the effect of human activities on the environment is well documented (Likens 1989; Burt et al. 2008; Dodds et al. 2012). Sustained ecological research over long temporal spans can reveal complex or subtle ecological processes that may be difficult to detect with short-term studies, but are important for solving environmental problems (Franklin 1987; Burt et al. 2008). Perhaps one of the best examples in aquatic systems are the long-term studies of stream biogeochemisty at Hubbard Brook, which unexpectedly revealed the effect of acid rain deposition on stream ecosystems (Likens and Bormann 1974) and ultimately led to widespread awareness and public policy regarding sulphur emissions in the 1990s (Likens 1999).

Long-term investigations have also made important contributions to stream macroinvertebrate (invertebrate) ecology including: population dynamics (Gudbergsson 2004; Bêche et al. 2006), phenology (Resh 1992; Gasith and Resh 1999; Briers et al. 
2004), colonization and recovery (Stone and Wallace 1998; Schloesser et al. 2000; Bêche et al. 2009; Vinson 2001) and community stability (Collier 2008; Bêche et al. 2009). For example, the interactive effect of climate and land use on community stability and persistence was documented through 10- and 20-year investigations of New Zealand (Collier 2008) and California streams (Bêche et al. 2009). Long-term investigations have also revealed invertebrate recovery patterns after major disturbances such as logging and fire. During a long-term study at the Coweeta Hydrologic Laboratory in North Carolina, it was shown that while clearcut logging increased invertebrate abundance, it also changed the food web from an allochthonous base to autochthonous base and recovery back to reference conditions was still evident 16 years later. Long-term studies of fire disturbance showed recovery of invertebrate was also slow ( $>10$ years) and dependent on both post-fire landscape condition and climate conditions (Minshall et al. 2001; Minshall et al. 2003). Long-term studies have also documented the seasonal and interannual variability of stream invertebrate (Bêche et al. 2006; Bêche et al. 2007).

From a stream management perspective, documenting the natural variability of stream invertebrates would be a useful outcome of long-term studies. However, there are relatively few long-term studies of stream invertebrates (Jackson and Füreder 2006) and fewer still that document the influence of broad-scale climate conditions on stream invertebrates. Climate is a well-known source of variability in stream systems (Resh et al. 2013) and is related to invertebrates through seasonal and interannual changes in stream temperature (Vinson 2001; Durance and Ormerod 2007) and precipitation-related flow regimes (Jackson et al. 1999; Milner 2006). Long-term climate variation, such as the North American Oscillation (NAO) and the El Niño Southern Oscillation (ENSO), drive 
regional weather patterns, which subsequently influence several aspects of stream invertebrate communities including growth rate and phenology (Briers et al. 2004), abundance (Bradley and Ormerod 2001), functional traits (Lawrence et al. 2010) and bioassessment metrics (Mazor et al. 2009).

In the United States, the most extensive long-term studies of climate and stream invertebrates have been conducted in the Mediterranean climate of California, which is characterized by cool wet winters and hot dry summers. In Mediterranean climates, precipitation and flooding follow a predictable annual pattern of wet and dry conditions with high seasonal and interannual variability (Gasith and Resh 1999). Consequently, flow variability acts as a strong control on stream habitat (Bonada et al. 2007; Resh et al. 2013), thereby influencing invertebrate diversity (McElravy et al. 1989), composition (Bêche et al. 2009), stability (Bêche and Resh 2007b) and functional traits (Bêche and Resh 2007a).

Understanding the effects of climatic conditions on stream systems is necessary for predicting the effects of climate change on stream communities. For example, the strong influence of climate on invertebrates in Mediterranean climates has led to the development of specific indicator metrics to monitor climate change (Lawrence et al. 2010). However, the relationship between climate variability and stream invertebrates is likely to be region specific (Gasith and Resh 1999). Therefore, the climate-invertebrate relationships documented in one climate region may not apply to another. A good example of this is in the Pacific Coastal ecoregion of the Pacific Northwest, which is geographically close to California's Mediterranean climate but is a much cooler and wetter maritime climate. Therefore, the strong controls of drought and flow in the 
Mediterranean may not act as strongly in Pacific Coastal streams. Moreover, the projected impacts of climate change in the two regions are different. Climate models predict both regions will likely become warmer, but maritime climates are expected to get wetter in the winter, while the Mediterranean is likely to get drier and more variable in the summer (Cayan et al. 2009; Karl et al. 2009).

Region-specific long-term studies of stream invertebrates would provide important information about the influence of precipitation and temperature on stream invertebrates in the Pacific Coastal ecoregion and other maritime climates. However, a literature review did not find any published long-term studies of invertebrates in the Pacific Coastal region of the Pacific Northwest of the United States. The purpose of this study is to examine long-term variation of stream invertebrates in response to broad-scale climate conditions using long-term data sets ( 9 years) collected biannually from two Oregon streams. To increase applicability of findings, sites were located in two different ecoregions with varying levels of land cover and landuse intensity and different stream invertebrate communities (Edwards, unpublished data). Study objectives were: (i) to relate precipitation and temperature to stream invertebrate assemblage and functional traits, and (ii) to test the hypothesis that stream invertebrates at both stream sites would associate with broad-scale climate conditions.

\section{Methods}

\subsection{Study sites}

The maritime climate of the Pacific Northwest extends from the west slope of the Cascades to the Pacific Ocean and north from around the California border to Alaska. The sites in this study fall within the Willamette Valley and Cascades ecoregions of 
Oregon. On average, the Willamette Valley is generally warmer and drier than the Cascades, but the majority of precipitation in both regions occurs in the winter. Significant snowfall accumulation is typical at the Cascades sites but rare in the Willamette Valley. Invertebrate data were collected at three sites on two streams (Balch Creek and Lookout Creek) in Oregon. Streams were chosen in two basins reflecting different levels of land use intensity at two scales: the watershed scale (land development) and the reach scale (channelization).

Balch Creek is situated in the northern Willamette Valley along the West Hills of Portland. Balch Creek is situated within the eastern edge of the Oregon Coast Range where the climate is relatively mild with cool dry summers and wet winters (Table 2.1). Mean average temperature is $12.0^{\circ} \mathrm{C}$ and mean average precipitation is $92 \mathrm{~cm}$. The Balch Creek data collection site (BCS 1) is located at Forest Park, a public park within the urban growth boundary of Portland, Oregon (Figure 2.1). The majority of the Balch Creek basin is covered with dense forests of Douglas-fir (Pseudotsuga menziesii) and western hemlock (Tsuga heterophylla); however, about $18 \%$ of the basin is developed as single family residential (Table 2.1). Balch Creek was chosen for this study because of its location in an urban setting, but the majority of the watershed is naturally forested. Preliminary unpublished bioassessment has shown Balch Creek to be moderately impacted. Lookout Creek is located in the central Cascades within the HJ Andrews experimental forest (Table 2.1). Due to higher elevation, the climate at Lookout Creek is substantially cooler and wetter than at Balch Creek, particularly in the winter. Mean annual temperature at Lookout Creek is $9.5^{\circ} \mathrm{C}$ and the mean annual precipitation is 222 $\mathrm{cm}$. The watershed for Lookout Creek is heavily forested with Douglas-fir and has no 
land development; however, there is some scattered logging associated with experimental manipulations. At Lookout Creek, two sites with different reach characteristics were examined (Figure 2.1). Lookout Creek Site 1 (LCS 1) is located in an old growth forest with a natural stream channel, abundant large woody debris and a dense canopy. Lookout Creek Site 2 (LCS 2) is located about $7 \mathrm{~km}$ downstream where the stream had been channelized, large woody debris removed and the riparian canopy open. Preliminary unpublished bioassessment of Lookout Creek found LCS 1 to be unimpacted and LCS 2 moderately impacted. Land cover for each basin was determined using two different data sets. Balch Creek data were categorized using Portland's Regional Land Use Information System (RLIS; Metro 2001; 1:400 scale). Land cover data for the Lookout Creek basin were obtained from the National Land Cover data base (NLCD; Fry et al 2006).

\subsection{Stream invertebrates}

Invertebrates were collected by undergraduate students on field trips each May and November 2005-2012 using a non-lethal bioassessment technique. To ensure data quality, collections were supervised and all identifications and counts were verified by the author. Invertebrates were collected by students working in groups using D-nets to collect three $0.1 \mathrm{~m}^{2}$ samples in riffles (Table 2.2). The three D-net samples were composited and $1 / 3$ of the sample was randomly sorted streamside (Figure 2.2). Over the duration of the study, multiple groups (5-10) collected invertebrate samples in the same reach at each site.

\subsection{Climate data}

Stream and climate data were assembled from various sources, including the National Oceanic and Atmospheric Administration (NOAA) climate stations, HJ 
Andrews Long Term Ecological Research Station (HJ LTER) datasets and gauges and city of Portland datasets (Table 2.1). Selection of climate stations was determined through exploratory analysis of multiple climate station locations (section 2.5). Four missing values at the Lookout Creek stations were replaced with values from the next nearest station at the same elevation ( $26 \mathrm{~km}$ distant). Current flow data were only available at Lookout Creek. Balch Creek flow data were not collected after 2002. At both streams, water chemistry data were incomplete, so two different time periods were used to compare streams. Monthly stream water chemistry for June 2005-2007 was used to compare monthly averages of nitrate $\left(\mathrm{NO}_{3}, \mathrm{mg} / \mathrm{L}\right)$, soluble reactive phosphorous $\left(\mathrm{PO}_{4}{ }^{3-}\right.$, $\mathrm{mg} / \mathrm{L})$, suspended solids $(\mathrm{mg} / \mathrm{L})$, conductivity $(\mu \mathrm{S} / \mathrm{cm})$ and temperature $\left({ }^{\circ} \mathrm{C}\right)$. Daily streamflow for both streams was compared using average June flow (L/S) from 19992002.

\subsection{Invertebrate data analysis}

For each sample, counts were averaged across groups to obtain an estimate of invertebrate density per $\mathrm{m}^{2}$ (Table 2.2 ). Invertebrate data were standardized for seasonal variance using $\mathrm{z}$ scores for fall and spring. Assemblage and functional aspects of stream invertebrates were related to climate parameters using ordination and linear modeling. Feeding group, voltinism and movement were selected as functional traits because of known associations with climate in other regions (Bêche et al. 2006; Lawrence et al. 2010) and variation at the genus-level, which made trait assignment difficult. Familylevel functional attributes were assigned using best professional judgment based on knowledge of the genera commonly found in the study streams (Table 2.4). Due to ambiguity at the family level, Chironmonidae were not assigned functional attributes. 
Ordinations were used to examine relationships between biotic variables and assemblage and to inform selection of variables to be used in linear modeling. Assemblage was evaluated using Non-metric Multidimensional Scaling (NMDS), which is an unconstrained ordination technique that examines the overall similarity of biologic communities among sites. NMDS is often used with invertebrate data because it preserves the inter-site rank relationships and better represents species distances (Legendre and Legendre 1998). Community similarity was evaluated using the BrayCurtis Dissimilarity Index and NMDS ordinations of relative abundance and functional traits were used to compare streams in two-dimensional ordination space. Assemblage similarity was evaluated spatially, seasonally and temporally for all streams using BrayCurtis Community dissimilarity indices and compared between streams using t-tests. Differences in macroinvertebrate assemblage between streams were determined by analysis of similarities (ANOSIM). The ANOSIM procedure tests the hypothesis that there is no difference between stream samples by comparing ranked similarity matrices of Bray-Curtis distances (McCune and Grace 2002). The test statistic R ranges from $0-1$. An $R$ value of 0 indicates random grouping between stream samples and a value of 1 indicates a $100 \%$ difference between stream samples. The statistical significance of $\mathrm{R}$ is calculated with a permutation test comparing randomly generated $\mathrm{R}$ values to the original $\mathrm{R}$ value. To examine relationships between assemblage and climate variables, a linear fitting function (Envfit) was used to fit climate vectors to ordinations of each stream. Envfit fits a vector to the ordination and a permutation test is used to determine psuedo $\mathrm{r}^{2}$ and significance. 
Line smoothing and linear models were used to examine temporal patterns and climate-invertebrate relationships. Kendall's tau $(t)$ was used to compare stream invertebrate density at each stream. Kendall's tau is a rank-based technique often used to analyze temporal patterns in environmental data sets (El-Shaarawi and Niculescu 1992), environmetrics and water quality data (Hirsch et al. 1982) because it is less sensitive to outliers (McCabe and Wolock 2002 USGS). To smooth lines, local regression (LOESS) was used to compare invertebrate density between streams. LOESS is a nearest-neighbor smoothing function that utilizes a user-defined moving window around each $\mathrm{x}$ value to estimate a y value using regression (Legendre and Legendre 1998). Linear models were developed using average temperature, total precipitation as climate predictors and invertebrate density (mean abundance $/ \mathrm{m}^{2}$ ) as response variables. All statistical analyses were performed using the "Vegan" package in R statistical software (R Development Core Team 2007).

\subsection{Climate data analysis}

Climate data characterization and organization was determined using exploratory analysis. Temperate and precipitation data were examined at the following intervals: water year (WY, beginning October 1st), monthly and at 10,100 and 200 days prior to invertebrate collection. Flow data (only available at Lookout Creek) daily mean, daily mean maximum and CV were evaluated at WY intervals and 10,100 and 200 days prior to invertebrate collection. Time intervals were chosen to capture the typical response time and life span of stream invertebrates and to reflect seasonal variability in flow and climate. Exploratory analysis within and among stream sites revealed a lack of consistency in which time periods were best correlated with invertebrate data. Given the 
small sample size and 6-month sampling interval, I chose a parsimonious approach to data organization and used daily maximum air temperature and total precipitation for the time-period between invertebrate samples. Flow data were expressed as mean daily flow for the WY and 10 days prior to sampling. All data were summarized and analyzed using seasonally standardized z-scores for total (precipitation only), mean and CV. El Niño Southern Oscillation (ENSO) conditions were characterized using the Multivariate ENSO Index (MEI) values obtained from NOAA Earth Centers Research Laboratory (accessed March 2013). ENSO is a coupled ocean-atmospheric phenomenon affecting global climate conditions (Cane and Zebiak 1985). In the Pacific Northwest, ENSO is associated with warm/dry and cool/wet conditions varying over a 5-10 year time scale (Mote et al. 2003). The MEI index, expressed as z scores, is a measure of the ENSO signal strength derived from six ocean-atmosphere variables (Wolter and Timlin 2011). The MEI index was used to build invertebrate-climate ENSO regression models.

\section{Results}

\subsection{Climate and site characteristics}

Climate and stream characteristics at Balch Creek and Lookout Creek showed distinct differences. The Lookout Creek basin was cooler and wetter than the Balch Creek basin (Table 2.1) and June flow at Lookout Creek was approximately double that of Balch Creek. However, when normalized for area, Balch Creek had higher summer flow (2.4 vs. 0.9 liters per second). Average June stream temperature was similar at both streams (Table 2.1). The stream water chemistry at Lookout Creek was comparatively dilute, with lower nutrients and conductivity than at Balch Creek (Table 2.1), while suspended sediment concentrations were slightly higher at Balch Creek. During the study 
period, ENSO conditions ranged from warm to cool phases with relatively strong warm ENSO events in Fall 2006 and Winter 2010 and relatively strong cool ENSO events in Spring 2008 and Fall 2010. Regional temperature and precipitation patterns during the study period were generally cool with average precipitation (with the exception of a dry year in 2005). Within the study period, two main climate patterns were observed in both study regions: warm/dry conditions in Fall 2006 and Spring 2007 and cool/wet conditions in Fall 2010 and Spring 2011.

\subsection{Stream invertebrates}

At all three sites, the invertebrate assemblages were dominated by mayflies, stoneflies and caddisflies. At all sites, Heptageniidae and Baetidae were the most common family. At Balch Creek, Leptophlebiidae, Nemouridae and Chironomidae were also common. At Lookout Creek, Ephemerellidae, Peltoperlidae, Perlidae, Chloroperlidae and Hydropsychidae were also common. Stream invertebrate density varied temporally and spatially. LCS 1 had the highest invertebrate density while BCS 1 had the lowest (Table 2.2). At LCS 1, median invertebrate density was significantly different than at LCS $2(\tau=0.4, \rho=0.05)$ and, at BCS 1 , median invertebrate density was strongly different than LCS $1(\tau=0.3, \rho=0.11)$. Temporal patterns of invertebrates were variable but appeared to be temporally correlated (Figure 2.3 and 2.4). For all streams, the highest seasonally standardized invertebrate density occurred in Spring 2007 and was relatively lower from 2008-2012 (Figure 2.4). The LOESS smoothed lines appeared to show a 3-4 year interannual cycle of invertebrate density.

Stream invertebrate community similarity and assemblage varied within streams and across study sites. Similarity among years was lowest at LCS 2 (average index $=$ 
0.32 ) and highest at Balch Creek (average index $=0.23$ ). Similarity was higher in the spring and significantly different from fall similarity only at BCS $1(\rho=0.03)$.

Ordinations based on relative abundance showed the three stream sites separated along NMDS Axis 1 and within stream variation generally along NMDS Axis 2 (Figure 2.6).

The assemblage at LCS 1 and LCS 2 varied along Axis 1 and 2, but in opposite directions (Figure 2.6). ANOSIM results (Table 2.3) showed the assemblages between the two streams were significantly different $(\mathrm{R}=0.7, \rho=0.001)$, and LCS 1 and LCS 2 at Lookout Creek were significantly different $(\mathrm{R}=0.3, \rho=0.003)$. Ordinations of relative abundance by season showed distinct assemblages in the spring and fall (Figure 2.7) with season associated with NMDS Axis 1 at the Lookout Creek sites and along NMDS Axis 1 and 2 for BCS 1. ANOSIM results showed significant seasonal differences for BCS 1 $(\mathrm{R}=0.7, \rho=0.001), \operatorname{LCS} 1(\mathrm{R}=0.7, \rho=0.002)$ and LCS $2(\mathrm{R}=0.2, \rho=0.04)$. Ordinations based on functional feeding group also showed similar, but stronger, results with distinct communities in the spring and fall, separated along NMDS Axis 1 for the Lookout Creek sites and NMDS Axis 1 and 2 for BCS 1 (Figure 2.8).

Vector analysis found generally weak associations between climate and invertebrate assemblage. Temperature vectors showed weak associations with relative abundance assemblage (Table 2.5, Figure 2.7) at BCS $1(\mathrm{r}=0.09, \rho=0.15)$, LCS $1(\mathrm{r}=0.24$, $\rho=0.18)$ and LCS $2(r=0.28, \rho=0.13)$. Temperature and ENSO showed slightly stronger correlations with FFG ordinations (Table 2.4, Figure 2.8) at BCS 1 (temperature: $\mathrm{r}=0.34$, $\rho=0.07$ ENSO: $r=0.26, \rho=0.16$ ) and LCS 2 (temperature: $r=0.28, \rho=0.13$ ENSO: $r=0.28$, $\rho=0.11)$. Voltinism at LCS 2 was associated with temperature $(r=0.28, \rho=0.12)$ and precipitation $(\mathrm{r}=0.60, \rho=0.002)$. No other climate vectors were associated with 
ordinations. Bubble plots of scrapers in Figure 2.9 show increased relative density of scrapers associated with increasing temperatures and decreasing precipitation, while long-lived invertebrates at LCS 2 were negatively associated with precipitation and positively associated with temperature.

Invertebrate density and function were associated with ENSO, temperature and precipitation but not flow. Linear models of invertebrate density showed significant, positive relationships with ENSO and temperature (Figure 2.10) at both BCS 1 and LCS 1. ENSO strength was positively associated with invertebrate density at $\mathrm{BCS} 1\left(\mathrm{R}^{2}=0.22\right.$, $\rho=0.04)$ and LCS $1\left(R^{2}=0.36, \rho=0.008\right)$. Temperature was positively associated with invertebrate density at BCS $1\left(R^{2}=0.32, \rho=0.01\right)$ and LCS $1\left(R^{2}=0.49, \rho=0.002\right)$. No climate-related variables were significantly related to invertebrate density at LCS 2 . Invertebrate-climate relationships were generally stronger in the fall; however, none of the regression models within season were significant.

Functional characteristics of the invertebrate community were also significantly related to temperature and precipitation at LCS 2 . Scraper density was positively associated with temperature at BCS $1\left(\mathrm{R}^{2}=0.18, \rho=0.06\right)$, $\mathrm{LCS} 1\left(\mathrm{R}^{2}=0.45, \rho=0.002\right)$ and LCS $2\left(\mathrm{R}^{2}=0.14, \rho=0.08\right)$. Precipitation was negatively associated with long-lived (semivoltine) invertebrates at LCS $2\left(\mathrm{R}^{2}=0.41, \rho=0.004\right)$.

\section{Discussion}

\subsection{Long-term climate and invertebrate patterns}

This study attempted to identify long-term patterns between stream invertebrates and climate variables from three sites in two Oregon streams. During the nine-year study period, two phases of a relatively strong El Niño and La Niña conditions were present, 
which likely contributed to warm/dry conditions in Fall 2006 and Spring 2007, and cool/wet conditions in Fall 2010 and Spring 2011. Over the course of the study and at all streams, invertebrate density was highly variable, which is similar to findings of other long-term studies conducted in California (Bêche and Resh 2007a; Bêche and Resh 2007b). In contrast, assemblage was relatively stable, which may reflect the coarse taxonomy of the study (family-level) or the persistence of invertebrates, which has been observed in other streams of western North America (Robinson et al. 2000; Bêche and Resh 2007a). The temporal trends in invertebrate density appear to follow a sinusoidal pattern with a three to four year interval that may parallel El Niño cycles, which has been observed in other streams (Resh et al. 2013). Overall, invertebrate density and function were strongly correlated with climate conditions, even though both streams had distinctly different invertebrate communities and stream characteristics. However, the relationship between climate variables and invertebrates was different between streams and sites.

\subsection{Relationships between invertebrates and climate}

The invertebrate community showed a strong seasonal component and generally weak association with climate-related variables. Invertebrate assemblage showed a weak association with temperature at LCS 1 and with temperature and precipitation at LCS 2 . In the ordination of LCS 2 , temperature and precipitation were inversely related to each other and precipitation appeared to be associated with fall invertebrate communities. Other research has documented the association of invertebrates with dry season precipitation in Mediterranean climates (Bêche and Resh 2007b), which may help explain the patterns in Lookout Creek where fall sampling is preceded by 3-4 months of relatively low precipitation and stream flow. The lack of significant relationships between 
climate variables and relative abundance is likely due to the strong seasonal patterns controlling stream invertebrate communities. This is evident in the ordinations, which clearly show a strong seasonal component at all sites.

Ordinations based on invertebrate function showed stronger relationships with climate variables (Figure 2.9). In the ordinations based on functional feeding group, the climate vectors appeared to be independent of season, suggesting that functional groupings may be a better indicator of climate-invertebrate relationships, which has been documented in Mediterranean climates of California (Bêche et al. 2006). Bubble plots of invertebrate scrapers and those with long life cycles (semivoltine) reveal functional associations with climate patterns. Scrapers were associated with increasing maximum temperatures at BCS 1 and LCS 2 and negatively associated with precipitation only at LCS 2 , which may be partially explained by increasing growth rates of algae in warmer temperatures (DeNicola 1996). However, at BCS 1 and LCS 2, temperature vectors were tangentially associated with scrapers, while the remaining variance may be associated with in-stream processes such as nutrient concentrations. At LCS 2, long-lived invertebrates were positively associated with temperature and negatively with precipitation. This may be due to flow variability or benthic-scouring flood events occurring at LCS 2, where the stream is channelized and lacks large woody debris, thereby making it unsuitable habitat for large-sized or long-lived organisms. This relationship was also found in highly intermittent streams in Mediterranean climates of California (Lawrence et al. 2010).

Invertebrate density showed stronger, and significant, associations with climate variables across seasons. However, while climate-invertebrate relationships were 
generally stronger in the fall, none of the linear models based on season were significant, likely due to low sample size. Invertebrate density was strongly associated with ENSO strength and temperature at BCS 1 and LCS 1 (Figure 2.11a, 2.11b) across both seasons. At LCS 1, nearly half of the variance in invertebrate density was explained by average monthly maximum temperature. These findings suggest that invertebrate communities in the Pacific Coastal region and other maritime climates may be temperature limited; whereas, in drier climates such as the Mediterranean, they appear to be precipitation limited (Bêche and Resh 2007b). Functional attributes also showed stronger relationships with climate variables and may elucidate some of the mechanisms underlying invertebrate association with temperature and precipitation. At all sites, scrapers showed a strong positive association with temperature (Figure 2.11a, 2.11b, 2.11c). This may be the result of increased algal growth in warmer stream conditions (DeNicola 1996); however, increased temperatures may also increase growth rates or alter the phenology of stream invertebrates. For example, studies have shown that larval hatching, development and emergence is triggered and regulated by physiological processes related to temperature (Vannote and Sweeney 1980; Frady et al. 2007; Li et al. 2011). In this regard, the increased density of invertebrates across years observed in this study may be due to phenological shifts by invertebrates to optimize growth and development regulated by temperature. This is supported by the strong association of univoltine invertebrates with temperature at BCS 1 and LCS 1 (Figure 2.11d, 2.11e) where the timing of emergence may change the abundance of larval forms present in the stream. This pattern was not apparent at LCS 2 (Figure 2.11f) where semivoltine invertebrates had a strong association with precipitation and univoltine invertebrates were not related to 
temperature. At LCS 2, the flow regime, as opposed to temperature, may exert a stronger control over invertebrates. The lack of a strong relationship with flow may be explained by the difference in scales between the ecological processes relevant to flow and the invertebrate sampling schedule. During high flow events, invertebrates will find refugia from fast moving water and will quickly rebound from a flood event as long as the channel has not completely scoured (Hart and Finelli 1999). In this study, two of the stream sites (BCS 1 and LCS 1) have natural stream channels and therefore can find places to avoid high flows; however, in the third site (LCS 2), there is comparatively little habitat complexity and consequently no refuge from fast moving water. This supports the findings that only the channelized site (LCS 2) showed an association between invertebrates and precipitation. In this study, the sampling schedule did not result in samples right after a high flow event so it's unlikely that data would show a strong flowsignal on invertebrates unless there was a major scouring event in the previous 6 months.

\subsection{Invertebrate stability}

The different invertebrate-climate responses observed among study streams may be explained by community similarity and stability. Stability and persistence refer to temporal changes in a population of organisms around an equilibrium point as a result of perturbations (Collier 2008; Connell and Sousa 1983). Stability (abundance) refers to changes in abundance over time and persistence characterizes changes in the presence or absence of taxa over time. Persistence, while typically associated with presence-absence data, has also been used to examine assemblage data (e.g. Scarsbrook 2002). Invertebrate similarity over the study period was lowest at the LCS 2 where channelization and lack of woody debris likely creates harsh conditions during high flow events. At BCS 1 and LCS 
1, the relatively high similarity over the study period and weak association between assemblage and climate suggest high persistence (Table 2.5), while at LCS 2, the strong association of assemblage with climate indicates low persistence (Figure 2.10).

Conversely, the strong association of invertebrate density to climate at BCS 1 and LCS 1 suggest low stability, while the relatively stronger association of assemblage and climate at LCS 2 suggest low persistence. Other studies have found high persistence in streams with stable flow regimes and high stability in unstable streams (De'ath and Winterbourne 1994; Scarsbrook 2002; Milner et al. 2006). In the present study, the high persistence of invertebrates in stable sites and low persistence in unstable sites may reflect a shift from biotic to abiotic dominated controls. In stable stream systems, the importance of predation and competition may drive changes in assemblage, while abundance is controlled by climate-related factors (Gasith and Resh 1999). In the unstable site, assemblage may be controlled through selection of traits that increase fitness for harsh flow conditions (Bêche and Resh 2007).

\subsection{Implications for climate monitoring}

In Mediterranean streams, precipitation-related climate variability, such as droughts and floods, are clear drivers of stream biotic communities (Resh et al. 2013). While the present study only examined data from two streams, the findings suggest a temperature-driven climate control on invertebrates in maritime climates. This is logical given the relatively stable flow regime and cooler temperature of maritime streams in comparison to Mediterranean streams. In cooler streams, invertebrate growth may be limited by temperature, which is known to influence penology and body size (Vannote and Sweeney 1980; Elliott 1984). In streams within the regions that are influenced by the 
North Atlantic Oscillation (NAO), invertebrates are associated with increased warmer winter temperatures driven by the warm phase of the NAO (Briers et al. 2004). From a climate monitoring perspective, the findings here indicate that, unlike the Mediterranean climate, invertebrates in maritime streams may be linked to climate change through temperature. In addition, the lower community similarity and generally stronger association with climate variables in the fall invertebrate samples suggest that climate monitoring may yield more useful information during the fall. Furthermore, the impacts of climate change may vary as a function of natural or human disturbance. For example, invertebrate persistence in reference streams may not change as a result of climate change but stability would. A decoupling of the invertebrate response from the climate signal may indicate a stream that is unstable because of human-related pressures. 
Figure 2.1 Map of study streams and basins in Oregon. Black circles represent data collection locations. Dark area is the Portland urban growth boundary.

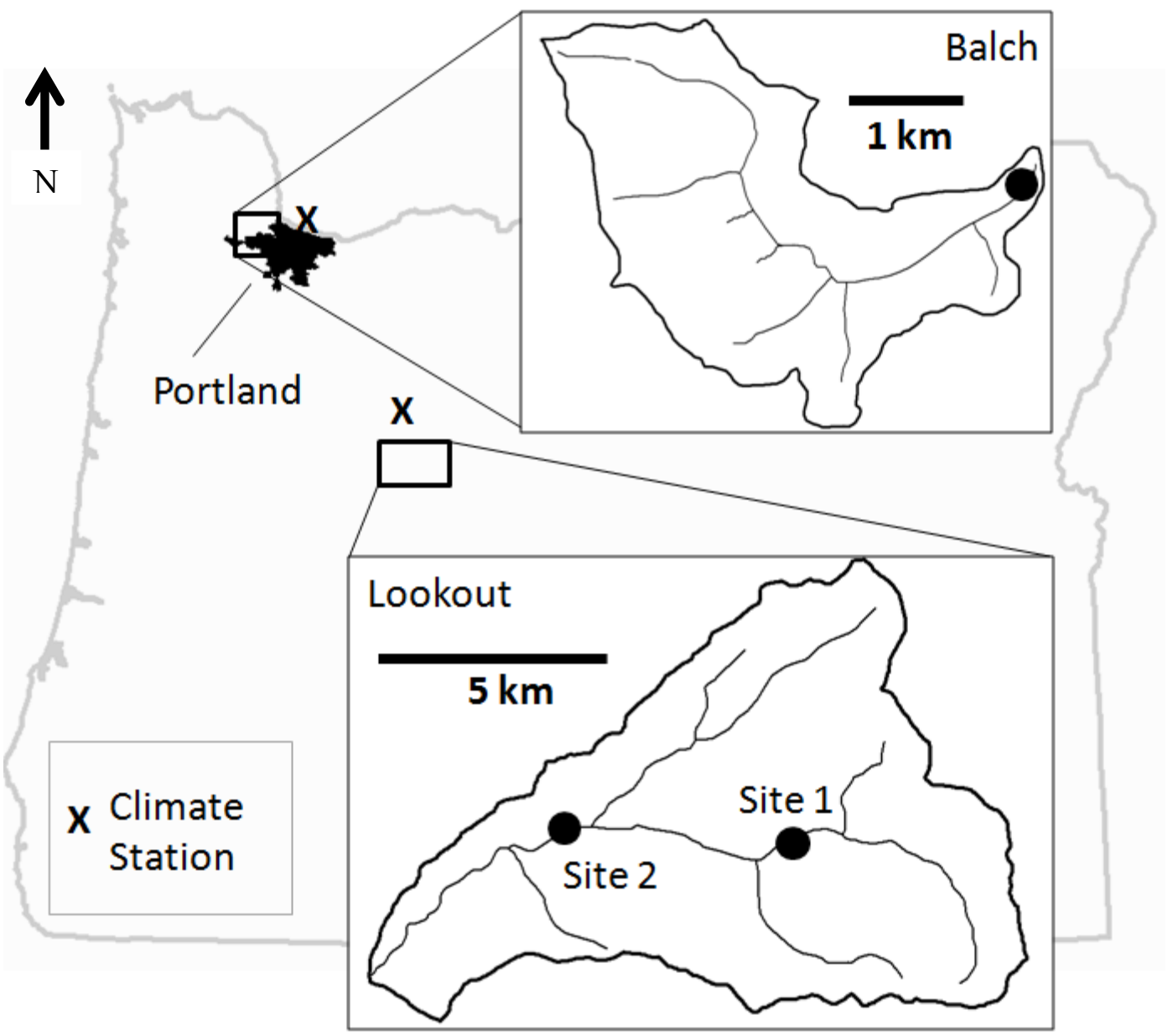


Figure 2.2 Randomized field technique. Three D-net benthic samples are collected (a), composited into a plastic tub (b) and then transferred to the Field subsampling tray (c). Five cells $(\mathrm{X})$ are randomly chosen from which macroinvertebrates are counted and identified.

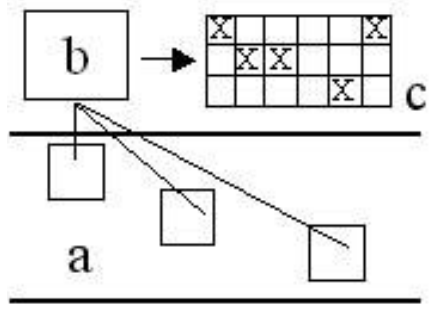


Figure 2.3 Invertebrate abundance per area for the three study streams. $\mathrm{X}$ axis shows Fall (F) and Spring (S) samples from 2005-2012 (05-12).

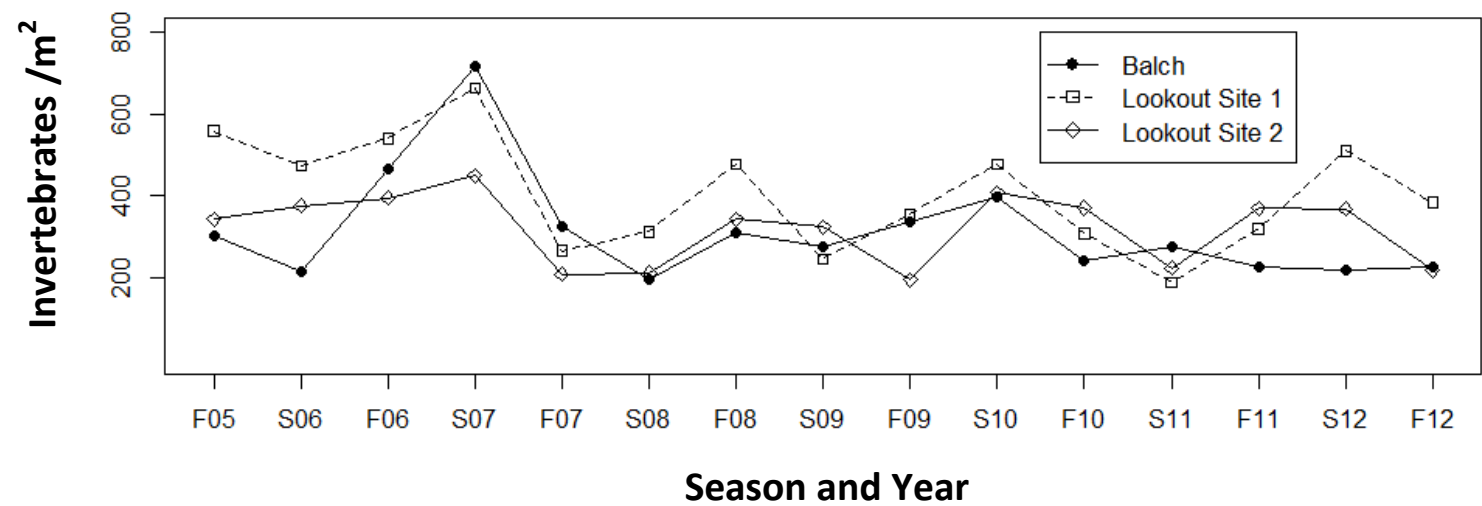


Figure 2.4 Invertebrate density over time (z score) for three streams (a), ENSO and all streams (b), temperature and Balch (c) and Lookout sites (d), precipitation and Balch (e) and Lookout sites (f) . The Y axis shows standardized invertebrate density and the $X$ axis shows Fall (F) and Spring (S) samples from 2005-2012.
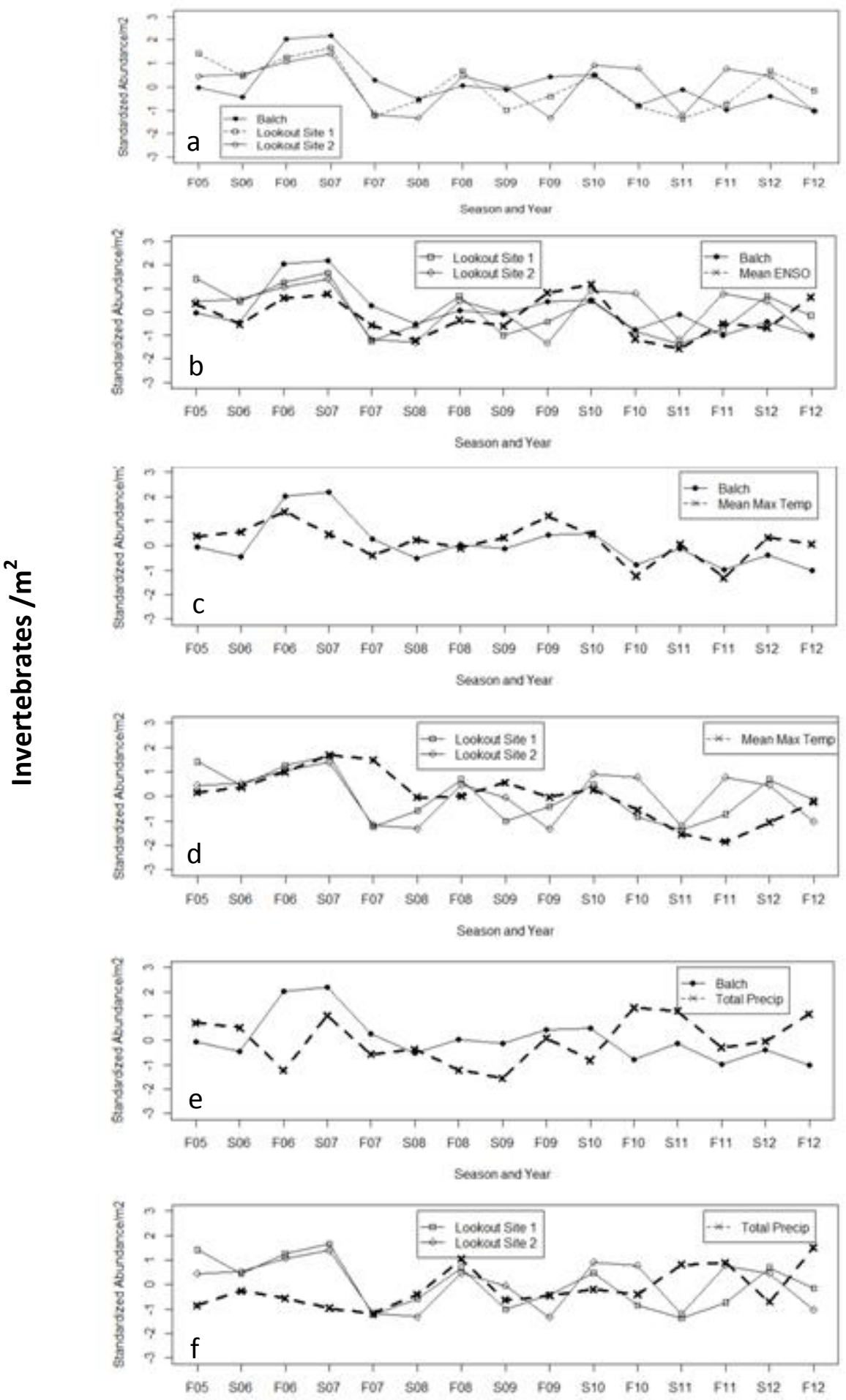

Season and Year 
Figure 2.5 LOESS ( $\operatorname{span}=0.65$ ). Stream comparison of invertebrate density using Kendall's $\tau$. X axis shows Fall (F) and Spring (S) samples from 2005-2012.

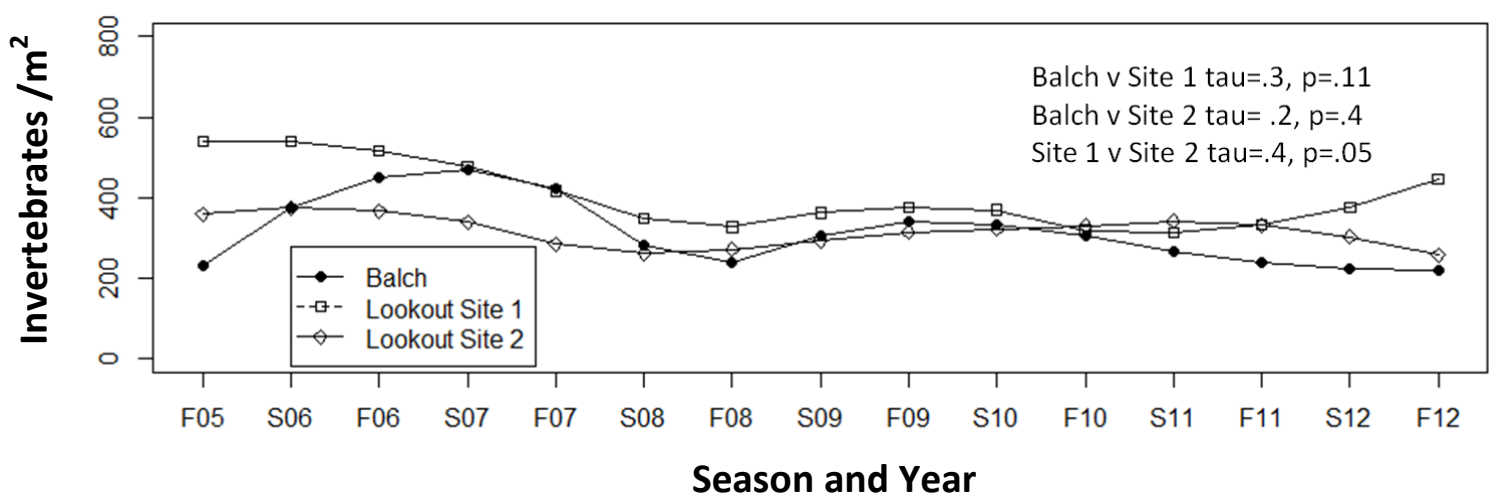


Figure 2.6 Assemblage in Balch Creek and Lookout Creek (Sites 1 and 2) for all seasons and years.

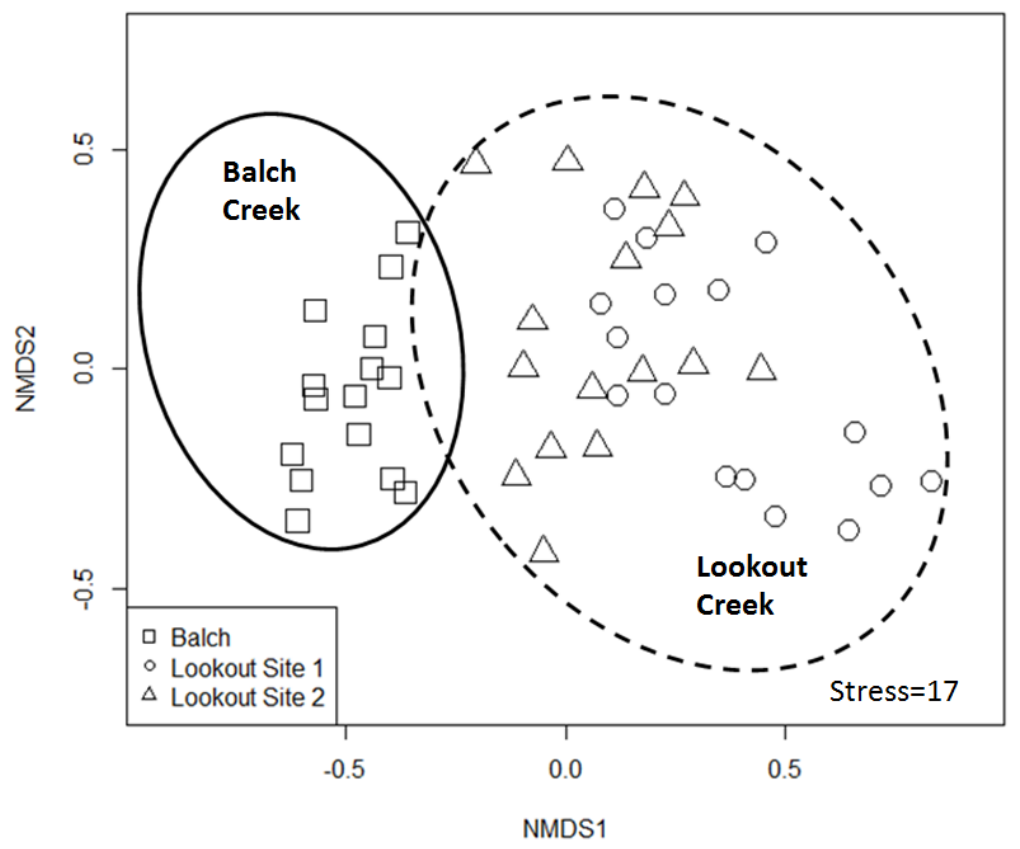


Figure 2.7 Ordinations based on relative abundance with climate vectors for Balch Creek 1 (BCS 1), Lookout Creek 1 (LCS 1) and Lookout Creek 2 (LCS 2). Only vectors with $\rho<0.20$ are shown. Filled symbols are Spring, open symbols are Fall. Stress $<15$ for all ordinations. Mean Temperature (Temp), Total Precipitation (Precip).
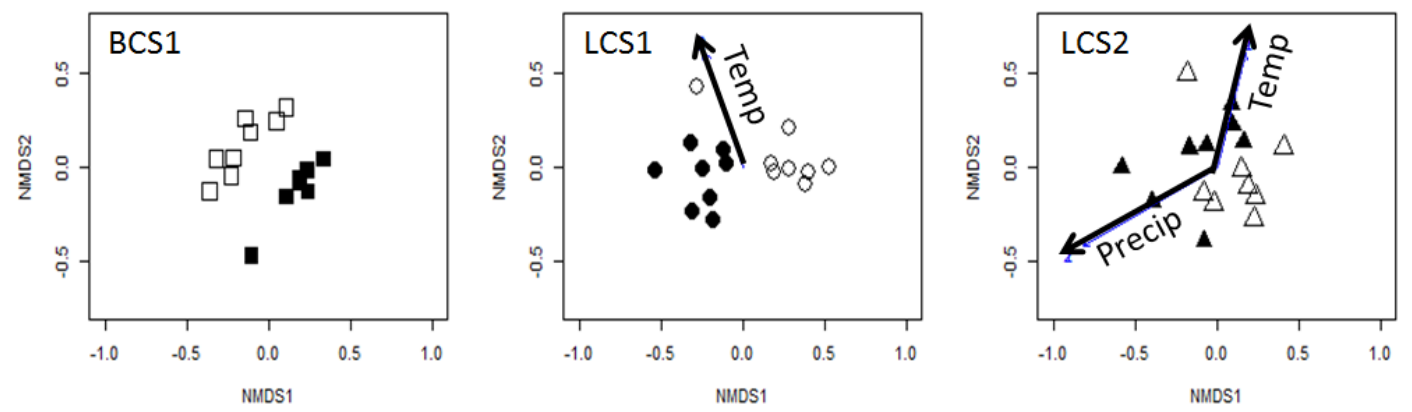
Figure 2.8 Ordinations based on functional feeding group with climate vectors. Only vectors with $\rho<0.20$ are shown. Filled symbols are Spring, open symbols are Fall. Stress $<10$ for all ordinations.
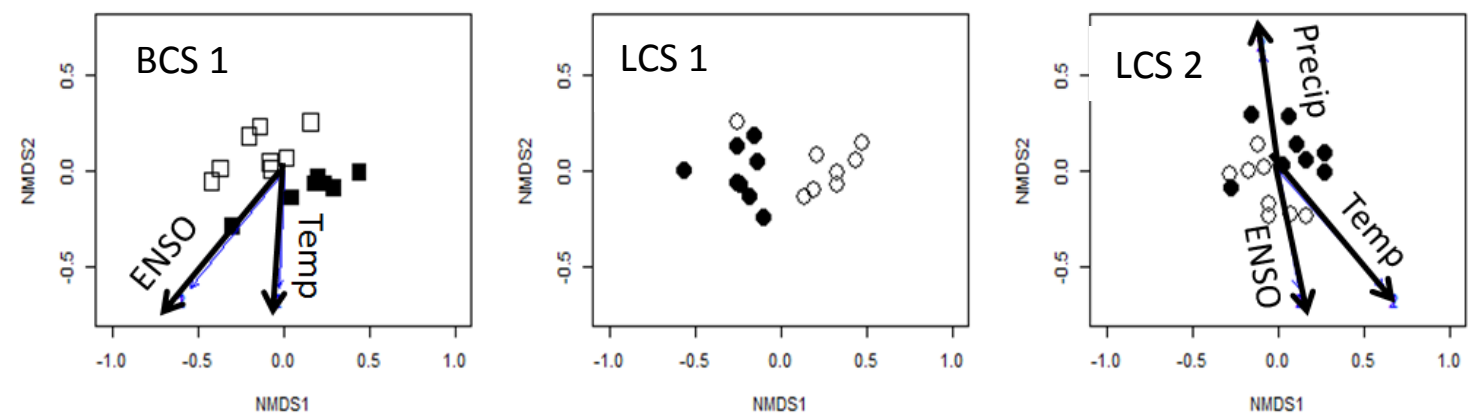
Figure 2.9 Balch Creek and Lookout Creek ordinations based on functional feeding group $(a, b)$ and life length (c). Bubble plots show relative abundance of scrapers or semivoltine. Only temperature and climate vectors with $\rho<0.20$ are shown.
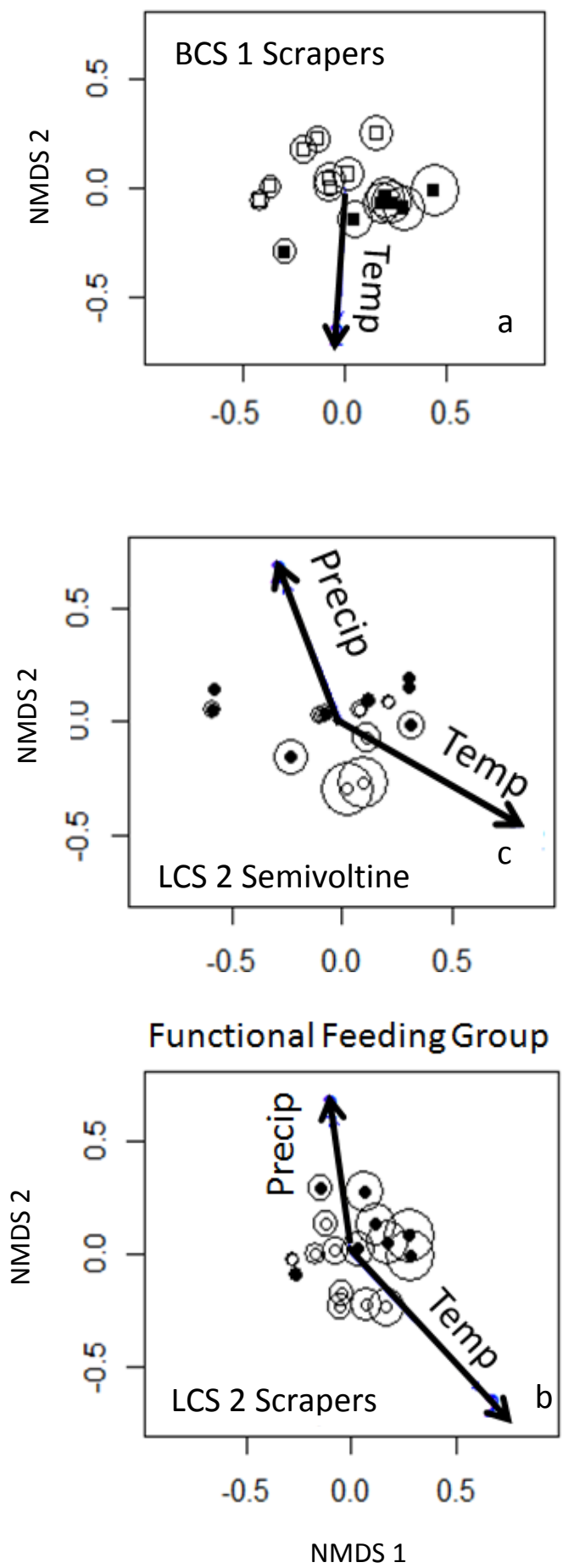
Figure 2.10 Scatter plots for significant linear models of standardized ( $Z$ score) invertebrate density as a function of $\operatorname{ENSO}(a, b)$, or mean maximum temperature (Max Temp c,d). $\mathrm{R}^{2}$ and $\mathrm{p}$-value for each model shown in plot. Only models with $\mathrm{p}<0.10$ are shown. Symbols are Fall (F) and Spring (S). There were no significant models for Lookout Site 2.

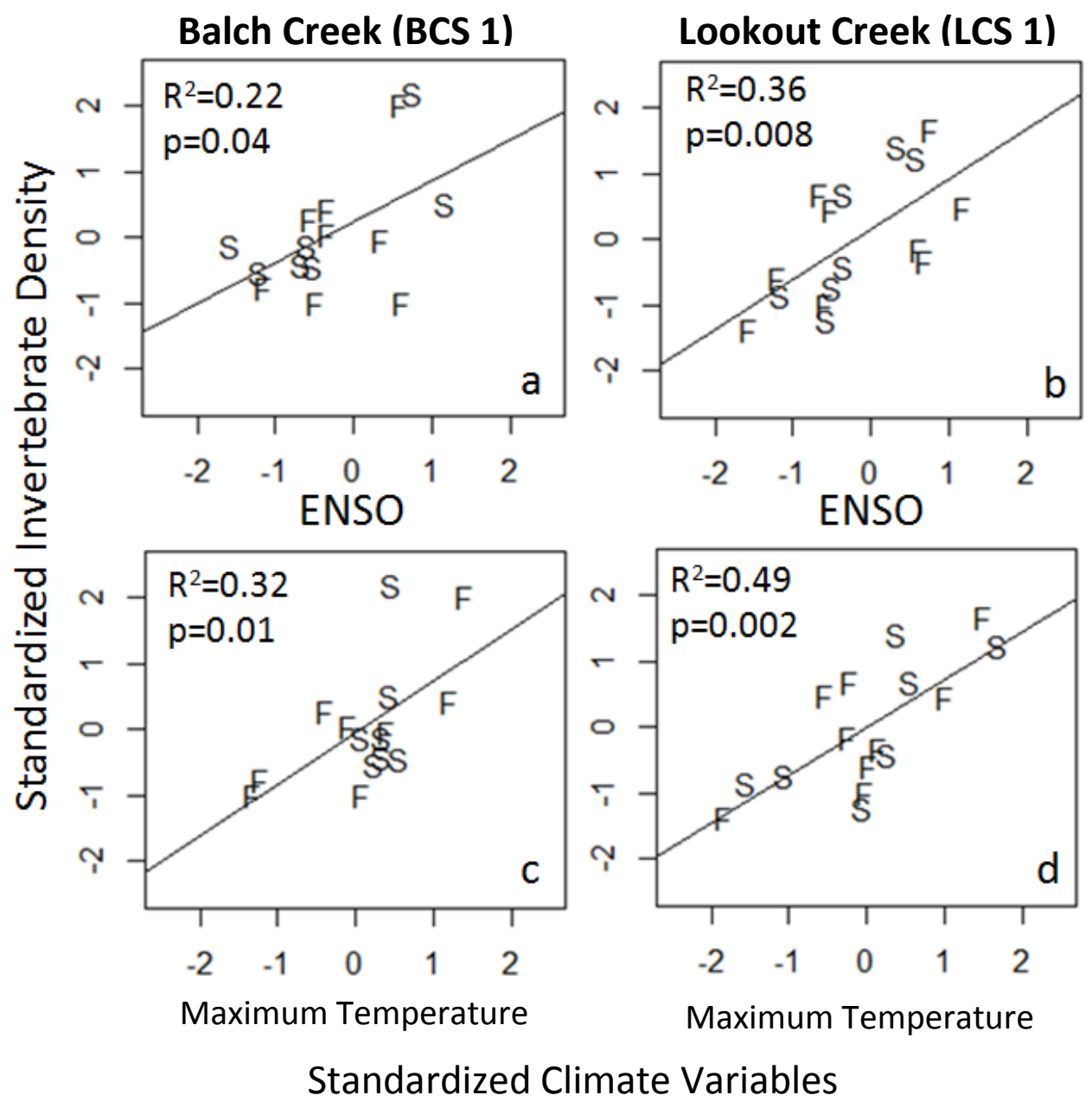


Figure 2.11 Standardized ( $Z$ score) invertebrate functional density for scrapers $(\mathrm{a}, \mathrm{b}, \mathrm{c})$ and voltinism $(\mathrm{d}, \mathrm{e}, \mathrm{f})$ as a function of average monthly maximum temperature (Max Temp, a,b,c,d,e) and average monthly precipitation (f). $\mathrm{R}^{2}$ and $\mathrm{p}$-value for each model shown in plot. Only models with $\mathrm{p}<0.10$ are shown. Symbols are Fall (F) and Spring $(\mathrm{S})$.

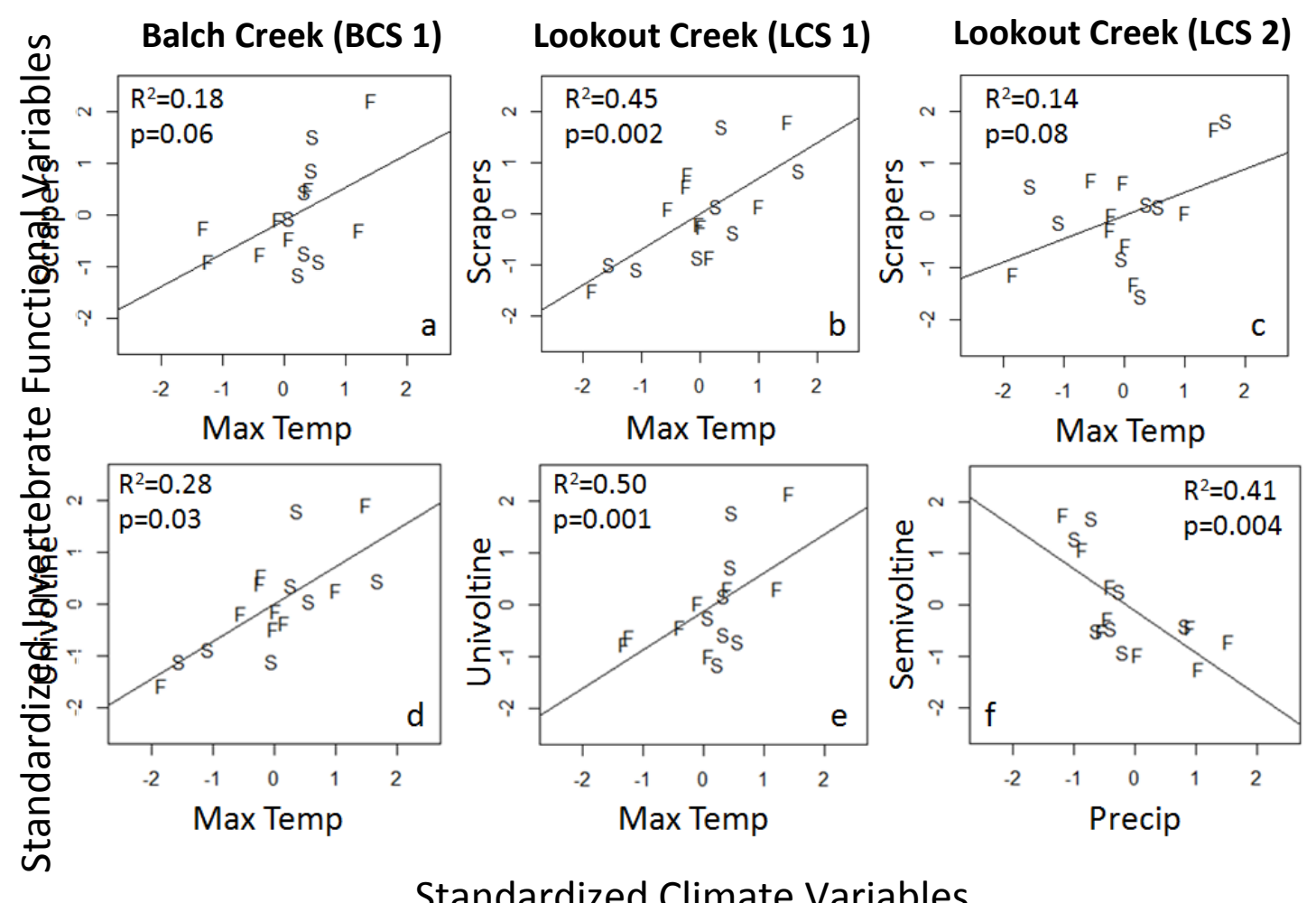

Standardized Climate Variables 
Table 2.1 Basin characteristics, stream physiochemical and climate summary data for study streams. Less than detection limit (LDL). Balch Land use data were obtained from RLIS (2001) and Lookout land cover data were obtained from the NLCD (Fry et al 2006). Elevation data were obtained from the USGS (2014).

\begin{tabular}{|c|c|c|}
\hline & Balch Creek & Lookout Creek \\
\hline \multicolumn{3}{|l|}{ Watershed } \\
\hline Area $\left(\mathrm{km}^{2}\right)$ & 9.1 & 62.4 \\
\hline$\%$ Forest & 81 & 100 \\
\hline$\%$ Agriculture & 0 & 0 \\
\hline$\%$ Rural Residential & NA & 0 \\
\hline \% Single Family Residential & 18 & 0 \\
\hline Mean Elevation (m) & 233 & 978 \\
\hline Minimum/Maximum Elevation (m) & $384 / 14$ & $1622 / 418$ \\
\hline Mean Slope $\left({ }^{\circ}\right)$ & 16 & 21 \\
\hline \multicolumn{3}{|l|}{ Station Information } \\
\hline Climate Station ID & USC00356750 & USS0022E07S \\
\hline Elevation & $6 \mathrm{~m}$ & $1067 \mathrm{~m}$ \\
\hline Distance from sampling site & $20 \mathrm{~km}$ & $70 \mathrm{~km}$ \\
\hline Gauging Station ID & NA & GSLOOK \#HFOO4 \\
\hline Stream Water Chemistry & NA & GSLOOK \#CFOO2 \\
\hline Climate & Mean (min-max) & Mean (min-max) \\
\hline Monthly Precipitation (cm) & $57.8(18.3-105.1)$ & $112.1(5.7-192.7)$ \\
\hline Monthly Max Temperature $\left({ }^{\circ} \mathrm{C}\right)$ & $22.0(11.8-24.0)$ & $12.8(5.5-20.4)$ \\
\hline Stream & Mean (min-max) & Mean (min-max) \\
\hline June streamflow (liters/sec) & $22.0(5.1-52.7)$ & $56.7(34.0-112.0)$ \\
\hline Area-normalized streamflow (liters/sec) & $2.4(0.6-5.8)$ & $0.9(0.5-3.1)$ \\
\hline Temperature $\left({ }^{\circ} \mathrm{C}\right)$ & $14.9(14.1-15.5)$ & $15.7(12.8-17.4)$ \\
\hline Conductivity (uS/cm) & $163.7(159.0-167.0)$ & $37.6(36.2-38.6)$ \\
\hline Nitrate (mg/L) & $0.6(0.58-0.73)$ & LDL \\
\hline Soluble Reactive Phosphate (mg/L) & $0.1(0.07-0.08)$ & $0.01(0.01)$ \\
\hline Suspended Solids (mg/L) & $10.3(2.0-21.0)$ & $5.6(2.1-11.6)$ \\
\hline
\end{tabular}


Table 2.2 Summary invertebrate data from study sites. Fall (F), Spring (S)

\begin{tabular}{|c|c|c|c|}
\hline & $\begin{array}{c}\text { Balch Creek } \\
\text { BCS } 1\end{array}$ & $\begin{array}{c}\text { Lookout Creek } \\
\text { LCS } 1\end{array}$ & $\begin{array}{c}\text { Lookout Creek } \\
\text { LCS } 2\end{array}$ \\
\hline Sampling period & F05-F13 & S05-F13 & S05-F13 \\
\hline Number of samples & 15 & 16 & 16 \\
\hline Mean area sampled $\mathrm{m}^{2}$ (min-max) & $1.0(0.46-1.4)$ & $0.70(0.56-.93)$ & $0.69(0.46-0.93)$ \\
\hline Mean total abundance (min-max) & $330(103-800)$ & $279(106-502)$ & $219(109-302)$ \\
\hline Mean density $\mathrm{m}^{2}$ (min-max) & $278(200-717)$ & $403(190-664)$ & $317(196-450)$ \\
\hline
\end{tabular}


Table 2.3 Results of ANOSIM tests of differences between streams and season. Lookout Creek Sites 1 and 2 (LCS 1, LCS 2). Balch Creek (BCS 1).

\begin{tabular}{llr}
\hline & $\mathrm{R}$ & $\rho$-Value \\
\hline All Sites & .72 & 0.001 \\
LCS 1 vs LCS 2 & .27 & 0.003 \\
BCS 1 season & .66 & 0.001 \\
LCS 1 season & .70 & 0.002 \\
LCS 2 season & .16 & 0.04 \\
\hline
\end{tabular}


Table 2.4 Attributes for each family used in functional analysis. Multivoltine (MV), Univoltine (UV), Semivoltine (SV).

\begin{tabular}{lrr}
\hline & \multicolumn{2}{c}{ Functional } \\
Feeding Group & Life length \\
\hline mayfly & Collector & UV \\
Ameletidae & Collector & MV \\
Baetidae & Scraper & UV \\
Heptageniidae & & UV \\
Leptophlebiidae & & \\
Stonefly & Predator & UV \\
Chloroperlidae & Shredder & UV \\
Leuctridae & Shredder & UV \\
Nemouridae & Shredder & SV \\
Peltoperlidae & Predator & SV \\
Perlidae & Predator & UV \\
Perlodidae & Shredder & SV \\
Pteronarycidae & & \\
Caddisfly & Scraper & UV \\
Glossossomatidae & Collector & SV \\
Hydropsychidae & Scraper & UV \\
Limniphilidae & Predator & SV \\
Rhyacophilidae & & \\
Diptera & NA & NA \\
Chironomidae & Collector & UV \\
Simulidae & Shredder & UV \\
Tipulidae & & \\
Other & Collector & SV \\
Elmidae & Shredder & UV \\
Gammarus & & \\
\hline
\end{tabular}


Table 2.5. Results of vector analysis. Only vectors with p-values $<0.20$ are shown. Lookout Creek Sites 1 and 2 (LCS 1, LCS 2). Balch Creek (BCS 1). $\mathrm{r}^{2}=$ psuedo $r^{2}$

$R^{2} \quad \rho$ value

Assemblage ordination

$\begin{array}{lll}\text { All Sites Mean maximum temperature } & 0.09 & 0.15\end{array}$

LCS 1 Mean maximum temperature $\quad 0.24 \quad 0.18$

LCS 2 Mean maximum temperature $\quad 0.24 \quad 0.14$

$\begin{array}{lll}\text { LCS } 2 \text { Mean total precipitation } & 0.28 & 0.11\end{array}$

FFG ordination

$\begin{array}{lll}\text { BCS } 1 \text { Mean maximum temperature } & 0.34 & 0.07\end{array}$

BCS 1 ENSO

$0.26 \quad 0.16$

LCS 2 Mean maximum temperature $\quad 0.28 \quad 0.13$

LCS 2 Mean total precipitation $\quad 0.30 \quad 0.11$

LCS 2 ENSO

$0.28 \quad 0.11$

Life Length ordination

LCS 2 Mean maximum temp $\quad 0.28 \quad 0.12$

\begin{tabular}{lll} 
LCS 2 Mean total precipitation & 0.60 & 0.002 \\
\hline
\end{tabular} 


\title{
Chapter 3 Invertebrate Indicators of Excessive Fine Sediment in Streams of the Oregon Coast Range.
}

\begin{abstract}
Sedimentation is a leading cause of stream pollution and is a well-known source of habitat degradation in the salmon-bearing streams of the Pacific Coastal region. However, because sediment transport and deposition are natural processes, it is difficult to determine when sedimentation levels are excessive and may be affecting stream function. This study examines the use of macroinvertebrates as indicators of the presence of excessive fine sediment in streams of the Oregon Coast Range. Data from a synoptic spatially-balanced survey (randomized stream selection but with equal numbers of stream orders) of 214 wadeable streams $\left(1^{\text {st }}-3^{\text {rd }}\right.$ order, 1:100,000 USGS topographic maps) were used to develop and evaluate taxonomic and trait-based indicators of fine sediment $(<2$ $\mathrm{mm}$ ) and bed stability. Exploratory analysis was used to identify important environmental and invertebrate variables that were then used in a subsequent analysis to identify potential invertebrate indicators. Mantel tests and non-metric multidimensional scaling showed that macroinvertebrate assemblage was significantly related to forty-five environmental variables across spatial scales including substrate size and stability, reach and watershed characteristics, stream water chemistry and basin land and forest cover. Linear models showed macroinvertebrates were in general weakly associated with fine sediment. However, when the effect of reach slope was factored-out, relationships improved in eight of sixteen metrics. In both erosive and resistant geologies, scrapers were negatively significantly related to percent fines $\left(R^{2}=0.14 \rho<0.05\right.$ and $R^{2}=0.11 \rho$
\end{abstract}


$<0.001$, respectively). In erosive geologies, Paraleptophlebia $\left(\mathrm{R}^{2}=0.21 \rho<0.01\right)$ was positively related to fines and invertebrates with external gills $\left(R^{2}=0.16 \rho<0.01\right)$ showed a significant negative relationship with fines. In resistant geologies, Rhithrogena and mayfly, stonefly and caddisfly (EPT) richness were both negatively related to fines $\left(\mathrm{R}^{2}=0.10 \rho<0.01\right.$ and $\mathrm{R}^{2}=0.10 \rho<0.001$, respectively). The results of this study support the use of scrapers as a potential functional metric to monitor for excessive fines in streams of the Oregon Coast Range.

\section{Introduction}

The Pacific Coastal region of the United States contains large tracts of economically important forestlands that also serve as critical stream habitat for anadromous fish (Hall et al. 2004). In the Pacific Coastal region, the major source of human disturbance is logging and road building, activities known to increase sediment supply and delivery to surface waters (Binkley and Brown 1993; McClain et al. 1998; May 2002). Excessive deposition of fine sediment $(<2 \mathrm{~mm})$ on the stream benthos is a leading cause of stream impairment known to degrade stream habitat and impact endangered salmon populations (Nehlsen et al. 1991; Wood and Armitage 1997; USEPA 2006). However, because of high natural variability, it is difficult to determine when a stream is experiencing sedimentation levels that are detrimental to biota (Griffith et al. 2009; Shearer and Young 2011). This is particularly true in the Pacific Coastal region, which has high environmental heterogeneity and relatively moderate human disturbance (Hershey and Lamberti 1998; Richardson and Danehy 2007). From a management perspective, there is increased interest in developing regional biotic indicators, such as 
stream invertebrates, which can be used to determine when biologically relevant changes in stream sediment are occurring (Karr 1998).

The impact of excessive fine sediment on streams is well documented. High levels of suspended sediment and turbid conditions reduce stream productivity (DaviesColley et al. 1992; Parkhill and Gulliver 2002). Sediment deposited on the benthos fills interstitial spaces, decreasing habitat availability and degrading salmon-spawning habitat (Suttle et al. 2004; Kaufmann et al. 2009). Stream invertebrates are particularly vulnerable to sediment fining. For example, substrate armoring from sediment deposition limits invertebrate migration in hyporheos (Stanley and Boulton 1993), which is an important refuge for invertebrates during hydrological extremes. Deposited fine sediment on the stream substrate clog invertebrate structures for filter feeding, reduce food availability to grazers and can damage invertebrate gill structures (Lemly 1982; Rabeni et al. 2005). Saltating sediment scours the substrate, creating harsh conditions that induce invertebrate drift and alter functional aspects of the invertebrate community (Bond and Downes 2003; Rabeni et al. 2005; Larsen et al. 2010).

Strong external and internal controls of sediment result in highly variable sediment conditions within and among streams. The size and distribution of sediment in streams is largely dependent on the interplay between stream supply and transport rates (Wilcock 1998). Sediment transport rates are a function of stream velocity and particle size and shape (Dietrich et al. 1989), while supply and delivery rates are largely dependent on basin characteristics such as slope, watershed area, land cover and geology (Kaufmann et al. 2009). In general, as sediment supply exceeds transport capacity, the benthic substrate composition becomes finer and the mean particle size decreases 
(Jackson et al. 2001); however, human activities and natural stream characteristics, such as channel form, can exert strong controls on sediment supply and transport processes (Buffington and Montgomery 1999). In the heavily-forested watersheds of the Pacific Coast, runoff and erosion are rare, so much of the natural sediment supply is through soil slumping and landslides (Cheng 1988; Swanson et al. 1987; Grant and Wolff 1991; Benda et al. 1998; Hassan et al. 2005). Erosion from human activities such as tree harvesting (Rice et al. 2004) and road building (Waters 1995; Luce and Black 2001) can accelerate erosion and increase sediment supply and delivery to streams. Once sediment is in the stream, internal controls such as slope, velocity, channel form and large woody debris act to control storage and transport of sediment (Jackson et al. 2001; Hassan et al. 2005).

Substrate fines are an important physical characteristic of the stream ecosystem; however, the primary interest of environmental managers is monitoring the effect of sediment fining on stream function. Consequently, there is increased interest in developing biotic indicators that may serve as a proxy for traditional sediment measurements (e.g. Relyea et al. 2012). Stream invertebrate sensitivity and tolerance to sediment is well documented in field studies. For example, the mayflies Paraleptophlebidae and Baetidae are known to be tolerant of high sediment conditions, while other mayflies such as Heptageniidae and Ephemerellidae are known to be sensitive (Relyea et al. 2012; Larsen and Ormerod 2010; Angradi 1999). While the mechanisms of tolerance are not well known, the recognition of invertebrate sensitivity has led to the development of invertebrate-based metrics for monitoring sediment fines (e.g. Richards et al. 1997; Zwieg and Rabeni 2001; Vieira et al. 2006; Relyea et al. 2012). 
However, it is unclear which metrics are broadly reliable and few have been examined in areas, such as the Pacific Coastal ecoregion, with relatively moderate human disturbance and high environmental heterogeneity (Allan and Johnson 1997; Richards et al. 1997; Davies et al. 2000). In the Pacific Coastal region, the use of invertebrates as indicators of sediment fining presents several challenges. First, invertebrates are strongly related to other stream characteristics and thus increase the likelihood of a Type I error (Townsend et al. 2003). For example, in the Pacific Coastal region, stream biotic communities are known to be correlated with basin size, geology, land use and canopy cover (Herlihy et al. 2005; Weilhoefer and Pan 2006; Naymik et al. 2005; Banks et al. 2007; Cole et al. 2003; Mazor et al. 2009). Second, because sediment delivery and transport in streams is a natural process, it is difficult to know when sediment fining is outside the range of natural variability or due to anthropogenic sources (Montgomery and Buffington 1997; Shearer and Young 2011). Therefore, biotic indicators must reflect stream sedimentation levels that are detrimental to stream habitat and function. Finally, traditional taxonomic metrics such as richness or assemblage may not detect moderate sediment disturbance (e.g. Larsen and Ormerod 2010) because it simply alters total habitat space, not stream function. Functional characteristics of the invertebrate community may provide a more useful indicator of sediment fining because it reduces taxonomic effort, is based on morphological and behavioral traits, may reflect changes in functional aspects of streams and are a source of food for salmon (Merritt and Cummins 2006; Cummins et al. 2005; Angermeier and Karr 1994; Wallace and Webster 1996).

The purpose of this study is to identify potential macroinvertebrate indicators of sediment fining in streams of the Oregon Coast Range. The objectives of this research are 
to: 1) identify major environmental gradients controlling stream invertebrates across the Coast Range within erosive and resistant geologies; 2) examine correlation between environmental conditions and stream invertebrates in the region; and 3) evaluate potential invertebrate indicators of disturbance and stream fine sediment in basins with resistant and erosive geologies. Three specific hypotheses were tested. The first was that both stream invertebrates and fine sediment would be related to basin-scale (watershed slope) and reach-scale (canopy cover) characteristics. The second hypothesis was that statistical relationships between stream invertebrates and fine sediment would be improved by accounting for covariance between slope, sediment and invertebrates. The final hypothesis was that invertebrate traits would be correlated with substrate stability and fine sediment cover.

\section{Methods}

\subsection{Study area}

The Pacific Coastal region is located along the western edge of the northern United States and Canada (Figure 3.1). It is characterized by a maritime climate with cool dry summers and wet winters and contains one of the largest temperate rainforests in the world (Ryan 1994). The Pacific Coastal Region is densely covered with stands of tall coniferous trees and heavily dissected by streams, which support some of the last highly productive salmon habitat remaining in the United States. While the region has enough homogeneity to be considered a single ecoregion, there is large environmental and biotic variability at smaller spatial scales (Naiman and Bilby 1998). The Oregon Pacific Coast region has steep slopes with elevations from sea level to $1,249 \mathrm{~m}$, but most of the ridgelines occur between 450 and 750 ms (Franklin and Dyrness 1973). Geology in the 
Oregon Coast Range varies from north to south and is mainly composed of marinederived sediments and basalts. Geology in the southern part, below the Yamhill River, is mainly sandstones (Tyee formation) with igneous mountain peaks. In the north, the geology is mixed sedimentary and volcanic with siltstones, sandstones and basalts (Franklin and Dyrness 1973). Average annual precipitation in the Oregon Coast Range ranges from $250 \mathrm{~cm}$ to $760 \mathrm{~cm}$ in the upper elevations, temperature is generally mild, with average January minimum temperature as low as $0^{\circ} \mathrm{C}$ and the July maximum average temperature at around $25^{\circ} \mathrm{C}$ (Franklin and Dyrness 1973). Oregon's Coast Range contains a temperate coniferous rainforest characterized by Sitka spruce in the lower coastal elevations and western hemlock Douglas-fir inland (Franklin and Dyrness 1973). Riparian forests are structurally complex with mixed patches characterized by coniferous trees, alder, cottonwood and willow (Naiman et al. 1998).

\subsection{Data collection}

Environmental data and macroinvertebrates were collected in wadeable streams randomly sampled across the Oregon Coast Range. Data were collected by the Oregon Department of Environmental Quality (DEQ) as part of an effort to monitor the Oregon Plan for Salmon and Watersheds (OPSW 2003). The OPSW is an Oregon-wide effort to monitor environmental factors that impact watersheds and stream habitat, particularly in regard to salmon migration and reproduction (OPSW 2003). The DEQ study utilized a spatially-balanced synoptic survey to collect biotic and abiotic data across a range of scales. This design allows for inference to unsampled streams, thereby providing an opportunity to make predictions about key ecological processes across Oregon's Coast Range. A full description of the sampling design can be found in Herlihy et al. (2000). 
Sampling locations were selected using a two-step spatially-random process. First, a 40 $\mathrm{km}^{2}$ area was randomly selected from 1:100,000-scale USGS quadrants. Second, stream segments within the $40 \mathrm{~km}^{2}$ area were randomly selected and sampling sites along stream segments were systematically selected and georeferenced for field location. A sample reach $($ mean $=200 \mathrm{~m})$ was forty times the mean wetted width of the stream.

\section{2a Environmental Data}

Environmental data were collected using standard EPA protocols. Habitat data were characterized using a systematic design proportioned to the channel width (Kaufmann and Robison 1998). Thalweg profile (e.g. depth, habitat and presence of soft sediment) was measured at 100-150 equally-spaced intervals. Woody debris total was estimated from 10 segments between 11 transects. Channel and riparian characterizations were obtained with visual estimates from each of 11 transects. Discharge was measured at 0.6 depth at 15 to 20 intervals. Substrate size and embeddedness was measured systematically across at 11 transects (Kaufmann and Robison 1998). Five random substrate pieces from each transect were visually categorized by size class. Water chemistry was collected by in situ measurements or shipped to a lab (Herlihy 1998). Exploratory analysis focused on 51 environmental variables across a range of spatial scales (Table 3.1). I determined basin geology using a Geographic Information System (GIS) to categorize the major geologic unit within the subdelineated basin. GIS data were derived from the geologic map of Oregon (1:500,000; Walker and MacLeod 1991) and available from the USGS (Walker et al. 2003). Sub-basins with greater than $80 \%$ homogenous geology were categorized as either erosive (siltstone, sandstone, shale, 
mudstone, alluvium or mafic pyroclastic) or resistant (mafic volcanic flow or mafic volcanic intrusive).

Stream sedimentation was quantified using substrate size, percent benthic sand and fines and bed stability. Substrate size data were collected using pebble counts and presented as the log of the geometric mean diameter. Percent sand $(0.6-2.0 \mathrm{~mm})$ and fines $(<0.6 \mathrm{~mm})$ was determined using pinch tests and then visually estimated as percent cover (Kaufmann et al. 1999; Kaufmann et al. 2009). Percent fines (size categories in Table 3.1) were chosen for analysis to represent the amount of fine material that may be clogging interstitial space. Streambed stability was evaluated using an index known as the Log Relative Bed Stability (LRBS), developed to account for bed form roughness such as large woody debris or pools. LRBS is the log of the ratio of particle size to critical diameter (at bankfull flow) relative to the bed form (Kaufmann et al. 2009). LRBS is generally negative and decreases as substrate stability decreases. Low values of the LRBS indicate that the average streambed particle size is smaller than the stream competency, making the substrate relatively unstable (Kaufmann et al. 2008). In this study, LRBS was used to assess potential indicator traits and compare observed relationships between indicator traits and percent fines.

\section{2b Macroinvertebrates}

Macroinvertebrates were collected in the summer from riffles and pools from nine transects in the middle, left or right of the channel using a modified kick net $(595 \mu \mathrm{m}$ mesh) from $0.5 \mathrm{~m}^{2}\left(4.5 \mathrm{~m}^{2}\right.$ total $)$ of the benthos. Invertebrate samples from multiple transects were pooled into one sample per site, elutriated in the field and randomly subsampled in the lab to 500 organisms. Taxonomic identification was standardized by 
grouping all species to genera except midges, which were grouped by tribe. Functional attributes (Table 3.2) were determined using tolerance values found in Vieira et al. (2006) and Carlise et al. (2007). If no genus-level information was available, family-level information was used for all genera in that family. To further explore the relationship between invertebrate feeding traits and sediment fines, invertebrates were classified as brushers or gougers based on the studies of Arens (1989). Brushers use brush-like structures to sweep organic material into their mouths (Figure 3.5). Gougers use gougelike structures to pry up diatoms and other adhered algae. Invertebrate assemblages were represented by relative abundance (RA) of the total organisms found at each site. To reduce the influence of rare taxa, organisms representing less than $1 \%$ relative abundance and found at less than 3 sites were removed. This process resulted in the removal of 24 taxa.

\subsection{Statistical Analysis}

\section{3a Environment and Invertebrates}

Major environmental gradients across the Coast Range and within both erosive and resistant lithologies were evaluated using Principal Components Analysis (PCA), Non-metric Multidimensional Scaling (NMDS) ordination and vector analysis. Environmental data were scaled and log transformed to normalize distributions. PCA was used to examine major patterns in environmental conditions across the sites. PCA uses eigen analysis to reduce a complex data set to a smaller number of composite variables called principal components (McCune and Grace 2002). Invertebrate community was evaluated using NMDS to ordinate assemblage data based on relative abundance. NMDS is an unconstrained ordination technique that examines the overall 
similarity of an assemblage (McCune and Grace 2002). NMDS is often used with invertebrate data because it preserves the inter-site ranked relationships and better represents species distances (Legendre and Legendre 1998). The relationship between assemblage and environmental variables was examined using a linear fitting function (Envfit) to fit environmental vectors to the ordinations. Envfit fits a vector to the ordination and a permutation test is used to determine importance (psuedo $\mathrm{r}^{2}$ ) and significance $(\rho<0.05)$. The results of the Envfit analysis were used to select a subset of variables to represent the major environmental gradients in the Coast Range within each lithology.

\section{3b Collinearity}

Multivariate collinearity between environmental variables and invertebrates was examined using Mantel tests and partial correlation (Mantel 1967). The Mantel test estimates the correlation between matrices (Legendre and Legendre 1998; Urban 2003). Partial Mantel tests are used in ecological studies to compare more than two matrices and control for the effect of interdependence between the matrices (Legendre and Legendre 1998). Partial Mantel tests are frequently used to control for the effect of spatial autocorrelation often present in environmental data (Urban 2003; King et al. 2005). In this study, partial Mantel tests were used to control for the effect of reach slope on environmental variables and invertebrate assemblage within each geology (resistant or erosive).

\section{3c Potential invertebrate indicators}

Potential invertebrate indicators of stream fine sediment were evaluated using vector analysis and linear models. Vectors of major environmental gradients were fitted 
to invertebrate assemblage within resistant and erosive geologies. Vectors and bubble plots were used to examine the relationship between environmental variables, invertebrate indicators and fine sediment. Based on vector analysis results, a subset of invertebrate variables were selected for use in indicator analysis (Table 3.2) and examined using partial correlation. Partial correlation is used to remove the effect of intercorrelated variables (Naymik et al. 2005; King et al. 2005). In this study, partial correlation was used to control for the effect of slope on stream invertebrates and to assess relationships with sediment fines while controlling for the effect of slope. To improve reliability of the findings, a subset of streams was used to develop linear models. Streams with basins larger than $10,000 \mathrm{~km}^{2}$, width greater than $10 \mathrm{~m}$ and slopes greater than $10 \%$ were removed. Sample size was reduced from 121 to 67 in erosive geology and 45 to 30 in resistant geology. All statistical analyses were performed using the "Vegan Package" in R statistical software (R Development Core Team, version 2.14.0, 2011).

\section{Results}

\subsection{All Coast Range Sites}

\section{1 a Environment and Assemblage}

A total of 214 sites across the Oregon Coast Range were used for analysis (Figure 3.1). Sampled streams were generally small (Table 3.1 , mean width $<6.3 \mathrm{~m}$ ) and shallow (mean depth $<32 \mathrm{~cm}$ ), steep (mean slope $>3.4 \%$ ) and well-shaded (mean $>45 \%$ ) with relatively low nutrients (mean Total Nitrogen $<0.20 \mathrm{mg} / \mathrm{L}$ ). The majority of sites were situated in relatively small basins $\left(<15 \mathrm{~km}^{2}\right)$ densely covered with coniferous forests. Substrate size was generally smaller in erosive stream sites, which had more sand and fines (Figure 3.6, erosive mean $=30 \%$, resistant mean $=15 \%$ ) and fines (Figure 3.6, 
erosive mean $=22 \%$, resistant mean $=8 \%$ ). Precipitation was variable across the sites, ranging from $100-400 \mathrm{~cm}($ mean $=226 \mathrm{~cm})$ and was related to elevation (range $3-1037$ $\mathrm{m}$, mean $=196 \mathrm{~m})$. In general, study streams had relatively large substrate size and abundant woody debris in the channel. The majority of human disturbance is from clearcut logging and associated road building (Hershey and Lamberti 1998). Other types of landuse in the basin is relatively low with an average of $1 \%$ urban development (range $0-14 \%$ ) and $2 \%$ agriculture (range $0-11 \%$ ) in the study basins. Summary environmental data are shown in Table 3.1 .

PCA analysis of the environmental variables revealed three gradients accounting for $28 \%$ of the variance in environmental characteristics of the streams (Table 3.3). PCA Axis I (13\% of total variance) was mainly composed of substrate characteristics (i.e. high positive and negative loadings of gravel and fines, respectively). PCA Axis II (10\% of total variance) represented a stream size gradient (i.e. high positive and negative loadings of slope and width x depth, respectively). PCA Axis III explained only 5\% of the variance and loadings were comparatively low. Correlation analysis revealed a latitudinal gradient across sites and intercorrelations between major environmental gradients (Table 3.4). The latitude gradient was positively associated with increasing canopy $(r=0.27)$ and negatively associated with slope $(\mathrm{r}=0.10)$. Based on PCA results, 23 environmental variables across a range of spatial scales were selected for indicator analysis (Table 3.1).

Across all sites in the Coast Range, 111 taxa from six invertebrate orders were found in streams. The invertebrate community of Coast Range streams was dominated by mayflies, caddisflies, stoneflies and Diptera (Appendix A7-A10). The most common taxa were the Chironomidae, which were present in all but one site and represented $11 \%$ of the 
total abundance (Appendix A7). Median taxa richness was 20 (range 7-35), and median EPT richness was 13 (range 4-27). Scrapers, collector-gatherers and clingers were the most common functional feeding groups.

Assemblage across all Coast Range sites were best characterized by a threedimensional solution ( stress $=16$ ) obtained for the NMDS ordination. The ordination pattern shows a continuous gradient along NMDS Axis I and II, suggesting that invertebrates are likely responding to a gradual change in environmental variability across the region. There was no clear separation of sites based on geology (Figure 3.2). NMDS Axis I was negatively correlated with the sensitive stoneflies Yoraperla and Moselia and positively correlated with the tolerant Dipteran Simulium and the moderately tolerant stonefly Plumiperla. NMDS Axis I may represent an invertebrate tolerance gradient with positive values indicating greater tolerance. NMDS Axis II was negatively correlated with the caddisfly genera Psychoglypha and the dragonfly Gomphidae, which both prefer slow-water habitat, and positively correlated with the caddisfly Neothremma and the stonefly family Nemouridae, both commonly found in small-forested streams. NMDS Axis II likely represents a stream-size gradient reflecting slower water and higher sediment.

Environmental vector fitting identified 23 environmental variables (Table 3.1) and 11 functional metrics (Table 3.2), that were selected to characterize three major environmental gradients associated invertebrate assemblage (Figure 3.2). Ordination of species with fitted environmental vectors revealed three major environmental gradients related to invertebrate assemblage. NMDS 1 represents human disturbance gradients, which was also correlated with invertebrate tolerance scores. NMDS 2 represents a 
stream-size gradient with canopy, density and slope related to shredders and scrapers, suggesting an upstream/downstream pattern predicted by the River Continuum Concept (Vannote et al. 1980). A weaker orthogonal gradient is suggested by substrate size, functional feeding and dissolved oxygen, which are correlated with each other but not well represented on the ordination plot.

\subsection{Basins with Erosive and Resistant Geology}

\section{2a Environment and Invertebrates}

GIS analysis resulted in 55 resistant basins and 159 erosive basins selected for analysis. Differences between streams in erosive and resistant basins were most evident at the reach and substrate scales. At the basin scale, erosive watersheds were slightly larger with lower average elevation and more agriculture land use (Appendix A2.a, A2.b and A2.f). Resistant basins were relatively steeper with more stream power (Appendix A5.a and A2.d). Water chemistry was similar between sites, but turbidity and temperature were slightly higher at erosive sites (Appendix A1.f and A1.d). At the reach and patch scale, the differences between the sites were more apparent. Streams in the erosive site were slightly wider and deeper (Appendix A3.d and A3.c) with slightly less canopy cover (Appendix A3.f). Substrate at the erosive sites was generally smaller (Figure 3.6, Appendix A4.a, A4.b, A4.c and A4.d) with more of the substrate area covered with fines (Figure 3.6, Appendix A3.f).

Invertebrate communities across all sites were dominated by Baetis mayfly and two subfamilies of Midges (Chironominae and Orthocladiinae, Appendix A7). Other common taxa included stoneflies (Zapada; Appendix A9), caddisflies (Rhyacophila; Appendix A10) and beetles (Optiservus and Zaitzevia). Assemblage of each geology was 
characterized by a three-dimensional solution with a stress of 16 and 17 for resistant and erosive, respectively (Figure 3.3). The variance explained by NMDS Axis 1, 2 and 3 was $27 \%, 21 \%$ and $20 \%$, respectively, at the erosive sites and $33 \%, 30 \%$ and $17 \%$ at the resistant sites. In the erosive sites, Axis 1 was positively correlated with the caddisfly Dicosmoecus and negatively correlated with the coldwater stenotherm stonefly Yoraperla. Axis 2 was positively correlated with the caddisfly Goera, which is typically found in larger streams, and negatively correlated with the coldwater stenotherm stonefly Soliperla. Axis 3 was positively correlated with the sensitive stonefly Paraperla and negatively correlated with tolerant Simulium. In the resistant sites, Axis 1 was positively correlated with the stonefly shredder Zapada and Isoperla, both typically found in small coldwater streams, and negatively correlated with the tolerant Simulium. Axis 2 was positively correlated with the tolerant mayfly Acentrella and negatively correlated with the tolerant Dipteran Clinocera. Axis 3 was also positively correlated with Clinocera and negatively correlated with the moderately tolerant scraper Glossosoma.

Examination of the environmental vectors within geology identified 12 variables across a range of spatial scales that were strongly related to assemblage and most relevant to the objectives of this study (Table 3.5). The relationship of vectors and assemblage was different within each geology. In erosive geology, slope was negatively associated with NMDS Axis 1 and 2, while fines and stream size were associated with Axis 1. Agriculture and logging were significantly and positively associated with NMDS Axis 2 . In resistant geology, stream size (width $\mathrm{x}$ depth), nutrients and canopy were strongly associated with assemblage (Figure 3.3). Stream size was negatively associated with 
NMDS Axis 1 and 2, while slope and fines were positively associated with NMDS Axis 1 and 2. Agriculture and logging were weakly associated with assemblage (Figure 3.3). Assemblage within both geologies was significantly correlated with environmental vectors related to stream size, slope and substrate size and weakly associated with logging and agricultural disturbance (Table 3.5). Among geologies, there were slight differences in the relationship between assemblage and environmental vectors. In the erosive sites, assemblage was related to temperature and dissolved oxygen, whereas in resistant sites, assemblage was associated with total nitrogen. In both geologies, percent fines and slope vectors have similar associations with assemblage (Figure 3.3).

\subsection{Collinearity}

Mantel tests showed environmental variables across spatial scales were correlated with assemblage within both geologies (Table 3.6). The strongest associations were found at basin scale, with slope related to assemblage at erosive $(\mathrm{r}=0.30, \rho<0.001)$ and resistant sites $(\mathrm{r}=0.11, \rho<0.01)$. In erosive sites, assemblage was significantly related to logging $(\mathrm{r}=0.06, \rho<0.05)$ and agriculture disturbance $(\mathrm{r}=0.10, \rho<0.01)$, while in the resistant sites, only logging was significant $(r=0.15, \rho<0.05)$. When the effect of slope was removed with partial Mantel tests, the relationship between assemblage, fine sediment and stability was the same (Table 3.7), while the relationship with land disturbance showed mixed results (Table 3.7). In the erosive sites, the relationship between assemblage and disturbance substantially improved; however, this was not the case with fines, which slightly declined.

\subsection{Potential macroinvertebrate indicators of disturbance and sediment}


Exploratory analysis resulted in a subset of 13 invertebrate indicators (functional and taxonomic) chosen for evaluation as indicators of sediment fining in Coast Range streams (Table 3.2). Partial correlation and examination of bubble plots and vectors resulted in eight potential invertebrate indicators (Table 3.8). Partial correlation using residuals of the slope linear model improved linear correlations of invertebrate indicators with percent fines in five of the metrics (Table 3.9). In resistant geologies, external gills and Paraleptophlebia had the strongest relationship with percent fines (Table 3.9, Figure 3.4). In erosive basins, scrapers and EPT richness had the strongest relationships with percent fines (Table 3.9, Figure 3.4). Across both geologies, scrapers had the most consistent relationship with \% fines (Table 3.9, Figure 3.4). A similar relationship was observed in the analysis using bed stability (Table 3.9).

\section{Discussion}

\subsection{Environment and Invertebrates}

In the Oregon Coast Range, stream biotic and abiotic variables are strongly controlled by environmental gradients across a range of landscape scales. Within erosive and resistant basins, stream physical characteristics showed distinct differences, but the overall invertebrate assemblage was relatively similar. Erosive basins were generally larger, with lower stream power, smaller substrate and with more human disturbance than resistant basins. At all sites, the invertebrate assemblage was dominated by mayfly, stonefly and caddisfly taxa typically found in small-forested streams with low to moderate anthropogenic disturbance. Assemblages across all sites were strongly associated with slope, stream size, canopy and substrate and weakly associated with logging. In erosive sites, assemblage was also related to agriculture, temperature and 
dissolved oxygen. While in resistant sites, assemblage was also related to nitrogen. In both basins, fines were related to assemblage as slope increased and stability decreased. This suggests that slope is an important environmental characteristic acting on sediments and invertebrates. However, this relationship is confounded by canopy cover, which also covaries with slope. The effect of canopy on stream biotic communities has been previously observed in Oregon's Coast Range (e.g. Naymik et al. 2005). Given the purpose of this study, slope was examined as an environmental intermediary for sediment fining and invertebrate assemblage.

Covariance between environmental variables and invertebrates suggests that environmental intermediaries across spatial scales likely control sediment fining and assemblage. For example, in both geologies, invertebrates show an association between slope, fines and invertebrates. However, the strong covariance of environmental variables likely obscures relationships with sediment fining and human disturbance. This is a wellknown limitation of using land cover to infer causal relationships (King et al. 2005). In the present study, controlling for effect of slope on invertebrate communities substantially improved correlations with fines, stability, logging and agriculture in the erosive basins; however, in resistant basins, only correlations with fines improved. This is likely due to different sediment supply rates and slope within each geology (O'Connor et al. 2014). In the resistant basins, low sediment supply and high transport rates result in sediment levels well within the tolerance range of stream invertebrates; therefore, the effect of sediment is not as pronounced. In this analysis, accounting for the covariance of slope with invertebrates increased correlation between substrate fines and selected indicator metrics. 
The findings of this study point to several taxonomic and functional invertebrate measures which may be useful to indicate sediment fining at levels detrimental to stream biota in Oregon's Coast Range. EPT richness was significantly and negatively correlated with \% fines and positively correlated with bed stability only in erosive sites. EPT richness is a well-known indicator of human disturbance and sediment (e.g. Matthaei et al. 2006); however, because of strong environmental controls in the Coast Range, the relationship of EPT and sediment fining is likely confounded by canopy cover. In both geologies, \% scrapers were positively associated with bed stability and negatively associated with \% fines and may provide a functional indicator of sediment fining. While algal biomass is strongly related to canopy cover, it is also affected by both substrate stability and fines (Schofield et al. 2004). Furthermore, several studies show that excessive fine sediment in algae may affect scraper mouthparts and feeding behavior (Arens 1990; Lancaster and Downes 2013).

The observed relationships with Rhithrogena and Paraleptophlebia may indicate a mechanistic explanation for the effect of sediment on stream invertebrates. The scraper mayfly Rhithrogena was positively associated with stability and negatively associated with higher fines, while Paraleptophlebia was negatively associated with stability and positively associated with higher fines. This pattern is at least partially due to algalsubstrate relationships. Rhithrogena are scrapers feeding primarily on periphytic algae, whereas Paraleptophlebia are collector-gatherers feeding on a wide variety of deposited organic material. The mandibles of Rhithrogena consist of stiff, comb-like bristles used to scrape food off of rocks into the mouth where the algae is strained by the mandibular molae before it passes into the stomach (McShaffrey and McCafferty 1988, Figure 3.5). 
Fine sediment may wear down these structures and reduce feeding efficiency of Rhithrogena (Arens 1990; Massey and Hartley 2009; Lancaster and Downes 2013). The mandibles of Paraleptophlebia contain fine hairs used to brush deposited organic material into the mouth where it is cut and crushed into smaller pieces (Mattingly 1987, Figure 3.5). In contrast to Rhithrogena, Paraleptophlebia may be tolerant to sediment in food sources because the maxillae hairs and mandibles are not affected by hard organic particles or the sweep action of the maxillae does not result in sediment moving to the mouth. The findings of this study support the theory that scraper feeding is somehow disrupted by increasing inorganic fines on the benthos and/or loss of bed stability; however, without examining mouthparts, it is difficult to confirm this relationship or to rule out the effect of canopy on algae as a causal mechanism.

Using biota to determine if a stream's function has been degraded by human activities is common practice in stream management. However, because of strong covariance with environmental characteristics, the use of stream invertebrates as indicators is vulnerable to false positives. In this study, while accounting for environmental covariance improved estimates and reduced the likelihood of error, it is still unclear if the proposed indicators are indeed responding to increased sediment fines or some other environmental factors, such as canopy. Future research should examine response to sediment fining in a controlled environment and explore the mechanistic relationships between feeding, mouthparts and sediment-contaminated food sources. 
Figure 3.1 Map of study sites in Oregon's Coast Range. Dark and stippled areas are resistant geology, grey areas are erosive geology.

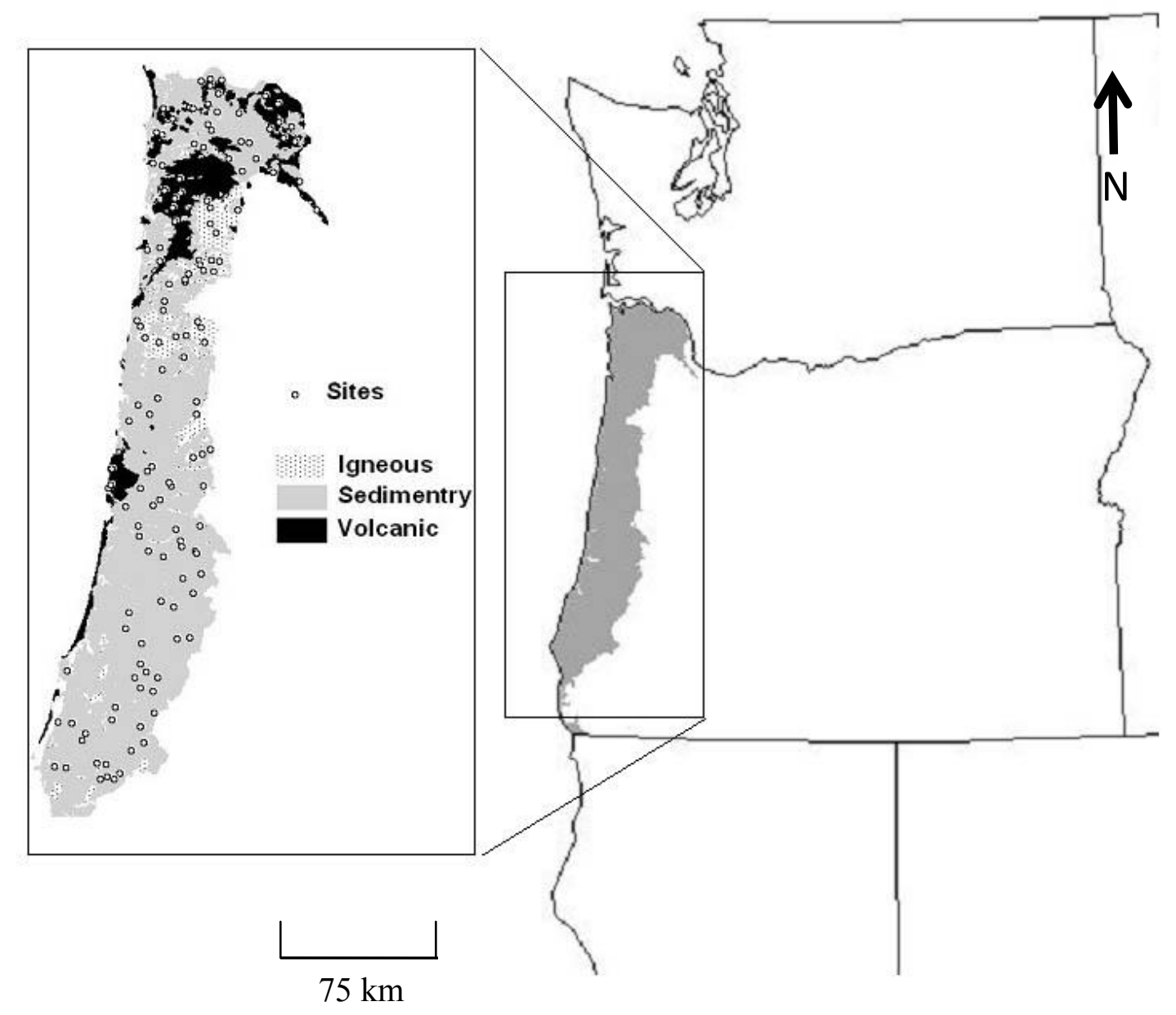


Figure 3.2 Ordination of invertebrates and hypothesized major environmental gradient. Grey-dashed line represents an orthogonal gradient. Closed circles are resistant and open circles are erosive geologies. Gradients were interpreted and only used as a framework for exploratory analysis.

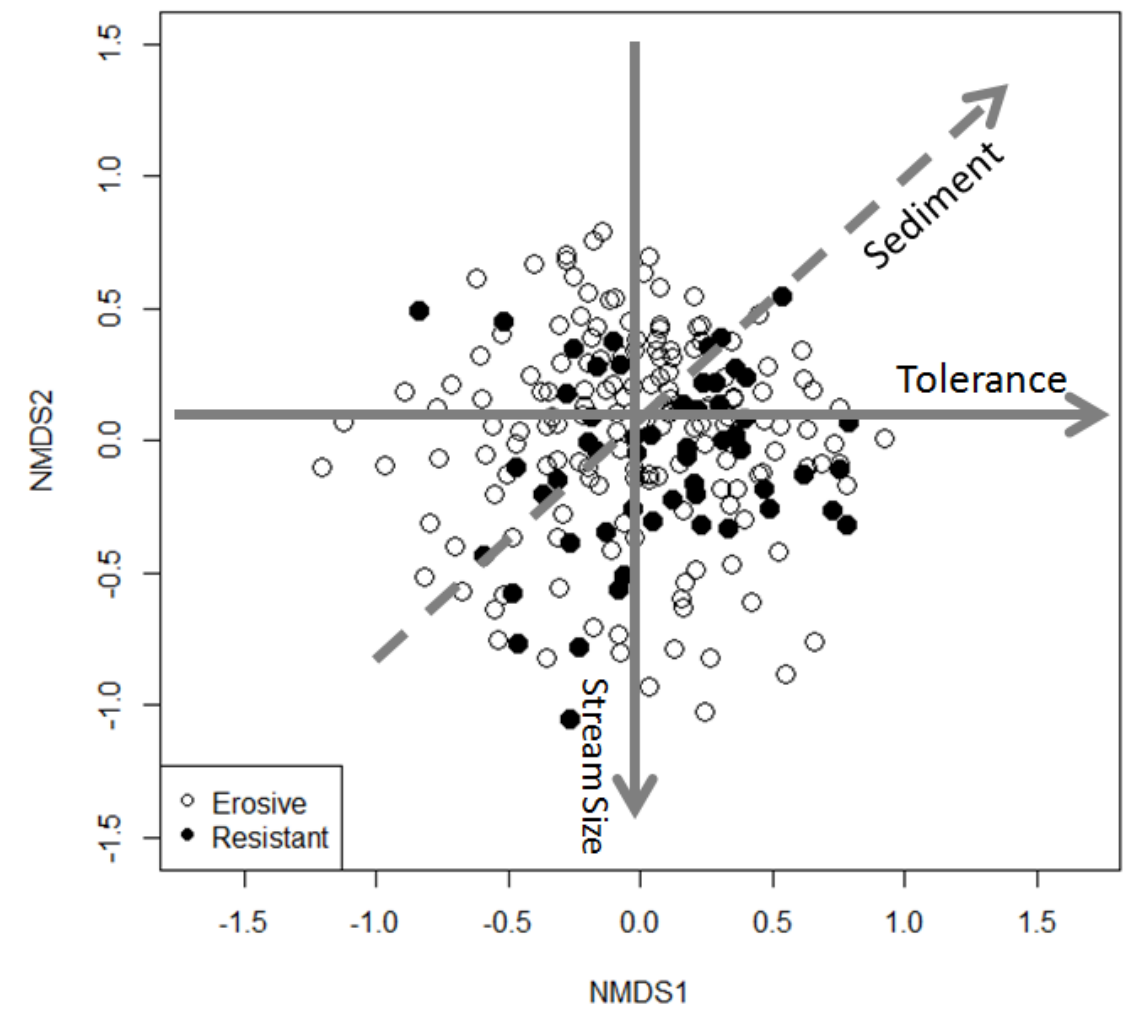


Figure 3.3 Relationships between major significant environmental gradients and invertebrate assemblage within resistant and erosive geologies. Slope and size are important in both basins, while landuse is only significant in erosive basins. Figure also illustrates the different associations between assemblage and vectors within each geology.
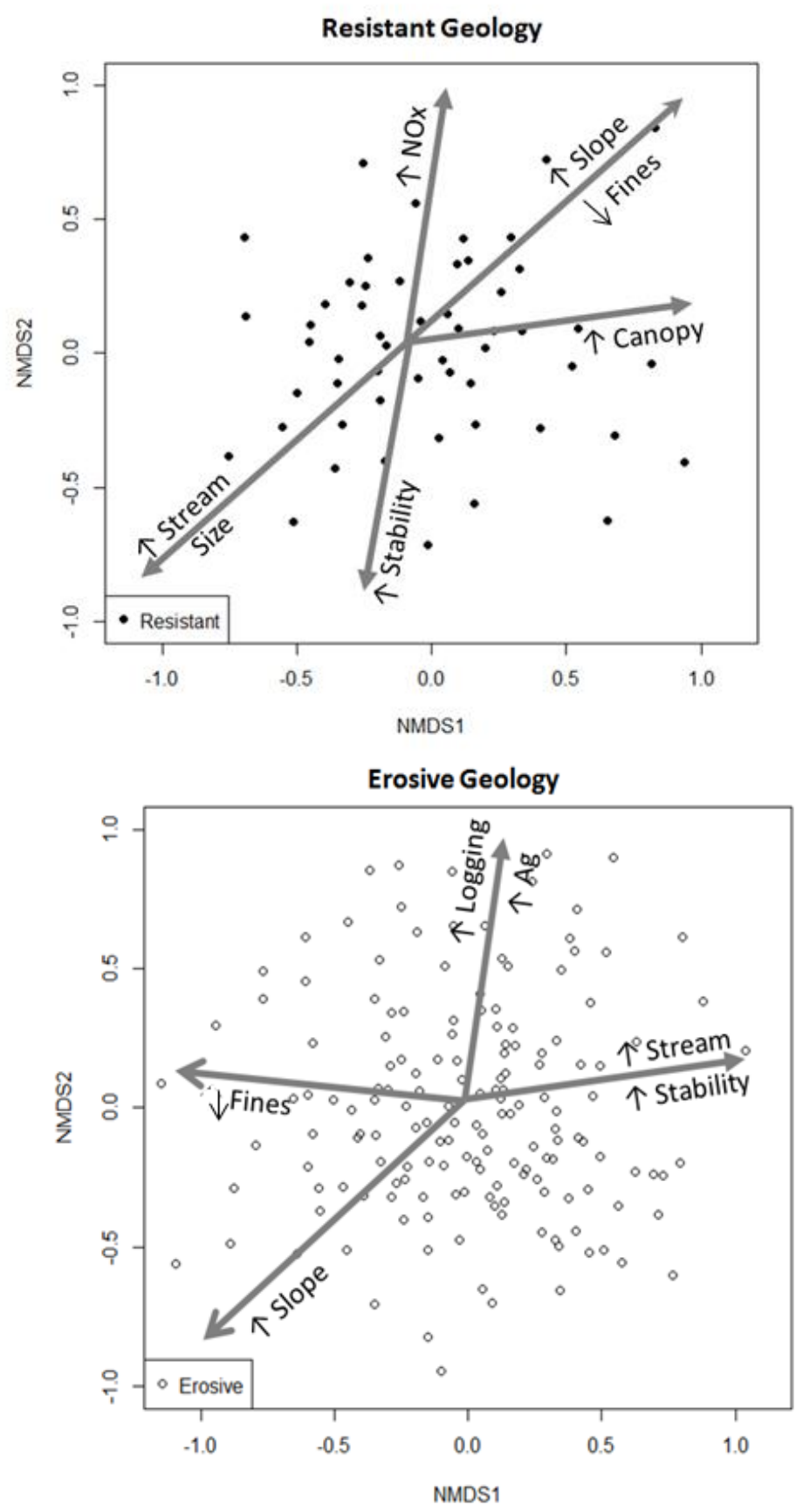
Figure 3.4 Linear models of selected indicator residuals as a function of percent fines in both geologies. Residuals are unexplained variance from a linear model of slope and each indicator. Dashed trend line is for erosive sites, solid line is for resistant sites. Significant relationships for both geologies were found in Scrapers (a) and Gougers (c). In Erosive geologies, Brushers (b) and Rhithrogena (d) were significant. In resistant geologies, Paraleptophlebia (e) and External Gills (f) were significant. See Table 3.9 for $\mathrm{R}^{2}$ and $\rho$-values.
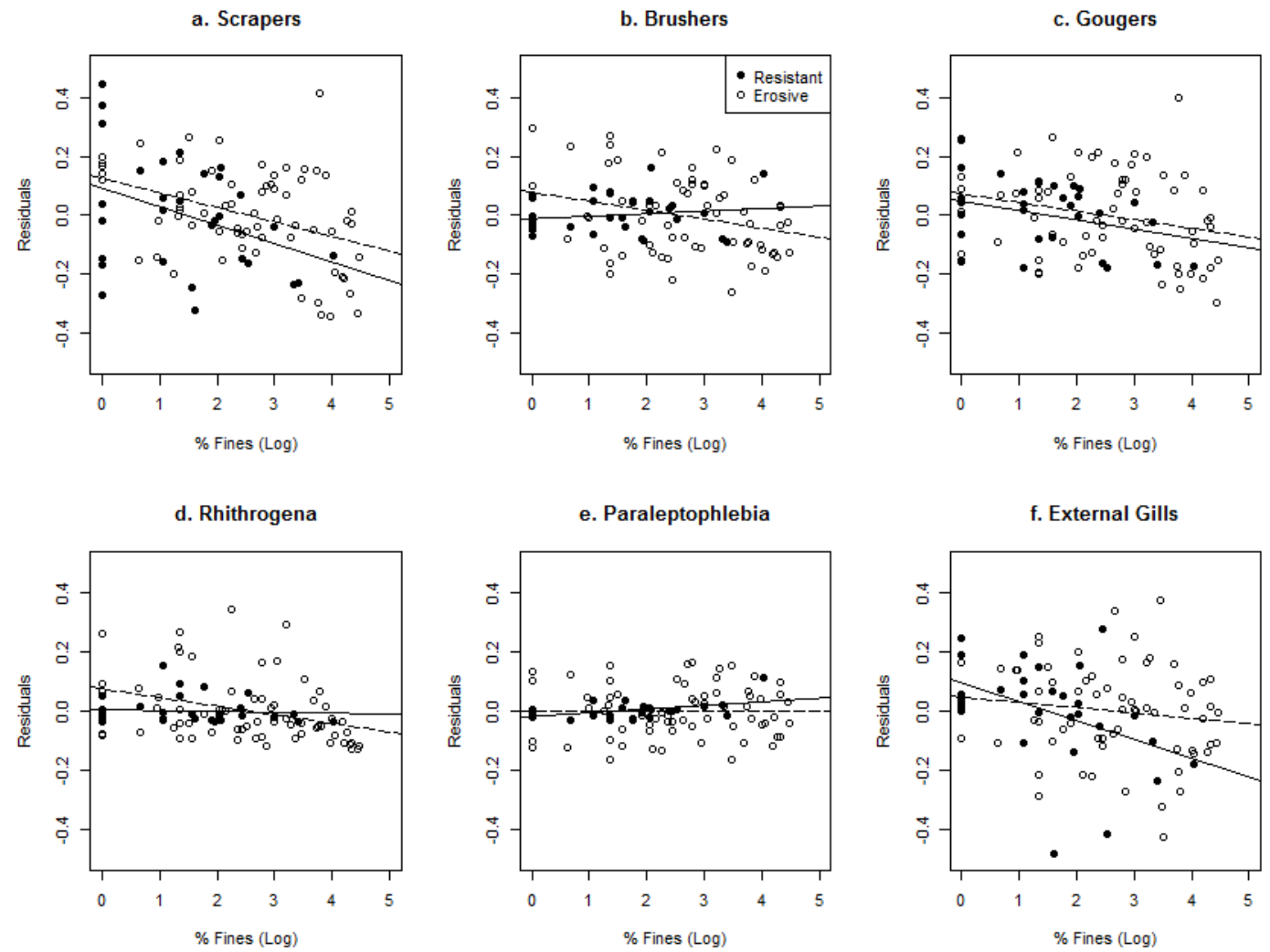
Figure 3.5. Illustration of the different mouthpart structures and feeding strategies of two mayfly grazers: Rhithrogena and Paraleptophlebia. Photos by Karouna and Fuller (1992) and McShriffey and McCafferty (1988). Rhithrogena mouthparts contain combs (A) that are used to scrape-up periphytic algae and molae (B) to grind food particles. In contrast, Paraleptophlebia uses hairs (C) to brush-up loose organic material and teeth to cut-up food particles (D). It is hypothesized that invertebrate response to fine sediment in food sources will be largely dependent on feeding traits.
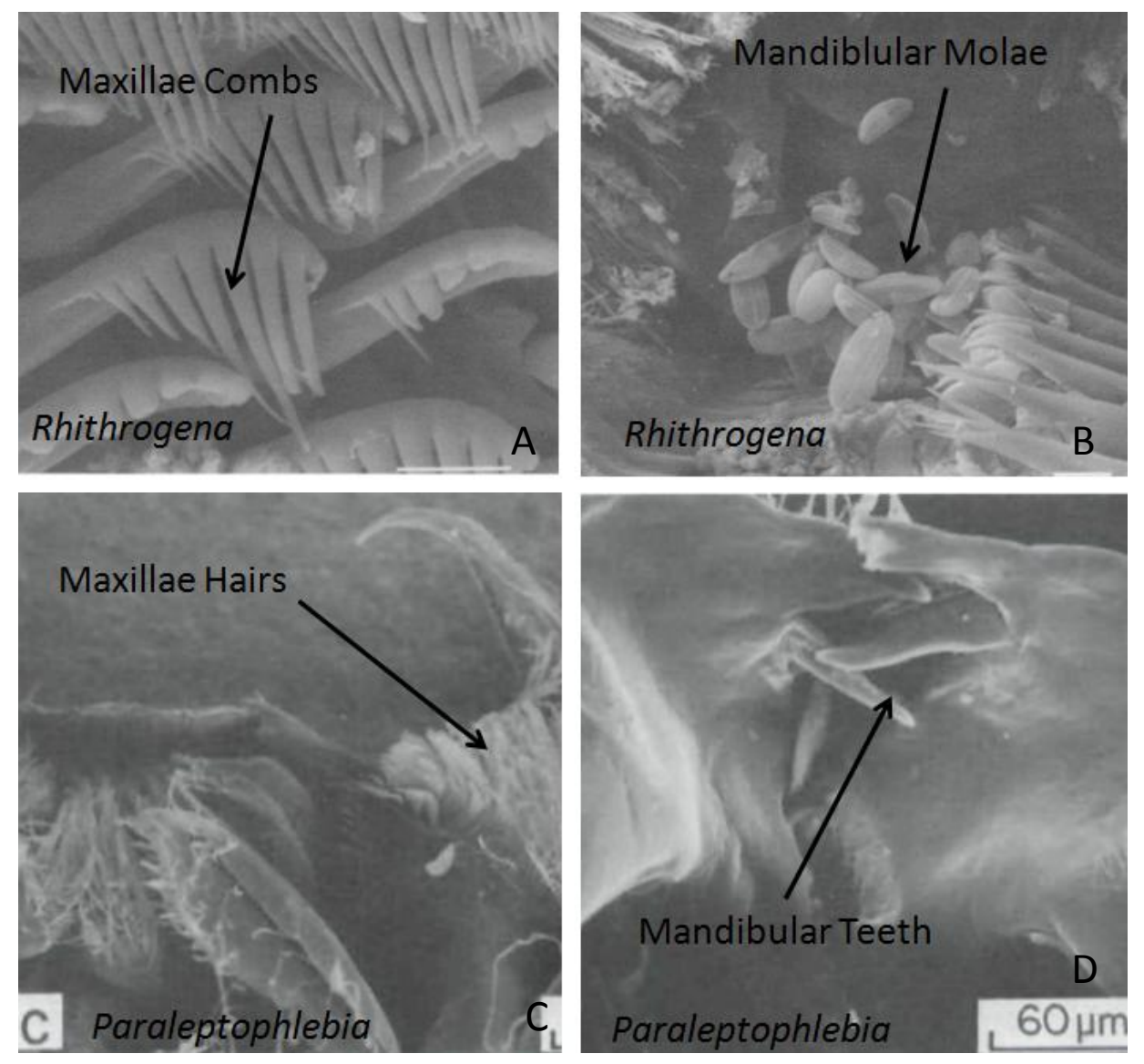
Figure 3.6 Boxplots of percent fines and sand covering the stream substrate in each geology.
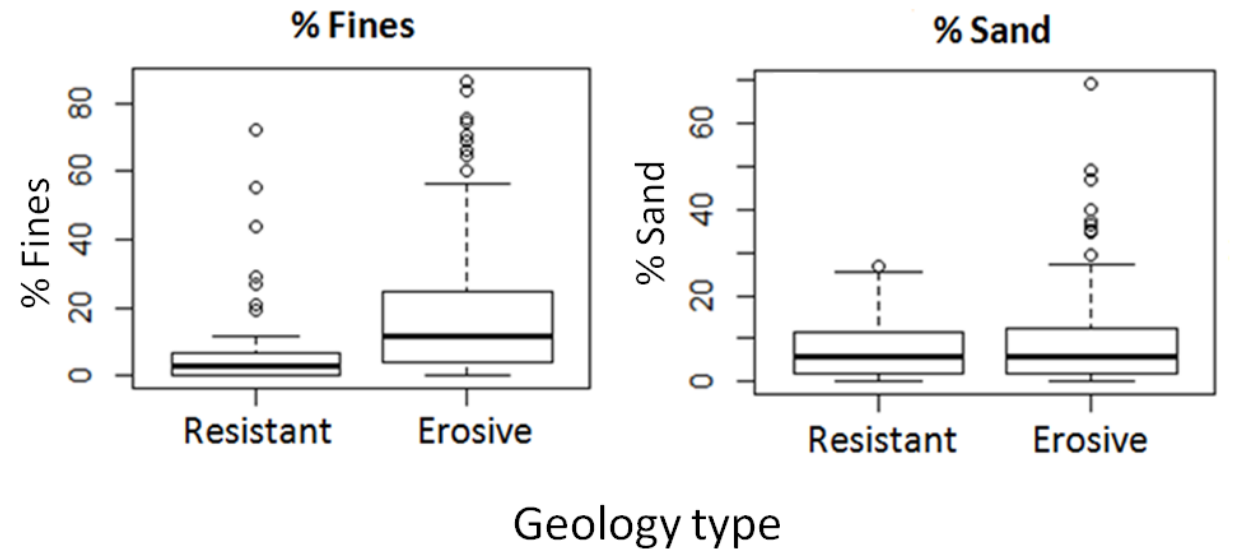
Table 3.1 Environmental variables used in indicator analysis and subset of variables used for indicator analysis $(\mathbf{X})$. Standard deviation (SD).

\begin{tabular}{|c|c|c|c|}
\hline Variable & Erosive & Resistant & Analysis \\
\hline Substrate Characteristics & Mean (SD) & Mean (SD) & \\
\hline Log Substrate Diameter & $0.8(0.3)$ & $1.5(0.8)$ & $\mathbf{x}$ \\
\hline Log Relative Bed Stability & $-0.9(1.0)$ & $-0.6(0.8)$ & $\mathbf{x}$ \\
\hline$\%$ Bedrock & $6(10)$ & 9 (9) & \\
\hline \% Boulders (250-400 mm) & $50(26)$ & $70(20)$ & \\
\hline$\%$ Cobbles $(64-250 \mathrm{~mm})$ & $19(24)$ & $21(17)$ & \\
\hline$\%$ Coarse Gravel (16-64 mm) & $27(11)$ & $32(12)$ & \\
\hline \% Fine Gravel (2-16 mm) & $12(9)$ & $9(3)$ & \\
\hline \% Sand (.06-2mm) & $8(10)$ & $8(7)$ & $\mathbf{x}$ \\
\hline \% Fines (silt/clay/muck) & $22(23)$ & $8(14)$ & $\mathbf{x}$ \\
\hline$\%$ Sand and Fines & $30(22)$ & $15(16)$ & $\mathbf{x}$ \\
\hline$\%$ Hardpan & $2(4)$ & $4(1)$ & \\
\hline$\%$ Organics & $5(4)$ & $4(4)$ & \\
\hline \multicolumn{4}{|l|}{ Reach Characteristics } \\
\hline Thalweg mean depth $(\mathrm{cm})$ & $25.6(14.1)$ & $31(12.1)$ & \\
\hline Wetted width $(\mathrm{m})$ & $4.0(2.2)$ & $6.2(2.9)$ & \\
\hline SD depth $(\mathrm{cm})$ & $15.3(8.6)$ & $19.8(9.4)$ & \\
\hline SD width (m) & $1.5(1.1)$ & $3.0(2.0)$ & \\
\hline Width $x$ Depth & 1.2 & $2.2(1.8)$ & $\mathbf{x}$ \\
\hline Width $\times$ Depth SD & $0.9(1.1)$ & $1.8(1.9)$ & \\
\hline Mean bank angle & $43.2(12.9)$ & 41.6 (15.7) & \\
\hline Sinuosity $(\mathrm{m} / \mathrm{m})$ & $1.3(0.3)$ & $1.2(0.1)$ & \\
\hline Channel incision height $(\mathrm{m})$ & $0.4(0.5)$ & $0.3(0.30)$ & \\
\hline$\%$ Fast water habitat & $48(24)$ & $53(20)$ & \\
\hline$\%$ Slow water habitat & $51(62)$ & $50(20)$ & \\
\hline Reach with Agriculture (Index) & $0.1(0.3)$ & $0.01(0.01)$ & \\
\hline Reach Human Disturbance (Index) & $1.1(0.9)$ & $0.62(0.7)$ & $\mathbf{x}$ \\
\hline \% Canopy cover midstream & $44(18)$ & $45(17)$ & $x$ \\
\hline \% Rip Cover Tree (>3 m diameter) & $25(16)$ & $21(14)$ & \\
\hline$\%$ Areal Large woody debris & $11(11)$ & $14(16)$ & $\mathbf{x}$ \\
\hline$\%$ Slope of reach & $2.6(2.1)$ & $3.4(2.1)$ & $\mathbf{x}$ \\
\hline \% Embeddedness & $52(20)$ & $40(15)$ & \\
\hline \multicolumn{4}{|l|}{ Stream Water Chemistry } \\
\hline Orthophospate (mg/L) & $0.01(0.01)$ & $0.01(0.01)$ & $\mathbf{x}$ \\
\hline Conductivity $(\mathrm{uS} / \mathrm{cm})$ & 75.9 (3.7) & $67(18)$ & $\mathbf{x}$ \\
\hline Total Nitrogen (mg/L) & $0.20(0.19)$ & $0.18(0.1)$ & $\mathbf{x}$ \\
\hline Temperature (C) & $13.0(1.9)$ & $12.6(1.8)$ & $\mathbf{x}$ \\
\hline Total Suspended Solids (mg/L) & $3.3(1.0)$ & $0.9(1.1)$ & $\mathbf{x}$ \\
\hline Turbidity (NTU) & $1.9(1.9)$ & $0.75(0.42)$ & $\mathbf{x}$ \\
\hline \multicolumn{4}{|l|}{ Basin Characteristics } \\
\hline Area $\left(\mathrm{km}^{2}\right)$ & $9.5(9.1)$ & $14.5(11.6)$ & $x$ \\
\hline Elevation (m) & $189(138)^{\prime}$ & 250 (179) & $x$ \\
\hline Precipitation $(\mathrm{cm})$ & $222.2(60.4)$ & 252.0 & $x$ \\
\hline Stream Power $\left(\mathrm{w} / \mathrm{m}^{2}\right)$ & $59.9(38)$ & $100.6(50)$ & $\mathbf{x}$ \\
\hline \% Map Slope & $3.0(2.5)$ & $3.5(2.4)$ & \\
\hline \% Agriculture in Basin & $1(2)$ & $2(1)$ & $\mathbf{x}$ \\
\hline \% Urban in Basin & $2(3)$ & $2(2)$ & \\
\hline$\%$ Deciduous Forest & $13(10)$ & $14(13)$ & $\mathbf{x}$ \\
\hline$\%$ Evergreen Forest & $65(17)$ & $69(17)$ & $\mathbf{x}$ \\
\hline
\end{tabular}


Table 3.2 Invertebrate functional metrics and selected taxa used for indicator selection for both geologies. Relative abundance (RA) used in final analysis (X).

\begin{tabular}{|c|c|c|c|}
\hline Variable & $\begin{array}{c}\text { Erosive } \\
\text { Mean (range) }\end{array}$ & $\begin{array}{c}\text { Resistant } \\
\text { Mean (range) }\end{array}$ & $\begin{array}{l}\text { Indicator } \\
\text { Analysis }\end{array}$ \\
\hline \multicolumn{4}{|l|}{ Life Cycle } \\
\hline \% Semivoltine & $18(1-53)$ & $18(1-67)$ & \\
\hline \% Univoltine & $49(21-80)$ & $48(18-88)$ & \\
\hline$\%$ Multivoltine & $22(2-60)$ & $20(0-61)$ & \\
\hline \multicolumn{4}{|l|}{ Breathing } \\
\hline$\%$ Cutaneous & $34(4-74)$ & $38(6-84)$ & \\
\hline \% Spiracle & $3(0-310$ & $3(0-19)$ & $x$ \\
\hline$\%$ Tracheal & $63(25-92)$ & $59(16-92)$ & \\
\hline \% Atmospheric Breathers & $0(0-7)$ & $1(0-24)$ & $\mathbf{x}$ \\
\hline \% External Gills & $63(24-91)$ & $55(17-89)$ & \\
\hline \multicolumn{4}{|l|}{ Feeding } \\
\hline \% Scraper & $28(4-76)$ & $27(1-68)$ & $x$ \\
\hline$\%$ Filterers & $10(0-61)$ & $11(0-67)$ & $\mathbf{x}$ \\
\hline \% Gatherers & $22(5-52)$ & $21(4-49)$ & \\
\hline \% Shredders & $10(0-35)$ & $11(0-61)$ & \\
\hline \% Brushers & $10(0-11)$ & $11(1-29)$ & $\mathbf{x}$ \\
\hline$\%$ Gougers & $24(0-69)$ & $27(3-56)$ & $x$ \\
\hline \multicolumn{4}{|l|}{ Movement } \\
\hline \% Clingers & $56(16-89)$ & $53(14-90)$ & \\
\hline \% Burrowers & $10(1-46)$ & $11(0-42)$ & \\
\hline \% Sprawlers & $8(0-38)$ & $8(0-51)$ & \\
\hline \% Swimmers & $14(3-59)$ & $13(1-38)$ & \\
\hline \multicolumn{4}{|l|}{ Tolerance Values } \\
\hline Suspended Sediment & $4.0(2.6-6.3)$ & $4.1(1.6-6.3)$ & \\
\hline Deposited Sediment & $4.5(2.8-6.7)$ & $4.7(1.7-7.2)$ & \\
\hline \% Sediment Sensitive & $17(0-45)$ & $13(0-42)$ & \\
\hline \% Sediment Tolerant & $9(0-6)$ & $13(0-60)$ & $\mathrm{x}$ \\
\hline General Tolerance & $4.0(2.7-5.8)$ & $4.1(1.5-5.8)$ & \\
\hline \multicolumn{4}{|l|}{ Other } \\
\hline Taxa Richness & $35(21-53)$ & $32(13-50)$ & $x$ \\
\hline EPT Richness & $24(12-42)$ & $21(8-34)$ & $\mathbf{x}$ \\
\hline \% RA Paraleptophlebia & $1(0-15)$ & $2(0-11)$ & $\mathbf{x}$ \\
\hline \% RA Rithrogena & $4(0-0.19)$ & $3(0-30)$ & $x$ \\
\hline$\%$ RA Cinygma & $1(0-0.10)$ & $1(0-12)$ & $x$ \\
\hline$\%$ RA Isoperla & $1(0-0.02)$ & $1(0-11)$ & $\mathbf{x}$ \\
\hline
\end{tabular}




\begin{tabular}{|c|c|c|c|}
\hline & PC1 & PC2 & PC3 \\
\hline$\%$ Fines & -0.23 & 0.03 & -0.05 \\
\hline \% Big Rocks & 0.23 & -0.06 & 0.06 \\
\hline Width*Depth & -0.01 & -0.23 & -0.17 \\
\hline Slope & 0.11 & 0.20 & 0.03 \\
\hline Canopy & 0.03 & 0.05 & -0.25 \\
\hline Nitrogen & -0.02 & 0.03 & 0.14 \\
\hline
\end{tabular}


Table 3.4 Spearman Correlation Coefficients for latitude, slope, canopy and fines in Resistant (R) and Erosive (E) basins. Table shows a correlation matrix for four variables in each geology.

\begin{tabular}{lccccl} 
Resistant Variables & E Latitude & E Slope & E Canopy & E Fines & Erosive Variable \\
Resistant Latitude & & 0.14 & 0.19 & 0.10 & Erosive Latitude \\
Resistant Slope & 0.31 & & 0.44 & -0.21 & Erosive Slope \\
Resistant Canopy & 0.39 & 0.45 & & 0.18 & Erosive Canopy \\
Resistant Fines & -0.12 & -0.13 & -0.26 & & Erosive Fines \\
& R Latitude & R Slope & R Canopy & R Fines & \\
\hline
\end{tabular}


Table 3.5 Results from vector analysis for environmental variables in resistant $(\mathrm{n}=55)$ and erosive geologies $(\mathrm{n}=159)$ across a range of scales (basin to in-stream). Values are pseudo $\left(r^{2}\right)$ with $\mathrm{p}$ values: $\rho<0.10^{\mathrm{x}}, \rho<0.05^{*}, \rho<0.01^{* *}, \rho<0.001^{* * *}$, not significant (NS).

\begin{tabular}{|c|c|c|}
\hline Variable & $\begin{array}{c}\text { Resistant } \\
\text { Basin }\end{array}$ & $\begin{array}{c}\text { Erosive } \\
\text { Basin }\end{array}$ \\
\hline \multicolumn{3}{|l|}{ Basin } \\
\hline \% Reach Slope & $* * * 0.28$ & $* * * 0.34$ \\
\hline$\%$ Logged (medium fragmentation) & ${ }^{x} 0.08$ & $* * 0.07$ \\
\hline$\%$ Agriculture & NS & $* * 0.07$ \\
\hline \multicolumn{3}{|l|}{ Reach } \\
\hline \% Canopy cover & $* * * 0.27$ & $* * * 0.31$ \\
\hline Stream width $\mathrm{x}$ depth $\left(\mathrm{m}^{2}\right)$ & $* * * 0.26$ & $* * * 0.38$ \\
\hline Large Woody Debris $\left(\mathrm{m}^{3} / \mathrm{m}^{2}\right)$ & NS & $* * * 0.13$ \\
\hline \multicolumn{3}{|l|}{ In-Stream } \\
\hline$\%$ Fines & ${ }^{x} 0.09$ & $* * * 0.10$ \\
\hline Bed Stability (LRBS) & $* 0.23$ & $* * * 0.16$ \\
\hline Temperature $\left({ }^{\circ} \mathrm{C}\right)$ & ${ }^{x} 0.08$ & $* * * 0.20$ \\
\hline Nitrogen (mg/L) & $* 0.25$ & 0.06 \\
\hline Conductivity ( $\mu \mathrm{S} / \mathrm{cm})$ & ${ }^{x}$ NS & ${ }^{x} 0.05$ \\
\hline Dissolved Oxygen (mg/L) & ${ }^{\mathrm{x}} 0.16$ & $* * * 0.16$ \\
\hline
\end{tabular}


Table 3.6 Results from Mantel test relating environmental matrices to invertebrate matrix at three scales in both lithologies across a range of scales (basin to in-stream). Mantel $r$ statistic and p value is shown. $\rho<0.10^{x}, \rho<0.05^{*}, \rho<0.01^{* *}$, $\rho<0.001^{* * *}$, not significant (NS).

\begin{tabular}{|c|c|c|}
\hline Variable & $\begin{array}{c}\text { Resistant } \\
\text { Basin }\end{array}$ & $\begin{array}{c}\text { Erosive } \\
\text { Basin }\end{array}$ \\
\hline \multicolumn{3}{|l|}{ Basin level } \\
\hline \% Reach Slope & $* 0.11$ & $* * * 0.30$ \\
\hline$\%$ Logged (medium fragmentation) & $* 0.15$ & ${ }^{*} 0.06$ \\
\hline$\%$ Agriculture & NS & $* * 0.10$ \\
\hline \multicolumn{3}{|l|}{ Reach } \\
\hline \% Canopy cover & NS & $* * 0.12$ \\
\hline \multicolumn{2}{|l|}{ Large Woody Debris $\left(\mathrm{m}^{3} / \mathrm{m}^{2}\right)$} & $* * * 0.21$ \\
\hline In-Stream & *0.19 & $* * 0.12$ \\
\hline$\%$ Fines & NS & $* * 0.08$ \\
\hline Bed Stability (LRBS) & NS & $* * * 0.13$ \\
\hline Temperature $\left({ }^{\circ} \mathrm{C}\right)$ & NS & NS \\
\hline Nitrogen mg/L & NS & NS \\
\hline Conductivity $(\mu \mathrm{S} / \mathrm{cm})$ & ${ }^{x} 0.14$ & NS \\
\hline Dissolved Oxygen (mg/L) & & \\
\hline
\end{tabular}


Table 3.7 Results from partial Mantel test relating environmental matrices to invertebrate matrix at three scales in both lithologies. Model shows the relationship with fines after the effect of slope on invertebrates has been removed. Mantel $\mathrm{r}$ statistic is shown. $\rho<0.10^{\mathrm{x}}, \rho<0.05 *, \rho<0.01^{* *}$, $\rho<0.001^{* * *}$, not significant (NS).

\begin{tabular}{lrr}
\hline Mantel Model & $\begin{array}{c}\text { Resistant } \\
\text { Basin }\end{array}$ & \multicolumn{1}{c}{$\begin{array}{c}\text { Erosive } \\
\text { Basin }\end{array}$} \\
\hline Invertebrates/Slope/Fines & ${ }^{*} 0.14$ & $* * * 0.25$ \\
Invertebrates/Slope/Bed Stability & $0.14^{*}$ & $* * 0.25$ \\
Invertebrates/Slope/Logging & ${ }^{\times} 0.09$ & $* * * 0.26$ \\
Invertebrates/Slope/Agriculture & ${ }^{\times} 0.10$ & $* * 0.28$ \\
\hline
\end{tabular}


Table 3.8 Adjusted $\mathrm{R}^{2}$ and $\mathrm{p}$-values for selected indicators and correlation with slope and $\%$ fines (Fines) in resistant $(n=30)$ and erosive $(n=67)$

streams. Relative abundance (RA). Slope direction indicated (+/-). $\rho<0.10^{\mathrm{x}}, \rho<0.05^{*}, \rho<0.01^{* *}, \rho<0.001^{* * *}$, not significant (NS).

\begin{tabular}{|c|c|c|c|c|}
\hline Variable & $\begin{array}{c}\text { Resistant } \\
\text { Slope } \mathbf{R}^{2}\end{array}$ & $\begin{array}{c}\text { Erosive } \\
\text { Slope } \mathbf{R}^{2}\end{array}$ & $\begin{array}{c}\text { Resistant } \\
\text { Fines } \mathbf{R}^{2}\end{array}$ & $\begin{array}{c}\text { Erosive } \\
\text { Fines } \mathbf{R}^{2}\end{array}$ \\
\hline Sediment tolerant (RA) & $* * 0.17(-)$ & $* * * 0.33(-)$ & NS & NS \\
\hline Scrapers (RA) & NS & *0.07 (-) & NS & $* * * 0.06(-)$ \\
\hline Brushers (RA) & NS & NS & NS & $* * 0.12(-)$ \\
\hline Gougers (RA) & ${ }^{x} 0.08(-)$ & $* * 0.10(-)$ & NS & NS \\
\hline External Gills (RA) & NS & $* 0.07(+)$ & $* 0.18(-)$ & $* 0.05(-)$ \\
\hline EPT richness & $* * * 0.22(+)$ & $* * * 0.28(+)$ & NS & $* * * 0.25(-)$ \\
\hline Paraleptophlebia(RA) & $* * 0.13(+)$ & $* * 0.05(+)$ & $* 0.10(+)$ & NS \\
\hline RA Rhithrogena (RA) & NS & ${ }^{x} 0.04(-)$ & NS & ${ }^{x} 0.04(-)$ \\
\hline
\end{tabular}


Table 3.9 Adjusted $\mathrm{R}^{2}$ and $\mathrm{p}$-values for selected indicators residuals (rsd) and correlation with bed stability (Bed Stbl) and \% fines (fines) in resistant $(n=30)$ and erosive $(n=67)$ streams. Relative abundance $(R A)$. Slope direction indicated (+/-). $\rho<0.10^{\mathrm{x}}, \rho<0.05^{*}, \rho<0.01^{* *}, \rho<0.001^{* * *}$, not significant (NS).

\begin{tabular}{|c|c|c|c|c|}
\hline Variable & $\begin{array}{c}\text { Resistant } \\
\text { Bed Stbl R } \mathbf{R}^{2}\end{array}$ & $\begin{array}{c}\text { Erosive } \\
\text { Bed Stbl } \mathbf{R}^{2} \\
\end{array}$ & $\begin{array}{c}\text { Resistant } \\
\text { rsd fines } R^{2} \\
\end{array}$ & $\begin{array}{c}\text { Erosive } \\
{\text { rsd } \sim \text { fines } R^{2}}^{2}\end{array}$ \\
\hline Sediment tolerant (RA) & NS & NS & NS & $* 0.06(-)$ \\
\hline Scrapers (RA) & NS & $* 0.08(+)$ & $* 0.11(-)$ & $* * * 0.14(-)$ \\
\hline Brushers (RA) & NS & $* * 0.08(+)$ & NS & *0.07 (-) \\
\hline Gougers (RA) & NS & NS & ${ }^{x} 0.07(-)$ & $* * 0.04(-)$ \\
\hline External Gills (RA) & $* 0.15(+)$ & NS & $* 0.16(-)$ & NS \\
\hline EPT richness & $* 0.13(+)$ & $* * * 0.23(+)$ & NS & $* * 0.11(-)$ \\
\hline Paraleptophlebia (RA) & $* * * 0.35(-)$ & NS & $* * 0.21(+)$ & NS \\
\hline Rhithrogena (RA) & NS & $* * 0.19(+)$ & NS & $* * * 0.10(-)$ \\
\hline
\end{tabular}




\title{
Chapter 4 An in-situ experiment to test the effect of natural sediment supply on stream invertebrate response to fine sediment addition in naturally colonized mesocosms
}

\begin{abstract}
Forests of the Pacific Coastal ecoregion contain large tracts of economically important forestlands that also serve as critical stream habitat for endangered salmonids. Excessive fine sedimentation deposition in streams used for salmon reproduction is a major environmental concern in the region and currently there is increased interest in developing biologic indicators, such as stream invertebrates, to monitor fine sediment conditions in streams. To examine the effect of geology on invertebrate response to fine sediment addition, I conducted an in situ manipulative experiment in streams flowing through two different geologic settings. Four streams in both erosive and resistant geologies were selected and 10 mesocosms were placed in each stream and allowed to naturally colonize with stream invertebrates ( $n=40$ in each geology). Randomly selected mesocosms received a treatment of repeated increasing sediment doses $(<2 \mathrm{~mm})$ over four days and mesocosm controls received a methodological control. Invertebrate assemblage between geologies was different, but the response to sediment addition was not the same. In resistant basins, treatment mesocosms lost $15 \%$ more taxa on average $(\mathrm{P}<0.01)$ than in erosive basins. Within geologies, erosive basins showed a stronger functional response (invertebrate grazing traits) to sediment dosing $(\rho<0.05)$ and habitat loss $\left(\mathrm{R}^{2}=0.20\right.$, $\mathrm{P}<0.01$ ); while in resistant basins, only invertebrate abundance was significantly related to dosing $(\mathrm{P}<0.01)$ and habitat loss $\left(\mathrm{R}^{2}=0.15, \mathrm{P}<0.05\right)$. Categorizing invertebrate grazers as brushers generally improved observed relationships over other classifications (e.g.
\end{abstract}


gougers, scrapers). The findings of this study illustrate the role of sediment supply in shaping invertebrate assemblage and provide evidence that sediment-tolerant invertebrate communities can develop in basins with naturally high levels of sediment. Furthermore, the results presented here also provide information about which invertebrate metrics may be useful in different geologic settings. For stream managers in the Pacific Coastal ecoregion, these findings provide important information needed to develop reliable sediment biomonitoring programs and identify biologically-relevant changes in stream fine sediment condition.

\section{Introduction}

Sedimentation is a leading cause of surface water impairment in the United States. A national survey conducted in 2006 found that excessive sediment, in conjunction with increased nutrient levels, were responsible for degrading nearly half of the total stream length in the United States (Wood and Armitage 1997; USEPA 2006). Sediment delivery and transport is a natural hydrologic process controlled by the amount of erodible material available in the environment and stream carrying capacity (Wilcock 1998). However, human activities such as agriculture, natural resource extraction and land development increase sediment delivery to streams at levels that exceed natural conditions and result in stream degradation (Wood and Armitage 1997). The Pacific Coastal Region of the United States contains large tracts of economically important forestlands that also serve as critical stream habitat for anadromous fish (Spies and Johnson 2007; Hall et al. 2004). As efforts expand to manage and restore salmon 
populations, there is an increased interest in developing biological criteria that can be used to monitor stream sediment conditions (Spies and Johnson 2007).

Stream conditions and invertebrate communities are shaped by environmental factors across spatial scales that are hierarchically structured (Frissell et al. 1986; Poff 1997). Geology acts as large-scale control of sediment supply to the streams and thereby indirectly shapes stream invertebrate communities (Richards et al. 1996; Townsend et al. 2003; O'Connnor et al. 2014). For example, Richards et al. (1997) found that invertebrate communities were shaped indirectly by geology and the effect of land use was masked by geology. In the Oregon Coast Range, the surficial geology is highly diverse and contains both highly resistant and erosive lithologies resulting in spatially variable sediment supply and transport rates (Hershey and Lamberti 1998; Richardson and Danehy 2007). In general, streams flowing through erosive basins should have more fine sediment and contain invertebrate communities that are adapted to high fine sediment conditions (Poff 1997). The natural heterogeneity of the Coast Range may act as strong controls of invertebrate communities and thereby presents a challenge for their use in stream monitoring. Efforts to identify biologic indicators of excessive fine sediment in Coast Range streams should account for invertebrate adaptation to geomorphic conditions.

Excessive sedimentation on the stream benthos reduces the average substrate particle size in a physical process known as sediment fining. Sediment fining results from an increased sediment supply that exceeds carrying capacity, and thus may indicate excessive sedimentation due to anthropogenic activities; however, fine sediment $(<2 \mathrm{~mm}$, Clapcott et al. 2011) is difficult to measure and quantify. Once in the stream, fine sediment is ephemeral, highly variable and not well characterized by traditional pebble 
counting methods. Furthermore, since sediment transport by streams is a natural process, it is difficult to establish relevant biological criteria for protecting ecological function. While sediment fining is an important physical characteristic, the primary interest of environmental managers is monitoring its effect on stream biota. Consequently, there is currently an increased interest in developing biologic-based invertebrate metrics that may serve as a proxy for physical sediment measurements (i.e. Relyea et al. 2012).

Stream invertebrate sensitivity to sediment fining is well documented (Waters 1995, Figure 1.4). Observational and experimental research has shown that sediment fining can change macroinvertebrate assemblage (Larsen et al. 2010; Extence et al. 2013), reduce diversity (Matthaei et al. 2006; Larsen et al. 2010) and alter ecological function of streams (Schofield et al. 2004; Griffith et al. 2009). Several mechanisms are thought to be responsible for the observed effects of fine sediment on stream invertebrates (Figure 1.4). For example, deposited fine sediment fills interstitial space and alters foodwebs (Suttle 2004; Schofield et al. 2004; Griffith et al. 2009). Sediment in the washload lowers productivity (Parkhill and Gulliver 2002) and creates harsh conditions (Culp 1986). Fine sediment has also been shown to affect the macroinvertebrate physiology by acting as a vector for gill infections (Lemly 1982) or reducing food quality (Broekhuizen et al. 2001; Peeters et al. 2006).

The sensitivity of stream invertebrates to fine sediment makes them useful for monitoring benthic sediment conditions and considerable effort has been devoted to identifying reliable invertebrate indicators and metrics (Relyea et al. 2009; Larsen and Ormerod 2010; Clapcott et al. 2011; Extence et al. 2013). However, there is neither a consensus on which metrics are reliable across broad regions nor is there an adequate 
understanding of the mechanisms associated with invertebrate sensitivity to sediment fines. Several studies have shown that invertebrate feeding characteristics, such as algal grazing or scraping on the epilithon, are sensitive to sediment fines and may have potential as indicators (Rabeni et al. 2005; Zweig and Rabeni 2001). Stream invertebrates, such as mayflies, have highly specialized mouthparts for harvesting epilithic organic matter and transferring it to the mouth opening for consumption (Arens 1989). For example, both the mayflies Rhithrogena and Baetis are known to feed on epilithic algae (Arens 1989); but have different mouthparts for harvesting it. The maxillary palps of Rhithrogena consist of short brushes composed of stiff bristles to brush or scrape loose epilithic algae into the mouth (Figure 4.2, McShaffrey and McCafferty 1988). The mandibles of Baetis have a gouge-type structure that is used to pry up diatoms adhered to the epilithon (Figure 4.2, Arens 1989). Excessive fine sediment on the epilithon may interfere with grazer feeding (Arens 1990), but its effect may be mitigated by mouthpart structures. For example, invertebrates that brush food into their mouths may move more inorganic material into their mouths than gougers and thus consume lower quality food (Broekhuizen et al. 2001; Peeters et al. 2006).

To test the effect of geology on invertebrate response to fine sediment addition, I conducted an in situ manipulative experiment in eight small streams of the Oregon Coast Range. Two hypotheses were tested. The first was that selective adaption to natural levels of fine sediment would result in an invertebrate community structure that responds differently to increasing amounts of fine sediment (Poff 1997; Townsend and Hildrew 2006). This was achieved by comparing streams in basins with either dominant erosive or resistant geologies. The second hypothesis examined the use of invertebrate grazing traits 
as an indicator of excessive fine sediment in the benthos. In this case, selective forces would result in invertebrate communities with similar feeding traits that are shaped by natural sediment conditions (Poff 1997; Townsend and Hildrew 2006). For the second hypothesis, I predicted that brushing grazers would be more sensitive to sediment addition than gouging grazers. This was achieved by adding increasing amounts of fine sediment to in situ mesocosms containing naturally colonized invertebrates.

\section{Methods}

\subsection{Study area and Experiment}

The Oregon Coast Range provides an ideal location to test hypotheses about invertebrates, sediment and geology. The Coast Range contains basins with relatively homogenous erosive or resistant geologies (Figure 4.3) and there is relatively little urban development. The Oregon Pacific Coast Region has steep slopes with elevations from sea level to $1,249 \mathrm{~m}$, but most of the ridgelines occur between 450 and $750 \mathrm{~m}$ (Franklin and Dyrness 1973). Geology in the Oregon Coast Range varies from north to south and is mainly composed of marine-derived sediments and basalts. In the north, the geology is mixed sedimentary and volcanic with both highly erodible (siltstones, sandstones) and resistant (Coast range Volcanics) surficial geology (Franklin and Dyrness 1973; Walker et al. 2003, O'Connor et al. 2014). The erosive basins of this region have some of the fastest stream bed-material attrition rates in the Coast Range (e.g. 80x faster, O'Connor 2014); therefore it is reasonable to assume that, all else being equal, streams in basins underlain by bed-material with high attrition rates will result in relatively more fine sediment in the bed-load. For example, a model developed for western Oregon found that the soft rocks of the Klamath terrane had sediment flux rates considerably higher than in 
resistant basins (O'Connor 2014). Average annual precipitation in the Oregon Coast Range ranges from $250 \mathrm{~cm}$ to $760 \mathrm{~cm}$ in the upper elevations, temperature is generally mild, with average January minimum temperature as low as $0^{\circ} \mathrm{C}$ and the July maximum average temperature at around $25^{\circ} \mathrm{C}$ (Franklin and Dyrness 1973). Oregon's Coast Range contains a temperate coniferous rainforest characterized by Sitka spruce in the lower coastal elevations and western hemlock Douglas-fir inland (Franklin and Dyrness 1973). Riparian forests are structurally complex with mixed patches characterized by coniferous trees, alder, cottonwood and willow (Naiman et al. 1998).

The area for this study was chosen based on a land cover analysis, relative proximity of the basin and reach site conditions (Figure 4.3). Within each geology, study basins were selected using a filtering process based on GIS analysis of geology and land cover (Figure 4.4). GIS analysis was conducted using the 1:500,000 scale USGS Geology layer (Walker et al. 2003), the 2006 National Land Cover data base (30 m spatial resolution, Fry et al. 2011) and vegetation data (10 m resolution) from the Coastal Landscape Analysis and Modeling Study (CLAMS 2014). All data were accessed in the fall of 2012. The first filter selected for basins with geology homogeneity $>80 \%$ resistant or erosive. The second filter removed basins with more than $10 \%$ mixed forests or croplands. In the last filter, basins with total clearcut areas greater than $20 \%$ were removed. From an initial pool of 66 basins, 19 basins were selected for preliminary reconnaissance. Reach site selections were based on access, stream velocity and the presence of coarse substrate and riffles. Reaches with deep water, soft sediments or human disturbance were not used. After filtering process and site reconnaissance, 8 streams (4 in each geology) were selected for study (Table 4.1). 
Mesocosms were designed so that multiple doses of sediment could be added to them over multiple days and then removed from the stream with both invertebrates and sediments contained inside. Mesocosms were constructed using plastic deli containers with a $1.24 \mathrm{~L}$ volume and $0.02 \mathrm{~m}^{2}$ of surface area at the top. For substrate, mesocosms were filled with consistently-sized landscape rocks (longest axis mean=13 mm). Thirtysix holes $(6 \mathrm{~mm})$ were drilled equidistant around each container such that when the containers were placed within each other, the holes were aligned. Thus, each mesocosm consisted of a nested pair of flow-through containers filled with substrate thus providing an average of $625 \mathrm{~cm}^{2}$ of interstitial habitat. Interstitial habitat was estimated by filling the 10 mesocosms with substrate and water and then measuring the volume of water in the mesocosm. Mesocosms were placed in the stream and buried in the benthos at least 5$15 \mathrm{~cm}$ deep where possible. To remove the mesocosm from the stream, the inner container was rotated counter to the outer container, the holes became misaligned and thereby allowed for the mesocosm to be closed in the stream and retain both fine sediment and invertebrates. Mesocosms were painted camouflage to minimize tampering risk and mesocosms were monitored (2-3 times per week) during the 3-5 week colonization period. Mesocosms found leaning during colonization were repositioned only if the substrate was still in the mesocosm. To compare the mesocosm invertebrate community to the natural stream community, D-net samples were collected at the end of the experiment and used to qualitatively evaluate the invertebrates richness in each geology.

The experiment design consisted of 4 streams with 10 replicates of treatments (sediment dose) or controls (no sediment) in each geology ( $\mathrm{n}=4$ resistant and $\mathrm{n}=4$ 
erosive). Total sample size was 40 (treatment $n=20$, control $n=20$ ) replicates within each geology and allowed for the comparison within and between geologies. In July of 2012, mesocosms were placed in the stream and allowed to colonize for 3-5 weeks, and on October $12^{\text {th }} 2012$ a dosing schedule was initiated. Sediment used to dose mesocosms was obtained from an eroded stream bank and screened through a $2 \mathrm{~mm}$ sieve $(50 \%$ $<0.15 \mathrm{~mm}$, organic content $<5 \%$ ). The original dosing schedule called for an increasing volume of sediment to be added each day for a total of five days (Figure 4.5). However, an approaching storm event required the duration to be shortened and dosing amounts increased to ensure an adequate gradient of sediment was achieved. In the end, there were three separate doses on three days and with a range of 100 to $1100 \mathrm{ml}$ of sediment (100 to $1100 \mathrm{~g})$. To dose, five randomly-selected mesocosms were isolated from the current using a bucket, sediment was added and allowed to settle and the isolation removed. Control mesocosms were also isolated as a methodological control. To remove mesocosms, the inner container was rotated, the container lid was put on and the entire mesocosm was quickly lifted out of the stream and placed in a plastic bucket. For periphyton analysis, three rocks were removed and frozen within 12 hours. Mesocosm contents (rocks, sediment and invertebrates) were poured into a larger container and fixed with isopropyl alcohol (90\%) in the field.

\subsection{Environmental Data and Invertebrates}

During the colonization period, environmental data were collected at each reach and each mesocosm. At each reach, canopy cover and stream water chemistry (Table 4.2) was determined using a densiometer and handheld field instrument (Model YSI 556 MPS). Streamflow was measured using a flow meter (Flow Mate Model 2000) at five 
spots equidistant across the stream. Depth and velocity at the top of the mesocosm were measured at each mesocosm and used to estimate flow. Sediment compostion of the sites was measured with shovel samples taken at the edge of the waterline nearest to the center of the arrays. Sediment samples were weighed and dry sieved. Biomass was estimated for periphyton, invertebrates and sediment organic content by determining the ash free dry mass (AFDM). Samples were dried for 24 hours at $100^{\circ} \mathrm{C}$ and weighed and burned at $500^{\circ} \mathrm{C}$ for one hour. Periphyton biomass samples were obtained by scrubbing three rocks with a toothbrush and rinsing with water. Invertebrate biomass was estimated using all invertebrates found in the mesocosms. Sediment texture and organic content were determined using sediment remaining in mesocosms after removal sediments were dried, ashed and then sieved. Sediment in control mesocosms was used to characterize sediment texture. Invertebrates were counted by sorting the entire contents of mesocosms under 10x magnification dissecting microscope (Lieder Model \# MZ 730X). All invertebrates found were counted and identified to genus level where possible. The small size and early instars resulted in some family-level identification. Grazing traits were based on information found in the published literature (Table 4.6) and examination of specimens found in the mesocosms (Appendix A11).

\subsection{Data Analysis}

To assess the performance of the mesocosms, invertebrate abundance and richness were compared between disturbed and undisturbed mesocosms using t-tests and coefficient of variation (CV). Environmental data were summarized and compared between geologies using t-tests. The invertebrate community was classified using presence/absence and relative abundance (RA). Invertebrate assemblages were 
characterized using Nonmetric Multidimensional Scaling (NMDS) ordinations and visually displayed using presence/absence charts of all taxa. NMDS is an unconstrained ordination technique that examines the overall similarity of an assemblage (McCune and Grace 2002). NMDS is often used with invertebrate data because it preserves the intersite relationships and better represents species distances (Legendre and Legendre 1998). The relationship between mesocosm assemblage and environmental variables was examined using a linear fitting function (Envfit) to fit environmental vectors to the ordinations. Envfit fits a vector to the species ordination and a permutation test is used to determine importance (psuedo $\left.r^{2}\right)$ and significance $(\rho<0.05)$. The results of the Envfit analysis were used to explore relationships between invertebrate assemblage and environmental variables. Correlation between environmental variables was explored with Pearson's R.

The effect of geology on invertebrate response to sediment addition was examined by averaging invertebrate metrics for treatments and controls in each stream so that sample size was four in each geology. Average difference between treatment and controls for richness, abundance and grazing traits were compared between geologies using 2-tailed t-tests. Dosing frequency within erosive or resistant geologies was analyzed using one-way ANOVA with dosing frequency (0-3) as the categorical variable. Habitat loss was estimated using remaining inorganic sediment as a proxy for the reduction of interstitial habitat space in the mesocosm. Habitat loss data were evaluated using partial correlations to account for the covariance of stream velocity with invertebrate data. Residuals from the invertebrate-velocity models were regressed against sediment remaining in the mesocosms (habitat loss). All data were log transformed to 
improve distributions. Models were developed using abundance, richness, RA grazers, RA brushers or RA gougers as response variables.

\section{Results}

\subsection{Mesocosm performance}

Out of 80 mesocosms placed in streams, 13 were lost or damaged. Six mesocosms were lost in one stream (Northrup) during high flow. More mesocosms were lost in erosive (10) than resistant (3) sites. Sediment dosing resulted in the mean addition of 337 (erosive) and 269 (resistant) $\mathrm{g}$ of sediment to the mesocosms and a mean of $106 \mathrm{~g}$ (erosive) and $64 \mathrm{~g}$ of inorganic sediment were retained. Habitat loss in the mesocosms was similar between geologies and ranged from $62-98 \%$ loss of interstitial habitat. Total invertebrate abundance in the erosive mesocosms was 11,381 per $625 \mathrm{~cm}^{2}$ (mean=379) and in resistant mesocosms was 12,036 per $625 \mathrm{~cm}^{2}$ (mean=326; Table 4.1). Taxa richness ranged from 7-19 and was generally higher in resistant basins. Abundance CV ranged from 0.2 to 0.5 and was generally lower in resistant basins (Table 4.1).

Invertebrate biomass in the mesocosms ranged from 4-179 $\mathrm{mg}$ per $625 \mathrm{~cm}^{2}$ and was significantly higher in the erosive controls (mean=70 $\mathrm{mg}$ ) and treatments (mean=66 $\mathrm{mg}$ ) than in resistant controls (mean=14 $\mathrm{mg}$ ) and treatments (mean=12 $\mathrm{mg}$, Table 4.5). Invertebrate abundance and biomass was correlated with velocity in erosive basins $(\mathrm{R}=0.75$ and 0.47 , respectively) but not in resistant basins. Summary mesocosm data are displayed in Table 4.5. Movement or disturbance (undisturbed and disturbed in Table 4.5) of mesocosms during the colonization period or experimental period did not result in significant differences in abundance.

\subsection{Environmental variables}


Study streams had a mean width of $3.7 \mathrm{~m}$ and depth of $0.1 \mathrm{~m}$ and generally had low flow $\left(0.001-0.7 \mathrm{~m}^{3} / \mathrm{sec}\right)$ and dense canopy cover $(55-92 \%$, Table 4.2$)$. Streams in erosive geologies were slightly smaller with lower flow and less canopy cover than resistant streams (Table 4.2). Erosive streams (Table 4.2) had significantly lower dissolved oxygen $(\rho<0.01)$, higher $\mathrm{pH}(\rho<0.05)$ and slightly higher nitrates $(\mathrm{mg} / \mathrm{L}$, $\rho<0.10$ ). Erosive sites has significantly higher average fine sand, very fine sand, and silt (Table $4.3,15 \%$ vs $3 \%, 7 \%$ vs $1 \%, 12 \%$ vs $1 \%$, respectively). Within mesocosms, inorganic sediment was significantly higher $(\rho<0.05)$ in erosive streams $($ mean=31g) than in resistant streams (Table 4.3, mean=60 mg). Organic content of the sediment $(\rho<0.01)$ and the epilithon $(\rho=0.06)$ in control mesocosms was higher in resistant streams (Table 4.3). Velocity above the mesocosms ranged from $0.01-0.55 \mathrm{~m} / \mathrm{s}$ and was slightly higher in erosive streams. Sediment dose ranged from 100-1100 $\mathrm{g}$ with a frequency of 1-3 times (Table 4.4). Sediment was slightly inversely correlated with velocity at both erosive $(\mathrm{R}=0.26)$ and resistant sites $(\mathrm{R}=0.15)$.

\subsection{Invertebrate assemblage}

The invertebrate community in both basins was dominated by mayflies, stoneflies, and caddisflies and the effect of dosing on invertebrate assemblage was subtle (Figures 4.6 and 4.7). The NMDS ordination of all streams and treatments showed that assemblage was distinctly different between geologies, but within geology there was no clear separation of streams (Figure 4.8). Ordinations of streams within each geology showed minor separation among streams (Figure 4.9). Assemblage in erosive streams was variable and slightly separated along NMDS Axis 1 and varied along NMDS Axis 2. NMDS Axis 1 was positively correlated with the stonefly (Zapada) and the Diptera 
Simulium and NMDS Axis 2 was positively correlated with the Zapada and Simulim and negatively correlated with Snails and the Beetle (Orobrevia). Both axes in the ordination of erosive basins may represent a tolerance gradient with more tolerant taxis found at the negative ends of both axes. In resistant basins, assemblage was less variable but appeared to separate along NMDS Axis 2 and were variable along NMDS Axis 1. NMDS Axis 1 was positively correlated with mayflies (Baetis and Paraleptophlebia) and negatively correlated with the Diptera Atherix and the caddisfly Brachycentrus. NMDS Axis 2 was positively correlated with the mayfly Rhithrogena and the stonefly Capniidae and negatively correlated with caddisfly Brachycentrus and Simulium. The major gradients represented in Axis 1 and 2 may also represent a tolerance gradient, but the pattern is not as clear as in the erosive basins.

Vector analysis of mesocosm environmental data showed two variables were significantly related to assemblage (Figure 4.11). In erosive basin, sediment remaining (psuedo $r=0.40, \rho<0.01$ ) and velocity (psuedo $r=0.27, \rho<0.05$ ) were related to assemblage, while in resistant basins, only sediment remaining (psuedo $r=0.17, \rho<0.01$ ) was significant. Neither total sediment added nor dosing frequency was significantly related to assemblage within either geology (Figure 4.9).

\subsection{Effect of sediment dosing frequency and habitat loss}

Invertebrates in different geologies showed some differences in their response to sediment addition (Figure 4.10, Table 4.7). Of the six metrics evaluated, only the percent change in richness showed a significant difference between geologies. Treatment mesocosms in resistant geologies lost a mean of $12 \%$ of their richness while erosive basins gained 3\% $(\rho<0.01)$. 
Within geology, invertebrate response to dosing was observed in abundance, richness and grazing traits (Figure 4.10, Table 4.7). In resistant basins, dosing frequency decreased abundance $(\rho<0.001$, Figure $4.10 \mathrm{~b})$ and richness $(\rho<0.10$, Figure $4.10 \mathrm{~d})$. In erosive basins, dosing frequency decreased relative abundance of grazers $(\rho<0.10$, Figure $4.10 \mathrm{~g})$ and brushers $(\rho<0.05$, Figure 4.10i). Gougers were not reduced by dosing frequency in either geology.

Habitat loss showed negative relationships with invertebrates in both geologies Figure 4.11, Table 4.7). In resistant basins, habitat loss was negatively and significantly associated with abundance $\left(R^{2}=0.15, \rho<0.01\right)$ and richness $\left(R^{2}=0.10, \rho<0.01\right)$. In erosive basins, habitat loss was negatively and significantly associated with abundance $\left(\mathrm{R}^{2}=0.17\right.$, $\rho<0.01)$, grazers $\left(R^{2}=0.20, \rho<0.001\right)$, brushers $\left(R^{2}=0.18, \rho<0.001\right)$ and gougers $\left(R^{2}=0.16\right.$, $\rho<0.010)$.

\section{Discussion}

\subsection{Hypothesis 1: The effect of geology on invertebrate response to sediment addition}

In support of my first hypothesis, my findings provide experimental evidence that in the absence of strong anthropogenic stressors, sediment-tolerant communities can develop in streams with naturally elevated sediment levels, and therefore will respond differently than invertebrates in streams with lower sediment. Fine sediment accumulation in the mesocosms was greater in erosive basins and there was a larger taxa loss in resistant basins. Within geologies, there also appeared to be different invertebrate responses to dosing frequency. In erosive basins invertebrate function (i.e. grazing traits) were more responsive to sediment addition, while richness and abundance loss were more pronounced in resistant basins. Furthermore, the pattern of loss across dosing frequency 
appeared to be different between geologies. In erosive basins, invertebrates appeared to recolonize mesocosms after the second dose (i.e. abundance, $\%$ grazers and $\%$ brushers), while in the resistant basins, there was a more systematic loss of taxa. The greater amount of sediment trapped in control mesocosms in erosive basins indicates that these basins had higher background levels of fine sediment than streams in resistant geologies. Increased fine sediment supply to the streams in erosive basins is likely due to increasing physical and chemical weathering of fine-grained surface lithology (Leopold et al. 1964) and resistant geologies generally have higher transport rates (Kelsen and Wells 1989). For example, Richards et al. (1996) found increased fines correlated with the proportion of geologic Lacustrine clays. The effect of geology on invertebrate response to fine sediment addition may be explained by the strong environmental forces acting on stream invertebrates through sediment supply and transport in the stream and result in communities which have similar functional attributes (Poff 1997; Townsend and Hildrew 1994). This has been observed in other studies. For example, Zweig et al. (2005) found a distinct decreases in scraper densities as the percent surface cover of fines $(<2 \mathrm{~mm})$ increased. Burdon et al. (2013) observed a strong threshold response of invertebrates to fine sediment cover which was associated with habitat loss and impact to periphytonbased food resources. The findings of my study provide in situ experimental evidence that invertebrate grazers are sensitive to excessive fine sediment in the benthos. Adaptation to excessive fine sediment conditions, such as drift, avoidance and feeding plasticity has been documented in other studies (i.e. Larsen and Ormerod 2010; Francouer and Biggs 2006; Runde and Hellenthal 2000; McClelland and Brusven 1980; Peeters 2006). In contrast, the lack of an assemblage response observed in my study does 
not support the first hypothesis. While assemblages were significantly different between basins, the effect of sediment addition did not strongly alter assemblages within geologies. The lack of change in assemblage is partially due to the high variability among streams, but may also reflect the importance of habitat loss, which would not necessarily alter assemblage. The lack of assemblage response to increased levels of fine sediment has been observed in other sediment studies (Larsen and Ormerod 2010). The findings presented here help explain the lack of consistent findings of other research. For example, several studies have found little to no invertebrate response to fine sediment (i.e. Angradi 1999; Kruetzweiser et al. 2005; Cover et al. 2008; Kaller and Hartman 2004; Matthaei et al. 2006; Richards and Bacon 1994). While other studies have shown a strong taxonomic and functional response to increased levels of fine sediment (Zwieg and Rabeni 2001; Rabeni et al. 2005; Larsen et al. 2010).

\subsection{Hypothesis 2: Brushers as indicators}

Brushers showed significant negative associations with sediment dosing within erosive basins and appeared to be more sensitive than gougers. Within both geologies, neither scrapers nor gougers were significantly affected by sediment dosing. The negative association of brushers with sediment is supported by other experimental research; for example, a study by Broekhuizen et al. (2001) found the addition of fine sediment to food source reduced growth rate of the Leptophlebiia (brusher) and Arens (1990) showed increased wear of Rhithrogena mouthparts when forced to feed on diatoms growing on sand paper. Gougers did not appear to be affected by sediment dosing in this study, possibly due to less mouthpart damage or reduced transfer of inorganic material to the mouth. These findings are supported by several experimental and observational studies. 
For example, an in situ experiment conducted by Angradi (1999) showed that Baetids (gouger) were positively associated with increased $\%$ fine substrate and, in a broad spatial-scale study, several Baetid genera were identified as only slightly sensitive to fine sediments (Relyea et al. 2012). These findings make sense in light of habitat template theory regarding the development of community traits through selective environmental pressures (Poff 1997; Townsend and Hildrew 1994). In resistant basins, fine sediment was naturally low and did not present a strong selective pressure favoring sedimentadapted traits. As fine sediment was artificially increased, invertebrates could not adapt to conditions and simply left the mesocosms; as sediment dosing increased taxa richness and abundance correspondingly decreased. On the other hand, in erosive basins, the high levels of sediment act as a strong environmental filter towards community traits that are adapted to these conditions. The nested nature of stream communities (Larsen et al. 2010) provides a source of sediment-adapted invertebrates in erosive basins, and as sediment was artificially increased in erosive mesocosms, less tolerant traits (i.e. brushing) were replaced by more tolerant traits (i.e. gougers).

\subsection{Habitat loss vs. invertebrate sensitivity}

The findings of this research also help illuminate the mechanisms related to habitat loss and invertebrate sensitivity to fine sediment. Several correlative studies have identified habitat loss as the primary mechanism associated with increased fines deposition (i.e. Griffith et al. 2009; Burdon et al. 2013). In this study, habitat loss played an important role in both basins; however, in erosive basins there was slightly stronger functional trait response to habitat loss than what was observed in abundance or richness. These findings suggest that while habitat loss was a primary driver of community change, 
invertebrate physiological sensitivity to fine sediment was also evident as indicated by sediment-tolerant traits. The results associated with habitat loss in resistant basins are more difficult to interpret. One possibility is that the loss of habitat in resistant mesocosms was not large enough to be detected by the design on this experiment. On the other hand, without community traits that are adapted to fine sediment, a preference for one trait over another would not be expected in resistant basins. Further confounding these findings is the likely difference in algal food source. Resistant mesocosms contained less periphyton and may not have supported much algal feeding. In this case, the lack of response may be more closely associated with food availability.

\subsection{Implications for Management}

Ecological investigations across scales can provide important information about environmental filters and resulting stream community (Poff 1997; Townsend and Hildrew 1994). The findings presented here provide evidence that basin geology was an important environmental force possibly acting on invertebrate grazing through sediment production and subsequent selection of feeding strategies, such as gouging, that may limit ingestion of inorganic sediment. Furthermore, this study also presents evidence of invertebrate adaptation to localized sediment conditions within streams. The use of functional traits is a widely-used approach for both ecological and applied research (Poff 1997; Pollard and Yuan 2010) and these findings provide insight into how feeding mechanisms may be affected by fine sediment and the use of grazing traits as an indicator of fine sediment in streams. For example, the apparent observed adaptation of invertebrates to sediment may result in the underestimate of benthic sedimentation in erosive basins and overestimate it in resistant basins. This is important information for stream management that is focused 
on reproduction habitat for salmonids. Conversely, the relative lack of invertebrate adaptation to sediment in resistant basins may make them a more sensitive indicator of anthropogenic sources of excessive stream sedimentation. Another important implication for management is related to the use of scrapers as a functional indicator. Invertebrate scrapers, such as the Heptageniidae family, are characterized by having mouthparts with stiff brushes that are used to scrape periphyton into their mouths. Invertebrate collectors such as Leptophlebiidae also use brushes to feed but are classified differently because they are generally thought of as eating a wide variety of organic material, not just periphyton. Given the well-known invertebrate flexibility of food source, it may be more ecologically and evolutionarily appropriate to develop indicators based on feeding mechanism only and ignore food source. The findings of this study support this approach and reflect ecological theories about adaptation and community trait development (Townsend and Hildrew 1994; Poff 1997; Orians 1980).

The extrapolation of small-scale ecological experiments to larger scale process requires caution (Lamberti and Steinman 1993). The duration, spatial scale and mesocosms themselves may affect colonization rates, assemblage and food webs (Angradi 1999). In this study, the assemblage found in the mesocosms represents only $80 \%$ of the taxa observed in the study reaches. Common shredders and burrowers such as Peltoperlidae and Pteronarcyidae were noticeably absent from the mesocosms and in general the invertebrates colonizing mesocosms were small and early instars. In this study, it appears that erosive streams had comparatively higher productivity, and this was reflected in the relatively high biomass content of the erosive mesocosms. Given this fact, it is hard to separate the effect of sediment addition from overall habitat quality and 
productivity in the mesocosms. Furthermore, because of low periphyton biomass in the resistant mesocosms, invertebrate feeding may have shifted from grazing to collecting non-algal organic matter. Invertebrate plasticity in feeding may explain the lack of response by grazers in resistant streams. On the other hand, the high quality of periphyton in erosive mescosms compared to surrounding substrate may stimulate grazing in the mesocosm.

\subsection{Conclusion}

Excessive fine sediment in streams is a major concern for efforts to manage or improve salmonid reproductive habitat in Oregon's coastal forests. Currently, there is increased interest in developing functional or trait-based macroinvertebrate indicators to monitor the benthic sediment conditions of streams used for salmon spawning. Although derived from a limited study in one ecoregion, this study presents evidence of invertebrate adaptation to fine sediment and demonstrates the role of geology in shaping invertebrate response to sedimentation. The results of this experiment also support correlative studies that have found that invertebrate grazers are a useful indicator for fine sediment. Furthermore, the categorization of grazing types such as gougers or brushers contributes to a mechanistic explanation of sediment sensitivity and suggests that invertebrates may be responding to food quality in addition to interstitial habitat loss. From a management perspective, understanding the role of geology in shaping invertebrate functional response to sediment addition will help design sediment monitoring programs and interpret results of such studies. 
Figure 4.2 Mouthpart structures of Rhithrogena (Brusher), and Baetis (Gouger), Scale difference, image by Arens (1989).

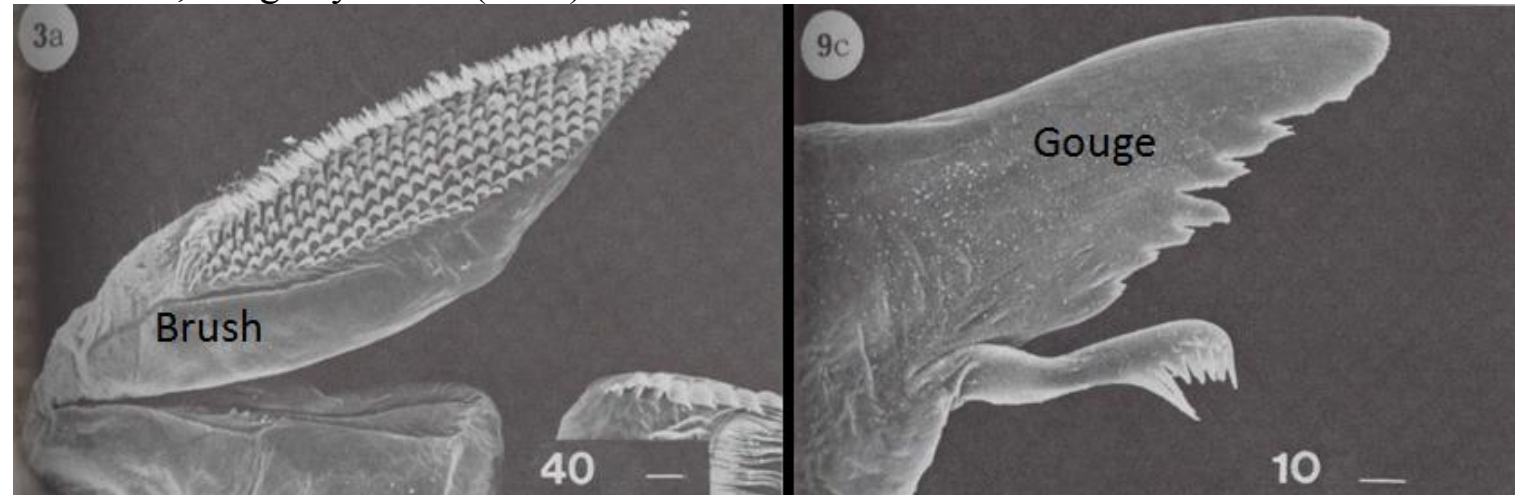


Figure 4.3 Map of study area and final site selections. Erosive basins: Beaver (Bevr), Pebble (Peb), Scappoose (Scap) and Northrup (North). Resistant basins: Drift, Jones, Jordon (Jord) and South Fork of the Wilson river (SF).

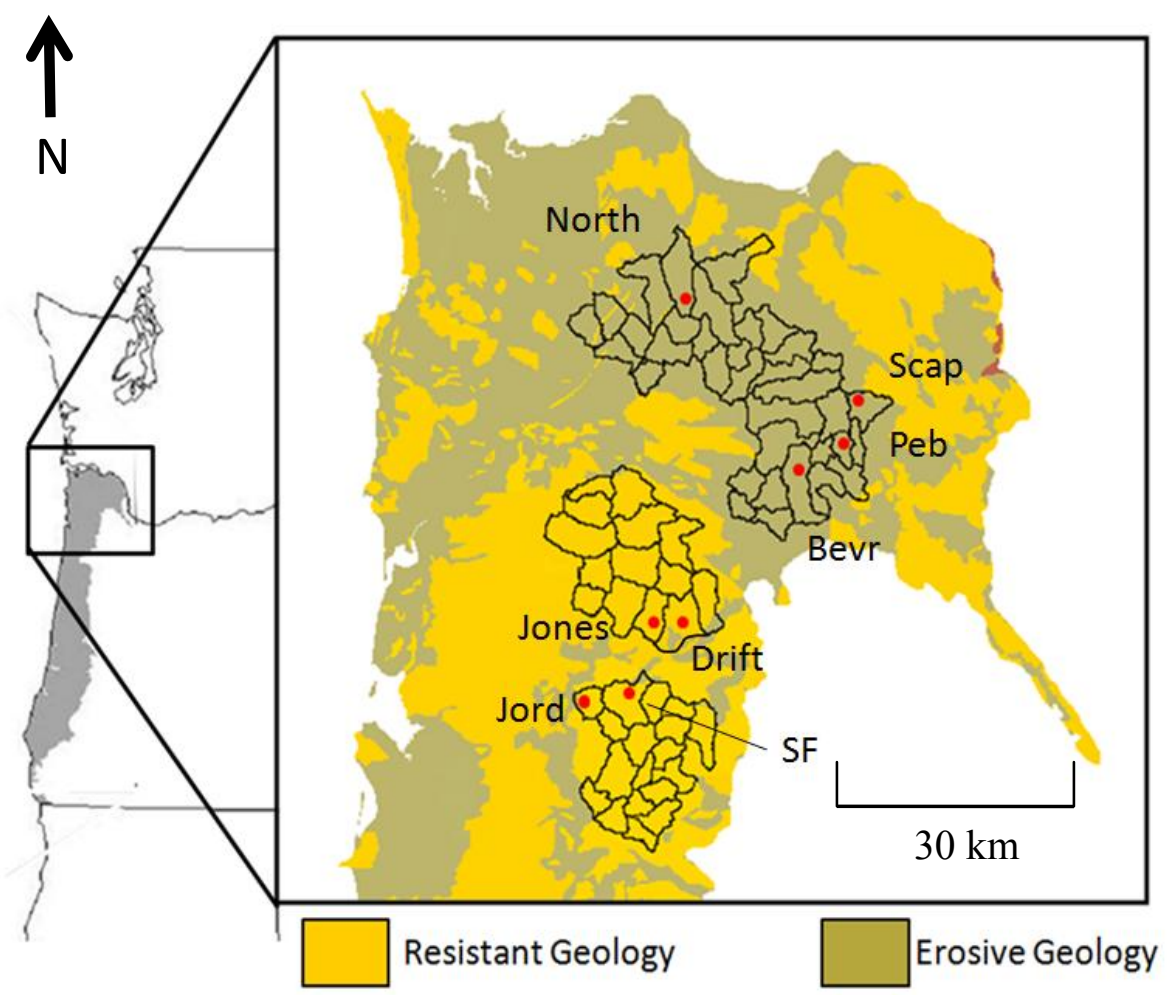


Figure 4.4 Schematic diagram showing basin selection process. Data source shown in italics. Geology data were obtained from USGS and based on the maps of Walker and MacLeod (1991), logging data were obtained from the Coastal Analysis and Modeling Study (CLAMS 2005), and landcover data were obtained from the National Landcover Data base (NLCD 2006).

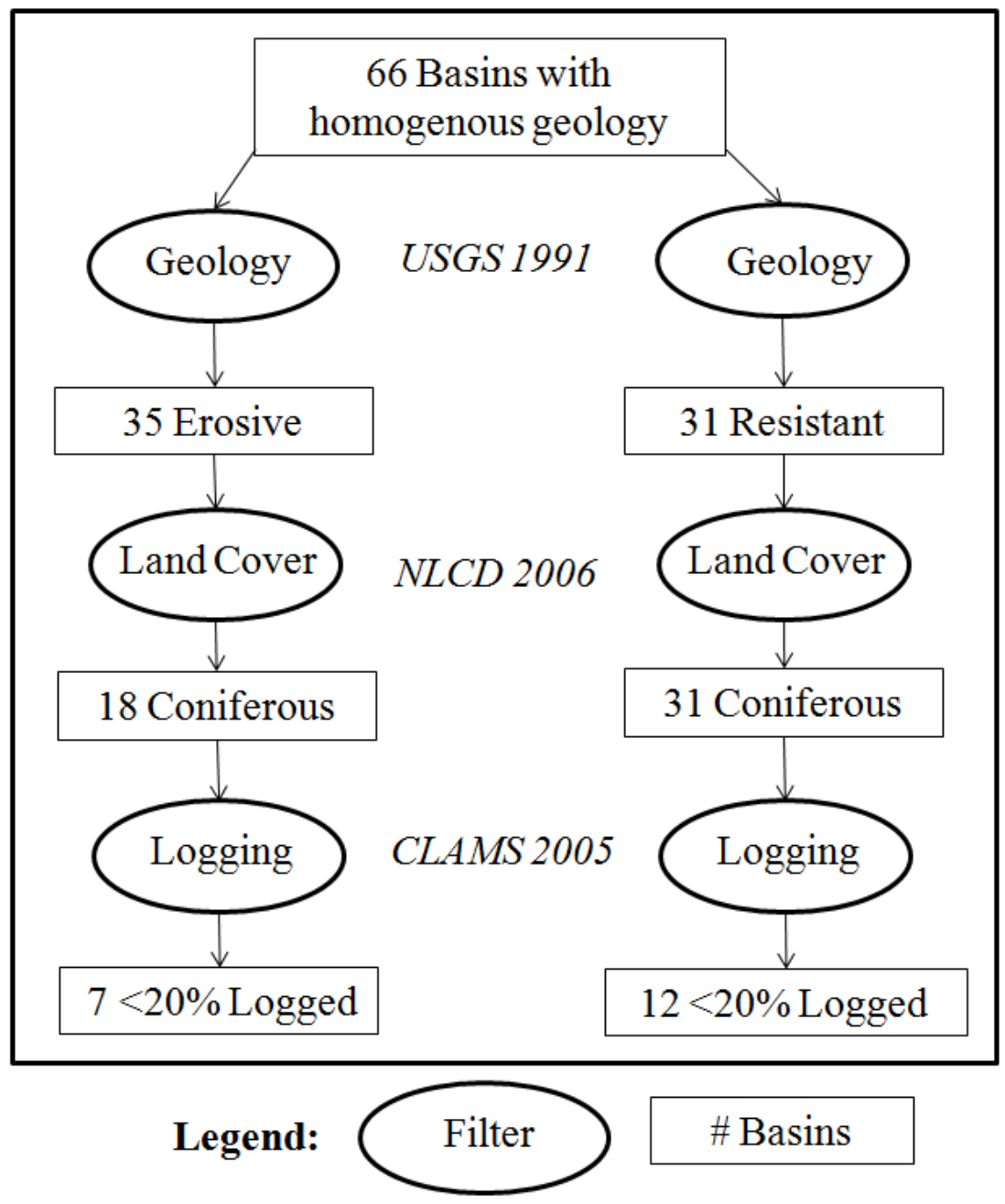


Figure 4.5 Sampling schematic and planned dosing schedule. Top figure illustrates experimental set-up with randomly selects treatment (solid lines) and control (dashed lines) mesocosms. The lower figure shows the dosing and sampling schedule and amount of sediment added to each mesocosm. High flows on the third day of sampling resulted in an alteration of the schedule and only three sediment doses.
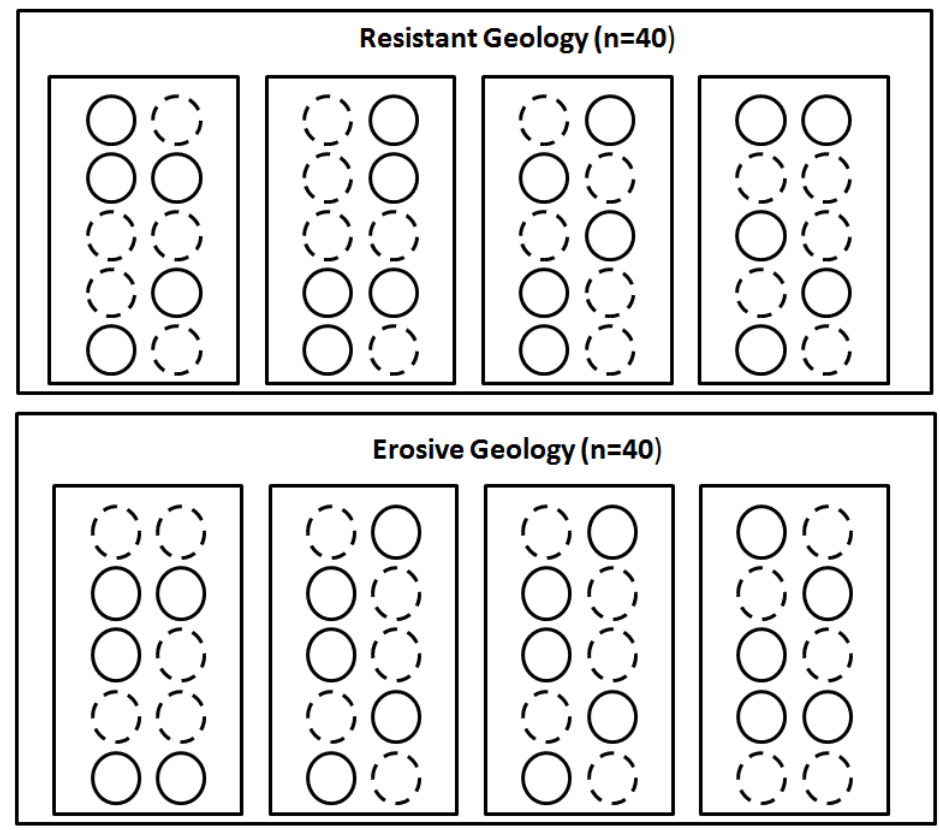

100

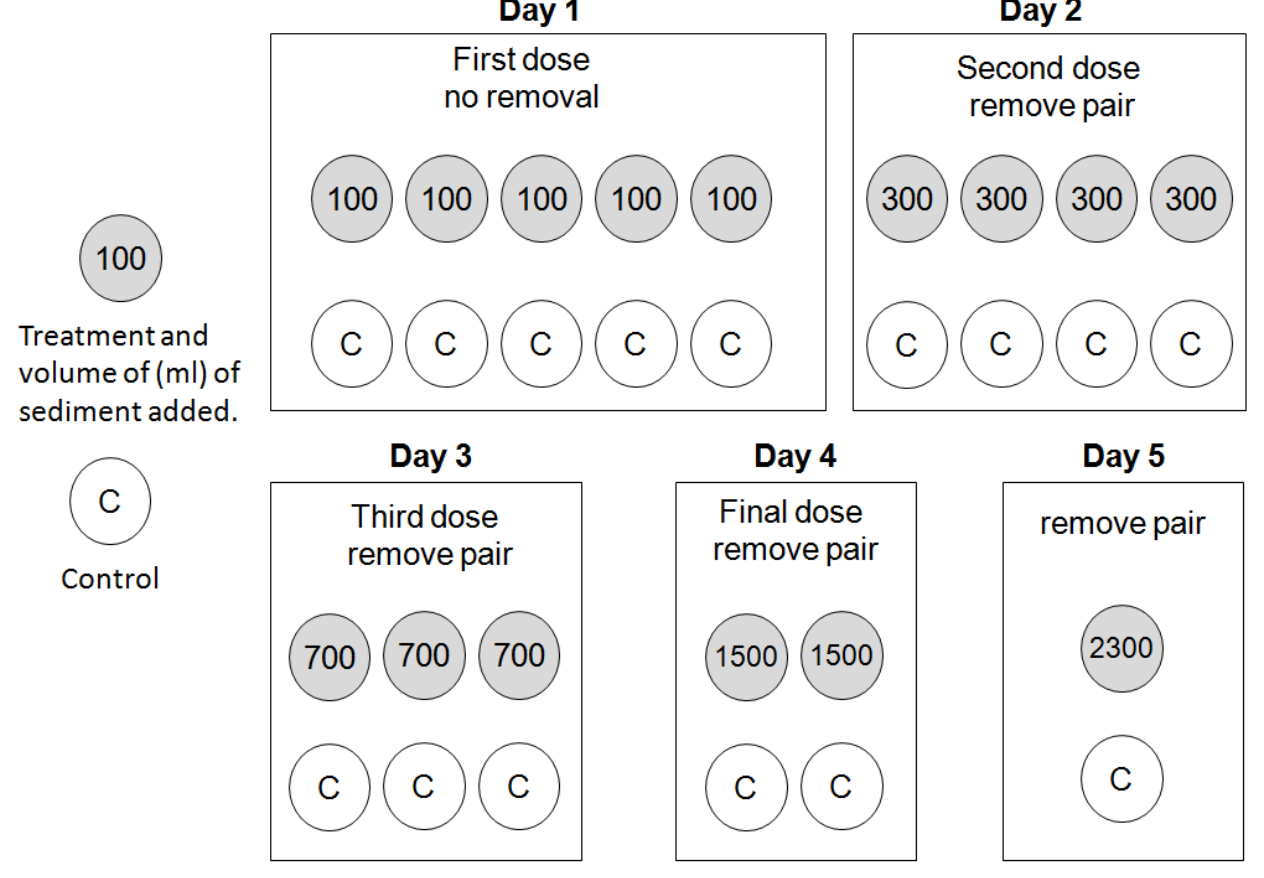


की

送

赔

过

Eิ

응

을

뜰

के

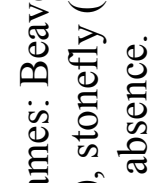

엄요

달

क

की

政

웡

․․

言 要专

क क

递

娄

논

응

8

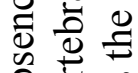

ब

㪡

递

잉

몰

完

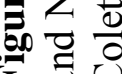

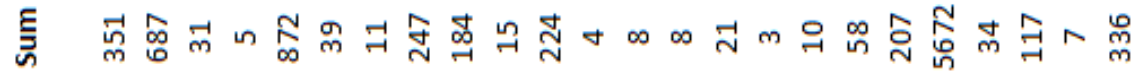

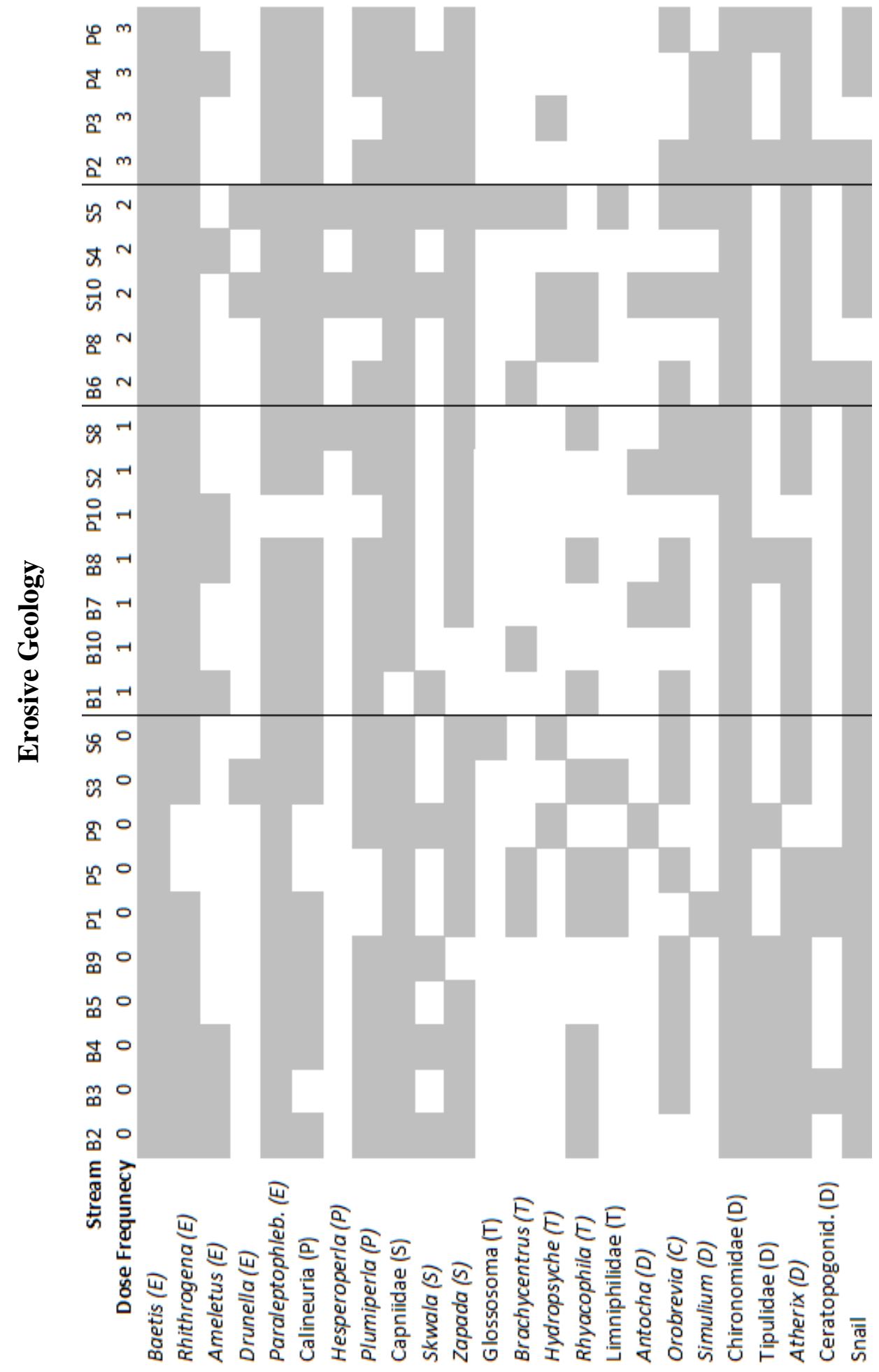




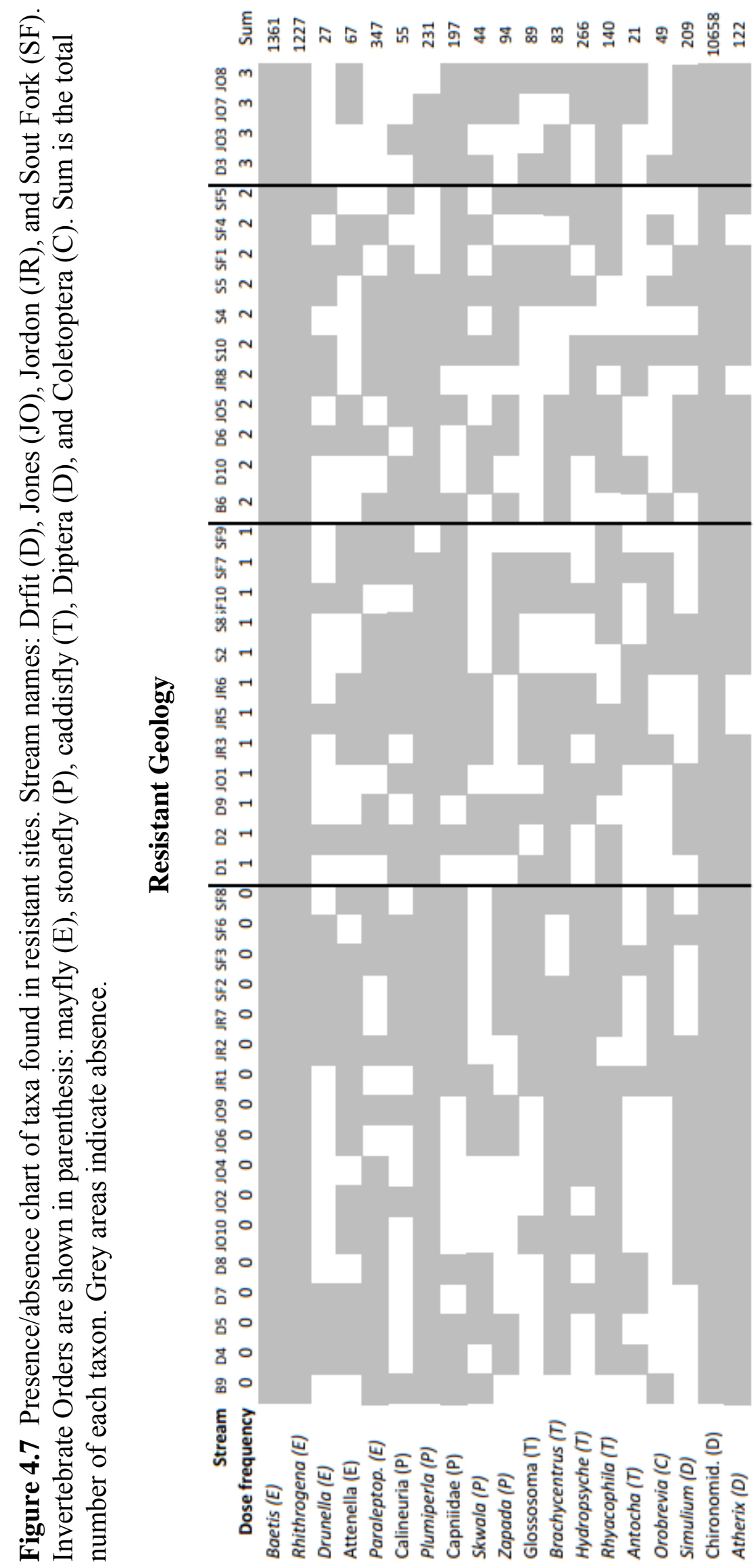


Figure 4.8 Ordinations based on presence/absence and relative abundance of all streams within each geology.
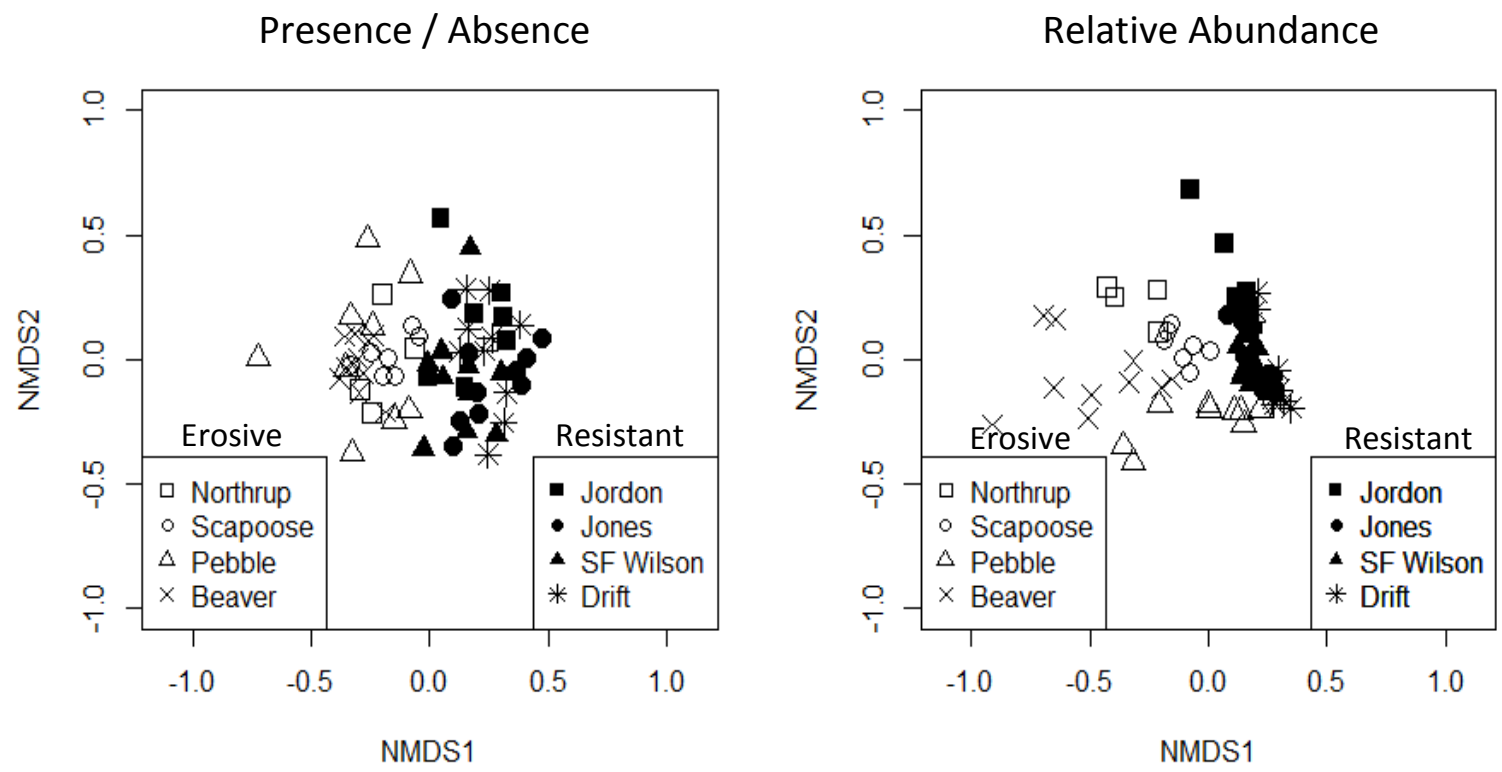
Figure 4.9 NMDS ordinations based on relative abundance of each mesocosm and dosing frequency for each stream. Symbols correspond to symbols in Figure 4.7. Numbers show dosing frequency associated with each mesocosm assemblage at each stream. Northrup samples were mixed up in the high flow event. No significant relationship between dosing frequnency and assemblage was observed in any of the streams.

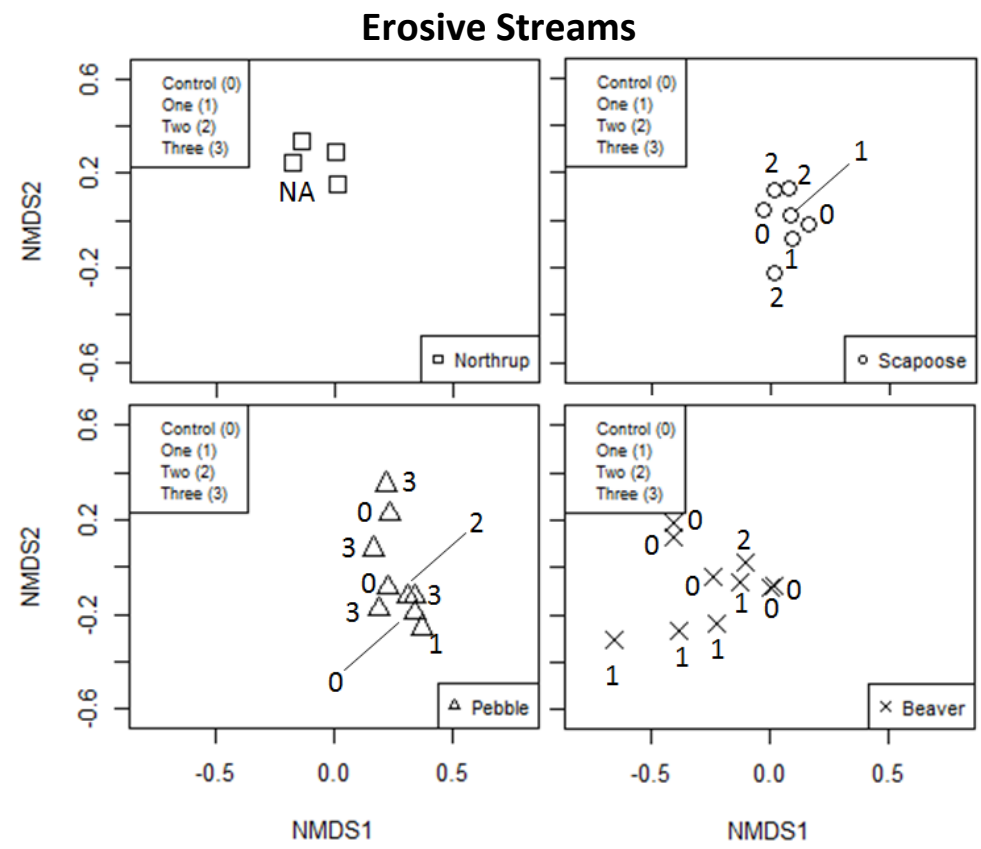

Resistant Streams

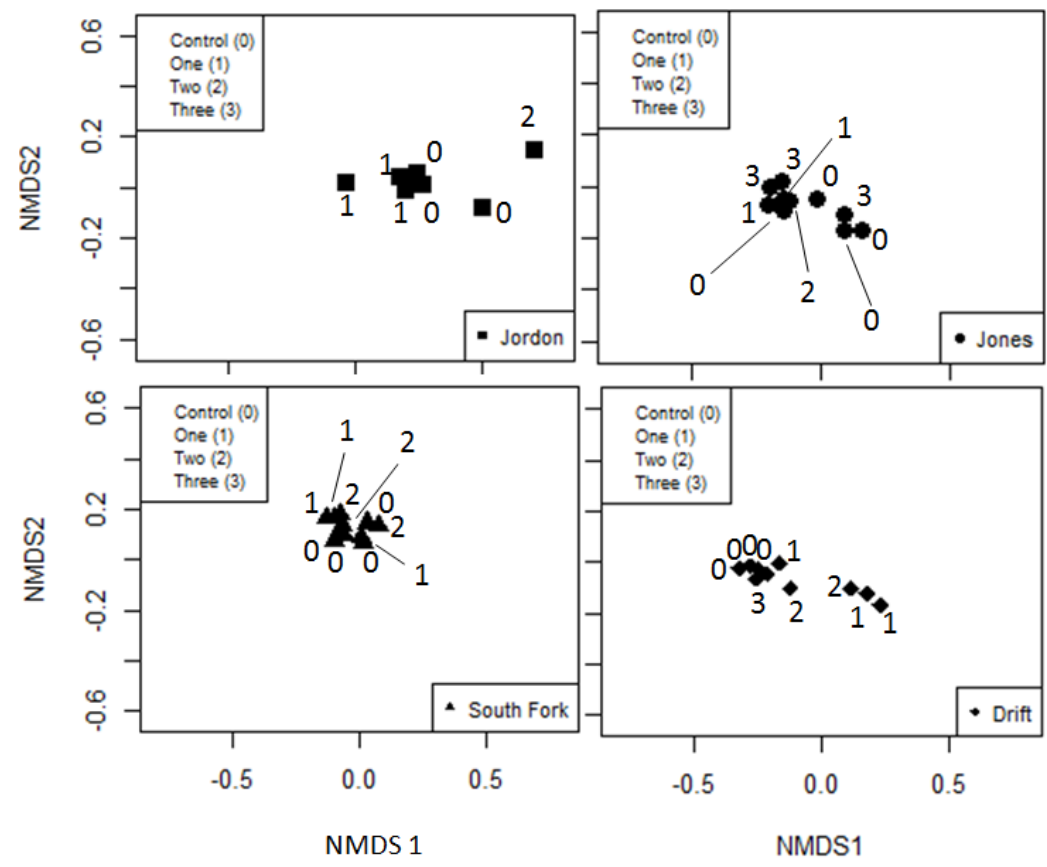


Figure 4.10 Dose frequency boxplots of invertebrates for both geologies. Shows the response of invertebrate abundance (number per mesocosm, a), richness (b), biomass (c), grazer (d), brusher (e) and gouger (f) relative abundance (Rel. Abund). Results of ANOVA analysis shown (NS=not significant).
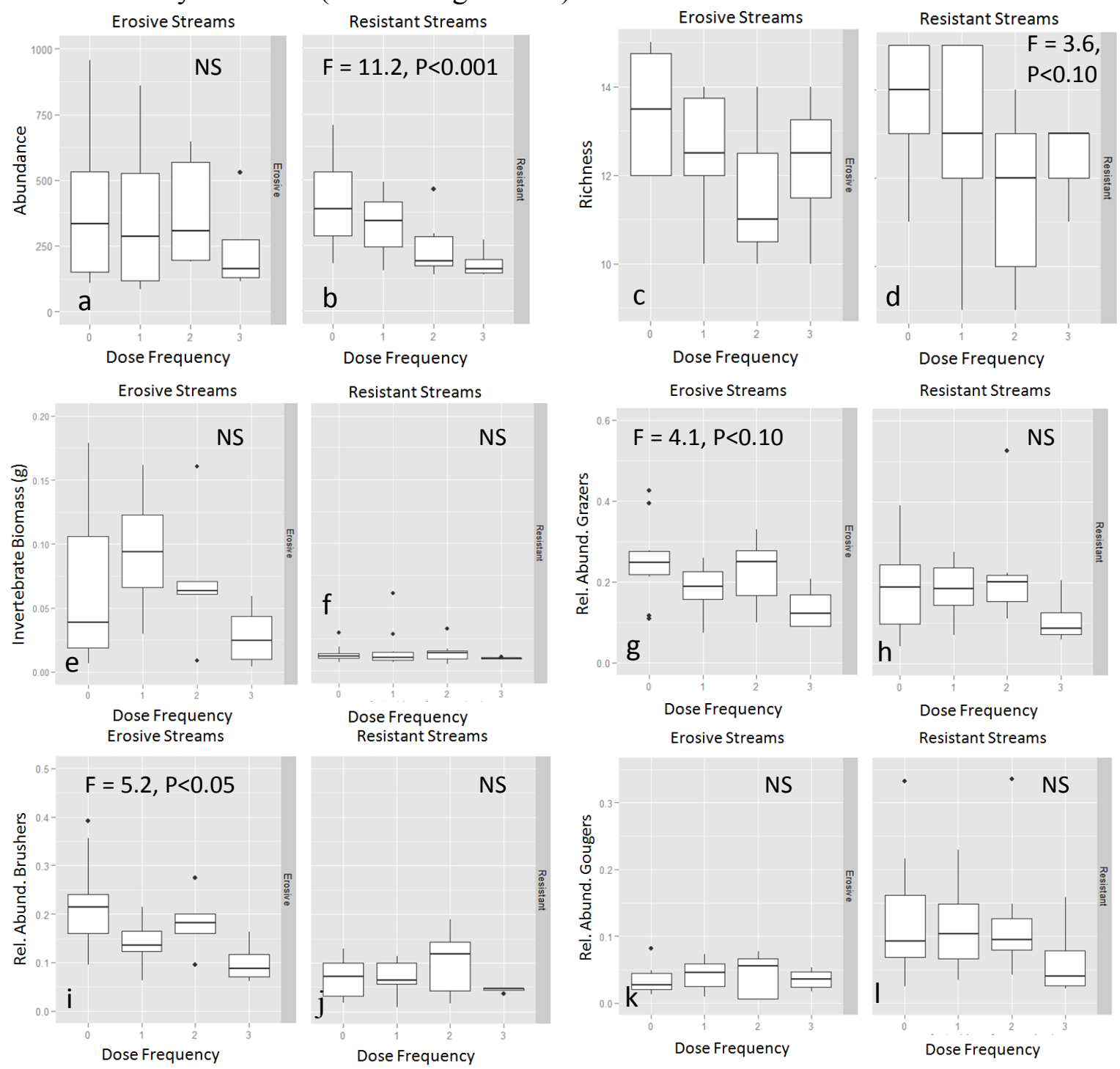
Figure 4.11 Ordinations and sediment (Sed.) vectors for both geologies (a,b). Bubble plots show relative abundance of grazer $(c, d)$, brushers $(e, f)$ and gougers $(g, h)$.
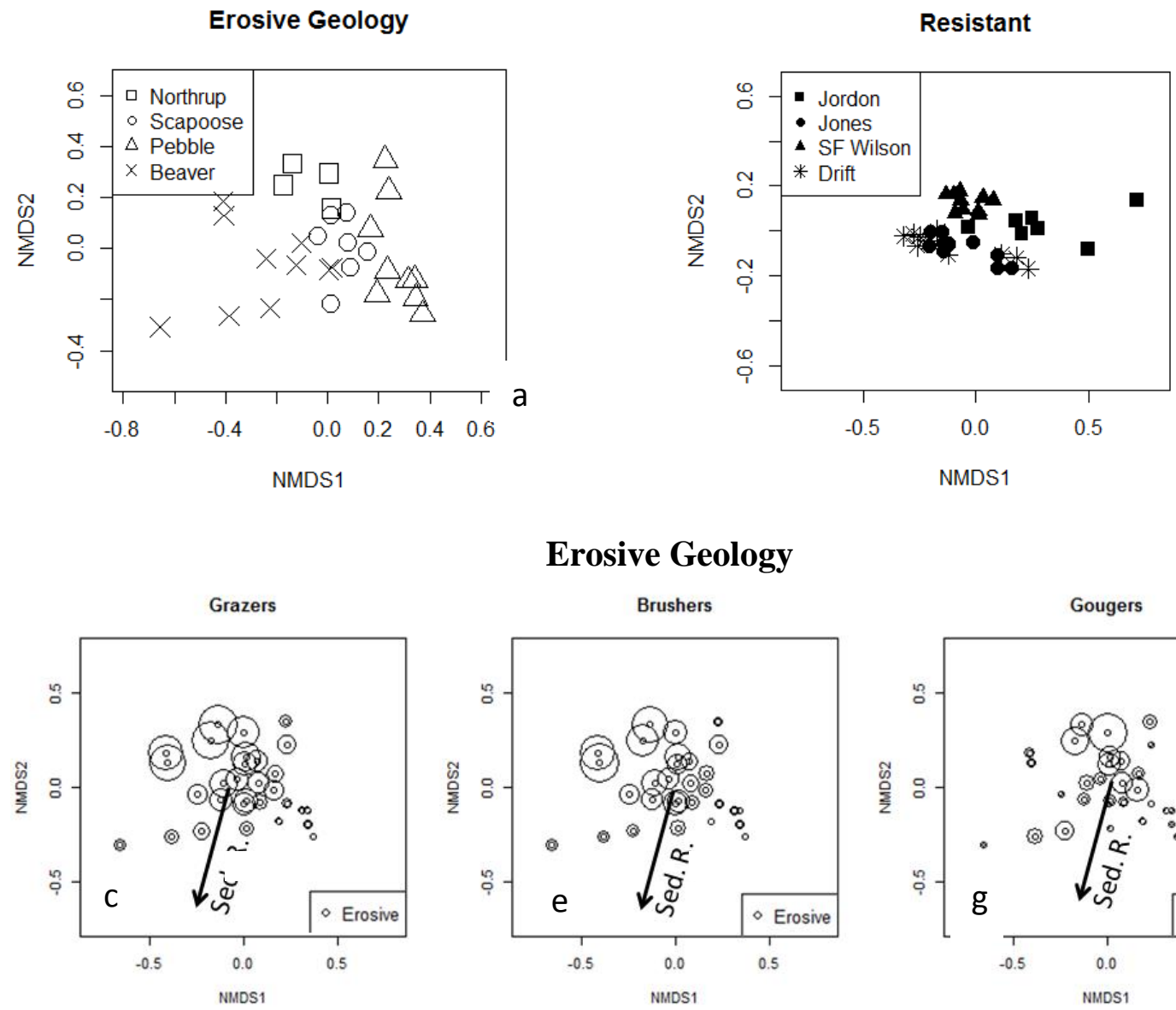

\section{Erosive Geology}
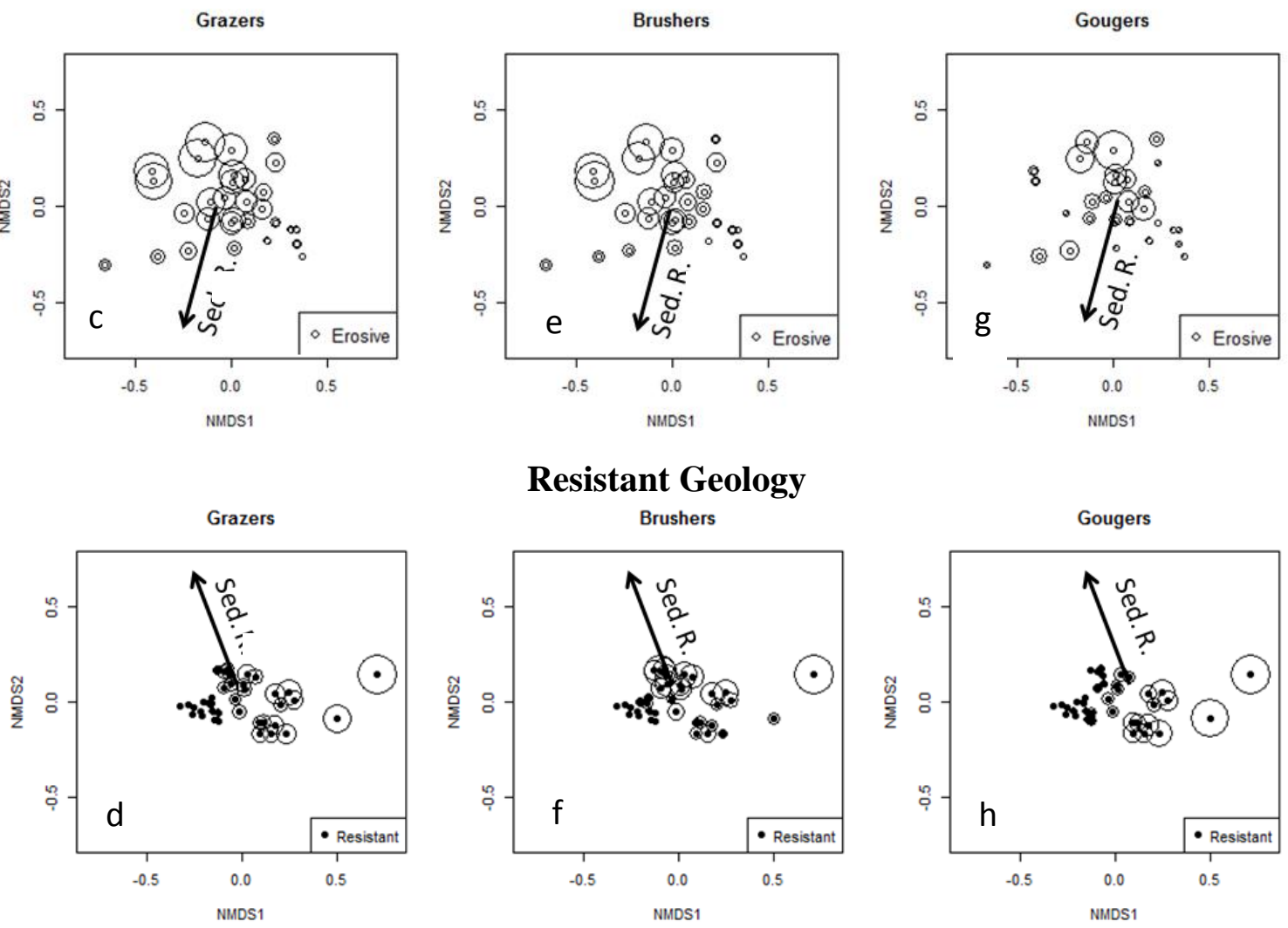

\section{Resistant Geology}
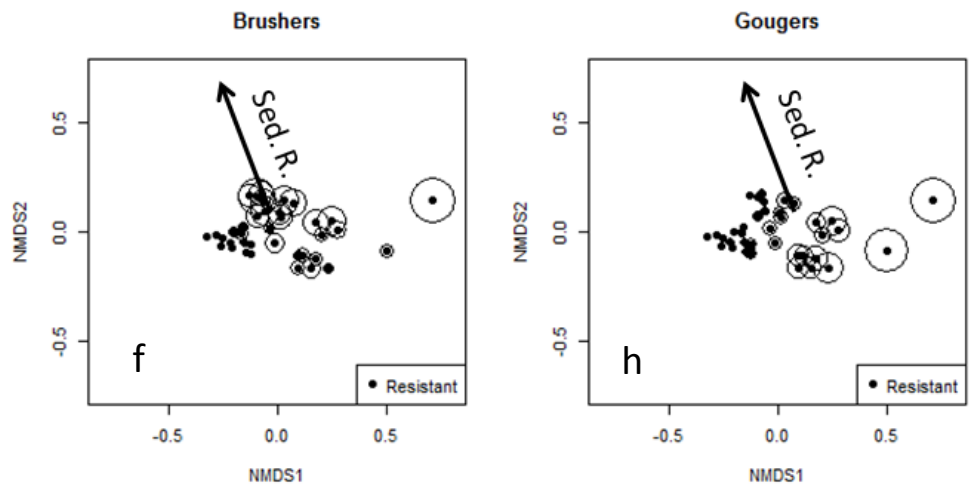
Figure 4.12 Linear models of velocity-adjusted models of invertebrates as a function of inorganic sediment remaining in mesocosms. $\rho<0.10^{+}, \rho<0.05^{*}$, $\rho<0.01^{* *}$

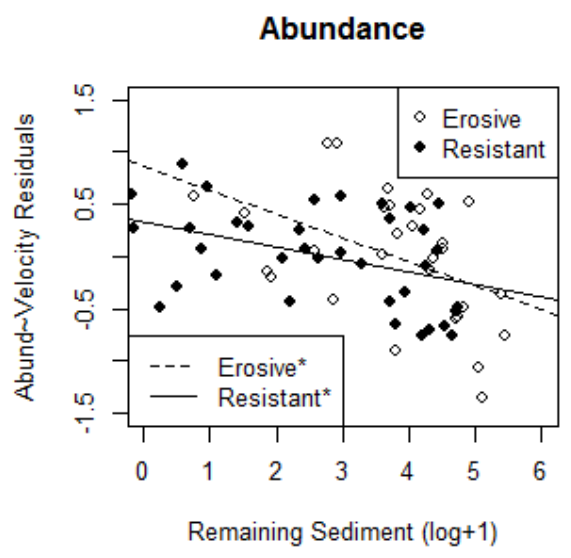

Grazers (RA)

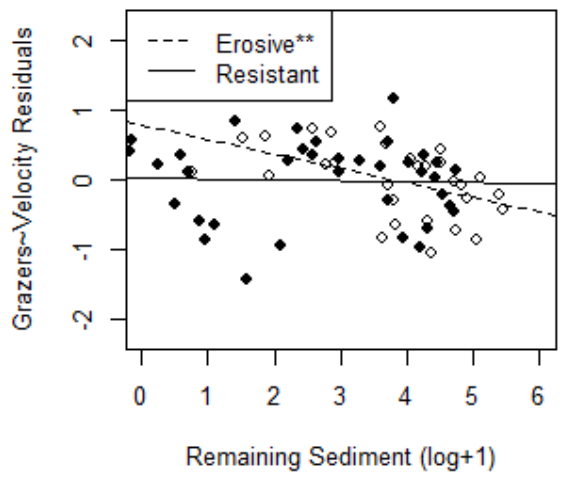

Taxa Richness

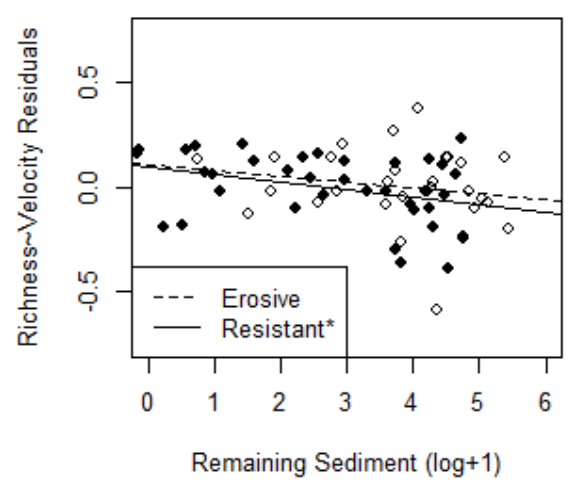

Brushers (RA)

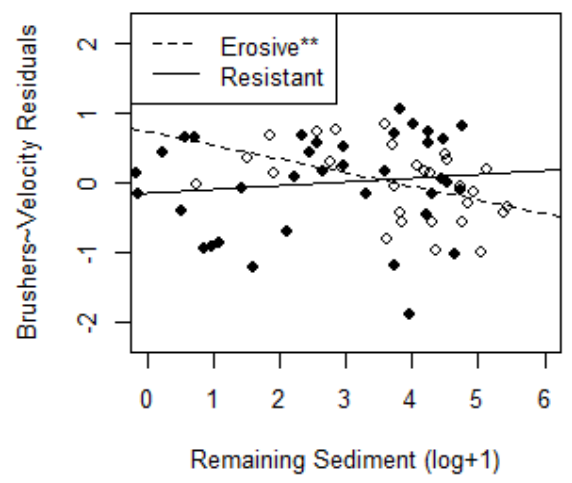




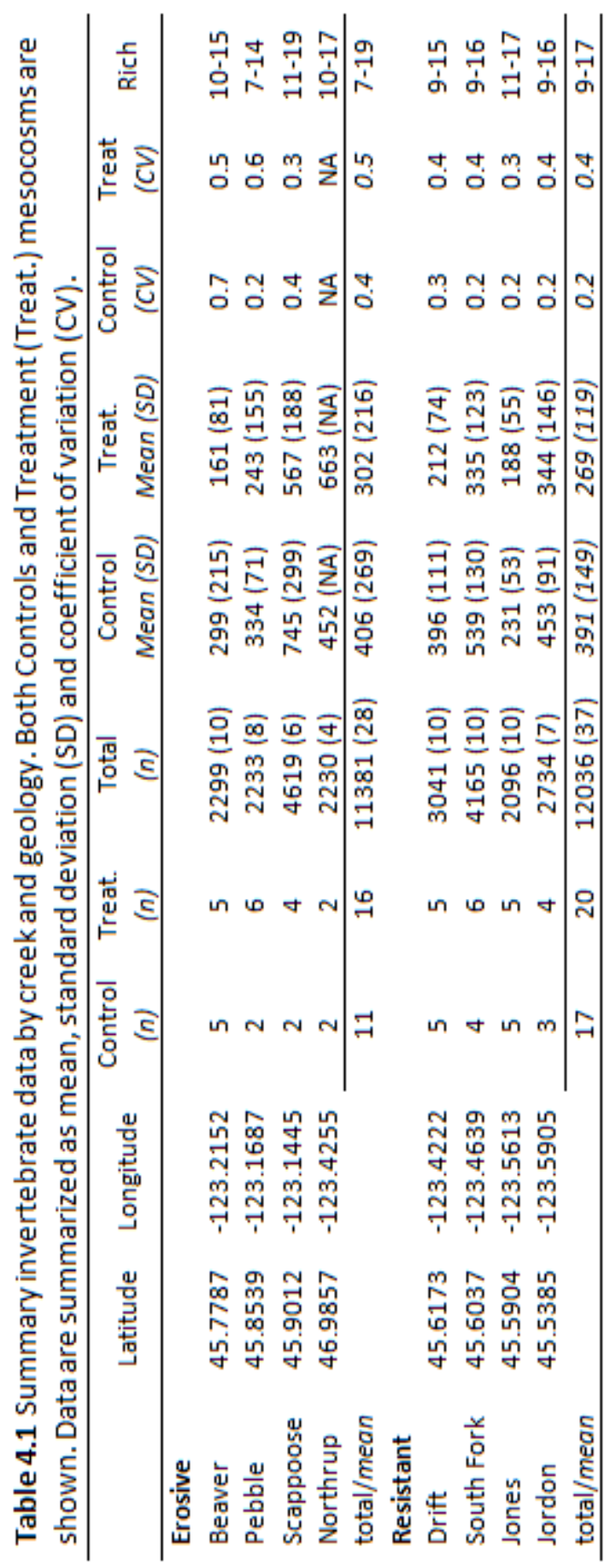




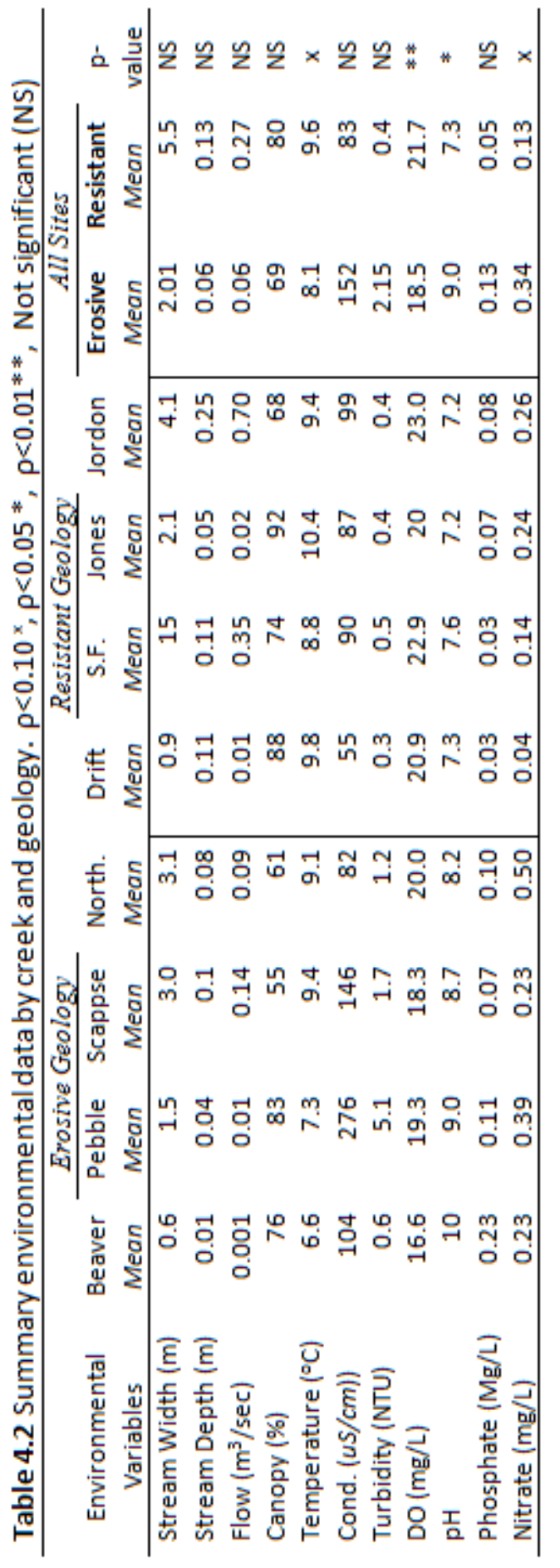


Table 4.3 Summary data and t-test results comparing control mesocosms (meso) and in-stream sediment data for each geology. Values are expressed as mean, minimum (min) and maximum (max) for biotic, environmental and sediment size-class data (\% volume). Note sample size is different for in-stream sediment samples. $\rho<0.10 \mathrm{x}, \rho<0.05 *$, $\rho<0.01 * *, \rho<0.001^{* * *}$, Not significant (NS)

\begin{tabular}{|c|c|c|c|}
\hline Variable & Erosive $(n=9)$ & Resistant $(\mathrm{n}=17)$ & $p$-value \\
\hline Control Biotic data & Mean (min-max) & Mean (min-max) & \\
\hline Abundance & $405(120-956)$ & $391(182-707)$ & NS \\
\hline Richness & $14(12-15)$ & $14(11-16)$ & NS \\
\hline Invertebrate Biomass (mg/meso) & $66(7-179)$ & $14(7-30)$ & $*$ \\
\hline Periphyton Biomass (mg/meso) & $18(4-93)$ & $6(2-19)$ & $x$ \\
\hline Control Environmental data & Erosive $(n=9)$ & Resistant $(n=17)$ & \\
\hline Sediment Remaining (g/meso) & $31(2-92)$ & $6(1-20)$ & $*$ \\
\hline$\%$ Organics in the Sediment & $9(3-17)$ & $34(3-70)$ & $* * *$ \\
\hline Velocity (m/s) & $0.15(0.01-0.55)$ & $0.08(0.01-0.23)$ & NS \\
\hline$\%$ Habitat remaining & $95(85-100)$ & $99(97-100)$ & NS \\
\hline Control Sediment Size & Mean (SD) & Mean (SD) & \\
\hline$\%>2$ mm Very Fine Gravel & $7(6)$ & $5(7)$ & NS \\
\hline$\%>0.6 \mathrm{~mm}$ Coarse Sand & $17(13)$ & $12(13)$ & NS \\
\hline$\%>0.25 \mathrm{~mm}$ Medium Sand & $37(16)$ & $23(12)$ & $*$ \\
\hline$\%>0.15 \mathrm{~mm}$ Fine sand & $17(11)$ & $18(8)$ & NS \\
\hline$\%>0.075 \mathrm{~mm}$ Very Fine Sand & $11(6)$ & $20(11)$ & $*$ \\
\hline$\%<0.075 \mathrm{~mm}$ Silt & $11(7)$ & $23(14)$ & $*$ \\
\hline In-Stream Sediment Size & Erosive $(n=3)$ & Resistant $(n=4)$ & \\
\hline$\%>0.6 \mathrm{~mm}$ Coarse Sand & $26(9)$ & $56(12)$ & $*$ \\
\hline$\%>0.25 \mathrm{~mm}$ Medium Sand & $40(7)$ & $43(16)$ & NS \\
\hline$\%>0.15 \mathrm{~mm}$ Fine sand & $15(5)$ & $3(3)$ & $*$ \\
\hline$\%>0.075 \mathrm{~mm}$ Very Fine Sand & $7(1)$ & $1(1)$ & $* *$ \\
\hline$\%<0.075 \mathrm{~mm}$ Silt & $12(1)$ & $1(1)$ & $* * *$ \\
\hline
\end{tabular}


Table 4.4 Summary data and t-test results comparing treatment mesocosms (meso) in each geology. Values are expressed as mean, minimum ( $\min$ ) and maximum ( $\max$ ) for biotic and environmental data in both resistant and erosive geology. $\rho<0.10^{\mathrm{x}}, \rho<0.05^{*}, \rho<0.01^{* *}$, Not significant (NS)

\begin{tabular}{lrrc}
\hline \multicolumn{1}{c}{ Variable (N/N) } & $\begin{array}{c}\text { Erosive Treatment } \\
(\mathrm{n}=16)\end{array}$ & $\begin{array}{r}\text { Resistant Treatment } \\
(\mathrm{n}=20)\end{array}$ & p-value \\
\hline Biotic data & Mean (min-max) & Mean (min-max) & \\
Abundance (number/meso) & $337(86-860)$ & $269(138-490)$ & $\mathrm{NS}$ \\
Richness ( number/meso) & $13(7-19)$ & $12(9-17)$ & $\mathrm{NS}$ \\
Invertebrate Biomass (mg/meso) & $70(4-162)$ & $12(5-60)$ & $* *$ \\
Periphyton Biomass (mg/meso) & $14(4-76)$ & $7(0-23)$ & $\mathrm{X}$ \\
Environmental data & & & \\
Dose Amount (g/meso) & $393(100-800)$ & $415(100-1100)$ & $\mathrm{NS}$ \\
Sediment Remaining (g/meso) & $106(38-235)$ & $64(14-116)$ & $*$ \\
\% Organics in the sediment & $5(3-10)$ & $4(3-6)$ & $\mathrm{NS}$ \\
Velocity (m/s) & $0.14(0.01-0.49)$ & $0.08(0.01-0.23)$ & NS \\
\% Habitat loss dose (\%) & $63(16-100)$ & $66(16-100)$ & $\mathrm{NS}$ \\
$\%$ Habitat remaining (\%) & $82(62-94)$ & $88(61-98)$ & $\mathrm{NS}$ \\
\hline
\end{tabular}


Table 4.5 Summary data and t-test results comparing treatments and controls or disturbed and undisturbed mesocosms (meso) in each geology. Sample size is for each analysis is indicated in parenthesis $(\mathrm{N} / \mathrm{N})$ and grouping variable is indicated in the grouping column. indicated in

\begin{tabular}{lrrl}
$\rho<0.10^{\mathrm{X}}, \rho<0.05^{*}, \rho<0.01^{*}$, & Not significant $(\mathrm{NS})$ & \\
\multicolumn{1}{c}{ Variable (N/N) } & Grouping & Grouping & p-value \\
\hline Erosive (15/9) & Control & Treatment & \\
Mean Abundance (number/meso) & 337 & 406 & $\mathrm{NS}$ \\
Mean Richness ( number/meso) & 13 & 14 & $\mathrm{NS}$ \\
Invertebrate Biomass (mg/meso) & 70 & 66 & $\mathrm{NS}$ \\
Resistant (20/17) & Control & Treatment & \\
Mean Abundance (number/meso) & 269 & 391 & $* *$ \\
Mean Richness (number/meso) & 12 & 14 & $* *$ \\
Invertebrate Biomass (mg/meso) & 14 & 12 & $\mathrm{NS}$ \\
Erosive Controls (5/4) & Undisturbed & Disturbed & \\
Mean Abundance (number/meso) & 333 & 497 & $\mathrm{NS}$ \\
Mean Richness (number/meso) & 13 & 14 & $\mathrm{NS}$ \\
Invertebrate Biomass (mg/meso) & 80 & 56 & $\mathrm{NS}$ \\
Resistant Controls (2/15) & Undisturbed & Disturbed & \\
Mean Abundance (number/meso) & 387 & 392 & $\mathrm{NA}$ \\
Mean Richness (number/meso) & 16 & 14 & $\mathrm{NA}$ \\
Invertebrate Biomass (mg/meso) & 21 & 12 & $\mathrm{NA}$ \\
\hline
\end{tabular}


Table 4.6 Mouthpart structure and food source information. Total and mean invertebrates in each geology. References: Chapman and Demory (1993, CD), Hawkins (1985, H) Hawkins and Sedell (1981, HS), McShaffrey and McCafferty (1988, MM), Karouna and Fuller (1992, KF), Adams (2004, AD).

\begin{tabular}{lrrrrrr}
\hline \multicolumn{1}{c}{ Invertebrate } & $\begin{array}{c}\text { Erosive } \\
\text { Total (mean) }\end{array}$ & $\begin{array}{c}\text { Resistant } \\
\text { Total (mean) }\end{array}$ & $\begin{array}{c}\text { Mouth } \\
\text { Structure }\end{array}$ & $\begin{array}{c}\text { Food } \\
\text { Source }\end{array}$ & Setting & Citation \\
\hline Rhithrogena & $1077(36)$ & $866(23)$ & Brush & Algae & Lab, Cascades & MM, HS \\
Baetis & $543(18.1)$ & $1160(31)$ & Gouge & Algae & Coast Range & CD \\
Paraleptophlebia & $1150(38)$ & $60(2)$ & Brush & Mixed & Lab, Coast R. & CD, KF \\
Glossosoma & $8(\mathrm{NA})$ & $87(2)$ & Gouge & Algae & Coat Range & CD \\
Atenella & 0 & $67(2)$ & Gouge & Mixed & Cascades & H \\
Optioservus & $65(2)$ & $6(\mathrm{NA})$ & Gouge & Algae & Coast Range & CD, AD \\
Drunella & $6(\mathrm{NA})$ & $24(1)$ & Gouge & Algae & Cascades & H \\
\hline
\end{tabular}


Table 4.7 Results of ANOVA analysis and linear models. F values, adjusted $\mathrm{R}^{2}$ and $\mathrm{p}$-values are shown for sediment dose frequency (Dose Freq) and habitat loss (inorganic sediment remaining in mesocosms). Grazing traits are represented as relative abundance (RA). Slope direction indicated by + or - . $\rho<0.10^{x}, \rho<0.05 *, 0.01 * *, 0.001 * * *$, Not significant (NS)

\begin{tabular}{|c|c|c|c|c|}
\hline Variable & $\begin{array}{c}\text { Erosive }(n=29) \\
\text { Dose Freq (F) }\end{array}$ & $\begin{array}{c}\text { Resistant }(n=36) \\
\text { Dose Freq }(F)\end{array}$ & $\begin{array}{l}\text { Erosive }(n=29) \\
\text { Habitat Loss. }\left(\mathrm{R}^{2}\right)\end{array}$ & $\begin{array}{l}\text { Resistant }(\mathrm{n}=36) \\
\text { Habitat Loss }\left(\mathrm{R}^{2}\right)\end{array}$ \\
\hline \multicolumn{5}{|l|}{ Indicator } \\
\hline Abundance & NS & $* * 11.7(-)$ & $* 0.17(-)$ & $* 0.15(-)$ \\
\hline Richness & NS & $+3.6(-)$ & NS & $* 0.10(-)$ \\
\hline Scraper RA & NS & NS & NS & NS \\
\hline Grazer RA & ${ }^{+} 4.1(-)$ & NS & $* * 0.20(-)$ & NS \\
\hline Brush RA & *5.2(-) & NS & $* * 0.18(-)$ & NS \\
\hline Gouge RA & NS & NS & *0.16 (-) & NS \\
\hline
\end{tabular}




\section{Chapter 5 Summary}

The Pacific Coastal region of the Pacific Northwest contains large tracts of economically important forestlands that also serve as critical stream habitat for endangered salmonids. Excessive fine sediment is a major source of habitat degradation in the small streams of this region that are used by salmon for spawning. In order to balance socioeconomic needs with preservation of salmon spawning habitat, environmental managers in the region are working to develop biologic indicators of excessive fine sedimentation that may signal when stream function has been altered due to anthropogenic activities. My dissertation research supports these efforts by quantifying the major sources of temporal and spatial variability known to affect stream invertebrate communities and by proposing specific trait-based indicators that may be useful for sediment monitoring in streams of the Oregon Coast Range, which is located along the western edge of the Pacific Coastal Region.

The research for my dissertation began by evaluating a unique long-term data set collected in the fall and spring from 2005-2013 in two streams of western Oregon. Analysis of long-term patterns in the data revealed that stream invertebrate were highly variable both seasonally and interannually and much of this variance was related to broad-scale climate patterns. These results provide important information for the design and interpretation of biomonitoring programs based on stream invertebrates. The second phase of my research used spatially-balanced data to identify spatial relationships between environmental variables that directly and indirectly affect fine sediment conditions and stream invertebrate communities. The results of this investigation 
demonstrate the importance of accounting for covariance when using stream invertebrates to biomonitor fine sediment conditions. The final investigation for my dissertation utilized the geomorphic heterogeneity of Oregon's Coast Range to experimentally evaluate the effect of geology on invertebrate response to fine sediment addition. In the experimental phase of my dissertation research, I was able to show that invertebrate communities can adapt to naturally high levels of fine sediments that may exist in erodible geologies and thus they respond differently to increased levels of fine sediment in the benthos. The findings of this experiment confirm ecological theory regarding stream invertebrate natural selection and adaptation as well as provide important information for stream mangers attempting to interpret the results of bioassessment studies in regions with high geologic heterogeneity.

While the findings presented in my dissertation support the use of stream invertebrates to biologically monitor for fine sediment, there are several limitations worth considering. First the taxonomic resolution of the temporal study was relatively coarse (family-level) and there were not enough in-stream water chemistry and flow data to assess these components, which are well known to have strong controls on invertebrate communities. In the spatial study, observed relationships between fine sediment and stream invertebrates were correlative and therefore difficult to identify underlying causative or mechanistic relationships. Furthermore, strong covariance of environmental variables across the region increased the likelihood of making false associations between sediment, invertebrates and environmental factors. In the experimental study, colonization time was relatively short, so invertebrates in the mesocosm were generally early instars. Furthermore, the low sample size used when comparing between geologies 
increased the likelihood of a Type II error and thus may underestimate the effect of geology on stream invertebrates. And finally, while a mechanistic explanation of fine sediment sensitivity was supported by the data, no actual gut contents or mouthpart wear were evaluated. Future experiments should include analysis of food consumption and/or mouthpart condition of invertebrate grazers living in high sediment conditions.

The results of my dissertation add to a growing body of research supporting the use of trait-based biological monitoring and provide valuable information regarding the use of stream invertebrates as a biologic indicators of fine sediment conditions in streams of the Oregon Coast Range. For example, invertebrate adaptation to fine sediment may result in the underestimate of benthic sedimentation in erosive basins and overestimate in resistant basins. Furthermore, by accounting for major sources of environmental variation and using trait-based categorization of invertebrate communities, these findings can be extrapolated to other streams within the Pacific Coastal Region. Ultimately, the findings of my dissertation may help stream managers balance socioeconomic demands on the Oregon Coastal forests with the desire to preserve some of the last remaining productive salmon habitat in the region. 


\section{Citations}

Adams JW (2004) Stream bugs as biomonitors: Guide to Pacific Northwest macroinvertebrate monitoring and identification. CD-ROM. Xerces Society.

Allan JD (1975) The diversity and distributional ecology of benthic invertebrates in Cement Creek, Colorado, Ecology 56: 1040-1053.

Allan JD, Johnson LB (1997) Catchment-scale analysis of aquatic ecosystems. Freshwater Biology 37:107-111.

Allan JD, Erickson DL, Fay J (1997) The influence of catchment land use on stream integrity across multiple spatial scales. Freshwater Biology 37:149-162.

Allan JD (2004) Landscapes and Riverscapes: the influence of land use on stream ecosystems. Annual Review of Ecology and Systematics 35:257-284.

Allan JD, Castillo MM (2007) Stream ecology: structure and function of running waters. 2nd Edition. Springer, NY, NY.

Angermeier PL, Karr JR (1994) Biological integrity versus biological diversity as policy directives. BioScience 44: 690-697.

Angradi TR (1996) Inter-habitat variation in benthic assemblage structure, function and organic matter storage in three Appalachian headwater streams. Journal of the North American Benthological Society 15:42-62.

Angradi TR (1999) Fine sediment and macroinvertebrate assemblages in Appalachian streams: a field experiment with biomonitoring applications. The Journal of the North American Benthological Society 18:49-66.

Arens W (1989) Comparative functional morphology of the mouthparts of stream animals feeding on epilithic algae. Archiv für Hydrobiologie. Supplementband. Monographische Beiträge 83.3: 253-354.

Arens W (1990) Wear and tear of mouthparts: a critical problem in stream animals on epilithic algae. Canadian Journal of Zoology. 68: 1897-1914.

Banks JL, Li J, Herlihy AT (2007) Influence of clearcut logging, flow duration, and season on emergent aquatic invertebrates in headwater streams of the Central Oregon Coast Range. The Journal of the North American Benthological Society. 4: 620-632.

Bêche LA, McElravy EP, and Resh VH (2006) Long-term seasonal variation in the biological traits of benthic-macroinvertebrates in two mediterranean-climate streams in California, USA. Freshwater Biology. 51: 56-75. 
Bêche LA, Resh VH (2007a) Short-term climatic trends affect temporal variability of aquatic macroinvertebrates in California "mediterranean" streams. Freshwater Biology. 52: 2317-2339.

Bêche, LA, Resh VH (2007b) Biological traits of benthic macroinvertebrates in California mediterranean-climate streams: long-term annual variability and trait diversity patterns. Fundamental and Applied Limnology/ Archiv fur Hydrobiologie. 169:1-23.

Bêche LA, Connors PG, Resh VH, Merenlender AM (2009) Resilience of fishes and invertebrates to prolonged drought in two California streams. Ecography. 32: 778-788.

Benda LE, Miller DJ, Dunne T, Reeves GH, Agee JK (1998) Dynamic Landscape Systems. Pages 261-288 in R. J. Naiman and R. E. Bilby, editors. River Ecology and Management. Springer-Verlag, New York.

Binkley D and Brown TC (1993) Forest practices as nonpoint sources of pollution in North America. Water Resources Bulletin. 29: 729-740.

Bonada N, Rieradevall M, Prat N (2007) Macroinvertebrate community structure and biological traits related to flow permanence in a Mediterranean river network.

Hydrobiologia. 589: 91-106.

Bond NR, Downes BJ (2003) The independent and interactive effects of fine sediment and flow on benthic invertebrate communities characteristic of small upland streams. Freshwater Biology. 48:455-465.

Bourassa N, Morin A (1995) Relationships between size structure of invertebrate assemblages and trophy and substrate composition in streams. The Journal of the North American Benthological Society. 14:393-403.

Boyero L (2003) The quantification of local substrate heterogeneity in streams and its significance for macroinvertebrate assemblages. Hydrobiologia. 499: 161-168.

Bradley DC, Ormerod J (2001) Community persistenceamong stream invertebrates tracks the North Atlantic Oscillation. Journal of Animal Ecology. 70: 987-996.

Briers RA, Gee JH, Geoghegan R (2004) Effects of the North Atlantic Oscillation on growth and phenology of stream invertebrates. Ecography. 27: 811-817.

Brittain JE, Eikeland TJ (1988) Invertebrate drift: A review. Hydrobiologia. 166: 77-93.

Broekhuizen N, Parkyn S, Miller D (2001) Fine sediment effects on feeding and growth in the invertebrate grazers. Hydrobiologia. 457:125-132. 
Brown BL, Lawson RL (2010) Habitat heterogeneity and activity of an omnivorous ecosystem engineer control stream assemblage dynamics. Ecology. 91:1799-1810.

Buffington JM, Montgomery DR (1999) Effects of hydraulic roughness on surface textures of gravel-bed rivers, Water Resources Research. 35: 3507-3521.

Bunn SE, Hughes JM (1997) Dispersal and recruitment in streams: evidence from genetic studies. Journal of the North American Benthological Society. 16: 388-346.

Burdon FJ, McIntosh AR, Harding JS (2013) Habitat loss drives threshold response of benthic invertebrate communities to deposited sediment in agricultural streams.

Ecological Applications. 23: 1036-1047.

Burt TP, Howden NJK, Worrall F, Whelan MJ (2008) Importance of long-term monitoring for detecting environmental change: lessons from a lowland river in south east England. Biogeosciences. 5: 1529-1535.

Cane MA, Zebiak S (1985) A theory for El Niño and the Southern Oscillation. Science. 228: 1085-1087.

Carlise DM, Meador MR, Moulton II SR, Ruhl PM (2007) Estimation and application of indicator values for common macroinvertebrate genera and families of the United States. Ecological Indicators. 7: 22-23.

Cayan D, Tyree M, Dettinger M, Idalgo HH, As TD, Maurer E, Bromirski P, Graham N, Lick RF (2009) Climate change scenarios and sea level rise estimates for the California 2008 Climate Change Scenarios Assess-ment. CEC-500-2009-014-D. California Climate Change Center, Sacramento, California.

(http://www.energy.ca.gov/2009publications/CEC-500-2009-014/CEC-500-2009-014D.PDF).

Cellot B, Dole-Oliver MJ, Bornette G, Pautou G (1994) Temporal and spatial environmental variability in the Upper Rhone River and its floodplain. Freshwater Biology. 31: 311-325.

Chapman DW, Demory RL (1963) Seasonal changes in the food ingested by aquatic invertebrate larvae and nymphs in two Oregon streams. Ecology. 44: 140-146.

Cheng JD (1988) Subsurface stormflows in the highly permeable forested watersheds of southwestern British Columbia, Journal of Contaminant. Hydrology. 3: 171-191.

Clapcott JE, Young RG, Harding JS, Matthaei CD, Quinn JM, De'ath RG (2011) Sediment Assessment Methods: Protocols a guidelines for assessing the effects of deposited fine sediment on in-stream values. Cawthron Institute, Nelson, New Zealand. 
Collier KJ (2008) Temporal patterns in the stability, persistence and condition of stream macroinvertebrate communities: relationships with catchment land-use and regional climate. Freshwater Biology. 53: 603-616.

Connell JH (1978) Diversity in tropical rainforests and coral reefs. Science. 199: 13021310.

Corkum LD (1992) Spatial distributional patterns of macroinvertebrates along rivers within and among biomes. Hydrobiologia. 239:101-111.

CLAMS (2014) Coastal Landscape and Analysis Study. Website: www.fsl.orst.edu/clams/index.html.

Clements WH (1999) Metal tolerance and predator-prey interactions in benthic macroinvertebrate stream communities. Ecological Application. 9: 1073-1084.

Cline LD, Short RA, Ward JV (1982) Influence of Highway Construction on the Macroinvertebrates and Epilithic Algae of a High Mountain Stream. Hydrobiologia. 96:149-159.

Cole MB, Russell KR, Mabee TJ (2003) Relation of headwater macroinvertebrate communities to in-stream and adjacent stand characteristics in managed second-growth forests of the Oregon Coast Range mountains. Canadian Journal of Forest Research. 33: 1433-1443.

Connell JH, Sousa WP (1983) On the Evidence Needed to Judge Ecological Stability or Persistence. American Naturalist. 121: 789-824.

Cover MR, May CL, Dietrich WE, Resh VH (2008) Quantitative linkages among sediment supply, streambed fine sediment, and benthic macroinvertebrates in northern California streams, Journal North American Benthological Society. 27: 135-149.

Culp JM (1986) Experimental evidence that stream macroinvertebrate community structure is unaffected by different densities of coho salmon fry. Journal of the North American Benthological Society. 5:140-149.

Cummins KW, Klug MJ (1979) Feeding ecology of stream invertebrates. Annual Review of Ecology and Systematics. 10:147-172.

Cummins KW, Merritt RW, Andrade PC (2005). The use of invertebrate functional groups to characterize ecosystem attributes in selected streams and rivers in south Brazil. Studies on Neotropical Fauna and Environment. 40: 69-89.

Davies-Colley RJ, Hickey CW, Quinn JM, Ryan PA (1992) Effects of clay discharges on streams: 1. Optical properties and epilithon. Hydrobiologia. 248:215-234. 
Davies NM, Norris RH, Thoms MC (2000) Prediction and assessment of local stream habitat features using large-scale catchment characteristics. Freshwater Biology. 45: 343369.

De'ath RG, Winterbourn MJ (1994) Environmental stability and community persistence: a multivariate perspective. Journal of the North American Benthological Society 13:125139.

De'ath RG, Winterbourn MJ (1995) Diversity patterns in stream benthic invertebrate communities: the influence of habitat stability. Ecology. 76: 1446-1460.

De la Fuente J, Haessig PA (1993) Salmon Sub-Basin Sediment Analysis, USDA Forest Service, Klamath National Forest. \#96097-9549.

DeNicola DM, Eyto ED, Wemaere A, Irvine K (2006) Periphyton response to nutrient addition in 3 lakes of different benthic productivity. Journal of the North American Benthological Society. 25: 616-631.

Dietrich WE, Kirchner JW, Ikeda H, Iseya F (1989) Sediment supply and the development of the coarse surface layer in gravel-bedded rivers. Nature. 340: 215-217.

Dodds WK, Robinson CT, Gaiser EE, Hansen GJA, Powell H, Smith JM, et al. (2012) Surprises and Insights from Long-Term Aquatic Data Sets and Experiments. BioScience. 62: $709-721$.

Doeg TJ, Milledge GA (1991) Effect of experimentally increasing concentrations of suspended sediment on macroinvertebrate drift. Australian Journal of Marine and Freshwater Research. 42: 519526.

Downes BJ, Lake PS, Schreiber ESG, Glaister A (2000) Habitat structure, resources and diversity: the separate effects of surface roughness and macroalgae on stream invertebrates. Oecologia 123: 569-581.

Durance I, Ormerod SJ (2007) Effects of climatic variation on upland stream invertebrates over a 25 year period. Global Change Biology 13: 942-957.

Elliott JM (1984) Hatching time and growth of Nemurella pictetii (Plecoptera: Nemouridae) in the laboratory and a Lake District stream. Freshwater Biology. 14: 491499.

El-Shaarawi AH, Niculescu SP (1992) On Kendall's tau as a Test of Trend in Time Series data. Environmetrics 3: 385-411. 
Erman DC, Erman NA (1984) The response of stream macroinvertebrates to substrate size and heterogeneity. Hydrobiologia. 108: 75-82.

Erman DC, Ligon FK (1988) Effects of discharge Fluctuation and the addition of fine sediment on stream fish and macroinvertebrates below a water-filtration facility. Environmental Management. 12: 85-97.

Extence CA, Chadd RP, England J, Dunbar MJ, Wood PJ, Taylor ED (2013) The assessment of fine sediment accumulation in rivers using macro-invertebrate community response. River Research and Applications. 29: 17-55.

Feltmate BW, Williams DD (1991) Evaluation of predator-induced stress on field populations of stoneflies (Plecoptera). Ecology 72: 1800-1806.

Fisher SG, Likens GE (1973) Energy flow in Bear Brook, New Hampshire: an integrative approach to stream ecosystem metabolism. Ecol Monographs. 43: 421-39.

Fisher SG, Gray LJ, Grimm NB, Busch DE (1982) Temporal succession in a desert stream ecosystem following flash flooding. Ecological Monographs. 52: 93-110.

Fisher SG, Sponseller RA, Heffernan JB (2004) Horizons in stream biogeochemistry: flowpaths to progress. Ecology. 85: 2369-2379.

Flory EA, Milner AM (2000) Macroinvertebrate assemblage succession in Wolf Point Creek, Glacier Bay National Park, Alaska USA. Freshwater Biology. 44: 465-480.

Forman RTT, Godron M (1981) Patches and structural components for a landscape ecology. Bioscience 31: 733-740.

Frady C, Johnson S, Li J (2007) Stream macroinvertebrate community responses as legacies of forest harvest at the H.J. Andrews Experimental Forest, Oregon. Forest Science. 53: 281-293.

Francoeur SN, Biggs BJF (2006) Short-term effects of elevated velocity and sediment abrasion on periphyton communities. Hydrobiologia. 561: 59-69.

Franklin JF (1987) Importance and justification of LongTerm Studies in Ecology, p. 320. In G.E. Likens (ed.). Long-Term Studies in Ecology: Approaches and Alternatives. Springer-Verlag, New York, USA.

Franklin JF, Dyrness CT (1973) Natural vegetation of Oregon and Washington. U.S.D.A. Forest Service General Technical Report PNW-8. 
Frissell CA, Liss WJ, Warren CE, Hurley MD (1986) A hierarchical framework for stream habitat classification: viewing streams in a watershed context. Environmental Management. 10: 199-214.

Fry J, Xian G, Jin S, Dewitz J, Homer C, Yang L, Barnes C, Herold N, Wickham J (2011) Completion of the 2006 National Land Cover Database for the Conterminous United States, Photogrammetric Engineering and Remote Sensing, Vol. 77: 858-864.

Gasith A, Resh VH (1999) Streams in mediterranean climate regions: abiotic influences and biotic responses to predictable seasonal events. Annual Review of Ecology and Systematics 30: 51-81.

Gibbins CN, Vericat D, Batalla RJ, Gomez CM (2007) Shaking and moving: low rates of sediment transport trigger mass drift of stream invertebrates. Canadian Journal of Fisheries and Aquatic Sciences. 64: 1-5.

Gomi T, Moore RD, Hassan MW (2005) Suspended sediment dynamics of small forest streams of the Pacific Northwest. Journal of the American Water Resources Association. 41: 877-898.

Grant GE, Wolff AL (1991) Long-term patterns of sediment transport after timber harvest, western Cascade Mountains, Oregon, USA. In: Walling DE, Peters N. (eds) Sediment and Stream Water Quality in a Changing Environment, Proceedings of the Vienna IAHS Symposium, International Association of Hydrological Sciences Publ. No. 203, Oxfordshire, U.K.

Gray LJ, Ward JV (1982) Effects of sediment releases from a reservoir on stream macroinvertebrates. Hydrobiologia 96: 177-184.

Griffith MB, Daniel FB, Morrison MA,Troyer ME, Lazorchak JM, Schubauer-Berigan JP (2009) Linking Excess Nutrients, Light, and Fine Bedded Sediments to Impacts on Faunal Assemblages in Headwater Agricultural Streams. JAWRA Journal of the American Water Resources Association. 45: 1475-1492.

Grubaugh JW, Wallace JB, Houston ES (1996) Longitudinal changes of macroinvertebrate communities along an Appalachian stream continuum. Canadian Journal of Fish and Aquatic Science. 53: 896-909.

Gudbergsson G (2004) Arctic charr in Lake Myvatn: the centennial catch record in the light of recent stock estimates. Aquatic Ecology. 38: 271-284.

Hall JD, Cederholm CJ, Murphy ML, Koski KV (2004). Fish-forestry interactions in Oregon, Washington, and Alaska, USA. Pages 365-388 in T.G. Northcote and G.F. Hartman, editors. Fishes and forestry: worldwide watershed interactions and management. Blackwell Science, Oxford, UK. 
Halwas KL, Church M, Richardson JS (2005) Benthic assemblage variation among channel units in high-gradient streams on Vancouver Island, British Colombia. Journal of the North American Benthological Society. 24: 478-494.

Hart DD (1978) Diversity in stream invertebrates: regulation by rock size and microspatial complexity. Verh. Internat. Verein. Linmol. 20: 1376-1381.

Hart DD (1981) Foraging and resource patchiness: field ex- periments with a grazing stream invertebrate. Oikos. 37: 46-52.

Hart DD (1985) Causes and consequences of territoriality in a grazing stream invertebrate. Ecology. 66: 404-414.

Hart DD, Finelli CM (1999) Physical-biological coupling in streams: the pervasive effects of flow on benthic organisms. Annual Review of Ecology and Systematics, 30: 363-395.

Hartman GE (2004) Effects of forest management activities on watershed processes. Pages 271-302 in T.G. Northcote and G.F. Hartman, editors. Fishes and Forestry: Worldwide Watershed Interactions and Management. Blackwell Science, Oxford, UK.

Hassan MA, Church M, Lisle TE, Brardinoni F, Benda L, Grant GE (2005) Sediment transport and channel morphology of small, forested streams. Journal of the American Water Resources Association. 41: 853-876.

Hawkins CP (1985) Food habits of species of Ephemerellid mayflies (Ephemeroptera: Invertebratea) in streams of Oregon. American Midland Naturalist. 343-352.

Hawkins CP, Sedell JR (1981) Longitudinal and seasonal changes in functional organization of macroinvertebrate communities in four Oregon streams. Ecology 62(2): 387-397.

Hawkins CP, Murphy ML, Anderson NH (1982) Effects of canopy, substrate composition, and gradient on the structure of macro-invertebrate communities in Cascade Range streams of Oregon. Ecology. 63:1840-1856.

Hemphill N, Cooper SD (1983) The effect of physical disturbance on the relative abundances of two filter-feeding invertebrates in a small stream. Oecologia. 58, 378-383.

Herlihy AT (1998) Water Chemistry. Pages 57-65 in: J.M. Lazorchak, D.J. Klemm, and D.V. Peck (eds.). Environmental Monitoring and Assessment Program-Surface Waters: Field Operations and Methods for Measuring the Ecological Condition of Wadeable Streams. EPA/620/R-94/004F. U.S. Environmental Protection Agency, Washington, D.C. 
Herlihy AT, Larsen DP, Paulsen SG, Urquhart NS, Rosenbaum BJ (2000) Designing a spatially balanced, randomized site selection process for regional stream surveys: the EMAP Mid-Atlantic pilot study. Environmental Monitoring and Assessment. 63: 95-113.

Herlihy AT, Gerth WJ, Li J, Banks JL (2005) Macroinvertebrate community response to natural and forest harvest gradients in western Oregon headwater streams. Freshwater Biology. 50: 905-919.

Hershey AE, Lamberti GA (1998) Stream macroinvertebrate communities. Pages 169192 in R. E. Bilby and R. J. Naiman, Ecology and management of streams and rivers in the Pacific Northwest coastal regions. Springer, New York.

Hilborn R, Stearns SC (1982) On inference in ecology and evolutionary biology: the problem of multiple causes. Acta Biotheoretica. 31: 145-164.

Hirsch RM, Slack JR, Smith RA (1982) Techniques of trend analysis for monthly waterquality data: Water Resources Research. 18: 107-121.

Holomuzki JR, Biggs BJF (2003) Sediment texture mediates high-flow effects on lotic macroinvertebrates. Journal of the North American Society. 22: 542-553.

Hudson LA, Ciborowski JJ (1996) Spatial and taxonomic variation in incidence of mouthpart deformities in midge larvae (Diptera: Chironomidae: Chironomini). Canadian Journal of Fisheries and Aquatic Sciences. 53: 297-304.

Huryn AD, Wallace JB (1987) Local geomorphology as a determinant of macrofaunal production in a mountain stream. Ecology. 68: 1932-1942.

Huston MA (1979) A general hypothesis of species diversity. American Naturalist. 113: $81-101$.

Irons JG, Oswood MW, Bryant JP (1988) Consumption of leaf detritus by a stream shredder: influence of tree species and nutrient status. Hydrobiologia. 160: 53-61.

Jackson JK, McElravy EP, Resh, VI (1999) Long-term movements of self-marked caddisfly larvae (Trichoptera: Sericostomatidae) in a California coastal mountain stream. Freshwater Biology. 42: 525-536.

Jackson, JK and Füreder L (2006) Long term studies of freshwater macroinvertebrates: A review of the frequency, duration, and ecological significance. Freshwater Biology. 51: 591-603.

Jackson CR, Sturm CA, Ward J (2001) Timber harvest impacts on small headwater channels in the coast ranges of Washington. Journal of American Water Resources Association. 37: 1533-1550. 
Johnson LB, Breneman DH, Richards C (2003) Macroinvertebrate assemblage structure and function associated with large wood in low gradient streams. River Research and Applications. 19: 199-218.

Junk WJ, Bayley PB, Sparks RE (1989) The flood pulse concept in river-floodplain systems. p. 110-127. In D.P. Dodge [ed.] Proceedings of the International Large River Symposium. Canadian Special Publication Fish Aquatic Science. 106.

Kaller MD, Hartman KJ (2004) Evidence of a threshold level of fine sediment accumulation for altering benthic macroinvertebrate communities. Hydrobiologia 518: 95-104.

Karl TR, Melillo JM, Peterson TC (2009) Global Climate Change Impacts in the United States. (eds.). Cambridge University Press, 2009.

Kaufmann PR, Robison EG (1998) Physical Habitat Characterization. Pages 77-118 in J.M. Lazorchak, D.J. Klemm and D.V. Peck, editors. Environmental Monitoring and Assessment Program -- Surface Waters: Field Operations and Methods for Measuring the Ecological Condition of Wadeable Streams. EPA/620/R-94/004F.

Kaufmann PR, Levine P, Peck DV, Robison EG, Seeliger C (1999) Quantifying physical habitat in wadeable streams. Environmental Monitoring and Assessment Program, National Health and Environmental Effects Research Laboratory, Office of Research and Development, US Environmental Protection Agency. http://www.epa.gov/emap/html/pubs/docs/groupdocs/surfwatr/field/phyhab.html

Kaufmann PR, Faustini JM, Larsen DP, Shirazi MA (2008) A roughness-corrected index of relative bed stability for regional stream surveys. Geomorphology. 99: 150-170.

Kaufmann PR, Larsen DP, Faustini JM (2009) Bed Stability and Sedimentation Associated With Human Disturbances in Pacific Northwest Streams1. JAWRA Journal of the American Water Resources Association. 45: 434-459.

Karouna NK, Fuller R L (1992) Influence of four grazers on periphyton communities associated with clay tiles and leaves. Hydrobiologia. 245: 53-64.

Karr JR (1998) Rivers as sentinels: using the biology of rivers to guide landscape management. Pages 502-528 in RJ Naiman, RE Bilby (Editors), River Ecology and Management: Lessons from the Pacific Coastal Ecosystems. Springer, New York.

Kelson KI, Wells SG (1989) Geologic influences on fluvial hydrology and bedload transport in small mountainous watersheds, northern New Mexico, USA. Earth surface processes and landforms. 14: 671-690. 
King RS, Baker ME, Whigham DF, Weller DE, Jordan TE, Kazyak PF, Hurd MK (2005) Spatial considerations for linking watershed land cover to ecological indicators in streams. Ecological Applications. 15: 137-153.

Koetsier P (2005) Response of a stream diatom assemblage to top predator manipulations. Aquatic Sciences 67: 517-527.

Kreutzweiser DP, Capell SS, Good KP (2005) Effects of fine sediment input from a logging road on stream invertebrate communities: a large scale a large-scale experimental approach in a Canadian headwater stream. Aquatic Ecology 39: 55-66.

Lake PS (2000) Disturbance, patchiness, and diversity in streams. Journal of the North American Benthological Society. 19: 573-592.

Lake PS (2003) Ecological effects of perturbation by drought in flowing waters. Freshwater Biology. 48: 1161-1172.

Lamberti GA, Steinman AD (1993) Research in artificial streams: applications, uses, and abuses. Journal of the North American Benthological Society. 313-384.

Lancaster J, Downes BJ (2013) Aquatic Entomology. Oxford University Press.

Lawrence JE, Lunde KB, Mazor RD, Bêche LA, McElravy EP, Resh RV (2010) LongTerm Macroinvertebrate Responses to Climate Change: Implications for Biological Assessment in Mediterranean-Climate Streams. Journal of the North American Benthological Society. 29: 1424-1440.

Larsen S, Ormerod SJ (2010) Low-level effects of inert sediments on temperate stream invertebrates, Freshwater Biology. 55: 476-486.

Larsen S, Vaughan IP, Ormerod SJ (2009) Scale-dependent effects of fine sediments on temperate headwater invertebrates. Freshwater Biology. 54: 203-219.

Larsen S, Pace G, Ormerod SJ (2010) Experimental effects of sediment deposition on the structure and function of macroinvertebrate assemblages in temperate streams. River Research and Applications. 27: 257-267.

Legendre P, Legendre L (1998) Numerical ecology. Second edition. Elsevier, Amsterdam, The Netherlands.

Leibold MA, Holyoak M, Mouquet N, Amarasekare P, Chase JM, Hoopes MF, Hold RD, Shurin JB, Law R, Tilman D, Loreau M, Gonzalez A (2004) The metaassemblage concept: a framework for multi-scale assemblage ecology. Ecology Letters. 7: 601-613. 
Lemly AD (1982) Modification of benthic invertebrate communities in polluted streams: Combined effects of sedimentation and nutrient enrichment: Hydrobiologia. 87: 229-245.

Lenat DR, Penrose DI, Eagleson KW (1981) Variable effects of sediment addition on stream benthos. Hydrobiologia .79: 187-194.

Leopold LB, Wolman MG, Miller JP (1964) Fluvial processes in geomorphology. Courier Dover Publications.

Li J, Johnson S, Sobota JB (2011) Three responses to small changes in stream temperature by autumn-emerging aquatic invertebrates. Journal of the North American Benthological Society. 30: 474-484.

Likens GE, ed. (1989) Long-term studies in ecology: Approaches and alternatives. Springer-Verlag, New York, New York, USA.

Likens, GE (1999) The science of nature, the nature of science: Long-term ecological studies at Hubbard Brook. Proceedings of the American Philosophical Society. 143:558572.

Likens GE, Bormann FH (1974) Acid rain: a serious regional environmental problem. Science. 184: 1176-79.

Logan P, Brooker MP (1983) The macroinvertebrate fauna of riffles and pools. Water Research. 17: 263-270.

Luce CH, Black TA (2001) Spatial and Temporal Patterns in Erosion from Forest Roads. Land Use and Watersheds: Human Influence on Hydrology and Geomorphology in Urban and Forest Areas. Water Science and Application. 2: 165-178.

Mantel N (1967) The detection of disease clustering and a generalized regression approach. Cancer research, 27(2 Part 1), 209-220.

Massey FP, Hartley SE (2009) Physical defences wear you down: progressive and irreversible impacts of silica on invertebrate herbivores. Journal of Animal Ecology. 78: 281-291.

Matias MG, Underwood AJ, Hochuli DF, Coleman RA (2010) Independent effects of patch size and structural complexity on diversity of benthic macroinvertebrates. Ecology. 91: 1908-1915.

Matthaei CD, Peacock KA, Townsend CR (1999) Patchy surface stone movement during disturbance in a New Zealand stream and its potential significance for the fauna. Limnol. Oceanogr, 44: 1091-1102. 
Matthaei CD, Weller F, Kelly DW, Townsend CR (2006) Impacts of fine sediment addition to tussock, pasture, dairy and deer farming streams in New Zealand. Freshwater Biology. 51: 2154-2172.

Mattingly RL (1987) Handling of coarse and fine particulate organic matter by the aquatic invertebrates Paraleptophlebia gregalis and P. temporalis (Ephemeroptera: Leptophlebiidae). Freshwater Biology. 18: 255-265.

May CL (2002) Debris flows through different forest age classes in the central Oregon Coast Range. Journal of the American Water Resources Association. 38: 1097-1113.

Mazor R, Purcell A, Resh VH (2009) Long-term variability in benthic macroinvertebrate bioassessments: A 20-year study from two northern Californian streams. Environmental Management. 43: 1269-1286.

McCabe GJ, Wolock DM (2002) A step increase in streamflow in the conterminous United States, Geophysical Research Letters. 29: 2185-2188.

McClelland WT, Brusven MA (1980) Effects of sedimentation on the behavior and distribution of riffle invertebrates in a laboratory stream. Aquatic Invertebrates. 2:161169.

McElravy, EP, Lamberti GA, Resh VH (1989) Year-to-year variation in the aquatic macroinvertebrate fauna of a northern California stream. Journal of the North American Benthological Society. 8: 51-63.

McClain ME, Bilby RE, Triska FJ (1998) Nutrient Cycles and Responses to Disturbance, in River Ecology and Management: Lessons from the Pacific Coastal Ecoregion, edited by R. J. Naiman and R. E. Bilby, Springer-Verlag, New York.

McCune B, Grace JB (2002) Analysis of Ecological Communities. MJM Publishers, Gleneden Beach, OR.

McShaffrey D, McCafferty WP (1988) Feeding behavior of Rhithrogena pellucida (Ephemeroptera: Heptageniidae). Journal of the North American Benthological Society. 87-99.

Merritt RW, Cummins KW (2006) Trophic relationships., pp. 585-610. In: Hauer, F. R. and G. A. Lamberti (eds.). Methods in Stream Ecology (2nd ed.).

Metro (2001) Regional Land Information System (RLIS). Accessed September 2012. http://www.metro.dst.or.us/index.cfm/go/by.web/id=505. 
Milner AM, Conn SC, Brown LE (2006) Persistence and stability of macroinvertebrate communities in streams of Denali National Park, Alaska: implications for biological monitoring. Freshwater Biology. 51: 373-387.

Milner AM, Robertson AE, Monaghan K, Veal AJ, Flory EA (2008) Colonization and development of a stream assemblage over 28 years; Wolf Point Creek in Glacier Bay, Alaska. Frontiers in Ecology and the Environment. 6: 413-419.

Minshall GW, Minshall JN (1977) Microdistribution of benthic invertebrates in a Rocky Mountain. (U.S.A.) stream. Hydrobiologia. 55: 231-249.

Minshall GW, Petersen RC, Cummins KW, Bott TL, Sedell JR, Cushing CE, Vannote RL (1983) Interbiome comparison of stream ecosystem dynamics. Ecol. Monogr. 53: 125 .

Minshall GW, Petersen RC (1985) Towards a theory of Macroinvertebrate. Assemblage Structure in Stream Ecosystems. Arch. Hydrobiol. 104: 49-76.

Minshall GW, Petersen RC, Nimz CF (1985) Species richness in streams of different size from the same drainage basin. American Naturalist. 125: 16-38.

Minshall GW, Royer TV, Robinson CT (2001) Response of the Cache Creek macroinvertebrates during the first 10 years following disturbance by the 1988 Yellowstone wildfires. Canadian Journal of Fisheries and Aquatic Sciences. 58: 10771088.

Minshall GW (2003) Responses of stream benthic macroinvertebrates to fire.Forest Ecology and Management. 178: 155-161.

Molles Jr, MC (1982) Trichopteran communities of streams associated with aspen and conifer forests: long-term structural change. Ecology. 63:1-6.

Montgomery DR, Buffington JM (1997) Channel-reach morphology in mountain drainage basins. Geological Society of America Bulletin. 109: 596-611.

Montgomery DR, Schmidt KM, Greenberg H, Dietrich WE (2000) Forest clearing and regional landsliding: Geology. 28: 311-314.

Mote PW, Parson EA, Hamlet AF, Ideker KN, Keeton WS, Lettenmaier DP, Mantua NJ, Miles EL, Peterson DW, Peterson DL, Slaughter R, Snover AK (2003) Preparing for climatic change: The water, salmon, and forests of the Pacific Northwest. Climatic Change 61: 45-88. 
Naiman RJ, Bilby RE (1998) River ecology and management in the Pacific coastal ecoregion. Pages 1-10 in Naiman RJ, Bilby RE (Editors). River Ecology and Management: Lessons from the Pacific Coastal Ecoregion. Springer, New York.

Naiman RJ, Fetherston KL, McKay S, Chen J (1998) Riparian forests. Pages 289-323, in Naiman RJ and Bilby RE (Editors). River Ecology and Management: Lessons from the Pacific Coastal Ecoregion. Springer, New York.

Naiman RJ, Bilby RE, Bisson PA (2000) Riparian ecology and management in the Pacific coastal rain forest. BioScience. 50: 996-1011.

Naymik J, Pan Y, Ford J (2005) Diatom assemblages as indicators of timber harvest effects in coastal Oregon streams. Journal of The North American Benthological Society. 24: 569-584.

Nehlsen W, Williams JE, Lichatowich JA (1991) Pacific salmon at the crossroads: stocks at risk from California, Oregon, Idaho, and Washington. Fisheries. 16: 4-21.

O'Connor JE, Mangano JF, Anderson SW, Wallick JR, Jones KL, and Keith MK (2014). Geologic and physiographic controls on bed-material yield, transport, and channel morphology for alluvial and bedrock rivers, western Oregon. Geological Society of America Bulletin, B30831-1.

Obernborfer RY, Vaun McArthur J, Barnes JR, Dixon J (1984) The Effect of Invertebrate Predators on Leaf Litter Processing in an Alpine Stream. Ecology. 65: 1325-1331.

OPSW (2003) Oregon Plan for Salmon and Watersheds Monitoring Strategy Overview. Oregon Watershed Enhancement Board. Available:

http://www.oregon.gov/OWEB/docs/pubs/MonitoringStrategy.pdf.

Orians GH (1980) Micro and Macro in ecological theory. Bioscience 30:79.

Parkhill KL, Gulliver JS (2002) Effect of inorganic sediment on whole-stream productivity. Hydrobiologia. 472: 5-17.

Parsons M, Thoms MC, Norris RH (2003) Scales of macroinvertebrate distribution in relation to the hierarchical organization of river systems. Journal North American Benthological Society. 22: 105-122.

Paulsen SG, Mayio A, Peck DV, Stoddard JL, Tarquinio E, Holdsworth SM,Van Sickle J, Yuan LL, Hawkins CP, Herlihy AT, Kaufmann PR, Barbour MT, Larsen DP, Olsen AR (2008) Condition of stream ecosystems in the US: an overview of the first national assessment. Journal of the North American Benthological Society. 27: 812-821. 
Peeters E, Brugmans J, Beijer AJ, Franken RJM (2006) Effect of silt, water and periphyton quality on survival and growth of the mayfly Heptagenia sulphurea. Aquatic Ecology. 40: 373-380.

Pickett STA, White PS (1985) The Ecology of Natural Disturbance and Patch Dynamics. Academic Press, Inc. Orlando, Florida.

Poff NL (1997) Landscape filters and species traits: towards mechanistic understanding and prediction in stream ecology. Journal of the North American Benthological Society 16: 391-409.

Poff NL, Ward JV (1989) Implications of streamflow variability and predictability for lotic assemblage structure: a regional analysis of streamflow patterns. Canadian Journal of Fisheries and Aquatic Sciences. 46: 1805-1818.

Pollard AI, Yuan LL (2010) Assessing the consistency of response metrics of the invertebrate benthos: a comparison of trait-and identity-based measures. Freshwater Biology. 55: 1420-1429.

Poole GC (2002) Fluvial landscape ecology: Addressing uniqueness within the river discontinuum. Freshwater Biology. 47: 641-660.

Poole GC (2010) Stream hydrogeomorphology as a physical science basis for advances in stream ecology. Journal of the North American Benthological Society. 29: 12-25.

Power ME, Stout RJ, Cushing CE, Harper PP, Hauer FR, Matthews WJ, Moyle PB, Statzner B, Wais de Badgen IR (1988) Biotic and abiotic controls in river and stream communities. Journal of the North American Benthological Society. 7: 456-479.

Pringle CM (1985) Effects of chironomid (Invertebratea: Diptera) tube-building activities of stream diatom communities. Journal of Phycology. 21: 185-194.

Pringle CM, Bowers J (1984) An in situ substratum fertilization technique: Diatom colonization on nutrient-enriched sand substrata. Canadian Journal of Fisheries and Aquatic Sciences 41: 1247-1251.

Pringle CM, Naiman RJ, Bretschko G, Karr J, Oswood M, Webster J, Welcomme R, Winterbourn MJ (1988) Patch dynamics in lotic systems: The stream as a mosaic. Journal of the North American Benthological Society. 7: 503-524.

Quinn JM, Hickey CW (1990) Characterisation and classification of benthic invertebrate communities in $88 \mathrm{New}$ Zealand rivers in relation to environmental factors. New Zealand Journal of Marine and Freshwater Research. 24: 411-427. 
Quinn JM, Davies-Colley RJ, Hickey CW, Vickers ML, Ryan PA (1992) Effects of clay discharges on streams 2. Benthic invertebrates. Hydrobiologia. 248: 235-247.

Rabeni CF, Minshall GW (1977) Factors affecting microdistribution of stream benthic invertebrates. Oikos 29: 33-43.

Rabeni CF, Doisy KE, Zweig LD (2005) Stream invertebrate assemblage functional responses to deposited sediment. Aquatic Science. 67: 395-402.

Reece PF, Reynoldson TB, Richardson JS, Rosenberg DM (2001) Implications of seasonal variation for biomonitoring with predictive models in the Fraser River catchment, British Columbia. Canadian Journal of Fisheries and Aquatic Sciences. 58: $1411-1418$.

Relyea C, Minshall GW, Danehy R (2000) Stream Invertebrates as Bioindicators of Fine Sediment, Stream Ecology Center, Department of Biological Sciences, Idaho State University. Watershed Management 2000 Conference.

Relyea CD, Minshall GW, and Danehy RJ (2012) Development and validation of an aquatic fine sediment biotic index. Environmental Management. 49: 242-252.

Resh VH (1992) Year-to-year changes in the age structure of a caddisfly population following loss and recovery of a springbrook habitat. Ecography. 15: 314-317.

Resh VH, Brown AV, Covich AP, Gurtz ME, Li HW, Minshall GW, Reice SR, Sheldon AL, Wallace JB, Wissmar RC (1988) The role of disturbance in stream ecology. Journal of the North American Benthological Society. 7: 433-455.

Resh VH, Bêche L, Lawrence J, Mazor R, McElravy EP, Purcell AP, Carlson SM (2013) Long-term population and community patterns of benthic macroinvertebrates and fishes in northern California Mediterranean-climate streams. Hydrobiologia. 719: 93-118.

Rice SP, Greenwood MT, Joyce CB (2001) Macroinvertebrate assemblage changes at coarse sediment recruitment points along two gravel bed rivers. Water Resources Research. 37: 2793-2803.

Rice RM, Ziemer RR, Lewis J (2004) Evaluating forest management effects on erosion, sediment, and runoff: Caspar Creek and northwestern California. A century of forest and wildland watershed lessons. Society of American Foresters, Bethesda, MD, 223-238.

Richards C, Bacon KL (1994) Influence of fine sediment on macroinvertebrate colonization of surface and hyporheic stream substrates. Great Basin Naturalist. 54: 106113. 
Richards C, Host GE, Arthur JW (1993) Identification of predominant environmental factors structuring stream macroinvertebrate communities within a large agricultural catchment. Freshwater Biology. 29: 285-294.

Richards C, Johnson LB, Host GE (1996) Landscape-scale influences on stream habitats and biota. Canadian Journal of Fisheries and Aquatic Sciences. 53: 295-311.

Richards C, Haro RJ, Johnson LB, Host GE (1997) Catchment and reach-scale properties as indicators of macroinvertebrate species traits. Freshwater Biology. 37: 219-230.

Richardson JS, Danehy RJ (2007) Synthesis of the ecology of headwater streams and their riparian zones in temperate forests. Forest Science. 53: 131-147.

Rier ST, King DK (1996) Effects of inorganic sedimentation and riparian clearing on benthic assemblage metabolism in an agriculturally-disturbed system. Hydrobiologia. 339: 111-121.

Robinson CT, Minshall GW and Royer TV (2000) Inter-annual patterns in macroinvertebrate communities of wilderness streams in Idaho, USA. Hydrobiologia. 421: 187-198.

Rosalie B, Resh VH (2000) Invertebrates in intermittent and perennial streams: Is the hyporheic zone a refuge from drying? Journal of the North American Benthological Society 19: 680-696.

Rosemond AD, Reice SR, Elwood JW, Mulholland PJ (1992). The effects of stream acidity on benthic invertebrate communities in the south-eastern United States. Freshwater Biology. 27: 193-209.

Roy AH, Rosemond AD, Leigh DS, Paul MJ, Wallace JB (2003) Habitat-specific responses of stream invertebrates to land cover disturbance: biological consequences and monitoring applications. The Journal of the North American Benthological Society 22: 292-307.

Runde JM, Hellenthal RA (2000a) Effects of suspended particles on net-tending behaviors for Hydropsyche sparna (Trichoptera: Hydropsychidae) and related species. Annals of the Entomological Society of America. 93: 678-683.

Runde JM, Hellenthal RA (2000b) Behavioral responses of Hydropsyche sparna (Trichoptera: Hydropsychidae) and related species to deposited bedload sediment. Population Ecology. 29: 704-709.

Ryan JC (1994) State of the Northwest. Northwest Environmental Watch Report Number 1. Seattle, Washington, USA. 
Sabo J, Finlay J, Kennedy T, Post D (2010) The Role of Discharge Variation in Scaling of Drainage Area and Food Chain Length in Rivers. Science. 330: 965-967.

Scarsbrook, M R (2002) Persistence and stability of lotic macroinvertebrate communities in New Zealand. Freshwater Biology. 47: 417-431.

Schloesser DW, Krieger KA, Ciborowski JJH, Corkum LD (2000) Recolonization and possible recovery of burrowing mayflies (Ephemeroptera: Ephemeridae: Hexagenia spp.) in Lake Erie of the Laurentian Great Lakes. Journal of Aquatic Ecosystem Stress and Recovery. 8: 125-141.

Schofield K, Pringle CM, Meyer JL (2004) Effects of increased bedload on algal-and detrital-based stream food webs: experimental manipulation of sediment and macaroconsumers. Limnology and Oceanography. 49: 900-909.

Schumm SA (2005) River Variability and Complexity, Cambridge University Press, New York.

Scullion J, Parish CA, Morgan N, Edwards RW (1982) Comparison of benthic macroinvertebrate fauna and substratum composition in riffles and pools in the impounded River Elan and the unregulated River Wye, mid-Wales. Freshwater Biology. 12: 579-595.

Shaw EA, Richardson JS (2001) Direct and indirect effects of sediment pulse duration on stream invertebrate assemblages and rainbow trout (Oncorhynchus mykiss) growth and survival. Canadian Journal of Fisheries and Aquatic Sciences. 58: 2213-2221.

Shearer KA, Young RG (2011) Influences of geology and land use on macroinvertbrate communities across the Motueka River catchment, New Zealand. New Zealand Journal of Marine and Freshwater Research. 45: 437-454.

Spies TA, Johnson KN (2007) Projecting Forest Policy and Management Effects across Ownerships in Coastal Oregon. Ecological Applications. 17:3-4.

Spies TA, Johnson KN, Burnett KM, Ohmann JL, McComb BC, Reeves GH, Bettinger P, Kline JD, Garber-Yonts B (2007) Cumulative Ecological and Socioeconomic Effects of Forest Policies in Coastal Oregon. Ecological Applications. 17: 5-17.

Sponseller RA, Benfield EF, Valett HM (2001) Relationships between land use, spatial scale and stream macroinvertebrate communities. Freshwater Biology. 46: 1409-1424.

Stanford JA, Ward JV (1983) Invertebrate species diversity as a function of environmental variability and disturbance in stream systems. In JR Barnes and GW Minshall (Eds.). Stream ecology: application and testing of general ecological theory, pp. 265-278. New York Plenum. 
Stanley EH, Boulton AJ (1993) Hydrology and the distribution of hyporheos: perspectives from a mesic river and a desert stream. Journal of the North American Benthological Society. 12: 79-83.

Statzner B, Gore JA, Resh VH (1988) Hydraulic stream ecology: observed patterns and potential application. Journal of the North American Benthological Society. 7 :307-360.

Stone MK, Wallace JB (1998) Long-term recovery of a mountain stream from clear-cut logging: the effects of forest succession on benthic invertebrate community structure. Freshwater Biology. 39: 151-169.

Suren AM (2005) Effects of Deposited Sediment on Patch Selection by two Grazing Stream Invertebrates. Hydrobiologia. 549: 205-218.

Suttle KB, Power ME, Levine JM, McNeely C (2004) How fine sediment in riverbeds impairs growth and survival of juvenile salmonids. Ecological Applications. 14: 969974.

Swanson FJ, Brenda LE, Duncan SH, Grant GE, Megahan WF, Reid LM, Ziemer RR (1987) Chapter 2. Mass failures and other processes of sediment production in Pacific Northwest forest landscapes. In: Salo EO, T.W. Cundy, editors. Streamside Management. Forestry and Fishery Interactions. University of Washington, Institute of Forest Resources, Contribution 57: 9-38.

Thompson RM, Lake PS (2010) Reconciling theory and practise: The role of stream ecology. River Research and Applications. 26: 5-14.

Thorp JH, Bergey EA (1981) Field experiments on responses of a freshwater benthic macroinvertebrate assemblage to vertebrate predators. Ecology. 62: 365-375.

Thorp JH, Thoms MC, Delong MD (2006) The riverine ecosystem synthesis: biocomplexity in river networks across space and time. River Research and Applications. 22: $123-147$.

Thorp JH, Thoms MC, Delong MD (2008) The riverine ecosystem synthesis. Academic Press, Boston, MA, USA.

Townsend CR (1989) The patch dynamics concept of stream assemblage ecology. Journal of the North American Benthological Society. 8: 36-50.

Townsend CR, Scarsbrook MR (1997) The intermediate disturbance hypothesis, refugia, and biodiversity in streams. Limnology and Oceanography. 42: 938-949. 
Townsend CR, Doledec S, Norris R, Peacock K, Arbuckle C (2003) The influence of scale and geography on relationships between stream assemblage composition and landscape variables: description and prediction. Freshwater Biology. 48: 768-785.

Townsend CR, Hildrew AG (1994). Species traits in relation to a habitat templet for river systems. Freshwater biology. 31: 265-275.

Urban DL (2003) Spatial Analysis in Ecology: Mantel's Test. Unpublished. Available: www.nceas.ucsb.edu/files/scicomp/doc/SpatialEcologyMantelTest.pdf Retrieved September 2013.

USEPA: US Environmental Protection Agency (2006) Wadeable Streams Assessment: a collaborative survey of the Nation's streams. EPA/641/B-06/002. Office of Water, US Environmental Protection Agency, Washington, DC.

USGS: United States Geologic Survey (2104). StreamStats Program. Accessed May 2014. water.usgs.gov/osw/streamstats/

Usseglio-Polatera P, Tachet H (1994) Theoretical habitat templets, species traits, and species richness: Plecoptera and Ephemeroptera in the Upper Rhône River and its floodplain. Freshwater Biology. 31: 357-375.

Vannote RL, Sweeney BW (1980) Geographical analysis of thermal equilibria: a conceptual model for evaluating the effect of natural and modified thermal regimes on aquatic invertebrate communities. American Naturalist. 115: 667-695.

Vannote RL, Minshall GW, Cummins KW, Sedell KR, Cushing CE (1980) The River Continuum Concept. Canadian Journal of Fisheries and Aquatic Sciences. 37: 130-137.

Vieira NKM, Poff NL, Carlisle DM, Moulton II SR, Koski MK, Kondratieff BC (2006) A database of lotic invertebrate traits for North America: U.S. Geological Survey Data Series 187. Available: http://pubs.water.usgs.gov/ds187.

Vinson MR (2001) Long-term dynamics of an invertebrate assemblage downstream from a large dam. Ecological Applications. 11: 711-730.

Vinson MR, Hawkins CP (1998) Biodiversity of stream invertebrates: variation at local, basin, and regional spatial scales. Annual Review of Entomology. 43: 271-293.

Walde SJ, (1986) Effect of an abiotic disturbance on a lotic predator-prey interaction. Oecologia. 69: 243-247.

Walker GW, MacLeod NS (1991) Geologic Map of Oregon: U.S. Geological Survey, Reston, Virginia. 
Walker GW, MacLeod NS, Miller RJ, Raines GL, Connors KA (2003) Spatial digital database for the geologic map of Oregon: U.S. Geological Survey Open-File Report 0367, U.S. Geological Survey, Menlo Park, California.

Wallace JB, Webster JR (1996) The role of macroinvertebrates in stream ecosystem function. Annual Review of Entomology. 41: 115-139.

Wallace JB, Webster JR, Meyer JL (1995) Influence of log additions on physical and biotic characteristics of a mountain stream. Canadian Journal of Fisheries and Aquatic Sciences 52:2120-2137.

Ward JV, Stanford JA (1982) Thermal responses in the evolutionary ecology of aquatic invertebrates, Annual Review of Entomology and Systematics. 27: 97-117.

Ward JV, Stanford JA (1983) The intermediate-disturbance hypothesis: an explanation for biotic diversity patterns in lotic ecosystems. In: Bartell, S and Fontaine, T. (Editors), Dynamics of lotic ecosystems. Ann Arbor Science, Ann Arbor, MI.

Ward JV, Tockner K, Arscott DB, Claret C (2002) Riverine landscape diversity. Freshwater Biology. 47: 517-539.

Waters TF (1962) Diurnal periodicity in the drift of stream invertebrates. Ecology. 42: 532-537.

Waters TF (1995) Sediment in Streams: Sources, Biological Effects, and Control, American Fisheries Society, Bethesda USA.

Weilhoefer CL, Pan Y (2006) Diatom assemblages and their associations with environmental variables in Oregon coastal streams, USA. Hydrobiologia. 561: 207-219.

Wiens JA (2002) Riverine landscapes: taking landscape into the water. Freshwater Biology. 47: 501-516.

Wilcock PR (1998) Two-fraction model of initial sediment motion in gravel-bed rivers. Science. 280: 410-412.

Williams DD, Mundie JG (1978) Substrate size selection by stream invertebrates and the influence of sand. Limnology and Oceanography. 23: 1030-1033.

Winemiller KO, Flecker AS, Hoeinghaus DJ (2010) Patch dynamics and environmental heterogeneity in lotic ecosystems. Journal of the North American Benthological Society. 29: 84-99.

Wischmeier WH (1976) Use and misuse of the universal soil loss equation. Journal of Soil and Water Conservation. 31: 5-9. 
Wise DR, Johnson HM (2011) Surface-water nutrient conditions and sources in the United States Pacific Northwest: Journal of the American Water Resources Association, online 22 Aug 2011 in advance of print, 26 p. doi: 10.1111/j.1752-1688.2011.00580x

Wolter K, Timlin MS (2011) El Niño/Southern Oscillation behaviour since 1871 as diagnosed in an extended multivariate ENSO index (MEI.ext). International Journal of Climatology. 31: 1074-1087.

Wood PJ, Armitage PD (1997) Biological effects of fine sediment in the lotic environment. Environmental Management. 21: 203-217.

Zweig LD, Rabeni CF (2001) Biomonitoring for deposited sediment using benthic invertebrates: a test on four Missouri streams. The Journal of the North American Benthological Society. 20: 643-657. 


\section{Appendix: Supplementary Data and Images}

Appendix A1: Boxplots of environmental data for both resistant and erosive basins and streams in the Oregon Coast Range study area.
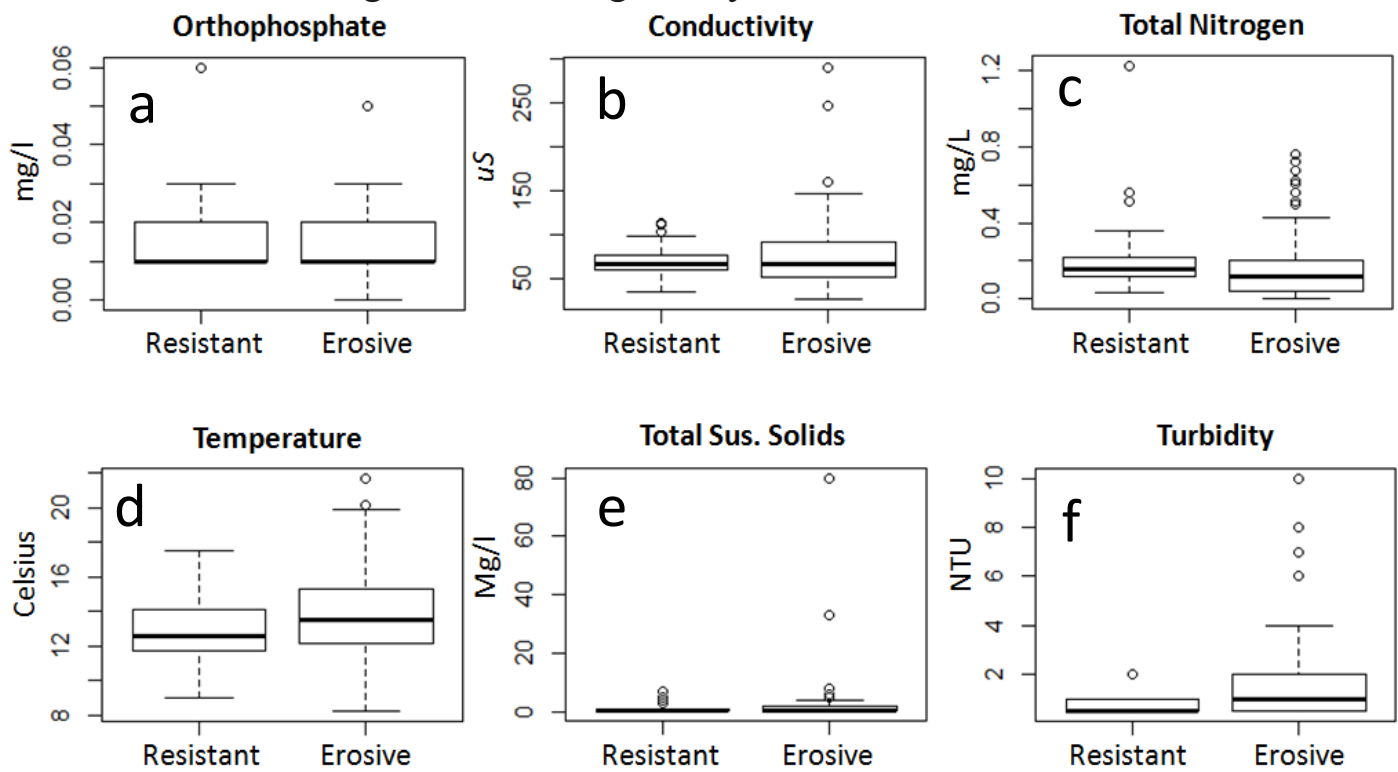
Appendix A2: Boxplots of environmental data for both resistant and erosive basins and streams in the Oregon Coast Range study area.
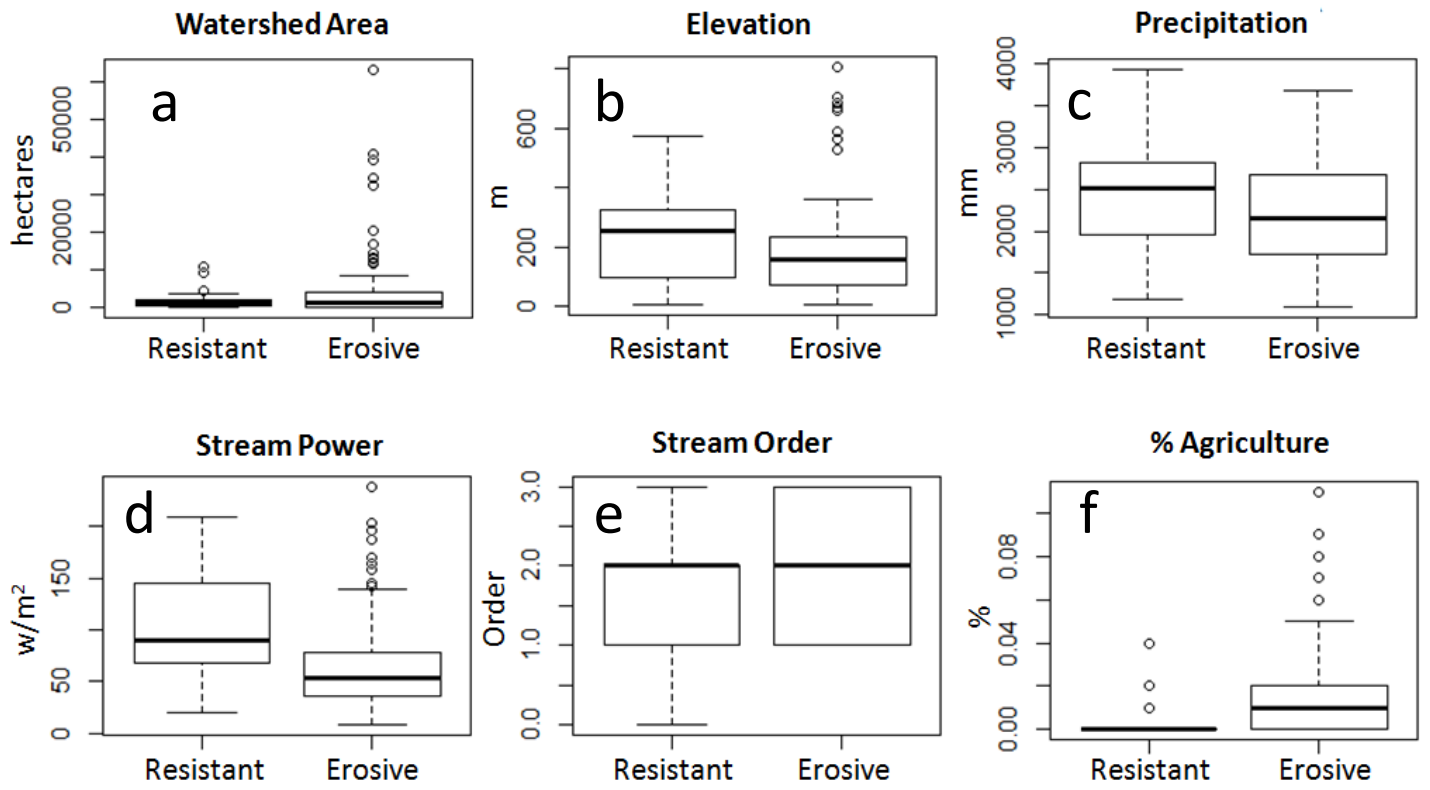
Appendix A3: Boxplots of environmental data for both resistant and erosive basins and streams in the Oregon Coast Range study area.
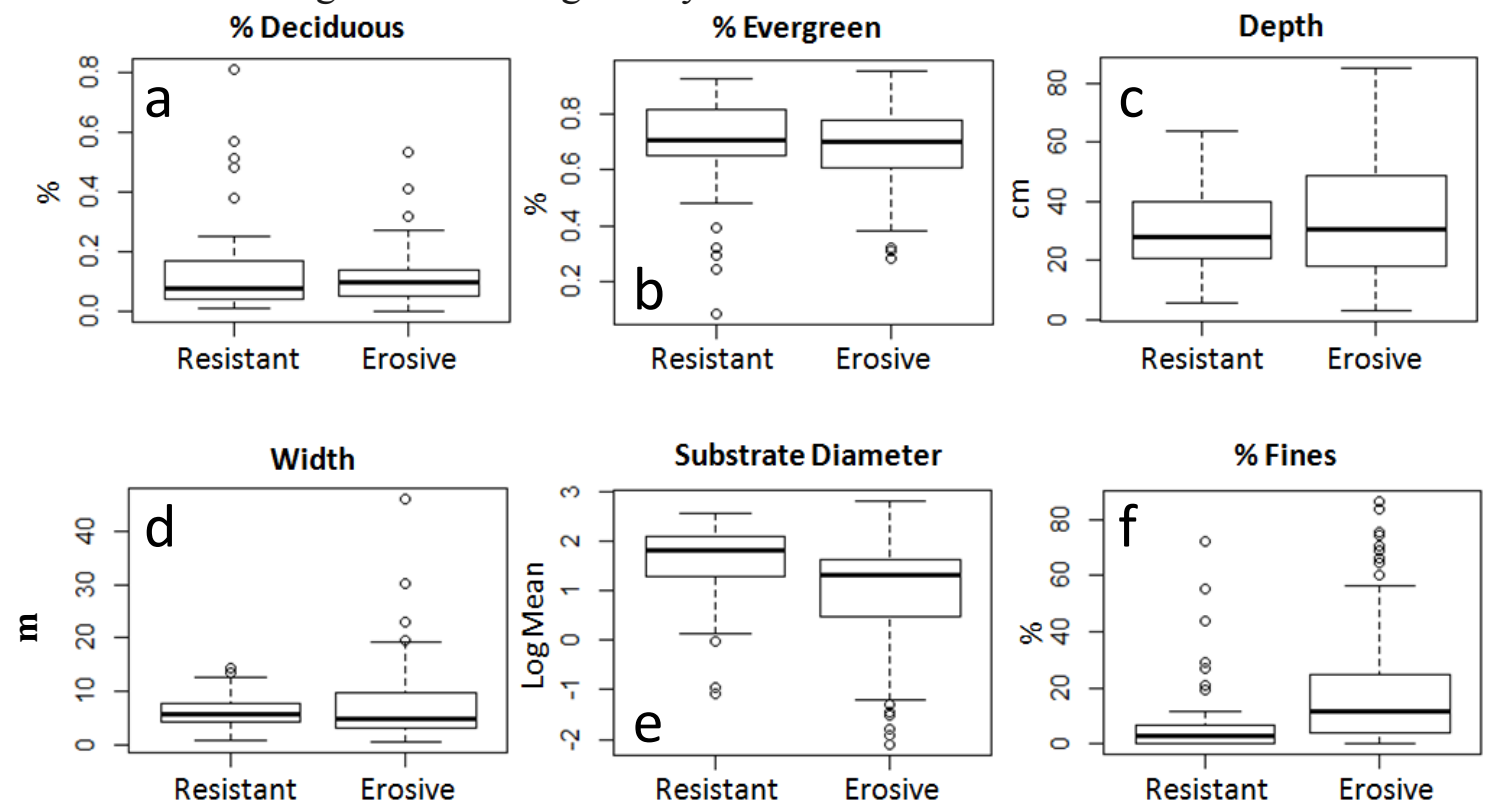
Appendix A4: Boxplots of environmental data for both resistant and erosive basins and streams in the Oregon Coast Range study area.
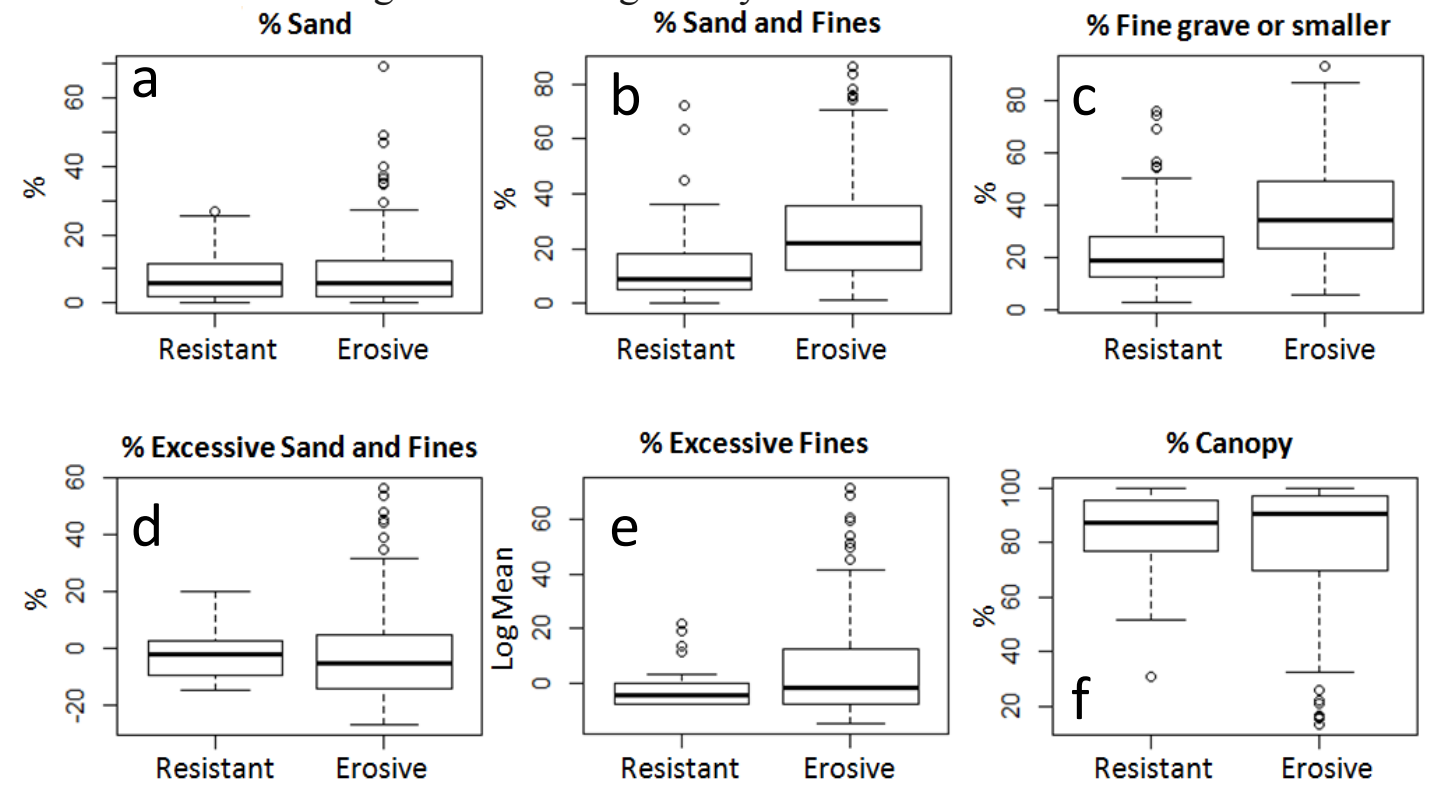
Appendix A5: Boxplots of environmental data for both resistant and erosive basins and streams in the Oregon Coast Range study area.

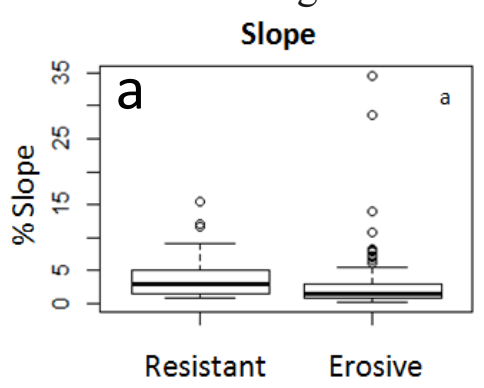

Logging (low. Frag.)

Reach Human Dist.
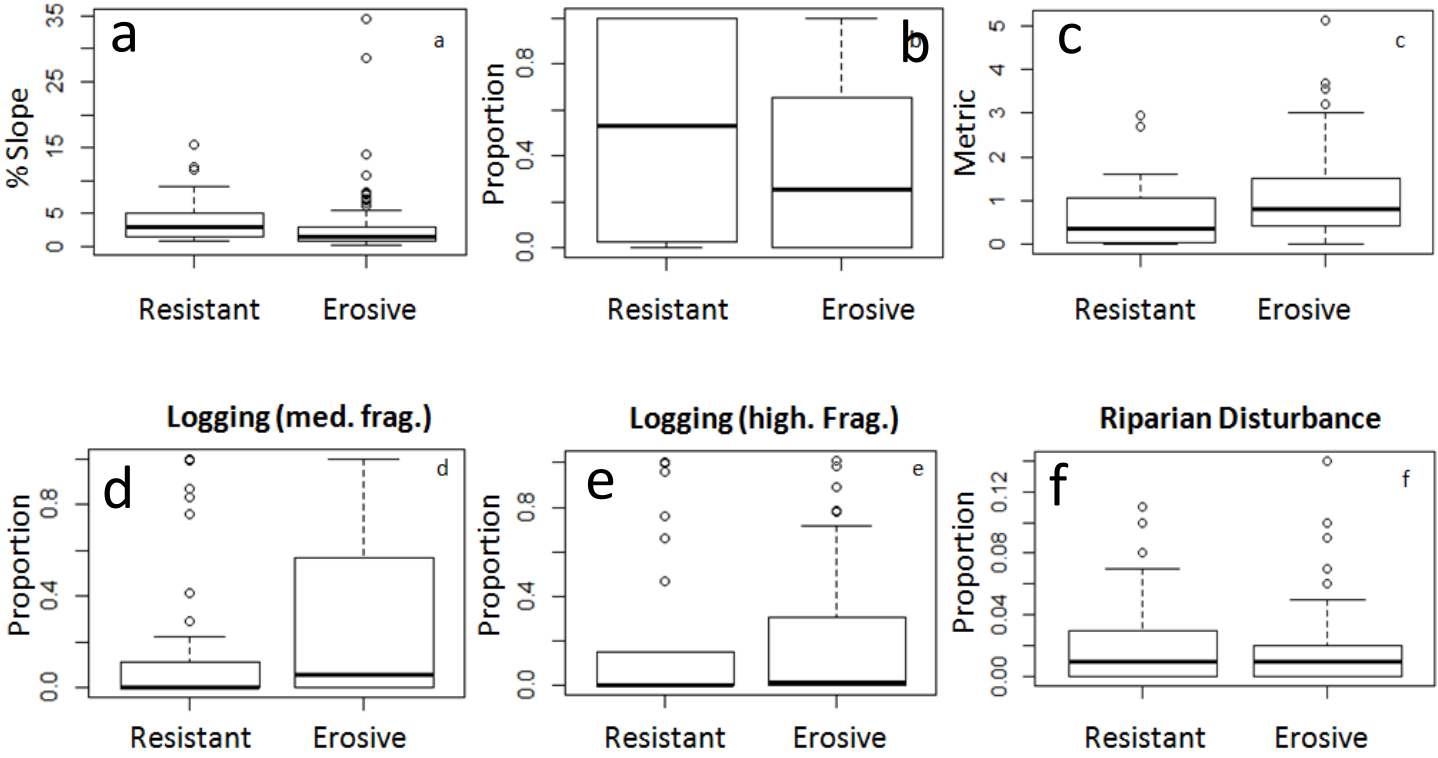
Appendix A6: Boxplots of environmental data for both resistant and erosive basins and streams in the Oregon Coast Range study area.
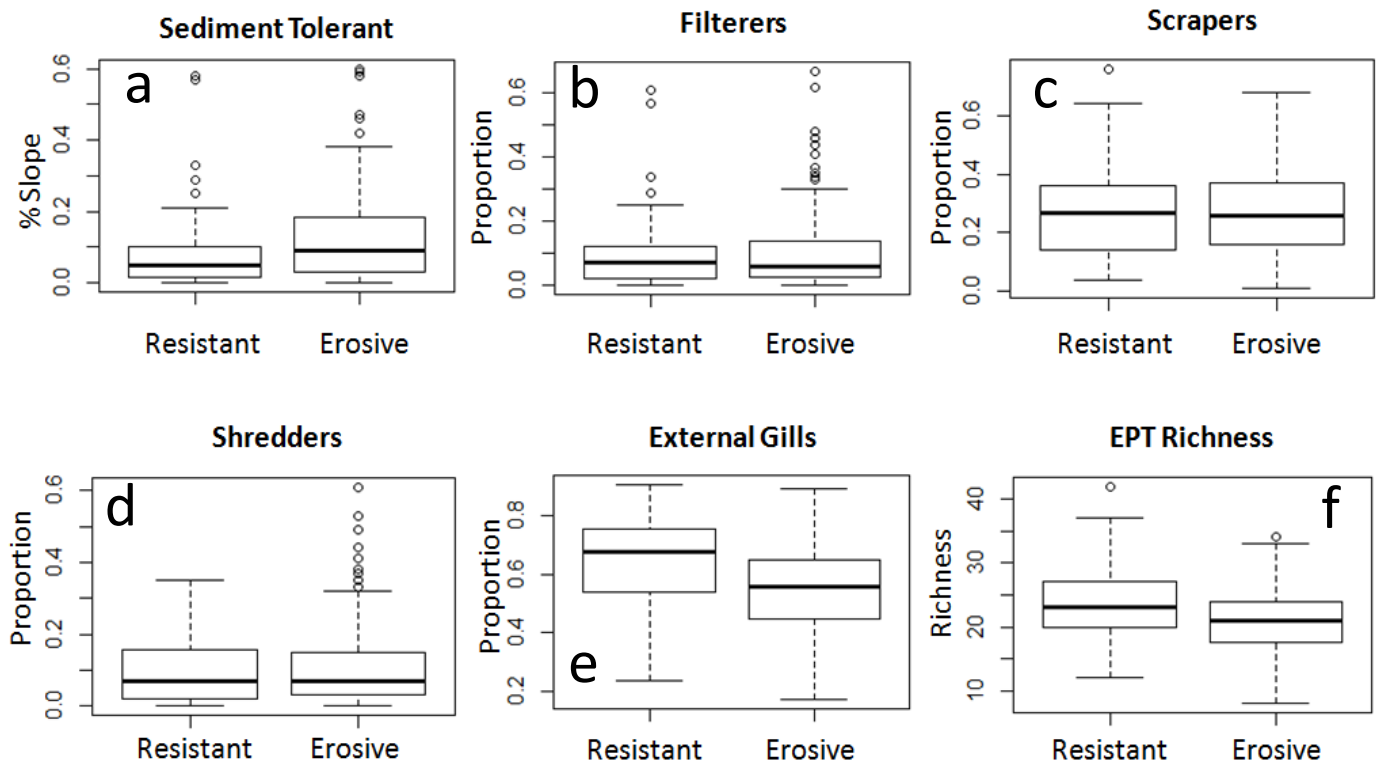
Appendix A7: Ten most abundant invertebrates in the Oregon Coast Range

\begin{tabular}{lllccccc}
\hline Order & \multicolumn{1}{c}{ Taxa } & Family (common name) & $\begin{array}{c}\text { Total Counts } \\
\text { (\% Rel. Abun.) }\end{array}$ & $\begin{array}{c}\text { s } \\
\text { sites }\end{array}$ & $\begin{array}{c}\text { Min } \\
\text { RA }\end{array}$ & $\begin{array}{c}\text { Median } \\
\text { RA }\end{array}$ & $\begin{array}{c}\text { Max } \\
\text { RA }\end{array}$ \\
\hline & & & & & & & \\
Diptera & Chironominae & Chironomidae (Midge) & $12272(13 \%)$ & 213 & 0 & 0.10 & 0.58 \\
mayfly & Baetis & Baetidae (Sm. Minnow) & $8686(9 \%)$ & 200 & 0 & 0.06 & 0.56 \\
Diptera & Orthocladiinae & Chironomidae (Midge) & $8210(8 \%)$ & 204 & 0 & 0.06 & 0.46 \\
Diptera & Simulium & Simuliidae (Black Fly) & $4366(5 \%)$ & 124 & 0 & 0.007 & 0.59 \\
Stonefly & Zapada & Nemouridae (Forestfly) & $4074(4 \%)$ & 159 & 0 & 0.02 & 0.48 \\
Caddis & Rhyacophila & Rhyacophilidae (Gr. R. W.) & $3604(4 \%)$ & 197 & 0 & 0.04 & 0.30 \\
Beetle & Optioservus & Elmidae (Riffle Beetle) & $3453(4 \%)$ & 116 & 0 & 0.04 & 0.59 \\
Caddis & Glossossoma & Glossossomatidae (S. Cse) & $2599(3 \%)$ & 141 & 0 & 0.03 & 0.20 \\
Mayfly & Rithrogena & Heptageniidae (Flat head) & $2514(3 \%)$ & 108 & 0 & 0.004 & 0.28 \\
Stonefly & Sweltsa & Chloroperlidae (Lt. Green) & $2337(2 \%)$ & 160 & 0 & 0.01 & 0.26 \\
& & & & & & & \\
\hline
\end{tabular}


Appendix A8: Five most common mayfly genera

\begin{tabular}{|c|c|c|c|c|c|c|}
\hline Order & Taxa & Family (common name) & $\begin{array}{c}\text { \# sites } \\
(n=214)\end{array}$ & $\begin{array}{c}\text { Min } \\
\text { RA }\end{array}$ & $\begin{array}{c}\text { Median } \\
\text { RA }\end{array}$ & $\begin{array}{c}\text { Max } \\
\text { RA }\end{array}$ \\
\hline mayfly & Baetis & Baetidae (Sm. Minnow) & 200 & 0 & 0.06 & 0.56 \\
\hline mayfly & Rithrogena & Heptageniidae (Flat head) & 108 & 0 & 0.004 & 0.30 \\
\hline mayfly & Cinygmula & Heptageniidae (Flat head) & 118 & 0 & 0.006 & 0.16 \\
\hline mayfly & Paraleptophlebia & Leptophlebiidae (Prong Gill) & 116 & 0 & 0.005 & 0.15 \\
\hline mayfly & Drunella & Ephemerillidae (Spiny Crwler) & 88 & 0 & 0.002 & 0.20 \\
\hline
\end{tabular}


Appendix A9: Five most common stonefly genera

\begin{tabular}{|c|c|c|c|c|c|c|}
\hline Order & Taxa & Family (common name) & $\begin{array}{c}\text { \# sites } \\
(n=214)\end{array}$ & $\begin{array}{l}\text { Min } \\
\text { RA }\end{array}$ & $\begin{array}{c}\text { Median } \\
\text { RA }\end{array}$ & $\begin{array}{c}\text { Max } \\
\text { RA }\end{array}$ \\
\hline Stonefly & Zapada & Nemouridae (Forestfly) & 159 & 0 & 0.02 & 0.48 \\
\hline Stonefly & Sweltsa & Chloroperlidae (Lt. Green) & 160 & 0 & 0.01 & 0.26 \\
\hline Stonefly & Malenka & Nemouridae (Forestfly) & 89 & 0 & 0.002 & 0.14 \\
\hline Stonefly & Calinueria & Perlidae (Golden) & 121 & 0 & 0.005 & 0.21 \\
\hline Stonefly & Yoraperla & Peltoperlidae (Roach-Like) & 45 & 0 & 0 & 0.53 \\
\hline
\end{tabular}


Appendix A10: Seven most common caddisfly genera

\begin{tabular}{lllllll}
\hline Order & Taxa & Family (common name) & $\begin{array}{l}\text { \# sites } \\
(\mathrm{n}=214)\end{array}$ & $\begin{array}{l}\text { Min } \\
\text { RA }\end{array}$ & $\begin{array}{l}\text { Median } \\
\text { RA }\end{array}$ & $\begin{array}{l}\text { Max } \\
\text { RA }\end{array}$ \\
\hline & & & & & & \\
Caddis & Rhyacophila & Rhyacophilidae (Grn Rck. Wr.) & 197 & 0 & 0.02 & 0.30 \\
Caddis & Glossossoma & Glossossomatidae (Saddle Cs.) & 141 & 0 & 0.01 & 0.20 \\
Caddis & Hydropsyche & Hydropsychidae (Net Spinner) & 112 & 0 & 0.001 & 0.23 \\
Caddis & Wormaldia & Philopotamidae (Finger Net) & 120 & 0 & 0.006 & 0.20 \\
Caddis & Lepidostoma & Lepidostmomatidae (Quilt Mr.) & 78 & 0 & 0 & 0.18 \\
& & & & & & \\
\hline
\end{tabular}


Appendix A11: Drawing of a Baetis (mayfly) mouthparts and gouge.

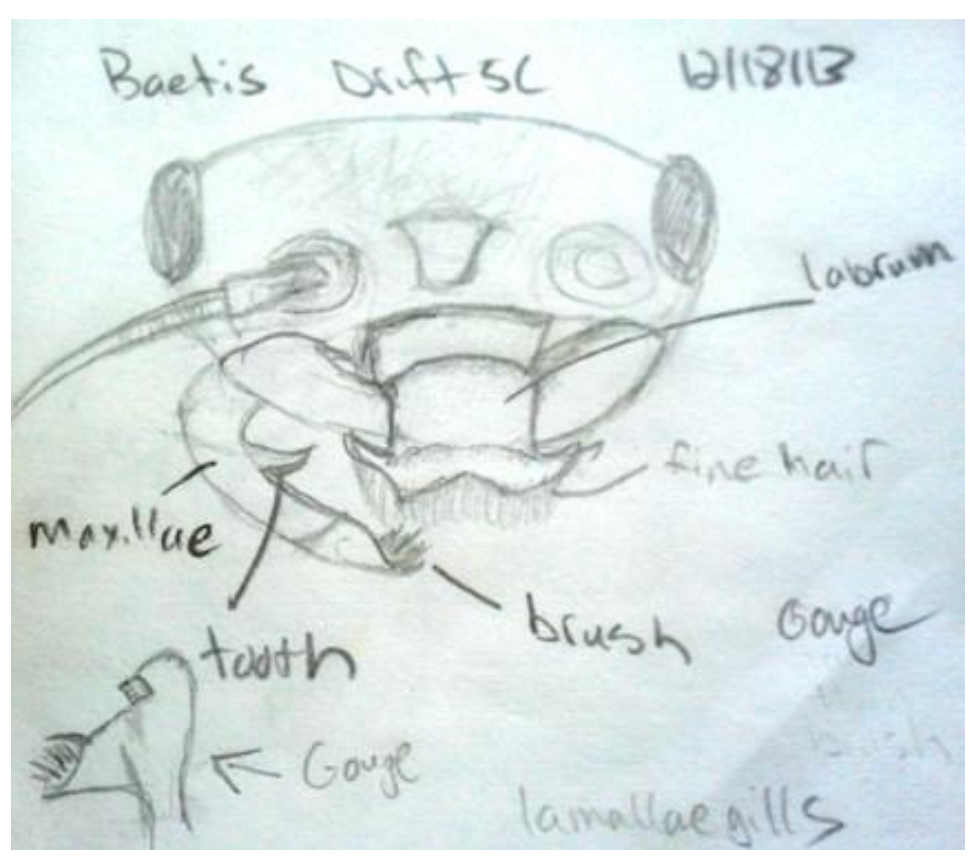


Appendix A12: Images of mesosocm and placement in stream. Mesocosm is made of two nested plastic mesocosms with flow-holes aligned. To remove the mesocosm, a lid is placed on the mesocosm and the inner container is rotated counter to the outer container thus misaligning the holes and allowing for the entire contents to be removed from stream.
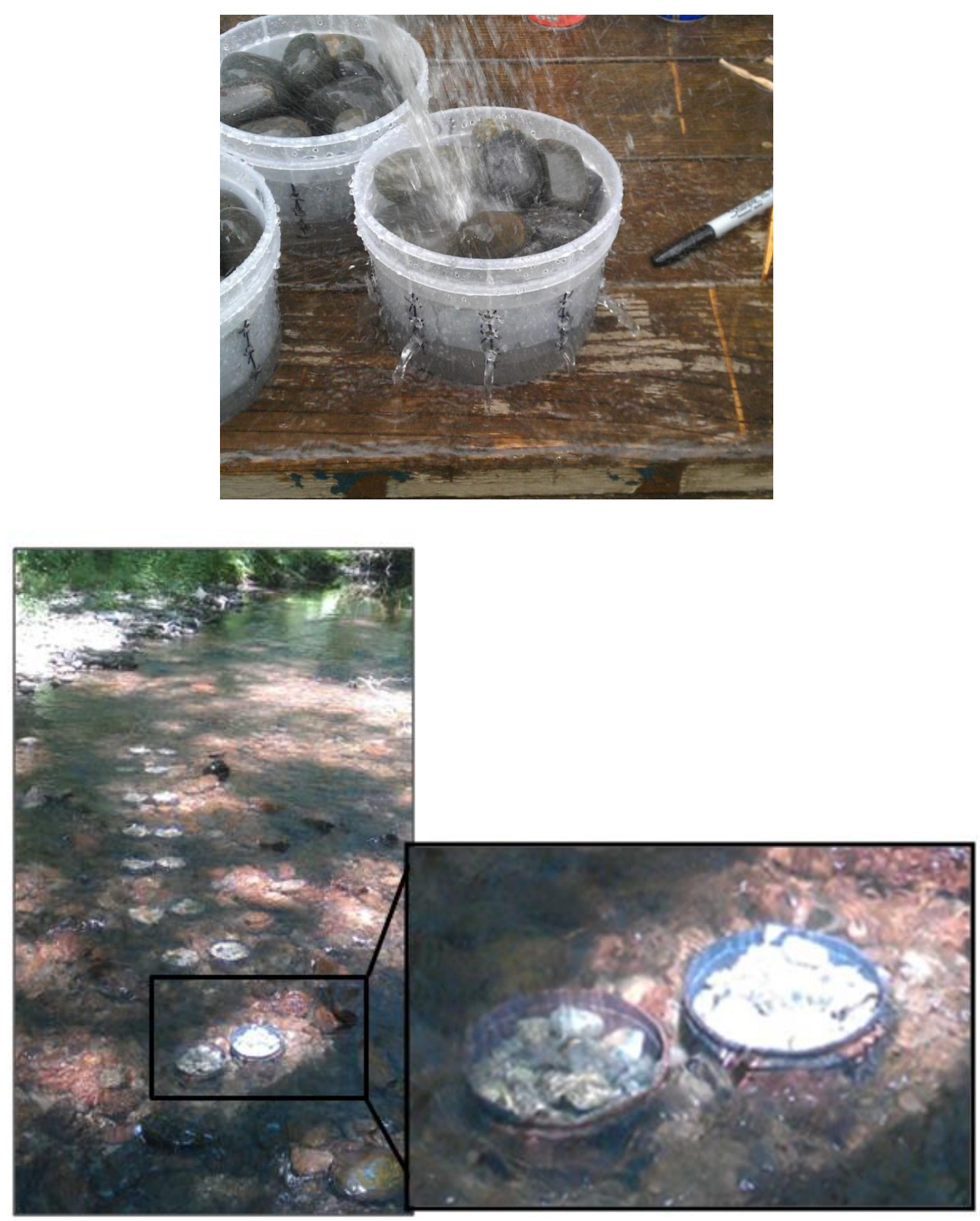